Western University

Scholarship@Western

Digitized Theses

Digitized Special Collections

1995

\title{
The Quality Of Mother-infant Interactions In Families At Risk For Maladaptive Parenting
}

Anne Krupka

Follow this and additional works at: https://ir.lib.uwo.ca/digitizedtheses

\section{Recommended Citation}

Krupka, Anne, "The Quality Of Mother-infant Interactions In Families At Risk For Maladaptive Parenting" (1995). Digitized Theses. 2561.

https://ir.lib.uwo.ca/digitizedtheses/2561

This Dissertation is brought to you for free and open access by the Digitized Special Collections at Scholarship@Western. It has been accepted for inclusion in Digitized Theses by an authorized administrator of Scholarship@Western. For more information, please contact tadam@uwo.ca, wlswadmin@uwo.ca. 
National Library

of Canada

Acquisitions and

Bibliographic Services Branch

395 Wellington Street

Ottawa. Ontano

KIAONA
Bibliotheque nationale

du Canada

Direction des acquisitions el

des services bibliographiques

395. rue Weilinglon

Onawa (Ontano) rour the vorretelerence

Ow the norre relerence

NOTICE

AVIS

The quality of this microform is heavily dependent upon the quality of the original thesis submitted for microfilming. Every effort has been made to ensure the highest quality of reproduction possible.

If pages are missing, contact the university which granted the degree.

Sorne pages may have indistinct print especially if the original pages were typed with a poor typewriter ribbon or if the university sent us an inferior photocopy.
La qualité de cette microforme dépend grandement de la qualité de la thèse soumise au microfilmage. Nous avons tout fait pour assurer une qualité supérieure de reproduction.

S'il manque des pages, veuillez communiquer avec l'université qui a conféré le grade.

La qualité d'impression de certaines pages peut laisser à désirer, surtout si les pages originales ont été dactylographiées à l'aide d'un ruban usé ou si l'université nous a fait parvenir une photocopie de qualité inférieure.

La reproduction, même partielle, de cette microforme est soumise à la Loi canadienne sur le droit d'auteur, SRC 197n, c. C-30, et ses amendements subséquents.
Reproduction in full or in part of this microform is governed by the Canadian Copyright Act, R.S.C. 1970, c. C-30, and subsequent amendments. 
The Quality of Mother-Infant Interactions in Families at Risk for Maladaptive Parentıng

\author{
by \\ Anne Krupka \\ Department of Psycholog $y$
}

Submitted in partial fulfilment of the requirements for the degree of Doctor of Philosophy

Faculty of Graduate Studies The University of Western Ontario

London, Ontario May, 1995

- Anne Krupka, 1995 
National Library of Canada

Acquisitions and Bibliographic Services Branch

305 Wellingion Street

Otruma Ontario

KIAON4
Bibliotheque nationale du Canada

Direction des acquisitions et des senvices bibliographiques

395, no Wellington Ortewa (Onierio) row the votre rencuence

Our the Norre reforence
THE AUTHOR HAS GRANTED AN IRREVOCABLE NON-EXCLUSIVE LICENCE ALLOWING THE NATIONAL LIBRARY OF CANADA TO REPRODUCE, LOAN, DISTRIBUTE OR SELL COPIES OF HIS/HER THESIS BY ANY MEANS AND IN ANY FORM OR FORMAT, MAKING THIS THESIS AVAILABLE TO INTERESTED PERSONS.
LAAUTEUR A ACCORDE UNE LICENCE IRREVOCABLE ET NON EXCLUSIVE PERMETTANT A LA BIBLIOTHEQUE NATIONALE DU CANADA DE REPRODUIRE, PRETER, DISTRIBUER OU VENDRE DES COPIES DE SA THESE DE QUELQUE MANIERE ET SOUS QUELQUE FORME QUE CE SOIT POUR METTRE DES EXEMPLAIRES DE CETTE THESE A LA DISPOSITION DES PERSONNE INTERESSEES.
THE AUTHOR RETANSS OWNERSHIP OF THE COPYRIGHT IN HIS/HER THESIS. NEITHER THE THESIS NOR SUBSTANTIAL EXTRACTS FROM IT MAY BE PRINTED OR OTHERWISE REPRODUCED WITHOUT HIS/HER PERMISSION.
L'AUTEUR CONSERVE LA PROPRIETE DU DROIT D'AUTEUR QUI PROTEGE SA THESE. NI LA THESE NI DES EXTRAITS SUBSTANTIELS DE CELLECI NE DOIVENT ETRE IMPRIMES OU AUTREMENT REPRODUITS SANS SON AUTORISATION. 
Nom ANAE KÁLPKA

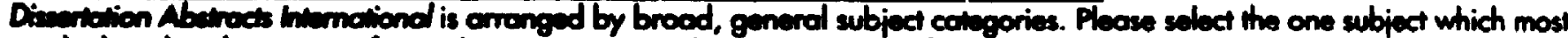
nesty deceribes the content of your diserertation. Enter the corresponding four-digit code in the spoces provided.

BSYCHOLOGY - CLINICAL

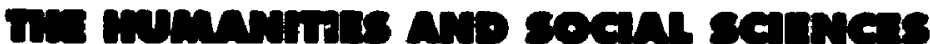

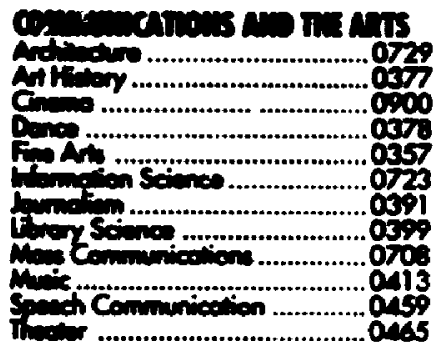

\section{TIII:}

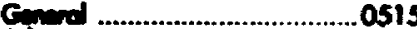

Aprinimation .........................051

Adt and Contining ....................0516

Aprialund ..............................0517

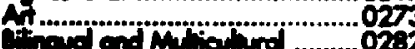

Grim

Commony Co cre..................0275

Crivaly and hidruction ..........072

Eoty atidood ...........................0518

Ervantor ................................052

and Coumeding

Guipros ond Counding ..........

ton.......................................078

ton d .............................. 0520

home Eoconomics ........................027

moned .........................052

lonevoes and lineroture ..............0279

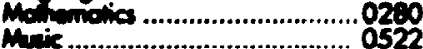

Milecenty of ............................0\%

Ansicel................0523

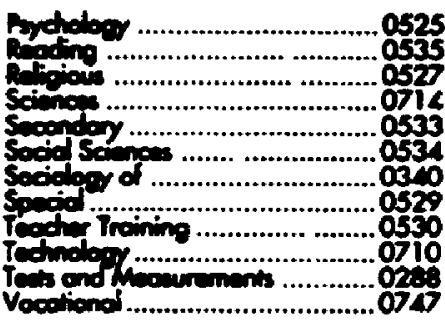

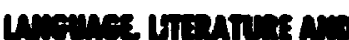

Inimillis

Iongege

Ant...........................0679

tincistica ........................ $02 \%$

Morem ...................................029

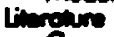

Gened............................. pop

Ozg

Mrid ....................0295

Modem ................................0298

Afrioen ...............................0310

Americon .............................. 0591

Canction (Enolish) .............0352

Condion (french) .................035

Eorodion (inmech) ...............0355

Gemonic ……..........................0311

Letin Americon ...................0312

Midde Eostem ...................031

Slavic and Eow Europeon .......0314

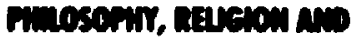

Itact

thilowioping

divion

.0422$$
\text { sith }
$$

Aivory of

Philory of

Theolegy

Ampricon Sudies

Antropolory

Antropology .......................0324

Cilund ………........................0326

cusiness Administrotion

Generd ............................0310

Acoounting ............................0272

Monotement ....................0454

Condion Sudies .......................... 0385

Economics

Griand ........................... OSO1

Coricumurol ..................... 0503

Fineme .......................... . 0508

History ......................... 0509

Lobor ................................. 0510

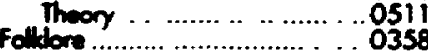

Geography .................... 036

Geroniology

Generol

0351

0578 chect Sudie:

\section{socul samas}

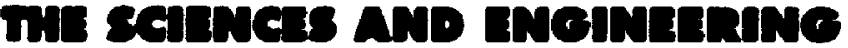

\section{mopereu somas}

Ariature

Gord ...........................0473

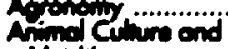

Nind potiolo...................0475

Food sciemes and

Tectinology ........

Forety ond widitif ............0478

Pron Calme .....................0479

hom fotrolo......................060

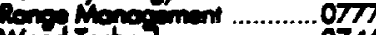

Wod Tudmology ...............0746

Bichogy

py

Anctony ................................ 0287

Compinites ........................030

conony ................................0309

C. $\ldots 379$

Codoey.......................... 2329

Entomology ........................ 0353

limas............................0793

Microbido. .......................0410

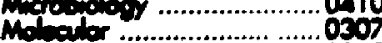

Nepracience .....................0317

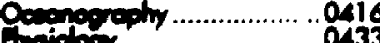

yryes ...................... 082

Vevinen science ................0778

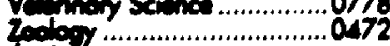

Diepinice

Condid..........................9786

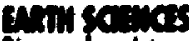

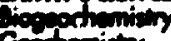

scincs

Eminonmend Sciences

Hudith Seiences
Goodey ................................0370

Goder ..................................0372

Hoptogy ...................................0388

Mirpology ..............................0411

Polocbotiony .......................... 0325

Peloentory .......................0418

Poldonodogy .. ..................... 0985

Potmaled f.........................0427

Phyiced Oceonogropiny ............ Osis

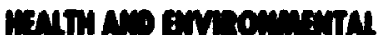

.0768

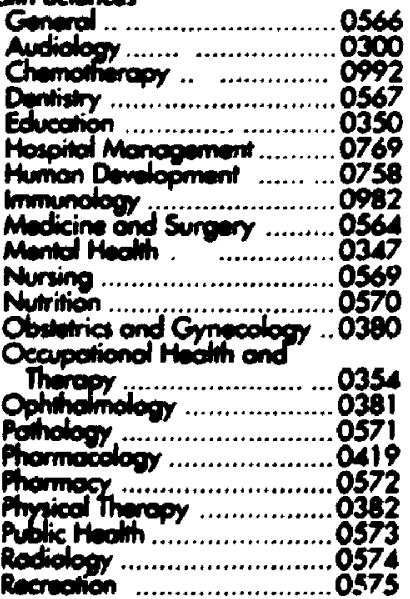

Spench Pothology

0460

Home Economics ... ... ...............038

Pursicel sa:uas

Pure Sciunces

Chemistry

Generol ...

Andticel

Broctiomiany

Inorgonic.

Nuctoonic

Prgenic . . .....

Phyiced

Poymer.

Mothemetios

Ptrrices

Generd.

Acoustics ........

Astronomy and

Atrophysics................0606

Amospheric Science .............0608

Alomic ........................0748

Eletronies ond Electricity .....0607

Elementory Porticles and

Hugh Energy.

.0798

Fhid and Ploy mo.................... 0759

Moleculor .............................0609

Nuctor

Orvies.

Reytivion

Solid Siras .............................. O611

Statiatics ...................................... 0163

Aprind Sciones:

Applied Muchanies

Compurir Sximes

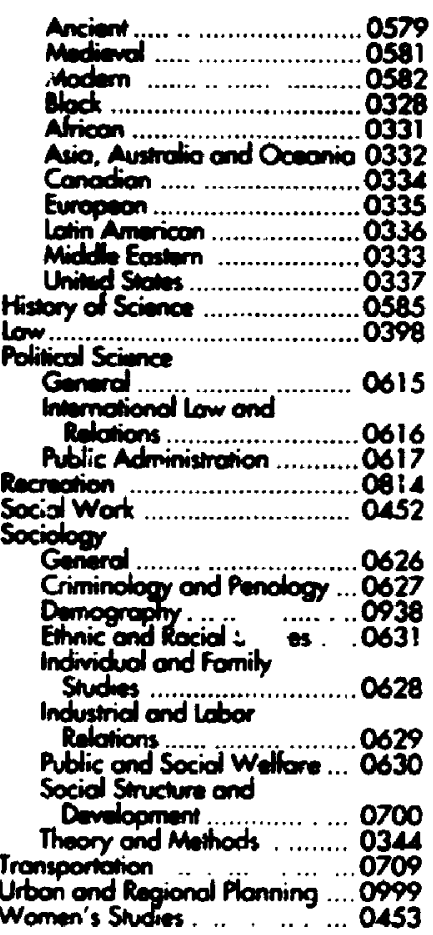

Enginerring

. . . . .0537

Agricuthrol ............ . . . . 539

Autemetive .. . . .0540

Biomedical .. ....... 054

Chemmod .. . .... ....0542

Eledronies ond Electrical ......054

Haot and Thermodynamies.. 0348

Hydroulic..... .. ......... OS45

Industrind ............ 0546

............054

Molurieds Serence .......... 079

Mechonicol . ...........0548

Macollurgy . ............. 0743

Mining ... . ........055

.0552

0765

Sonitory ond Municipal .........055

Syatem Science . ..........0790

Goonchnology . . . . . . 0428

Operctions Rexporch . ......... 0799

Textile Technology .................... 0994

Frouplery

Generd ............ 06 ?

ahovionol ....... ...........

Clinicol ............. ........622

Demiopmentol ...................6220.

E renimant . ...................... 0823

Personditiy . ..........................062

Prriolonicel .. .............. 0989

Psychobiology ... ......................0349

Psychomenties... ....................6332

Socid ...................................045 7 5

.

.




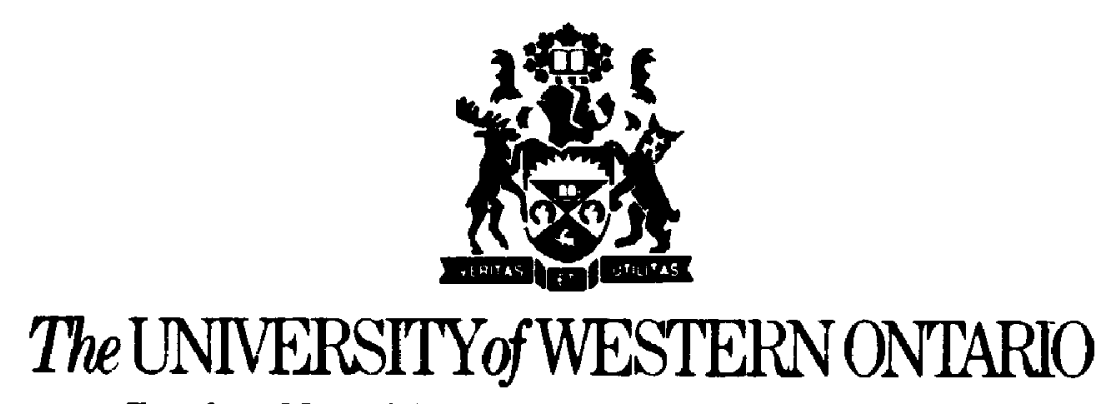

Faculty' of Soxial Science - Department of Psychology

Sept. 12, 1995

To whom it may concern,

We, the undersigned, give Anne Krupka permission to include the Maternal Bchaviour Q-sort items and the Domain-specific attachment items in the Appendix of her thesis.

Yours truly,

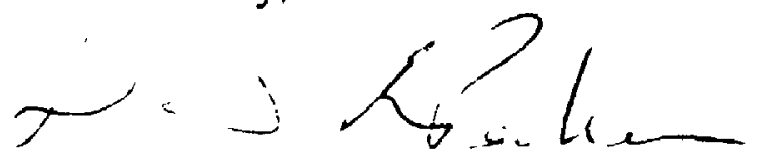

David Pederson, Ph.D.

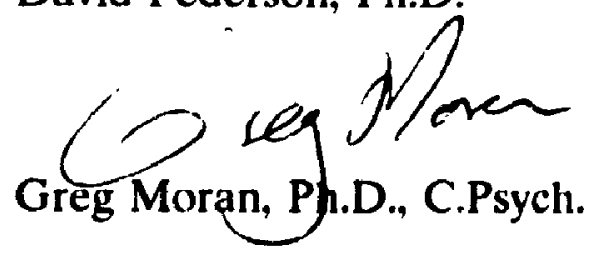




\section{ABSTRACT}

Two related studies of mother-infant interactions during the first year were carried out. In Study 1, the process of attachment was examined from a developmental psychopathology perspective. In Study 2, an intervention program based on attachment theory was evaluated. The findings revealed a possible pathway to insecure attachment relationships, and provided a rationale for theorybased early prevention.

Study 1 was cross-sectional and longitudinal with 68 high-risk mother-infant dyads (mean maternal age, 17.9 years). A multimethod approach including home observations, questionnaires, interviews, and coding of key episodes, was used to measure cognitive and socioemotional charasteristics of the infants and different aspects of maternal interactive behaviour, at three developmental periods, in order to assess the quality of mother-infant interactions and to identify precursors to disordered functioning. Attachment relationships were assessed using the Strange Situation procedure. Data were collected on 39 dyads with 13-month-old infants, 54 dyads with 6 month-old infants, and 22 dyads with 3-month-old infants. Withi, the cross-sectional groups, data were available from two longitudinal samples: 22 dyads seen at 3 and 6 months, and 25 dyads seen at 6 and 13 months.

Results shower that maternal sensitivity declined over the first year and $63 \%$ of the babies were insecurely attached at 13 months. Higher levels of sensitivity were associated with higher scores on stage-salient developmental tasks. Regression analyses revealed that sensitivity contributed to variability in attachment security; quality of social and emotional stimulation in the home, to variability in mental development; and quality of the mother's communication, to variability in language development. These findings suggest that sub-optimal mother-infant interactions may lead to difficulties in development since mastery of developmental issues at an earlier stage lays the foundation for subsequent competence.

In Study 2, 45 dyads from the cross-sectional sample with 6-month-olds were randomly assigned to intervention $(\mathrm{N}=22)$ and comparison $(\mathrm{N}=23)$ groups. 
Data were collected at 6 and 13 months, as in Study 1. In between, intervention group mothers received bi-weekly training sessions aimed at improving motherinfant interactions through play.

At 13 months, results showed the groups differed in maternal sensitivity. Sensitivity in the intervention group increased over the 7-month period whereas sensitivity in the comparison group decreased. Intervention infants had higher attachment-security scores (Attachment Behaviour Q-sort), than comparison infants, and a higher proportion were classified as securely attached (Strange Situation). 


\section{ACKNOWLEDGEMENTS}

I wish to express my appreciation and gratitude to those whose support and assistance have been invaluable to me. First, I would like to thank Dr. Greg Moran, my advisor, for his confidence in my abilities and for his continuing support and guidance throughout all stages of my graduate training. Next, I would like to thank Dr. David Pederson, a member of my advisory committee, who was always villing to "spare a minute" when advice was needed and who spent many hours coding the Strange Situation data. I was indeed fortunate to have not one but two extraordinary mentors.

I would also like to thank Dr. David Wolfe, the other member of my advisory committee, for his many useful suggestions, and especially for encouraging us to apply for the funding that made this research possible. I would like to than' Patricia Delmore, Kim Houtemeyers, Sally Jones, Tracey MacKay, Pat Pettit, and Michelle Zanon for their practical assistance in collecting the data and for their constant support throughout this project. I would like to thank all members of the Pederson-Moran research group, for their insightful comments and suggestions at various stages in the project. I would like to thank Dr. Barrie Evans and Ms. Shirley Lawrence for their invaluable help in recruiting subjects, and I would like to thank the young mothers and babies who participated in this project for the privilege of learning from them.

I would like to express my gratitude to the Institute for the Prevention of Child Abuse for funding the project, and to the Medical Research Council for the award of a studentship. Finally, I would like to thank my husband and my sons for their encouragement and patience throughout my graduate education. 
CERTIFICATE OF EXAMINATION $\ldots \ldots \ldots \ldots \ldots \ldots \ldots \ldots \ldots \ldots$ ii

ABSTRACT $\ldots \ldots \ldots \ldots \ldots \ldots \ldots \ldots \ldots \ldots \ldots \ldots \ldots \ldots \ldots \ldots \ldots \ldots$ iii

ACKNOWLEDGEMENTS $\ldots \ldots \ldots \ldots \ldots \ldots \ldots \ldots \ldots \ldots \ldots \ldots \ldots$

TABLE OF CONTENTS $\ldots \ldots \ldots \ldots \ldots \ldots \ldots \ldots \ldots \ldots \ldots \ldots \ldots \ldots$ vi

LIST OF TABLES $\ldots \ldots \ldots \ldots \ldots \ldots \ldots \ldots \ldots \ldots \ldots \ldots \ldots \ldots \ldots \ldots \ldots \ldots$

LIST OF FIGURES $\ldots \ldots \ldots \ldots \ldots \ldots \ldots \ldots \ldots \ldots \ldots \ldots \ldots \ldots \ldots \ldots \ldots \ldots$ xiii

LIST OF APPENDICES $\ldots \ldots \ldots \ldots \ldots \ldots \ldots \ldots \ldots \ldots \ldots \ldots \ldots \ldots \ldots \ldots \ldots \ldots$

CHAPTER I . . . . . . . . . .

Organization of the Thesis $\ldots \ldots \ldots \ldots \ldots \ldots \ldots \ldots \ldots \ldots \ldots \ldots$

Overview of the Literature $\ldots \ldots \ldots \ldots \ldots \ldots \ldots \ldots \ldots \ldots \ldots$

Experiments in Nature $\ldots \ldots \ldots \ldots \ldots \ldots \ldots \ldots \ldots \ldots \ldots \ldots$

Characteristics of Adolescent Parenting $\ldots \ldots \ldots \ldots \ldots \ldots \ldots, 4$

Characteristics of Effective Parenting ............... 5

Theoretical Approach and Conceptual Framework $\ldots \ldots \ldots \ldots \ldots, 8$

Attachment Theory ..................... 9

Antecedents of Attachment $\ldots \ldots \ldots \ldots \ldots \ldots \ldots \ldots \ldots \ldots$

Developmental Psychopathology ................. 12

Goals .......................... 14

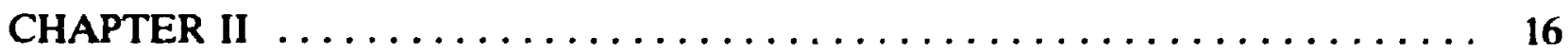

Research design and measures $\ldots \ldots \ldots \ldots \ldots \ldots \ldots \ldots \ldots \ldots \ldots .16$

Subject Recruitment ..................... 17

Subject Selection $\ldots \ldots \ldots \ldots \ldots \ldots \ldots \ldots \ldots \ldots \ldots \ldots \ldots \ldots \ldots$

Data Collection ...................... 19

Measures . ................... 20

Maternal Interactive Behaviour .............. 20

Maternal Perceptions and Beliefs ............. 25

Infant Characteristics $\ldots \ldots \ldots \ldots \ldots \ldots \ldots \ldots \ldots \ldots$

Interobscrver Reliability $\ldots \ldots \ldots \ldots \ldots \ldots \ldots \ldots \ldots \ldots \ldots \ldots \ldots$

CHAPTER III . . . . . . . . . . . . 35

Study 1: Relationships Between Babies and Mothers During the First Year . . . . 35

Salient Components of Maternal Sensitivity ............ 37

Correlates of Maternal Sensitivity ................. 39

Prior versus contemporaneous patterns of interaction $\ldots \ldots \ldots \ldots \ldots 41$

The current study $\ldots \ldots \ldots \ldots \ldots \ldots \ldots \ldots \ldots \ldots \ldots \ldots \ldots \ldots \ldots \ldots$

Hypotheses . . . . . . . . . . . . . . . . . 43 
Method .............................. 45

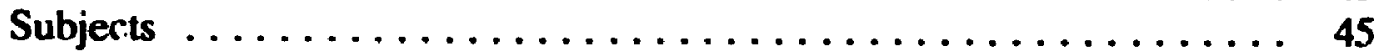

Procedure at 3 -months of age $\ldots \ldots \ldots \ldots \ldots \ldots \ldots \ldots \ldots, 46$

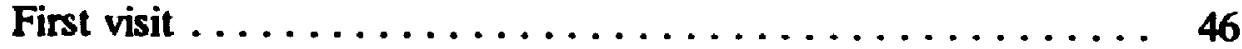

Second Visit ...................... 48

Procidure at 6-Months of Age $\ldots \ldots \ldots \ldots \ldots \ldots \ldots \ldots \ldots, 49$

Procedure at 13-Months of Age $\ldots \ldots \ldots \ldots \ldots \ldots \ldots \ldots, 50$

Resuits ............................. 52

Section 1: The Maternal isehaviour Q-Sort (MBQS) $\ldots \ldots \ldots \ldots \ldots 52$

Section 2: Cross-sectional Data - Relation of maternal sensitivity to mastery of developmental tasks .............. 57

Dyads with 3-month-old infants $(\mathrm{N}=22) \ldots \ldots \ldots \ldots \ldots \ldots 57$

Maternal interactive behaviours $\ldots \ldots \ldots \ldots \ldots \ldots, 57$

Infant characteristics .................. 59

Mastery of developmental tasks ........... 59

Test of Hypothesis 1 at 3 months ............ 61

Dyads with 6-month-old infants $(\mathrm{N}=54) \ldots \ldots \ldots \ldots \ldots 61$

Maternal interactive behaviours $\ldots \ldots \ldots \ldots \ldots \ldots 61$

Infant characteristics .................66 6

Mastery of developmental tasks ............ 66

Test of Hypothesis 1 at 6 months . . . . . . . . . 68

Dyads with 13 -month-old infants $(\mathrm{N}=39) \ldots \ldots \ldots \ldots \ldots .72$

Maternal interactive behaviours $\ldots \ldots \ldots \ldots \ldots \ldots 72$

Infant characteristics $\ldots \ldots \ldots \ldots \ldots \ldots \ldots \ldots, 78$

Mastery of developmental tasks ........... 78

Test of Hypothesis 1 at 13 months .......... 80

A second test of Hypothesis 1 at 13 months .......83

Section 3: Associations between Strange Situation Classification and

Behaviour Assessed in the Home - All dyads with 13 -month olds $(\mathrm{N}=61) \ldots \ldots \ldots \ldots \ldots \ldots \ldots \ldots .86$

Tests of Hypotheses $2 \mathrm{a}$ and $\mathbf{2 b}$ - Maternal sensitivity, infant temperament, and attachment security . 87

Tests of Hypothesis $2 \mathfrak{c}$ - Attachment classifications and domain-specific attachment behaviours $\ldots 89$

Differential effects of maternal interactive behaviours $\ldots \ldots \ldots \ldots \ldots \ldots \ldots \ldots \ldots 91$

Section 4: Longitudinal Data - Associations between maternal and infant behaviours across two ages $\ldots \ldots \ldots \ldots \ldots .96$ 
3-months to 6-months-ot-age $(\mathbf{N}=22) \ldots \ldots \ldots \ldots \ldots \ldots 98$

Stability of mother and infant behaviours $\ldots \ldots \ldots .98$

Correlations between maternal behaviour at 3 months and the infant's mastery of developmental tasks at 6 months ........ 98

Correlations between infant characteristics at 3 months and maternal behaviours at 6 months .. 101

Test of Hypothesis 3a: Continuity in adaptation ..... 101

6-months to 13-months-of-age $(\mathrm{N}=25) \ldots \ldots \ldots \ldots \ldots \ldots 102$

Stability of mother and infant behaviours ......... 102

Correlations between meternal behaviours at 6 months and infant characteristics at 13 months .................. 102

Correlations between infant characteristics at 6 months and maternal behaviouss at 13 months .................... 105

Test of Hypothesis 3a: Continuity in adaptation ..... 105

Test of Hypotheses $3 \mathrm{~b}$ and $3 \mathrm{c}$ - maternal sensitivity and infant temperament as predictors of security of attachment ............. 108

The effect of contemporaneous vs prior maternal interactive behaviour on attachment security $\ldots 109$

Section 5: Description of maternal perceptions $\ldots \ldots \ldots \ldots \ldots \ldots 110$

Maternal knowledge of infant development and perception of infant vocalizations $\ldots \ldots \ldots \ldots \ldots \ldots \ldots \ldots, 110$

Maternal perceptions of stress and social support $\ldots \ldots \ldots \ldots 112$

Discussion

CHAPTER IV . . . . . . . . . . . . . 126

Study 2: The benefits of early intervention $\ldots \ldots \ldots \ldots \ldots \ldots \ldots \ldots \ldots \ldots$

Intervention programs for high risk infant-mother dyads $\ldots \ldots \ldots \ldots 120$

Intervention in the current study ................ 131

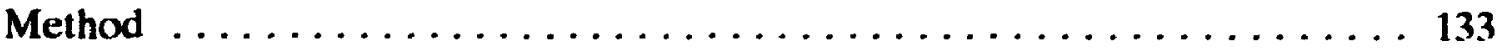

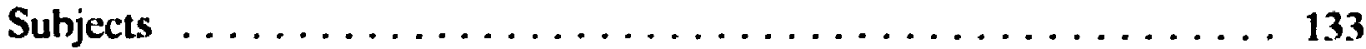

Procedure ......................... 134

Statistical Analyses $\ldots \ldots \ldots \ldots \ldots \ldots \ldots \ldots \ldots \ldots \ldots \ldots \ldots \ldots \ldots$

Results ............................... 137

Demographic analyses of intervention and comparison groups ..... 137

Descriptive analyses of maternal behaviours at infant-age 6 months . . 138

Maternal behaviours .................... 138

Maternal perceptions of stress ............... 138 
Maternal perceptions of inıant temperament .......... 141

Descriptive analyses of the intervention sessions . . . . . . . . . 141

Statistical analyses at 13 months ................. 143

Effect of intervention on maternal sensitivity and infant security of attachment $\ldots \ldots \ldots \ldots \ldots \ldots \ldots \ldots \ldots$

Infant characteristics . . . . . . . . . . . . . 147

Discussion $\ldots \ldots \ldots \ldots \ldots \ldots \ldots \ldots \ldots \ldots \ldots \ldots \ldots \ldots \ldots \ldots \ldots$

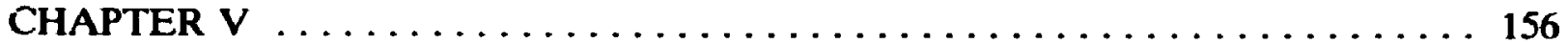

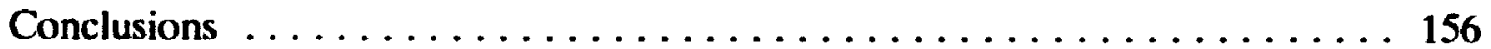

APPENDIX A $\ldots \ldots \ldots \ldots \ldots \ldots \ldots \ldots \ldots \ldots \ldots \ldots \ldots$

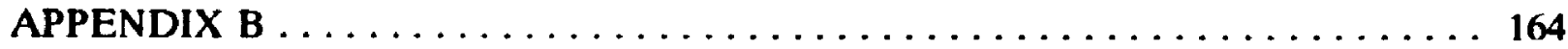

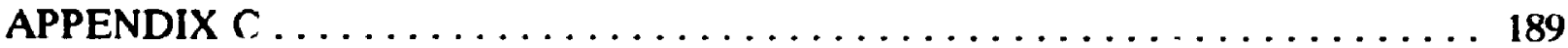

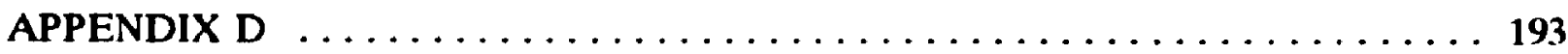

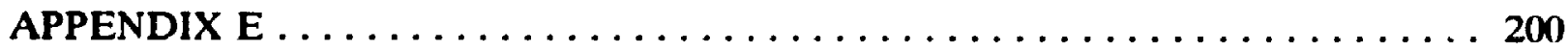

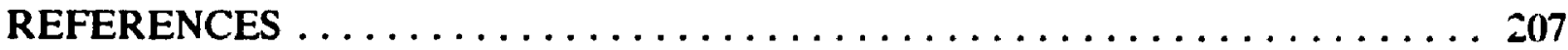

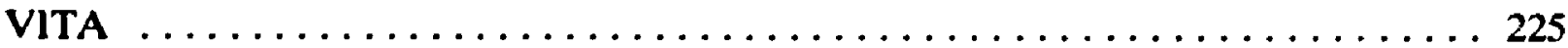




\section{LIST OF TABLES}

Table

Description

Page

$3.1 \quad$ Demographic variables $\ldots \ldots \ldots \ldots \ldots \ldots \ldots \ldots \ldots \ldots \ldots \ldots \ldots \ldots \ldots$

3.2 Correlations among measures of maternal behaviour:

Dyads with 3-month-old infants $(\mathrm{N}=22)$

3.3 Correlations among measures of maternal behaviour:

Dyads with 6-month-old infants $(\mathbf{N}=54) \ldots \ldots \ldots \ldots \ldots \ldots$

3.4 Correlations among measures of maternal behavic:' $r$ :

Dyads with 13 -month-old infants $(\mathrm{N}=39)$

3.5 Means and standard deviations for maternal behaviours:

Dyads with 3 -month-old infants $(\mathbf{N}=22) \ldots \ldots \ldots \ldots \ldots \ldots \ldots \ldots$

3.6 Means and standard deviations for child characteristics:

Dyads with 3 -month-old infants $(\mathbf{N}=22) \ldots \ldots \ldots \ldots \ldots$

3.7 Correlations among maternal variables and infant homeostasis:

Dyads with 3-month-old infants $(\mathrm{N}=22)$

3.8 Means and standard deviations for maternal behaviours:

Dyads with 6-month-old infants $(\mathrm{N}=54)$

3.9 Correlations among maternal age, perceptions, and

interactive behaviour: Dyads with 6-month-old infants $(\mathrm{N}=54) \ldots \ldots 5$

3.1() Means and standard deviations for child characteristics:

Dyads with 6-month-old infants $(\mathrm{N}=54)$

3.11 Correlations among maternal variables and infant variables:

Dyads with 6-month-old infants $(\mathrm{N}=54)$

3.12 Standard multiple regression of maternal behaviours. stress arid infant mental development on 6-month exploratory behaviour scores $(\mathrm{N}=51) \ldots \ldots \ldots$

3.13 Standard multiple regression of maternal behaviours, stress and infant mental development on 6 -month homeostasis scores $(\mathrm{N}=53) \ldots \ldots \ldots \ldots \ldots$

3.14 Means and standard deviations for maternal behaviours:

Dyads with 13-month-old infants $(\mathrm{N}=39)$

3.15 Correlations among maternal age, perceptions, and interactive

behaviour: Dyads with 13-month-old infants $(\mathrm{N}=39)$ 


\section{LIST OF TABLES (cont'd)}

Table

Description

Page

3.16 Means and standard deviations for child characteristics:

Dyads with 13 -month-old infants $(\mathbf{N}=39) \ldots \ldots \ldots \ldots \ldots \ldots$

3.17 Correlations between attachment security scores and maternal interactive behaviour and infant homeostasis and exploration: Dyads with 13-month-old

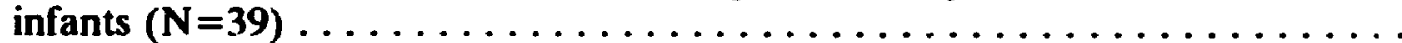

3.18 Standard multiple regression of maternal sensitivity, homeostasis, and task persistence on 13 -month attachment security scores $(\mathrm{N}=37) \ldots \ldots \ldots \ldots$

3.19 Maternal variables by group (secure vs. insecure attachemt). Means, standard deviations, and significance values at 13 months $(\mathrm{N}=38) \ldots \ldots \ldots \ldots \ldots$

3.20 Child variables by group (secure vs. insecure attachment). Means, standard deviations, and significance values at 13 months $(\mathbf{N}=38) \ldots \ldots \ldots \ldots$

3.21 Means and standard deviations by group (secure vs. insecure attachment). Maternal interactive behaviour and infant temperament at 13 months $(N=60)$

3.22 Means and standard deviations by group (secure vs. insecure attachment) for attachment security (AQS) scores and domain specific attachment behaviours at 13 months $(\mathrm{N}=60)$

3.23 Correlations between attachment security and maternal age, and maternal interactive behaviours and infant temperament: Dyads with 13-month-old

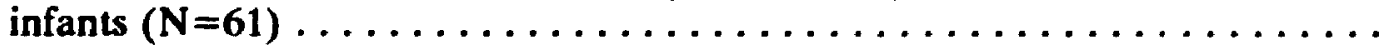

3.24 Standard multiple regression of maternal interactive behaviour on 13-month

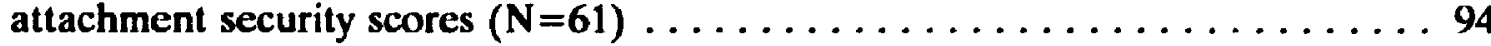

3.25 Standard multiple regression of maternal interactive behaviour on 13-month mental development scores $(\mathbf{N}=61) \ldots \ldots \ldots \ldots \ldots \ldots$

3.26 Standard multiple regression of maternal interactive behaviour on 13-month communicative ability scores $(\mathrm{N}=61)$

3.27 Means, standard deviations, and stability coefficients for maternal behaviours: Longitudinal data from 3 months to 6 months $(N=22) \ldots \ldots \ldots \ldots$

3.28 Means, standard deviations, and stability coefficients for child charactc.istics: Longitudinal data from 3 months to 6 months $(\mathrm{N}=22) \ldots \ldots \ldots \ldots \ldots$

3.29 Means, standard deviations, and stability coefficients for maternal behaviours: Longitudinal data from 6 months to 13 months $(N=25) \ldots \ldots \ldots \ldots$ 


\section{LIST OF TABLES (cont'd)}

Table

Description

Page

3.30 Means, standard deviations, and stability coefficients for child characteristics: Longitudinal data from 6 months to 13 months $(N=25) \ldots \ldots 104$

3.31 Correlations between maternal behaviours at 6 months and

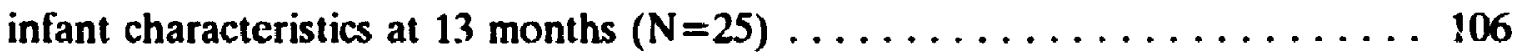

3.32 Correlations between infant characteristics at 6 months and maternal behaviours at 13 months $(\mathrm{N}=25)$

3.33 Maternal knowledge of infant development and maternal perceptions:

At infant ages 3 months, 6 months, and 13 months

4.1 Demographic variables: Intervention and comparison groups $\ldots \ldots \ldots 135$

4.2 Means and standard deviations by group (intervention vs. comparison):

Maternal behaviours at infant-age 6 months $\ldots \ldots \ldots \ldots \ldots \ldots$

4.3 Means and standard deviations by group (intervention vs. comparison):

Child characteristics at infant-age 6 months $\ldots \ldots \ldots \ldots \ldots \ldots \ldots$

4.4 Means and standard deviations by group (intervention vs. comparison):

Maternal behaviours at infant-age 13 months $\ldots \ldots \ldots \ldots \ldots \ldots$

4.5 Means and standard deviations by group (intervention vs. comparison):

Child characteristics a! infant-age 13 months 


\section{LIST OF FIGURES}

Figure

Description

Page

3.1 Global maternal sensitivity (MBQS) and maternal interactive behaviour during play (CARE) at infant ages 3, 6, and 13 months $\ldots \ldots \ldots 76$

3.2 Percentages of mothers reporting "difficult" temperament, clinically elevated levels of stress, and sources of support $\ldots \ldots \ldots \ldots \ldots 114$

4.1 Change in maternal sensitivity scores (MBOS) from 6 to 13 months in the Intervention and Comparison groups $\ldots \ldots \ldots \ldots \ldots \ldots \ldots \ldots . \ldots \ldots$

4.2 Significant differences in attachment security in the Intervention and Comparison groups, measured by two different methods $\ldots \ldots \ldots \ldots \ldots \ldots 148$ 


\section{LIST OF APPENDICES}

Appendix

Description

A Letters of information and consent form $\ldots \ldots \ldots \ldots \ldots$

B Maternal Behaviour Q-Sort $\ldots \ldots \ldots \ldots \ldots \ldots \ldots \ldots \ldots \ldots \ldots \ldots$

Domain specific attachment behaviours $\ldots \ldots \ldots \ldots \ldots \ldots \ldots \ldots \ldots$

Child-Adult Expcrimental Index . . . . . . . . . . . . . . . . 172

Mastery Motivation Tasks $\ldots \ldots \ldots \ldots \ldots \ldots \ldots \ldots \ldots \ldots$

C Schematic diagram of group composition $\ldots \ldots \ldots \ldots \ldots \ldots \ldots$

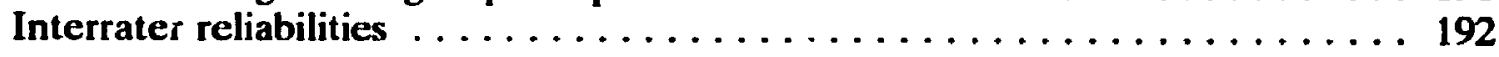

D Comparison of the two measures of infant temperament . . . . . . . . . . 194

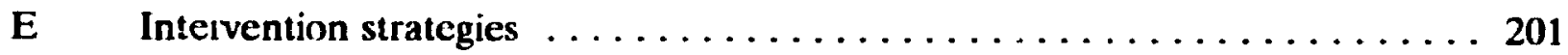


The author of this thesis has granted The University of Western Ontario a non-exclusive license to reproduce and distribute copies of this thesis to users of Western Libraries. Copyright remains with the author.

Electronic theses and dissertations available in The University of Western Ontario's institutional repository (Scholarship@Western) are solely for the purpose of private study and research. They may not be copied or reproduced, except as permitted by copyright laws, without written authority of the copyright owner. Any commercial use or publication is strictly prohibited.

The original copyright license attesting to these terms and signed by the author of this thesis may be found in the original print version of the thesis, held by Western Libraries.

The thesis approval page signed by the examining committee may also be found in the original print version of the thesis held in Western Libraries.

Please contact Western Libraries for further information:

E-mail: libadmin@uwo.ca

Telephone: (519) 661-2111 Ext. 84796

Web site: http://www.lib.uwo.ca/ 


\section{CHAPTER I}

Organization of the Thesis

The research is reported in five chapters. An overview of the literature on the links between mother-infant interaction and the child's social-emotional, language, and cognitive development is presented in Chapter I, and a rationale is provided for studying development in children "at risk". Because of the complex nature of the research design, an overview of the design and measures used is presented in Chapter II. This chapter serves several purposes: (1) to clarify the nature of the four cross-sectional and two longitudinal samples of Study 1 and the two longitudinal samples of Study 2; (2) to provide a rationale for the measures used in the two studies; and (3) to reduce redundancy in reporting material that is common to the eight distinct groupings of dyads and to the two studies. The two studies are presented separately, each with introduction, methods, results, and discussion sections. Study 1 , which addresses the first two broad goals of the research, is presented in Chapter III. Study 2, which addresses the third goal, is presented in Chapter IV. Conclusions drawn from the two studies are presented in Chapter V.

\section{Overview of the Literature}

The relevance of early experience to a variety of cognitive, motivational, and social parameters has long been recognized by clinicians (e.g. Freud, 1940) and researchers alike (e.g. Hunt, 1979; Ainsworth, 1972; Skeels, 1966). Indeed, Wachs and Gruen (1982) argue that "early experiences have a greater probability of having a more dramatic and longer lasting impact upon the organism than later 
experiences" (p. 4). Most of the evidence relating early experience to socialemotional, language, and cognitive development has involved mother-child interactions. Although the importance of these interactions, especially in the first few years, has been demonstrated (e.g. Stern, 1985; Schaffer, 1984; Bruner, 1982; Kaye, 1982; Blehar, Liberman, \& Ainsworth, 1977; Ainsworth \& Bell, 1974; Lewis \& Goldberg, 1969), it is still not clear which aspects of the interaction are most relevant to optimal development. Such information is essential, not only to our understanding of normal developmental processes, but to the planning of effective prevention/intervention programs for children at risk for behavioural maladjustment and/or developmental delays (Cicchetti, 1989).

Unfortunately, several difficulties, methodological rather than inherent, impede resolution of this important issue. First, differences in terminology and experimental approach often obscure similarities in the various developmental theories and in the research fundings related to mother-infant interactions. Wachs and Gruen (1982) suggest that inconsistencies in the results may reflect unclear conceptualizations of the constructs in question and inadequate operational definitions. For example, Sameroff \& Chandler (1975) propose that reciprocal transactions between parent and infant may be critical for the child's development. Numerous researchers have tested the hypothesis by focusing either on the degree of mutual interaction, the contingency of these interactions, or the sensitivity of the mother to the infant's siguals. The results, not surprisingly, have been inconsistent since contingency and/or sensitivity may or may not have been included in the operational definition of reciprocal interactions. As well, researchers have used different terms to describe these reciprocal mother-infant interactions [e.g. communication (Brazelton, Koslowski, \& Main, 1974), conversation (Newson, 1977, 1979), dialogue (Kaye, 1982), waltz (Stern, 1974, 1977)], and different approaches to study it [e.g. mutual play (Belsky \& Most, 1981), gaze alternation (Messer \& Vietz, 1984; Stern, 1974), patterns of vocalization (Stern, MacKain \& Spieker, 1982), and so on]. 
Second, the majority of these studies are correlational and preclude confident causal inferences. Since one cannot, for obvicus ethical reasons, experimentally expose infants to either high levels of maternal insensitivity or to low levels of interaction, the best way to clarify the reiationship between early experience and optimal development is to study populations where wide variation in mother-infant interactions oecur under natural circumstances. In keeping with this line of reasoning, the current research takes advantage of one of the many "natural experiments" available in our society, to explore the kinds of interactions that may lead to insecure infant-mother attachment relationships, developmental delays, and perhaps ultimately to child maltreatment (Crittenden \& Ainsworth, 1989). In addition to the obvious clinical relevance of such studies, the early interactions of disadvantaged young mothers and their infants may further our basic understanding of the developmental roots of dysfunctional patterns of interaction. Maladaptive interactions occurring in the families of these children make it possible to investigate hypotheses that are inaccessible in the constricted range of behaviour seen in low-risk families. Although maladaptive patterns of parenting occur in varying degrees at all socioeconomic levels, the more extreme forms occur disproportionately more often among economically and socially disadvantaged families (Wolfe, 1987). Moreover, relatively high levels of stress and limited access to sources of social and emotional support are likely to highlight the dependency of secure patterns of attachment on maternal sensitivity. Thus, our understanding of basic developmental processes can often be substantially furthered by studying development in "at risk" children. "Experiments in Nature"

Today, increasing numbers of unmarried adolescents are choosing to raise their babies rather than giving them up for adoption. Linfortunately, these young socially-disadvantaged parents often lack the skills necessary for effective parenting. Research findings suggest that adolescent mothers often provide less than optimal care-giving environments for their infants. Although they attend to their infants' basic physical needs, they appear to be less sensitive and less positive 
in face-to-face interactions and they provide less verbal stimulation than adult mothers (Culp, Culp, Osofsky, \& Osofsky, 1991; Stevens, 1989; Garcia Coll, Vohr, Hoffman, \& Oh, 1986; Landy, 1981). Their infants consistently show deficits in cognitive development and are more likely to be insecurely attached than infants of older mothers (Landy, 1981).

Many young, single mothers are teenagers still struggling with their own developmental needs. Normal adolescent characteristics, such as poorly defined identities, self-centredness, and an inability to anticipate the needs of others, put these young mothers at increased risk for maladaptive parenting. Their cognitive immaturity may well interfere with their ability to understand the need for providing frequent, sensitive mother-infant interactions, a hallmark of effective parenting. Often, they have not been exposed to good role models and thus may require help in learning to experience positive interactions. Programs that help young parents enjoy their parental role may prevent future maladaptive behaviour in both parent and baby.

\section{Characteristics of Adolescent Parenting}

Available evidence indicates that teenagers may be less than adequate as parents. Most studies suggest that teenage mothers have more negative and punitive attitudes toward their babies than do older mothers (e.g. Field, Widmayer, Stringer, \& Ignatoff, 1980). Aggressive, inappropriate behaviours, such as picking, poking, and pinching their infants have been reported in some adolescent mothers (Lawrence, McAnarney, Aten, et al., 1981). Many adolescent mothers lack knowledge about infant development and therefore have inappropriate expectations for their infants' behaviour in the first two years of life. They tend to overestimate the rate of physical development and often become impatient and intolerant when their infants fail to live up to these expectations (cf. Miller, 1988 for a review). Younger teens and those who underestimate infant needs and abilities engage in relatively little verbal interaction (Stevens, 1989; Osofsky \& Osofsky, 1970). When interacting with their infants, adolescent mothers usually display relatively low levels of affect. When they do engage in 
affective interactions, they tend to display more inappropriate and negative affect (Hann, Osofsky, Barnard, \& Leonard, 1990).

In general, a mother's age appears to affect the quality of mother-infant interactions. In one study, the younger the mother, the less she exhibited such appropriate maternal behaviours as touching her baby, altering the pitch of her voice, or using synchronous movements, and the less close she felt to her baby (McAnarney, Lawrence, \& Aten, 1979). In another study, younger mothers were less responsive during feeding sessions than older mothers, regardless of race and socioeconomic status or marital status (Jones, Green, \& Krauss, 1980). In teaching situations, older mothers demonstrated tasks more and talked more to their babies, and their babies vocalized almost twice as much as babies of teenage mothers (Levine, Garcia Coll, \& Oh, 1985).

\section{Characteristics of Effective Parenting}

There is widespread acceptance of parental sensitivity as the central component of effective parenting (e.g. Clark \& Seifer, 1983). This acceptance is well-founded since all prominent theories of development assign a major role to parental sensitivity in the social, emotional, and cognitive development of the child. According to Lamb \& Easterbrooks (1981), parental sensitivity is "perhaps the most important determinant of individual differences in infant social cognition" (p.127). At the very least, it is basic to the provision of adequate care and a stimulating psychological environment for infants (Wiesenfeld \& Malatesta, 1983). Parental sensitivity is operationally defined in many ways, but there is general agreement that the concept involves the ability of a parent to provide contingent, consistent, and appropriate responses to an infant's signals. A parent displays sensitive behaviour when s/he perceives the infant's cues, interprets these cues correctly, and responds appropriately. Insensitjve parental behaviour results when there is a breakdown in this process (Lamb \& Easterbrooks, 1981; Ainsworth, Blehar, Waters, \& Wall, 1978).

There is little doubt that an eficrtive parent creates an environment that supports the infant's optimal development in many different ways. Parents who 
show high levels of sensitive behaviour provide their infants with information and intellectual stimulation through verbal interactions. They allow their infants freedom to physically explore the environment, thereby encouraging the development of sensory and motor abilities. They support the infant's budding sense of effectance by responding to the infant's needs in a manner that is consistent with his or her developmental level, and they build up the infant's selfconcept through positive affect that accompanies all their supportive verbal and physical interactions (Wolfe, 1987, p. 44). However, relatively little is known about the antecedents of parental sensitivity.

Kaye (1982) proposes a biologically driven mother-infant "system" in which the actions of mothers and infants are dependent upon preadapted behaviours and universal patterns of interaction. Empirical evidence appears to support such a system (e.g. Trevarthen, 1980; Lewis \& Rosenblum, 1974), but studies have also shown that familial situational factors as well as infant constitutional factors affect how parents interact with their infants (Ainsworth, 1982; Sameroff \& Chandler, 1975). Maternal responsivity and receptivity to infants have been shown to vary with parental perception of stress (Loyd \& Abidin, 1985), with infant prematurity (Frodi \& Lamb, 1980), developmental level (Brooks-Gunn \& Lewis, 1984), delayed language development (Wurlbert, Inglis, \& Kriegsmann (1975), and handicapping condition (Wedell-Monnig \& Lumley, 1980; Fraiberg, 1974).

The manner in which parental sensitivity is said to affect development depends upon the specific theoretical perspective of the researcher. From the perspective of developmental psychopathology (Sroufe and Rutter, 1984), the parent's ability to recognize and respond effectively to the infant's changing needs facilitates successful resolution of stage-salient tasks associated with each developmental stage. Successful resolution of later stage-salient tasks depends on the successful resolution of earlier tasks making parental sensitivity crucial to optimal child development (Cicchetti, Toth, \& Bush, 1989; Sroufe \& Rutter, 1984). 
According to the contingency hypothesis (e.g. Dunham, Dunham, Hurshman, \& Alexander, 1989; Watson, 1985; Lewis and Goldberg, 1969; White, 1959), the infant's development of expectancy is facilitated by repeated pairings of parental responses and infant signals. These researchers stress that intentional behaviour develops as infants learn that their behaviour has consequences and that they can control and influence their environment. For example, much of the initial acquisition of communication skills occurs as mother and baby become finely tuned to each other through taking turns and acting reciproca' " with each other during social play. Mothers treat their newborns as if they are communicating partners, and in so doing, make it come true (Kaye, 1982; Newson, 1979). Whether babies are capable of intentionally communicating from the moment of birth as some theorists claim (e.g. Trevarthell, 1980; Brazelton, 1979), or only gradually do so (Schaffer, 1984; Kaye, 1982) appears to be irrelevant; the cyclical nature of infants' early behaviour, their striking perceptual skills, and their forceful demand signals make infants effective communicators, in their mother's eyes at least. It seems that a mother's responses in the "real world" create exactly the type of partial reinforcement schedule necessary for optimal learning to occur (Watson, 1985).

According to, attachrnent theory, parental sensitivity is the antecedent of a secure infant-parent attachment relationship, and the nature of this relationship has important developmental consequences for the child (Ainsworth, 1982; Bowlby, 1969, 1980). Because securely-attached infants are able to use their parents as secure bases to explore their environment, they do so more frequently and effectively and thereby gain cognitive competence and mastery of their social and physical environment (Schneider-Rosen \& Cicchetti, 1984; Ainsworth \& Bell, 1974). Taking slightly different slants, Sroufe \& Fleeson (1987) argue that early relationships shape the child's understanding of, and actions in, subsequent relationships, while Lipsett (1983) views secure attachment as a "stress reducer" which buffers the child as s/he learns to cope with nany stressful environmental factors. In contrast, insecure attachment has been associated with lower 
exploratory behaviour (Hazen \& Durrett, 1982), with poor peer relations and increased vulnerability to psychiatric disturbance (Garmezy, Masten, \& Tellegen, 1984; Lewis, Feiring, McGuffog, \& Jaskir, 1984), and with the formation of subsequent pathological relationships (Main \& Goldwyn, 1984).

Regar lless of which theoretical perspective one adopts, spontaneous, sensitive, social interactions between a mother and infant appear to be of the utmost importance for a child's development. There is disconcerting evic'snce in the literature for continuity between early interactional difficulties and later developmental delay (e.g. Pawlby \& Hall, 1980). Mothers who fail to respond to their child's communications or who intrude upon child-initiated activities distort the interactive process (Tronick, Ricks, \& Cohn, 1982; Stern, 1977), and disrupt the child's sense of competence in controlling his social environment (Watson, 1979, 1985; White, 1959). Failure to establish communication has detrimental consequences for the child's development in many ways; social interactions are often limited, giving the child fewer opportunities to learn and to use communicative skills, resulting in poor communicative abilities, which in turn, may restrict cognitive development as well as social interaction with peers.

\section{Theoretical Approach and Conceptual Framework}

The theoretical basis for the current research was drawn from the ethological theory of attachment (Bowlby, 1969, 1973, 1980) while the conceptual framework was derived from developmental psychopathology (Cicchetti, Toth, \& Bush, 1989; Sroufe \& Rutter, 1984). Although attachment has been viewed in other ways (e.g. Field, 1985; Dollard \& Miller, 1950), Bowlby's ethological theory is the most widely accepted and researched. Field (1985) places less emphasis on the primacy of the infant-mother bond and proposes that

attachment might be viewed as a relationship that develops between two or more organisms as their behavioral and physiological systems become attuned to each other. Each partner provides meaningful stimulation for the other and has a modulating effect on the other's arousal level. (p. 415) 


\section{Attachment Theory}

Attachment theory was initially formulated by Bowlby in order to explain the disturbed functioning of individuals who had experienced traumatic losses or early separations. It has since evolved into a theory of normal development based on "present-day biological principles with an emphasis on ethology and evolutionary theory, as well as control-systems theory and cognitive psychology" (Crittenden \& Ainsworth, 1989, p. 435). The theory has stimulated much research in the area of social-emotional development, and appears to offer explanations for some types of atypical development (Crittenden \& Ainsworth, 1989; Bowlby, 1980).

According to Bowlby, attachment is a behaviour system that has been selected for in the evolutionary history of the species. Through the process oi natural selection, human infants and adults have come to possess mutually complementary behaviours that are useful in promoting proximity. Infants form secure attachment relationships with individuals who consistently and appropriately respond to their proximity-promoting signals and behaviours. Through repeated interactions with these attachment figures, infants develop "internal working models" of the self and others. The formation of a secure attachment relationship allows the infant to develop positive internal working models which lead to feelings of efficacy and an ability to form satisfying future relationships. If an infant's needs are typically left unmet, the infant forms an anxious (insecure) attachment relationship with his primary caregiver and may develop negative internal working models of the self and of relationships in general. These models are thought to act outside of conscious awareness and so are resistant to change. However, change is possible (Sroufe, 1988; Bretherton, 1985; Bowlby, 1980). With the arivent of formal operational thought, adults may be able to rework existing negative representational models into more integrated models of attachment relationships (Main \& Goldwyn, 1984).

Ainsworth elaborated on Bowlby's ideas by developing an innovative methodology for assessing the quality of the attachment bond (Ainsworth \& 
Wittig, 1969). On the basis of the infant's behaviour in the Strange Situation procedure (eight 3-minute episodes arranged to create increasing amounts of stress for the baby), Ainsworth was able to classify infants into one of three groups -- A, B, C. Infants in the B group, considered to be "securely attached", exhibited proximity/contact seeking behaviours after brief separations and used their mothers as a secure base for exploring and interacting with the environment. Infants in the $A$ and $C$ groups were considered "insecurely attached." Those in the A group tended to avoid or ignore their mothers after brief separations, rather than seek interaction; they were classified as "Insecure-avoidant." Those in the C group showed both proximity/contact seeking behaviours and angry, rejecting behaviour toward their mothers; they were classified as "Insecure-ambivalent." The Strange Situation is now the most widely used attachment measure in the area of social-emotional development. Using this procedure, researchers in many parts of the world have shown the classifications to be reliable (e.g. Lamb, Hwang, Frodi, \& Frodi, 1982), to be stable over time (e.g. Vaughn, Egeland, Sroufe, \& Waters, 1979), and to have good predictive validity (Urban, Carlson, Egeland, \& Sroufe, 1991; Erickson, Egeland, \& Sroufe, 1985; cf. Waters \& Sroufe, 1983 for a review).

\section{Antecedents of Attachment}

Ainsworth and her colleagues (Ainsworth, Blehar, Waters, \& Wall, 1978; Ainsworth, Bell, \& Stayton, 1974; Ainsworth \& Wittig, 1969) propose that the quality of the attachment relationship is a function of early patterns of motherinfant interaction. In particular, Ainsworth identifies "sensitive responsiveness" to the infant's needs and signals for proximity and contact as the important determinant (Ainsworth, et al., 1978). In contrast, other theorists (Miyake, Chen \& Campos, 1985; Goldsmith \& Campos, 1982) argue that a child's temperament either plays a major role in shaping the quality of the attachment, or it influences Strange Situation behaviour independent of any differences in the quality of attachment. Additional characteristics of maternal interaction have also been 
linked to attachment quality but the findings are equivocal. In some studies, intrusive and overstimulating maternal behaviours have been found to promote avoidance relationships (Isabella \& Belsky, 1991), and in other studies, ambivalent relationships (Bohlin, Hagekull, Germer, Andersson, \& Lindberg, 1989).

Underinvolvement and too little stimulation have also been linked $t$ ambivalent relationships (Isabella \& Belsky, 1991).

Empirical evidence appears to support Ainsworth and her colleagues but recent reviews of the attachment literature have raised some questions about the robustness of the relation between maternal sensitivity and security of attachment (Goldsmith \& Alansky, 1987; Lamb, Thompson, Gardner, \& Charnov, 1985). Using meta-analysis, Goldsmith and Alansky (1987) found considerabie variability in the reported strength of the relation. Pederson and Moran (Pederson, Moran, Sitko, Campbell, Ghesquire, \& Acton, 1990) have suggested that the variability across studies is a result of difficulty in obtaining a valid assessment of maternal sensitivity rather than any inherent weakness in the theory. They argue that maternal sensitivity must be assessed in contexts where its more subtle attributes may be discerned. Mosi importantly, they stress that meaningful individual differences are unlikely to be observed in the situations of little or no stress commonly used in studies in the area.

Using a procedure that placed the mother in a situation of potentially conflicting demands (the mother was required to complete questionnaires while her infant played nearby), Pederson and Moran (Pederson, Moran, et al., 1990; Smith \& Pederson, 1988; Pederson, Bento, Evans, Chance, \& Fox, 1987) succeeded in developing reliable laboratory and home observational assessments of maternal sensitivity that differentiated between securely and insecurely attached infants. A strong relation between sensitivity and attachment was found in laboratory studies (Smith, 1988; Smith \& Pederson, 1988) as well as in home studies (Moran, Pederson, Pettit, \& Krupka, 1992; Pederson, Moran, et al. 1990).

Empirical evidence for the role played by infant temperament in determining quality of attachment is more contradictory. Some studies have 
shown that maternal ratings of infant temperament on standard questionnaires did not predict attachment classification (Bates, Maslin, \& Frankel, 1985; Belsky, Rovine, \& Taylor, 1984; Egeland \& Farber, 1984; Sroufe \& Egeland, 1981); nor did direct observations of infant temperament (Bates et al., 1985). Indeed, Sroufe (1985) argues that a sensitive caregiver compensates for a temperamentally difficult infant, finding ways to meet the infant's needs :vith warmth and responsiveness, thus ensuring a secure attachment relationship. A few studies have reported associations between temperament and attachment. For example, Frodi (1983) reported that infants classified as insecure-ambivalent at 12 months were rated by their mothers as more difficult, than secure and insecure-avoidant infants. In another study, Stevenson-Hinde \& Simpson (1985) reported that mother and father ratings of infant temperament correlated with attachment security as measured by Waters \& Deane's Q-sort done by the mothers.

It seems likely that temperament does not directly influence the quality of attachment. Current thinking appears to favour a complex, interactive link between temper.iment and attachment security (Bates \& Bayles, 15 Belsky \& Isabella, 1988; Crockenberg, 1981). However, little is known about the relation between infant temperament and maternal interactive behaviour because this. association is usually not analyzed in studies (Field, Dempsey, \& Shuman, 1981). In one study, mothers of fullterm infants who described their babies as difficult were reported to show less physiological response (as measured by heart rate change) to changes in their infants' facial expression (Donovan, Leavitt, \& Balling, 1978). In the current study, associations between maternal interactive behaviours and two measures of infant temperament were examined.

\section{Developmental Psychopathology}

Developmental psychopathology has provided a rich framework for conceptualizing how mother-infant interactions may affect adaptive and maladaptive developmental processes. Researchers within this special discipline of developmental psychology subscribe to an organizational, transactional model of development (Sroufe \& Rutter, 1984; Sameroff \& Chandler, 1975) and consider 
the process of development to be the same in all children, with competence/adaptation resulting from the mastery of a number of important ageand stage-appropriate tasks. Issues at one developmental period are seen as laying the groundwork for subsequent issues, so that the successful resolution of early tasks increases the likelihood of successful resolution of later tasks. A mother's ability to recognize and respond effectively to her infant's changing needs facilitates mastery at each developmental stage. An infant's failure to master a specific stage-salient task may be due to constitutional factors (e.g. neurological impairment), to environmental factors (e.g. inappropriate stimulation), or to a combination of both factors (Sroufe \& Rutter, 1984), and failure may lead to maladaptation anc incompetence. However, later experiences can modify and alter the effects of earlier failures allowing alternative outcomes to occur. If a child exhibits deviant development across time, it is assumed that the child has been involved in a continuous maladaptive process (Cicchetti, 1989).

Age-related developmental issues are "tasks which require the child to coordinate cognition, affect, and behaviour" (Cicchetti et al., 1989, p. 2). Three salient issues have been identified in the first year of life:

(1) Homeostatic regulation and the development of a reliable signalling system (0-3 months). Caretakers play a critical role in the infant's mastery of the tasks related to this issue. Although the behaviour of mother and infant is mutually influential (Lewis \& Rosenblum, 1974), mothers, nevertheless, control the environment that is available to the infant and may thus indirectly affect developmental outcome. They may facilitate homeostasis by providing a predictable and optimally stimulating environment or they may hinder it by providing a chaotic, unpredictable environment. The latter environment may also exacerbate biologically-based homeostatic difficulties such as excessive irritability, passivity, or an inability to be easily calmed (Cicchetti, 1989).

(2) The management of cognitively-produced arousal and the differentiation of affect (about 4 to 6 months). If the infant has successfully mastered the initial developmental tasks, his/her chances of resolving these tasks are increased. 
Because the infant can now signal his/her needs reliably, and balance inner state and external stimuli, $s / h e$ is able to turn his attention to the external environment. Behaviours that were previously internally stimulated are replaced by contingent responses to external stimulation (e.g. reflexive smiles give way to smiles in response to mother's play). As a result, the infant begins to interact with both people and objects in a more organized way.

(3) The development of a secure attachment relationship with the primary caretaker (6-12 mont/is). Although overt attachment behaviours become more evident in the latter half of the first year, the capacity for attachment is said to originate in earlier stages (Sroufe, 1979). Thus, an infant's ability to form a secure attachment relationship may be dependent upon the successful resolution of earlier developmental issues, as well as the mother's continued responsiveness to her infant's changing needs.

To summarize, the infant's ability to elicit maternal responsiveness, as well as the mother's sensitivity to her infant's cues appear to be critical for successful adaptation in the first year of life. If maladaptation at the early stages of development is to be prevented, the role of the mother and her ability to alter dysfunctional patterns of interaction must be addressed since developmental constraints limit direct intervention with the infant. By examining early transactions between high risk mothers and infants, it may be possible to determine when dysfunctional patterns of interaction begin, why they occur, and how they can be ameliorated.

Goals

The research had three broad goals:

The first goal was to examine the process of attachment from a developmental psychopathology perspective in order to gain a better understanding of the factors that may contribute to maladaptive mother-infant interactions and insecure attachment relationships in "at risk" dyads and to ascertain when maladaptive patterns of interaction may first appear. 
The second goal was to provide further validation of a new measure of maternal sensitivity that defines the construct in theory-driven, precise, behaviourally-based terms. The Maternal Behaviour Q-Sort (MBQS) was devised by Pederson \& Moran (1989) in response to perceived deficits in the ability of the sensitivity/insensitivity construct, as currently operationalized, to distinguish between the origins of insecure-avoidant and insecure-ambivalent attachment (Lamb, Thompson, Gardner, \& Charnov, 1985) and to criticisms about the robustness of the link between maternal sensitivity and attachment security (Goldsmith \& Alansky, 1987).

The third goal was to evaluate an early prevention/intervention program based on the principles of attachment theory and guided by a developmental psychopathology perspective. Intervention strategies were designed to enhance maternal sensitivity through positive changes in mother-infant social interactions, thus facilitating secure infant-mother attachments. 


\section{CHAPTER II}

Research design and measures

The present research comprised two studies. Study 1 was designed to investigate the links between mother-infant interactions and optimal development in the first year. A multimethod approach was used to measure different aspects of maternal interactive behaviour and an infant's mastery of important stagesalient tasks at 3, 6, and 13 months, in a sample of adolescent mothers and their babies, in order to assess the quality of mother-infant interactions at three developmental periods and to identify possible precursors to disordered functioning. This is a logical first step in planning intervention programs to prevent or ameliorate lower qualities of mother-infant interactions usually associated with "at risk" dyads (Cicchetti, 1989; Sroufe \& Rutter, 1984).

Study 1 had both a cross-sectional and a longitudinal component, with 68 mother-infant dyads participating. In this way, information concerning the patterns of interaction at the three age points cnuld be obtained from the largest number of dyads available at each age level, just as in the typical cross-sectional study. In addition, data concerning developmental changes that occurred for individual children between 3 and 6 months and 6 and 13 months could also be determined for a smaller number of dyads. By using a cross-sectional/longitudinal design, 137 sets of data were available for analyses: data were collected on 39 dyads with 13-month-old infants, 54 dyads with 6-month-old infants, and 22 dyads with 3-month-old infants. Within the cross-sectional groups, data were available from two longitudinal samples: 22 dyads seen at 3 and 6 months, and 25 dyads seen at 6 and 13 months. A schematic diagram of the composition of each sample 
appears in Appendix C. The design allo: :ed for a larger sample size at each age level in the cross-sectional sample and hence more powerful analyses of the results. At the same time, hypotheses regarding the power of a maternai sensitivity/infant temperament interaction to predict attachment security at $\mathbf{1 3}$ months could be tested in the smaller, longitudinal sample.

Study 2 was designed to evaluate the effectiveness of a theory-driven intervention strategy to enhance the quality of early mother-infant interactions, based on our understanding of the infant-mother attachment relationship and the process of maladaptation/adaptation from a developmental psychopathology perspective. It was longitudinal in design and included an intervention group of 22 mother-infant dyads, who received bi-weekly "intervention" sessions, and a matched comparison group of 23 mother-infant dyads, who did not. The groups were formed through random assignment of dyads with 6-month-old babies from Study 1. Individual differences in mother-infant interactions were used as the basis for the brief intervention [ 9 to 14 sessions] to improve dyadic interactions by changing the mother's interactive behaviour. The goal was to facilitate secure infant-mother attachment relationships through mutually rewarding parent-child interactions. Multivariate analyses were used to examine differences between the two groups in the mother's sensitivity to her baby and in the baby's security of attachment. Data from the two groups were included in the 6-month analyses in Study 1 , and where appropriate, in the 13-month analyses.

\section{Subject Recruitment}

Mother-infant dyads were recruited through various agencies and community groups in London: Bethesda Home for Unwed Mothers, Children's Aid Society, Madame Vanier Children's Services, Merrymount Children's Centre, City of London Social Services Department, and the Family Medicine Department of the University of Western Ontario. Criteria for inclusion in the research were as follows. Young mothers (under 23 years of age), with healthy infants under 13 months of age (no complications during delivery and normal developmental history based on parental report), who had one or more of three risk factors: 
being a teenager, being single, or being poor, and who were the infant's primary caretaker (less than 20 hours per week working outside of the home).

Involvement in a current intervention program was an exclusionary criterion but none of the mothers contacted were involved in interventions.

The author met with small groups of mothers [approximately 3 to 8 mothers] to speak about the research; mothers who expressed an interest in participating in the studies were given an information package containing a letter describing the study, a demographic sheet on which to record her baby's name and birth date, her name, address, birth date and telephone number, and a stamped, self-addressed envelope for returning the demographic sheet. Mothers who returned the sheet were telephoned and an appointment was arranged for the home visits. In addition, an information letter describing the study was included in one mailing of welfare cheques by the city's Social Services Department, and information packages were left at three Family Medicine Centres, to be given to young mothers when they brought their babies in for the 6-week checkup. Informed consent was obtained at the first home visit. [See Appendix A for copies of letters and consent forms.]

\section{Subject Selection}

Information packages were given to 66 mothers following the small-group talks. Sixty-two returned completed demographic sheets. The exact number of mothers who received an information letter through the City's Social Services department is unknown, but 18 mothers called to say that they were interested in participating in the study. Information packages were sent to 15 mothers who met the criteria. Three dyads were not suitable: in two cases, the mothers were beyond the cutoff age, in the other case, the baby was beyond the upper age limit. All 15 mothers who received information packages returned completed demographic sheets. Twenty-four information packages were left at the 3 Medical Centres. Three mothers returned completed demographic sheets. Appointments for home visits were set up with 71 of the $\mathbf{8 0}$ mothers. Six of the mothers could not be reached. Their telephones were not in service when calls were made, and 
they did not respond to letters requesting that they contact us. Two mothers were no longer interested in being in the study when called, and one baby died before a call was made. Three dyads were dropped from the study. Although appointments for initial assessment visits were repeatedly scheduled, the mothers were never at home when observers arrived for the visits. These 12 nothers did not differ on demographic variables from the 68 mothers who participated in the study.

All mothers received ten dollars for each assessment home visit and for the visit to the University. Mothers in the intervention group received five dollars for each training session. All mothers also received a copy of the videotape cf their child.

\section{Data Collection}

Data for the two studies were collected in the subjects' homes by two trained observers, during two home visits one week apart. Mothers were asked to choose a time for the visit when their infant typically was alert and "at his/her best." Each home visit lasted approximately 2 hours and was scheduled for a time that was mutually agreeable to the mother and the observers. During each visit, the behaviours of both mother and child were observed in order to complete Ainsworth Global Ratings Scales (Ainsworth et al. 1978), Maternal Behaviour Qsorts (Pederson \& Moran, 1989), Attachment Behaviour Q-sorts (Waters, 1986; Waters \& Deane, 1985) and the Home Observation for the Measurement of the Environment (Caldwell \& Bradley, 1984). Videotapes were made of key motherinfant interactions and of the infants engaged in all cognitive and communication tasks. These were later coded for both mother and infant behaviours by naive observers. Since the young mother's behaviour under conditions of competing demands was needed for pur . of the study, mothers were asked to respond to interview questions and to complete questionnaires at each visit, with the infant present. The Infant Temperament Questionnaire, Revised (Carey \& McDevitt, 1977) and the High Scope Knowledge Scale (Epstein, 1980) were completed on the first visit; the Parenting Stress Index (Abidin, 1983) and Parental Perceptions 
of Infant Vocalizations (MacLellan \& Miller, 1984) on the second visit. If the mother was unable to complete one of the questionnaires during the visit, it was left and picked up at the next visit. In addition, 13-month-old dyads were brought to the Social Sciences Centre at the University of Western Ontario for the laboratory Strange Situation procedure approximately one-week after the second visit. [See Measures section below for detailed descriptions of all measures and the rationale for their use.]

\section{Measures}

Multiple measures and methods were used to collect data on mother, infant, and dyadic behaviours. As well, mothers and infants were observed interacting in a variety of contexts: (1) semi-structured free-play in which the mother was free to attend only to the infant if she so wished; (2) a "statue game" episode in which the mother remained "still-faced" and unresponsive to her infant for a brief period; (3) a separation-reunion episode in which the mother left the room for short periods of time and then returned; (4) a situation of competing demands in which the mother was required to complete questionnaires and at the same time attend to the needs of her infant; and (5) everyday routines.

The same maternal measures were used at the three infant-age levels except for the Emotional Availability Scale which was not developed for use at 3 months of age. The measures used with the infants were age-appropriate and therefore some measures were used at only one or two age-levels. Where necessary, more detailed descriptions of the procedures associated with the individual measures are provided in the Methods sections of the two studies. Copies of relevant materials are in Appendix B.

\section{Maternal Interactive Behaviour}

In order to gain a better understanding of how relationships between a mother and her child develop, multiple facets of responsive, sensitive maternal behaviour were assessed to yield information about how different measures of maternal interactive behaviour relate to infant behaviours and to each other at 
different developmental levels and across time. Global measures of maternal interactive behaviour were obtained from the mother's overall behaviour observed in various contexts during the $\mathbf{2}$ home visits, while more specific aspects of maternal interactive behaviour were obtained from videotaped semi-structured free play episodes.

Three measures assessed maternal interactive behaviours globally. The first two assessed maternal sensitivity as traditionally conceptualized by Ainsworth and her colleagues (Ainsworth et al., 1978; Lamb \& Easterbrooks, 1981), which can be briefly stated as the ability of a parent to provide contingent, consistent, and appropriate responses to an infant's signals. The third assessed the social and emotional stimulation provided by the mother to the child in the home.

(i) Ainsworth Global Rating Scales (Ainsworth et al. 1978). The Ainsworth Global Rating Scales (AGRS) are nine-point rating scales that summarize the mother's accessibility, acceptance, cooperation, and sensitivity with respect to her child. Each scale contains a lengthy description of the concept in addition to a long paragraph anchoring the odd points on the scale. Interrater reliability is good, ranging frcm $\underline{r}=.82$ on the co-operation-interference scale to $\underline{r}=.98$ on the sensitivity-insensitivity scale in a sample of middle class mothers (Pederson, Moran, et al., 1990). The scales have been used extensively and apper i to be good predictors of attachment security (e.g. Ainsworth et al., 1978).

In the current study, each home observer rated the mother independently. Interrater reliabilities were excellent, with rs ranging from .82 at 3 months to .93 at 13 monihs, mean $\underline{I}=.93$ for the total score. The scores of the two observers were averaged for use in the analyses.

(ii) Maternal Behaviour O-Sort (Pederson \& Moran, 1989). The Maternal Behaviour Q-Sort (MBQS) consists of 90 items that describe parental behaviour derived primarily from Ainsworth's conceptualization of maternal sensitivity. The behaviourally-precise statements are sorted into 9 piles, ranging from very unlike (1) to very like (9), according to similarity with the mother's behaviour during observation periods. The forced distribution of choices facilitates statistical 
treatment of the data and may also prevent "response sets." The procedure produces a continuous measure of maternal sensitivity. The mother's score is the item-by-item correlation between the sort of a particular mother by an observer and a criterion sort descriptive of the ideal, prototypically sensitive mother. This procedure has good inter-observer reliability, $\underline{r}=0.95$ in a sample of middle class mothers and infants (Pederson, Moran, et al., 1990); and $\underline{r}=.97$ in a sample of mothers and high risk infants (Moran, Pederson, et al., 1992). Evidence is accumulating that shows the MBQS to be correlated with other measures of maternal sensitivity and to be a good predictor of attachment security (Moran, Pederson, et al., 1992).

In the current study, each home observer completed the Q-sort independently. Interrater reliability was excellent, with $\underline{\text { s }}$ ranging from .93 at 3 months to .97 at 13 months, mean $\underline{r}=.95$. The scores of the two observers were averaged for use in the analyses.

(iii) Home Observation for the Measurement of the Environment (Caldwell \& Bradley, 1984). The HOME was designed to measure the social and emotional aspects of the child's environment. It comprises six subscales: (1) emotional and verbal responsivity of the mother; (2) avoidance of restriction and punishment; (3) organization of physical and temporal environment; (4) provision of appropriate play materials; (5) maternal involvement with the child; and (6) opportunities for variety in daily stimulation. A total score, as well as six subscale scores are obtained from the number of "yes" answers.

Internal consistency reliabilities (Kuder-Richardson 20) are reasonable, ranging from .44 for Subscale 6 to .89 for Su! cale 4 , and .89 for total score. Test-retest reliability indicates moderate to high stability correlations: $\underline{r}=.45$ over a 9-month period (Allen, Affleck, McGrade, \& McQueeny, 1983) and $\underline{r}=.63$ over a 12-month period (Ramey, Yeates, \& Short, 1984). Moreover, the HOME has been found to predict cognitive outcomes in children when maternal IQ is controlled (Ramey, et al., 1984). 
In the current study $44 \%$ of the HOMEs were completed independently by the two observers. Interrater reliabilities were excellent, with rs ranging from .93 at 3 months to .95 at 13 months, mean $\underline{r}=.94$.

Two measures assessed more specific aspects of maternal interactive behaviour: the first assessed the mother's emotiona! availability during play, the quality of the mother's communication, and the mother's positive and negative affect; the second assessed the pattern of interactions during play, in terms of maternal responsiveness, intrusiveness, and unresponsiveness.

(i) Emotional Availability Scale (Osofsky, Culp, Eberhart-Wright, \& Hann, 1988). [at 6 and 13 months only] The Emotional Availability Scale (EAS) measures the mother's emotional availability in three domains: visual regard, physical contact, and talking, as well as affect exchanges between both members of the dyad. Visual regard was not included in data analyses in the present research. This is an optional domain in the scale and can only be coded when both mother and infant are in complete view during the majority of coded intervals.

The middle three minutes of the semi-structured play interactions in Visits 1 and 2 were divided into twelve consecutive 15 -second intervals with behaviours occurring at the border second scored in the next interval. Scoring the intervals required that the mother and child be visible on the videotape. Intervals in which both mother and child were off camera were not scored. Coding continued until twelve intervals were scored for each play interaction. In each interval, physical contact and talking were rated on a scale of 1 to 5 ranging from no availability to a high level of availability. In general, a score of 1 indicated the mother was unresponsive to her child's cues. A score of 2 indicated functional availability. A score of 3 indicated a mixture of responsiveness and unresponsiveness. A score of 4 indicated the mother's initiative in signalling her availability. A score of 5 indicated the mother was responsive to her infant's cues. Each score represented the best performance observed in a rated interval.

In the current research, scores for the Touching and Talking domains were computed by averaging scores from the two visits. Using the guidelines, outlined 
by Osofsky and her colleagues in their training manual, a global measure of Maternal Attentiveness was computed based on how contingently and consistently the mother responded to her infant's cues in the two domains measured. This score was used as a measure of the mother's emotional availability to her baby during play. The mother's average score in the Talking domain was used as the measure of the quality of her communications to her child. A score of 5 indicates a "turn-taking" mode of communication.

Affect exchanges were rated according to the facial and vocal expressions of the mother and child for each of the twelve 15-second intervals. Several categories of affect exchange were coded: none, shared positive, shared negative, mixed-appropriate, mixed-questionable, one-way mother positive and negative, and one-way child positive and negative. The score for each category wis the total number of intervals in which the particular category was observed. A Positive Affect score was computed for each mother by summing the scores on the shared positive, mixed-appropriate, and one-way mother positive categories. A Negative Affect score was also computed by summing the scores on the shared negative, mixed-questionable, and one-way mother negative.

All tapes were coded by observers who were not at the home visits. To assess reliability, $20 \%$ were coded by a second observer. Interrater reliabilities for the Attentiveness composite and for the Talking domain were good, with $\underline{\text { s }}$ ranging from .82 to .86 , mean $\underline{r}=.84$; reliabilities for the two affect scores were

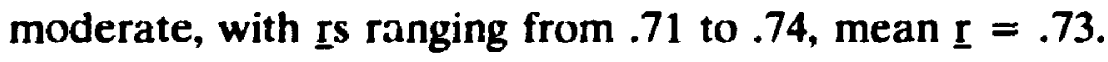

(ii) Child-Adult Relationship Experimental Index (Crittenden, 1981). This coding device was developed by Crittenden to categorize maternal patterns of interaction as controlling/intrusive, unresponsive, or responsive. The CARE contains items that identify differences in maternal behaviour across a wide range of infant ages. Items are also closely tied to the dyadic context so that the behaviours of both partners need to be considered in order to judge the appropriateness of a given behaviour. This measure yields three interrelated 
scores which can be aggregated to form an overall pattern of "responsiveness" score by using the equation:

(responsive score $\times 2$ ) - (intrusive score + unresponsive score)

The author reports interrater reliability of .88 . Using this coding scheme, $74 \%$ of mothers in one high-risk sample and $68 \%$ of mothers in a second high-risk sample were correctly classified according to their welfare service status.

The middle three minutes of the sem -structured play interaction in the second home visit were coded using the procedure outlined by Crittenden (1981). A Pattern of Responsiveness score was computed for each mother for use in data analyses. As well, the scores for Intrusiveness and Unresponsiveness were used in selecied analyses since these two maternal behaviours have been linked to attachment security in the literature (e.g. Belsky, et al. 1984).

All tapes were coded by observers who were not at the home visits. Twenty percent were coded by a second observer for reliability. Interrater reliabilities were computed using Cohen's kappa (Cohen, 1960) which accounts for chance agreement. Reliabilities were good, with kappa values ranging from .67 to .77 , mean $=.73$. Fleiss (1981) describes kappas of .60 to .75 as good, and over .75 as excellent.

\section{Maternal Perceptions and Beliefs}

The results of previous studies suggest that maternal perceptions of infants and events influence how mothers interact with their babies and may thus be important determinants of maternal sensitivity (Fernald, 1984). To test this hypothesis, four psychometrically-sound measures of maternal perceptions were chosen for their relevance to a study of adolescent mothers. It was further assumed that the measures would yield information useful in tailoring intervention sessions to individual dyads in Study 2.

(i) High Scope Knowledge Scale (Epstein, 1980). Scores on the High Scope Knowledge Scale (HSKS) were used to determine the extent to which the mothers in the sample had appropriate expectations of their infant's behaviour. Previous studies have shown that young, low SES mothers often lack knowledge 
about infant development and therefore have inappropriate expectations for their infants in the first two years of life (cf. Miller, 1988 for a review).

The HSKS was designed to assess the appropriatenes 3 of the respondent's expectations for infant development in the first two years of life. Each question requires the respondent to indicate the age (from among 6 age intervals derived from Piaget's substages of sensorimotor development) at which most babies begin to display a particular behaviour, e.g. "When do most babies begin to keep their heads upright and steady without any support?" Scoring procedures allow for a measure of appropriate expectations, as well as the direction of inappropriate expectations (underestimation or overestimation). Total correct, early, and late expectation scores were computed by adding the first, second, and third digits, respectively, across all circled responses. The total number of correct scores, which is a measure of appropriate expectations, was used in the analyses in the current study.

The HSKS has high internal consistency $(\underline{r}=.88)$ and scores correlate significantly with a second knowledge instrument (The Knowledge of Environmental Influences on Developmeni) and with HOME scores (Stevens, 1984).

(ii) The Infant Temperament Questionnaire Revised (Carey \& McDevitt, 1977). The ITQR was designed to assess infant temperament as conceptualized by Thomas \& Chess (1977). Parents are asked to rate the frequency of their infant's behaviour on a scale of 1 (almost never) to 6 (almost $\lrcorner y s$ ). There are 72 questions comprising nine dimensions of behaviour (activity level, rhythmicity, approach-withdrawal, adaptability, intensity of reaction, threshold of responsiveness, distractibility, attention span/persistence and quality of mood), which are then classified into one of 5 typologies: easy, difficult, slow-to-warm-up, intermediate-high; and intermediate-low. Temperament classifications were obtained for each infant through computer scoring of the questionnaires.

Test-retest reliability of the ITQR (1 month) is satisfactory, ranging from .69 (distractibility) to .89 (approach) with a median value of .81 . Alpha reliability 
coefficients are also satisfactory, with a median correlation of .70 , for the nine categories. Although there is some controversy regarding the validity of the ITQR as a measure of infant temperament per se (e.g. Vaughn, Taraldson, Crichton, \& Egeland, 1981), it is nevertheless, used widely in research (e.g. Prior, Kyrios, Oberklaid, 1987). It was chosen because of the concrete nature of the questions, deemed more suitable for the population in the present study.

In the current study, the maternal rating of infant temperament was obtained by summing five temperament dimensions from the ITQR (rhythmicity, approach, adaptability, intensity of reaction, and quality of moe" This measure is an index of the difficult/easy dimension and has been used in previous studies (e.g. Fullard, McDevitt, \& Carey, 1984; Thomas, Chess, \& Korn, 1982). A second composite score was obtained by averaging the sum of six temperament dimensions (scores were inverte 1 to reflect high rhythmicity, high adaptability, high approach, high soothability, high persistence, and positive mood). These rating scal s were selected to estimate the unrotated first factor extracted in factor analyses of the ITOR. (See Matheny, Wilson, \& Thoben, 1987; Wilson \& Matheny, 1981, for first factors reported in the literature, and Appendix D, for first factors extracted at the three age levels in the present sample.) Although this measure has not been used previously, ITQR first factor scores have been used by Matheny in comparisons of laboratory and maternal measures of infant temperament. In this study, it is used as one part of the composite score measuring ise developmental task at 3 months (homecstasis).

(iii) Parental Perceptions of Infant Vocalizations. (MacLellan \& Miller, 1984). The PPIV was used to assess maternal perceptions of their infant as a "communicating" partner. The willingness of a mother to engage in early "dialogues" with her infant may depend upon her ability to accept her infant's vocalizations as attempts at communication. Although most mothers seem to do this spontaneously (Kaye, 1982), young, low SES mothers may not (Fry, 1985).

In the PPIV, mothers indicate their level of agreement (on a scale of 1 to 7 , where $1=$ strongly disagree and $7=$ strongly agree) with a variety of 
statements that were designed "to measure their attributions of meaningfulness to infant vocalizations and their beliefs about the use of language alterations in speech addressed to infants" (p. 129). Two scores are obtained: an aggregate score of the degree to which mothers perceive their infants' vocalizations as "meaningful" and/or related to "real" language, and a Language Alieration score. The questionnaire has been shown to have moderate internal consistency and reliability (item-to-total score correlations ranged from $\underline{r}=.40$ to $.70, p<.005$ to .001 , while Cronbach's Alpha was .75 (Wong, 1986). This measure is relatively new but the authors report on three studies in their laboratory that have suggested that maternal speech to infants may be mediated, at least in part, by their view of the meaningfulness of the infants' vocalizations (Miller, 1988; MacLellan, 1983; Wong, 1986).

(iv) Parenting Stress Index (Abidin, 1983). Responses on the Parenting Stress Index (PSI) were used to determine the levels of stress perceived by the mother, pertaining to the qualities of the child or associated with parent functioning. It is well known that low SES ${ }^{-}$, associated with increased levels of stress, and being a young and single parent as well, may add to the burden. High stress levels, whether associated with the child or with outside factors, have been reported to interfere with a mother's ability to be a sensitive parent (Loyd \& Abidin, 1985). Mothers who had experienced high levels of stress were shown to be less responsive to infant cues and to have fewer positive feelings towards their infants than mothers who had experienced less stress (Crnic, Greenberg, Ragozin, Robinson, \& Basham (1983).

The PSI contains 101 items; 47 items assess stresses pertaining to the qualities of the child (the Child Domain subscale); 54 items assess stresses associated with parznt functioning (the Parent Domain subscale). Material ratings (on a scale of 1 to 5) are summed to yield three stress scores, one for the child domain, one for parent domain, and a total score.

The PSI is both internally consistent (e.g. Alpha reliability coefficients are .95 for the Total stress score, .89 for the Child Domain score, and .93 for the 
Parent Domain score), and stable ( $\underline{\underline{1}}=.96$ over a 3 -month interval) (Loyd \& Abidin, 1985).

Infant Characteristics

It is now widely acknowledged that infant constitutional factors as well as familial situational factors can affect maternal sensitivity and the mother-infant relationship (Ainsworth, 1982; Sameroff \& Chandler, 1975). Therefore, infant characteristics were examined at 3 months, 6 months, and 13 months of age using measures appropriate for the age of the infant.

a) Infant Temperament: The approach to infant temperament takes into account the ambiguity inherent in maternal ratings of temperament. In addition to the standard parent-administered questionnaire described above, the infant's observed behaviour was rated by independent observers using the Infant Behaviour Record (IBR), one component of the Bayley Scales of Infant Development (Bayley, 1969). The IBR consists of 30 descriptive rating scales for behaviours characteristic of children in the first $\mathbf{3 0}$ months of life. These rating scales focus on the child's social orientation, emotional tone, object orientation, attention span, goal directedness, interest focus, and energy. Ratings are based on observations of the child during administration of the BSID. Normative data are available for the different age levels.

The IBR is a relatively common measure of infant temperament (e.g. Goldsmith \& Gottsman, 1981; Matheny, 1980; Plomin \& DeFries, 1985; Wallace, 1989). Factor analyses reveal relatively consistent factors of Affect-Extraversion, Activity, and Task Orientation. For the purposes of this study, composite IBR scores reflecting the affect-extraversion and task orientation factors were computed by averaging the sum of scores on three behavioural dimensions (sociability toward the examiner, emotional tone, and co-operativeness) for the first cluster and four behavioural dimensions (goal directedness, object orientation, attention, and reactivity) for the second cluster. These rating scales were previously selected by Matheny $(1976,1983)$ to estimate the factors extracted from the IBR. 
The affect-extraversion composite was used as the experimenter's rating of infant temperament. The two composites together are seen as estimates of the first factor (unrotated) and as being roughly equivalent to the composite score reflecting the first unrotated factor obtained from the ITQR described in the previous section. The average of these two composites is used in computing the composite score measuring the developmental task at 3 months (homeostasis).

b) Infant Cognitive and Language Development:

(i) The Bayley Scales of Infant Development (Bayley, 1969). The BSID is the most widely used measure of infant development. It was designed to measure development during the first $\mathbf{3 0}$ months of life. The scales were standardized on a large sample of infants and yield three separate scores: the Mental Development Index (MDI) which is a measure of cognitive ability, the Psychomotor Development Index (PDI) which is a measure of motor development, and the Infant Behaviour Record (IBR) which assesses social-motivational variables.

Split-half reliability coefficients reported for the Mental Scale range from .81 to .93 with a median value of .88 , and standard error of measurement values range from 4.2 to 6.9. Inter observer reliability, on the Mental Scale was 89.4 with a standard deviation of 7.1 (Whatley, 1987).

(ii) Mastery Motivation Task (Vietze, Pasnak, Tremblay, McCarthy, and Klein, 1981). [at 6 and 13 months only] In the Mastery Motivation Task (MMT), infants can interact physically with the stimulus materials or they can merely look at them. Toys and objects are grouped according to three types of tasks: Effect Production tasks involve the infant manually producing a visual or an auditory effect (e.g. chime ball, activity centre); the Sensorimotor Skills tasks involve containers from which objects or pieces can be removed (e.g. peg board, objects in a tub); and the Problem Solving tasks involve situations in which an object can be obtained by overcoming a barrier of some kind (e.g. toy behind clear plastic barrier, animal on a string). Reported interrater reliability is satisfactory, ranging from .53 to .94 with a mean of .80 (Yarrow \& Messer, 1983). 
The procedure outlined by Vietze and his colleagues (1981) was followed in the current study, except that six different tasks were presented for 3 minutes each, rather than twelve tasks for 3 minutes each. The number of seconds the infant engaged in specific behaviours was coded in real time using a computer program developed for an earlier study of infant social competence (Symons, 1989). The proportion of time spent in the following behaviours were obtained from the computer print-out: visual attention alone; exploratory behaviour; taskand goal-oriented behaviour (mastery behaviour); off-task behaviour; and social behaviour. For the purposes of the present study, only exploratory behaviour and mastery behaviour scores were used in analyses. Exploratory behaviour scores at 6 months of age were used as an index of the infant's mastery of the stage-salient task for the 6-month developmental level. Mastery behaviour (task persistence) scores constituted a higher level in the hierarchy of exploration behaviours and are thought to be more characteristic of the exploratory behaviour of 13 month olds (Vietze, McCarthy, McQuistun, MacTurk, \& Yarrow, 1983).

All tapes were coded by observers not present at the home visits. Twenty percent were coded by a second observer and interrater reliability was satisfactory, $\underline{I}=.84$ at 6 months, and $\underline{I}=.82$ at 13 months for exploratory behaviour scores, and $\underline{I}=.91$ at both ages for task persistence scores.

(iii) Communication and Symbolic Behaviour Scales. (Wetherby \& Prizant, 1990) [at 13 months only]. The procedure outlined in the CSBS manual was followed, with an experimenter presenting a series of standaid situations designed to entice child-initiated communicative acts. For example, in one situation, the child is given a Cheerio to eat, the cap is replaced on the clear container halffilled with Cheerios while the child watches. The container, which cannot be opened by the child, is then placed in front of the child and the experimenter waits for a response from the child. If the child does not initiate a communicative act, the child is encouraged with a series of prompts. Eight stimulus items were presented and the episodes were videotaped for later coding by trained, naive observers. 
The authors reported interrater reliabilities ranging from 80 to $100 \%$ with an average of $88 \%$ (Wetherby, Cain, Yonclas, \& Prizant, 1988). The internal consistency coefficient, computed for CSBS Total score based on a sample of normally developing children was .93 , and the stability coefficient was .80 . The CSBS is currently being standardized on a sample of normally developing children between the ages of 8 and 24 months.

In the current study, only the number of infant intentional communicative acts per minute were calculated. An intentional communicative act was defined as an event in which the child directs a motoric and/or vocal act toward the adult and awaits a response from the adult. Twenty percent of the tapes were coded by a second observer and interrater reliability was satisfactory, $\underline{\mathbf{r}}=.79$.

c) Infant Security of Attachment: It is well established that the infant-parent attachment relationship is one of the critical areas of development often disrupted in maladaptive/abusive relationships (e.g. Aber \& Cicchetti, 1984). The majority of maltreated infants form insecure attachment relationships (Cicchetti et al., 1989) and those exhibiting early attachment problems are more likely to show developmental deficits in the critical areas of cognition, language, and social interaction (Wolfe, 1985). The infant's security of attachment was measured in two ways:

(i) The Attachment Behaviour Q-Sort (Waters, 1986). This procedure (AQS) consists of 90 descriptive statements which are sorted in 9 piles, ranging from very unlike (1) to very like (9), according to similarity with the infant's behaviour. The forced distribution of choices facilitates statistical treatment of the data and may also prevent "response sets." The procedure produces a continuous measure of security of attachment. The infant's score is the item-by-item correlation between this sort and a criterion sort descriptive of a prototypical securely attached 12-month-old infant. This procedure has good inter-observer reliability, $\underline{r}=.72$ in a sample of middle class mothers and infants (Pederson, Moran, et al., 1990); and $\underline{I}=.80$ in a sample of mothers and high risk infants 
(Moran, Pederson, et al., 1992). The procedure also shows some consistency with strange situation classifications (Galluzzo, 1989).

The AQS sorts were also used to generate scores on the five domains of infants' attachment behaviour derived by Pederson and Moran (1994): Secure Base Behaviour (14 items, Cronbach Alpha $=.81$ ), Affective Sharing ( 3 items, Cronbach Alpha = .76), Compliance ( 6 items, Cronbach Alpha $=.69$ ), Enjoyment of Physical Contact (5 items, Cronbach Alpha $=.93$ ), and Fussy/Difficult (14 items, Cronbach Alpha $=.85$ ). The items comprising each domain are shown in Appendix B.

In the current study, each home observer completed the Q-sorts independently after the second home visit. Interrater reliabilities were good, $\underline{r}=$ .85 , and scores of the two observers were averaged for use in the analyses.

(ii) The Strange Situation Procedure (Ainsworth \& Wit 'ig, 1969). The strange situation consists of eight 3-minute episodes, arranged so that the infant experiences increasingly stressful situations (being in an unfamiliar room, encountering a stranger in the mother's presence, separation from the mother but in the company of the stranger, reunion with the mother, separation from the mother and left alone, return of the stranger, return of the mother). The degree of stress is considered to be mild but if the infant becomes highly distressed on separation, the separation episodes are terminated after 20 seconds. The entire procedure was videotaped for later coding of the infant's responses to reunion with the mother, according to the Ainsworth system. The primary coder was trained by Alan Sroufe.

Classification of children into A (insecure-avoidant). B (securely attached), and $C$ (insecure-ambivalent) categories, on the basis of their behaviour in the Strange Situation, has been shown to be reliable (Lamb, et al., 1982), to be stable over time (Vaughn, Egeland, Sroufe, \& Waters, 1979), and to have good predictive utility (see Waters \& Sroufe, 1983 for reviews). Reported interrater agreement is satisfactory ( $r=.89$ to .93 , Egeland \& Sroufe, 1981). 
In the current study, $50 \%$ of the tapes were coded by a second observer. Interrater reliability was calculated by dividing the number of agreements by the total number of agreements plus disagreements. A $90 \%$ agreement rate was achieved for the three primary classifications.

\section{Interobserver Reliability}

To summarize, all of the Ainsworth Global Rating Scales, Miaternal Behaviour Q-Sorts, and Attachment Q-Sorts (at 13 months only) were completed by each observer independently after the second visit. Interobserver reliabilities were calculated using Pearson correlations. Forty-four percent of the HOME were completed by each observer independently and reliabilities were calculated using Pearson correlations. Twenty percent of the videotapes were coded by two observers and reliabilities were calculated using Pearson correlations or Cohen's kappa statistic, as appropriate. Overall, reliabilities were satisfactory to excellent the values are presented in the section describing the measure and a summary appears in Appendix C.

Six different observers were involved in the home visits and nine different observers were involved in the coding. To test for the presence of bias due to possible halo effects, the scores of Observer $A$ on one variable measured in the home (e.g. MBQS) were correlated with the scores of Observer B on a second variable measured in the horne (e.g. AQS). These correlations were compared with those obtained from averaged scores of the two observers. Since no differences were found, the averaged scores were used in all subsequent analyses in Study 1. In analysing the data in Study 2, further care was taken to minimize any possible bias. If the MBQS score of Observer $A$ was used at Time 1, then Observer B's MBQS score was used at Time 2, along with Observer C's AQS score. Videotapes of interactions in the home and in the Strange Situation were coded by observers who were not present at the particular home visit being coded. All observers with the exception of the author were blind to the experimental condition of the infants. 


\section{CHAPTER III}

Study 1: Relationships Between Babies and Mothers During the First Year

Cicchetti (1990) and other proponents of developmental psychopathology, contend that the nature and etiology of maladaptation in children must be understood before effective prevention/intervention programs can be devised for children at risk for behavioural problems and developmental delays. The paths leading to maladaptation may vary, and therefore, the time when dysfunctional patterns of behaviour first appear needs to be determined and precursors to disordered functioning need to be identified. However, before the patterns of interaction that promote or inhibit adaptive development can be identified, several issues must be addressed. First, the concepts of maternal sensitivity and infant temperament have to be clarified and adequately defined in operational terms (Wachs \& Gruen, 1982). Second, factors that influence maternal and infant behaviour and thereby indirectly affect the quality and quantity of mother-infant interactions have to be identified. Third, the relative importance of prior and contemporaneous interactions to infant development have to be determined.

According to attachment theory, maternal sensitivity plays a key role in the development of mutually satisfying mother-infant relationships (Ainsworth, 1982) but we still have little idea of what patterns of behaviour are critical to the sensitivity-insensitivity construct. Behavioural indices vary from study to study and there is little agreement on the reliability and validity of the measures used to assess this important construct (Goldsmith \& Alansky, 1987). As well, other terms describe very sim:lar behaviours: "responsiveness" (Ainsworth \& Bell, 1974; 
Bornstein \& Tamis-LeMonda, 1989); "contingent responsiveness" (Stevenson, VerHoeve, Roach, \& Leavitt, 1986); "contingency" (Watson, 1979, 1985); and "reciprocity" (Brazelton, Koslowski, \& Main, 1974), making it difficult either to adopt a uniform objective measure of sensitivity or to place the concept in a clear developmental framework.

Lamb and Easterbrooks (1981) list the defining characteristics of maternal sensitivity as contingency, consistency, and appropriateness of an adult's responses to an infant's signals and needs (p.127). Some researchers examining the links between mother-infant interactions and cognitive development stress the temporal contingency of infant signals and maternal responses with less emphasis on the qualitative aspects of maternal behaviour (e.g. Watson, 1979; Watson, Hayes, \& Vietze, 1982). Others, perhaps more interested in social-emotional development, emphasize the qualitative aspects of maternal behaviour, and argue that emotional availability of the caregiver in infancy may be "the most central growth-promoting feature of the early rearing experience" (Emde, 1988, p.32). They suggest that emotional communication is important to the formation of infant-mother relationships, and that consistent positive affective exchanges between mother and infant facilitate infant development (Osofsky \& Eberhart-Wright, 1988).

There is support for both points of view suggesting that different aspects of maternal behaviour may be important for different domains of child development. However, it is more likely that the nature and quality of early experiences have a powerful simultaneous effect on both cognitive and social-emotional development. Since cognition and emotion may be interrelated (Lewis, Sullivan, \& Michalson, 1984), it may not only be difficult to separate what is cognitive from what is socialemotional in early infancy, it may also be somewhat artificial (Wachs \& Gruen, 1982). Certainly, emotional signalling between infant and caregiver forms the basis for communicating needs, intentions, and satisfactions in early infancy (Cicchetti, Ganiban, \& Barnett, 1990) and striking effects of maternal emotional availability on infant exploration and play have been reported (Sorce \& Emde, 1981). As well, experimental studies using social and non-social stimuli provide 
ample eviderice that contingent stimulation facilitates learning in young infants and engenders positive affect and feelings of efficacy (Gekoski, Rovee-Collier, \& Carulli-Rabinowitz, 1984; Watson, 1985). The fact that infants only days old are capable of learning contingencies suggests that very early mother-infant interactions are important for optimal child development, since mothers not only create environments in which non-social contingencies are to be found, they themselves are contingent or noncontingent social stimuli (Lewis \& Goldberg, 1960; Watscn, 1985).

\section{Salient Components of Maternal Sensitivity}

Recently, several researchers have sought to identify salient components of maternal sensitivity. Bohlin and her colleagues (Bohlin, Hagekull, Germer, Andersson, \& Lindberg, 1989), delineated three components, namely: responsiveness to infant signals and communications, emotional physical contact, and intrusiveness (active maternal behaviour not geared to infant signals). They observed 116 Swedish mother-infant pairs in three situations: face-to-face Interaction, diaper change, and feeding, when infants were 4 months old, and in a separation-reunion series performed at home, when the infants were 12 months old. The combination of maternal physical contact and responsivity observed at 4 months was found to predict infant insecure-avoidant attachment behaviour at 12 months, whereas maternal intrusiveness álone predicted insecure-ambivalent attachment. A global rating of sensitivity added significantly to the prediction of ambivalent, but not avoidant, attachment behaviour.

Earlier, Belsky and his colleagues (Belsky, Rovine, and Taylor, 1984) saw the amount of stimulation provided by the mother as one aspect of sensitive parenting and tested the hypothesis that insecure-avoidant infants receive too much stimulation, insecure-ambivalent infants receive too little stimulation, and secure infants receive intermediate levels of stimulation during mother-infant interactions. Sixty middle-class mothers and their infants were observed in the home for 45 minutes when infants were 1,3 , and 9 months of age, and in the laboratory Strange Situation procedure when infants were 12 or 13 months of age. 
The researchers found, that at 9 months, avoidant infants experienced the most reciprocal interaction, ambivalent infants the least, with securely attached infants in between. They also found that insecurely attached infants were significantly more irritable at 3 and 9 months than securely attached infants, but found no significant difference in the amount of close bodily contact between secure and insecure infants.

In another study of middle-class mothers and infants, Bates and his colleagues (Bates, Maslin, \& Frankel, 1985) looked at five maternal behrviours including maternal affectionate contact, maternal responsiveness to infant cues, and intensity of positive and negative maternal involvement. Dyadic interactions were observed during two 3-hour home visits when infants were 6 months of age and one 3-hour home visit when infants were 13 months of age. The dyads were also seen in the laboratory Strange Situation at 13 months. In addition to behavioural observations, the $\mathrm{H}$ IE was completed as well as two measures of infant temperament (the Infant Characteristics Questionnaire (ICQ), Bates, Freeland, \& Lounsbury, 1979, and either the Infant Behaviour Questionnaire (IBQ), Rothbart, 1981 or the Revised Infant Temperament Questionnaire (ITQR), Carey and McDevitt, 1977. Sixty-six percent of the infants were classified as securely attached, $13 \%$ as insecure-avoidant, $16 \%$ as insecure-ambivalent, and $5 \%$ as mixed avoidant-ambivalent. The mother's affectionate contact observed in the home visits at 6-months of age was positively correlated with security of attachment at 13-months of age, as were the scores on three of the six HOME scales (Organization of the Environment, Emotional and Verbal Responsivity, and Maternal Invoivement).

Still other researchers have looked at maternal expressiveness during play (Estes, Lamb, Thompson, \& Dickstein, 1981), maternal voc '!zing, touching, and mutual interactions (Antonucci \& Levitt, 1984), maternal supportiveness (Matas, Arend, \& Sroufe, 1978), and at extremely maladaptive maternal caregiving, namely abuse and neglect (Lamb, Gaensbauer, Malkin, \& Shultz, 1985; SchneiderRosen \& Cicchetti, 1984). Although the findings support the general hypothesis 
that sensitive maternal behaviours are associated with secure attachment, Lamb and his colleagues (Lamb, Thompson, Gardner, \& Charnov, 1985, p. 94) argue that researchers may only be assessing a broader dimension of "good" vs "bad" mothering rather than constructs like maternal sensitivity. They suggest that defining maternal sensitivity in more precise, behaviourally-based terms may prove useful in testing more specific hypotheses concerning the origins of insecureavoidant and insecure-ambivalent attachment.

Wiesenfeld and Malatesta (1983), also, point out that the "original theoretical link between attachment and maternal sensitivity was based on a study of only 23 mother-infant pairs" (p. 174) and warn that much more research is needed before the effects of subtle variations in maternal sensitivity on infant development can be understood. According to these authors, sensitivity involves adaptation and change, and therefore, a single measure of maternal sensitivity may not be appropriate across all phases of the child's development.

\section{Correlates of Maternal Sensitivity}

Most studies have not looked at factors that may influence how mothers interact with their " fants. Research has only recently begun to focus on how maternal perceptions and cultural beliefs affect a mother's behaviour during mother-infant interactions, and thus indirectly influence child development. Crosscultural studies confirm that cultural beliefs concerning the rnle and status of the child determine how parents interact with infants (Schieffelin \& Eisenberg, 1984), and studies are now appearing that show personal beliefs (about their child's temperament, cognitive ability, language comprehension, appearance, and so on) may also determine how mothers interact with their babies. The effect of maternal perceptions on behaviour toward young infants is most clearly seen in the numerous studies showing that mothers adjust their speech to infants (e.g. Snow, 1977; Fernald, 1984). As well, studies of interactions between mothers and

their "at risk" infants support this hypothesis. For example, mothers may not hold their $\mathrm{pl}$-mature infants close during feeding because they perceive their babies to be frail (Goldberg, Brachfeld, \& Divitto, 1980), and they may not play with their 
young handicapped infants because they believe their babies to be incapable of exploring and playing (Mogford, 1977). Unfortunately, many of these studies only report mothers' comments anecdotally, most have no* measured maternal perceptions. Nonetheless, this is a highly plausible hypothesis: mothers who are made aware of their infant's capabilities through intervention, often alter their behaviour to reflect their new perceptions (Field, 1980, 1982; Widmayer \& Field, 1980).

The relationship between maternal behaviours and perceptions of their children's cognitive abilities has been measured in several studies (cf. Miller, 1988, for a review). In one study, behaviours were assessed through videotaped observations of mother-infant interactions and perceptions were assessed with the High Scope scale (Epstein, 1980). Modest relationships were found between maternal underestimation of infant ability and a no-taiking style of interaction. In another study (Fry, 1985), modest relationships were found between mothers' knowledge and several adaptive maternal behaviours, including verbal and physical stimulation of the infant and reciprocal interaction with the infant, behaviours thought to be important for development.

How maternal perceptions of infant temperament influence maternal behaviour is of considerable interest to researchers studying attachment. As with maternal sensitivity, there is some disagreement on how temperament should be operationally defined and measured. Most researchers agree that temperament refers to an individual's constitutionally-based, relatively enduring behavioural/emotional style (Campos, Barrett, Lamb, Goldsmith, \& Stenberg, 1983), but the ambiguity inherent in the standard measures of temperament is problematic. The measures bear some relation to the infant's observable behaviour, but they also bear some relation to the parent's own long standing characteristics (Bates, 1987), making clear interpretations difficult: the child may truly be irritable or only perceived to be irritable by the parent. This difficulty is cogently illustrated in a study by Larrance \& Twentyman (1983). When abusive, neglecting, and control mothers were presented photographs of their own and 
other children engaging in aversive and non-aversive behaviours, both abusive and neglecting mothers rated their children's behaviour more negatively than control mothers.

Researchers outside of attachment theory have argued that Strange Situation behaviour can be explained by temperamental differences rather than experiential history: some babies are constitntionally inclined to be more distressed by unfamiliar or unexpected events than other babies (Thomas, Chess, \& Korn, 1982; Kagan, 1982). Arguing for a more indirect link between temperament and quality of attachment, Goldsmith and Campos (1982) suggest that parents may not be able to read the signals of a "difficult" infant easily and may therefore have problems responding appropriately, or alternately, their own longstanding characteristics may make it difficult for them to manage these babies easily. In either case the outcome is the same: dyadic interactions are disrupted leading to insecure attachment.

Although there is no consistent evidence that infant temperament, whether perceived or real, has any direct effect on attachment, there is some evidence suggesting that there may be more indirect, interactive effects. For example, Crockenberg (1981) found that irritable babies were more likely to be insecurely attached when mothers reported low social support. However, there are relatively few studies that have evaluated these complex models and more are needed before the indirect influences of temperament can be ascertained.

\section{Prior versus contempolaneous patterns of interaction}

Early maternal behaviours have been linked to subsequent developmental outcome in cognitive, language, and social-emotional domains (Beckwith \& Cohen, 1984; Siegel, 1984; Crnic, Greenberg, Ragozin, Robinson, \& Basham, 1983). For example, maternal responsiveness during mother-infant interactions at 4 months of age was found to be related to the child's cognitive development at 12 months of age (Bornstein \& Tamis-LeMonda, 1989). Maternal contingent responsiveness during interactions with 20-week-old infants was found to be related to the child's language development at 27 months of age (Pawlby \& Hall, 1980). In a now 
classic study, Ainsworth and her colleagues (Ainsworth \& Wittig, 1969; Ainsworth, Bell, \& Stayton, 1974; Ainsworth, Blehar, Waters, \& Wall, 1978) examined the relationship between prior maternal behaviour observed during mother-infant interactions in the home and subsequent infant behaviour in the Strange Situation and came to the conclusion that the quality of attachment was related to early patterns of mother-infant interaction. Recent findings reported by Pederson and his colleagues support this conclusion. Maternal sensitivity ratings based on observations during home visits at 9 months of age predicted the quality of attachment at 12 months of age (Pederson, Moran, et al., 1990), and maternal sensitivity ratings at 12 months of age predicted attachment at 18 months of age (Pederson, Moran, \& Bento, 1993). In contrast, Lamb and his colleagues argue that contemporaneous rather than early interactions are predictive of attachment security, and suggest that significant associations between prior interactions and subsequent infant behaviour are due to continuity in maternal behaviours across time (Lamb et al., 1985).

The current study

In the current study, maternal sensitivity is conceptualized as the ability of a parent to provide contingent, consistent, and appropriate responses to the infant's needs and signals for proximity and contact (Ainsworth et al., 1978; Lamb \& Easterbrooks, 1981), and it was operationally defined in precise, behaviourallybased terms by the Maternal Behaviour Q-Sort. (See Measures section in Chapter II for a brief description of the MBQS and Appendix B for the 90 descriptive items.) To allow for further validation of the MBOS, maternal sensitivity was assessed by a second measure of sensitivity used extensively in research, and other more specific aspects of responsive maternal interactive behaviour (emotional availability during play, the quality of her communications to her infant, her intrusiveness during play, her positive and negative affect, and the provision of an optimally stimulating social and emotional environment in the home) were also assessed. Based on the findings reported by Pederson, Moran, et al., (1990), MBQS scores were expected to be significantly related to scores 
obtained from the other measures of maternal interactive behaviour. Further, it was expected that domain specific maternal behaviours, capable of distinguishing between insecure-avoidant and insecure-ambivalent dyads, would be identified in the MBQS, just as domain specific child attachment behaviours had been identified in the Attachment Behaviour Q-Sort (Pederson \& Moran, 1994).

Temperament was conceptualized as a constitutionally-based, relatively enduring behavioural/emotional style (Campos et al., 1983). In response to the inherent ambiguity in parental response measures, temperament was operationally

defined and measured in two ways: (1) by the affect/emotionality factor (sociability toward the examiner, co-operativeness, and mood) derived from the Infant Behaviour Record completed by the experimenter, and (2) by the difficult/easy temperament dimension (adaptability, approach/withdrawal, mood, intensity, and rhythmicity) derived from the mother's responses to the Infant Temperament Questionnaire - Revised. A comparison of the two measures is presented in Appendix D.

\section{Hypotheses}

Sensitivity is predicted to be the most important characteristic of maternal interactive behaviour influencing the developing attachment relationship. Three hypotheses were postulated:

1) Based on the Developmental Psychopathology perspective, maternal sensitivity was expected to be associated with the infant's mastery of stagesalient tasks during the first year: that is, with the regulation of physiological and affective arousal (homeostasis) at 3 months; with the infant's exploratory behaviour at 6 months; and with secure infant-mother attachment relationships at 13 months.

2a) Based on Attachment theory and on the results of previous studies, mothers of children in secure attachment relationships, as judged by Strange Situation classification, were expected to receive higher ratings in sensitivity than mothers of chilaren in anxious/insecure relationships; mothers of children in insecure-avoidant relationships were expected to be 
more intrusive in their interactions with their children than mothers of children in secure attachment relationships.

2b) Children in secure attachment relationships were not expected to differ in ratings of temperament from children in insecure relationships, although children in insecure-ambivalent relationships might be fussier or more "difficult" than children in secure attachment relationships.

2c) Children in secure relationships, as judged on the basis of their behaviour in the strange situation (B classification) were expected to have higher attachment security scores, as judged on the basis of their behaviour in the home (AQS scores). Furthermore, children in secure relationships were expected to engage in more secure base behaviour, to be more compliant, anc to engage in more affect sharing when interacting with their mothers at home, than children in insecure relationships; children in insecure-avoidant relationships were expected to enjoy contact less than children in secure or insecure-ambivalent relationships, whereas, children in insecure-ambivalent relationships were expected to be fussier than children in secure or insecure-avoidant relationships when interacting with their mothers at home.

3a) Based on the organizational perspective implicit in Developmental Psychopathology, higher scores in homeostasis at 3 months were expected to be associated with higher scores in exploratory behaviour at 6 months. Higher scores in homeostasis at 6 months and higher scores in exploratory behaviour at 6 months were expected to be associated with higher scores in attachment security at 13 months;

3b) Based on Attachment theory, higher levels of maternal sensitivity at 6 months were expected to be predictive of secure infant-mother attachment relationships at 13 months;

3c) Based on the equivocal findings in the literature, infant temperament at 6 months was not expected to be predictive of infant-mother attachment 
relationships at 13 months although an interaction between maternal sensitivity and temperament might add to prediction.

To test the first hypothesis, contemporaneous associations among various aspects of maternal interactive behaviour, infant characteristics, and the infant's mastery of stage-salient developmental tasks were assessed in three cross-sectional samples: 22 dyads with 3 month old babies, 54 dyads with 6 month old babies, and 39 dyads with 13 month old babies.

To test the second set of hypotheses, contemporaneous associations between infant-mother attachment relationships and several aspects of materna! interactive behaviour (sensitivity, intrusiveness, emotional availability) and infant characteristics (temperament), which have been linked to the quality of attachment, were assessed in a larger sample of dyads with 13 month old babies, which included the 39 dyads from the cross-sectional sample plus 22 dyads who had received a brief intervention aimed at increasing maternal sensitivity.

To test the third set of hypotheses, repeated observations across the first year were available on two longitudinal samples ( 3 to 6 months and 6 to 13 months). Associations between maternal interactive behaviour at 3 months and infant characteristics at 6 months (and vice versa) were assessed, as were associations between maternal interactive behaviour at 6 months and infant characteristics at 13 months (and vice versa).

\section{Method}

Subjects. Sixty-eight mother-infant dyads participated in Study 1 but the number of dyads assessed at the three age points varied due to the cross-sectional and longitudinal design of the study. The numbers and composition of each age group are presented in Appendix C. Briefly stated, in the cross-sectional component, the 3-month sample consisted of 22 of the dyads; the 6-month sample consisted of the 22 dyads seen at 3 months plus 32 new dyads for a total of 54 dyads; the 13-month sample consisted of 12 dyads seen at 3 and 6 months, 13 dyads seen at 6 months, and 14 new dyads fo: a total of 39 dyads. In the longitudinal component, the 3 to 
6 month sample consisted of the 22 dyads from the cross-sectional sample seen at 3 and 6 months; the 6 to 13 month sample consisted of 12 of these 22 dyads plus 13 of the other 32 dyads seen at 6 months from the cross-sectional sample.

Table 3.1 presents a demographic summary of the sample. At the time of the baby's birth, mothers ranged in age from 14 to 23 years (mean age $=17.85$, $\underline{\mathrm{SD}}=1.94)$. The low family incomes reported by the mothers indicate that the sample was economically disadvantaged. They may also have been socially disadvantaged since the lives of many of the young mothers appeared to lack stability, as reflected by the changes in demographic measures noted in the table. At some time during the course of the study, half of the mothers living at home moved out on their own, 9 of the 24 mothers living with a partner were no longer in the relationship, one of the married couples separated, and 5 single mothers began living with a partner. Approximately thirty-five percent of the mothers reported histories of abuse and/or neglect.

On the plus side, all mothers had received prenatal care and all infants were reported to be healthy and normally developing. Fifty-one percent of the babies were boys and forty-nine percent were girls; $85 \%$ of them were first-born. For the 3-month data collection, the average age of the babies at the time of the first assessment visit was 99.14 days ( $\underline{\mathrm{SD}}=9.42$ days, range 90 to 120 days), for the 6-month data collection, 187.76 days $(\underline{\mathrm{SD}}=7.47$, range $180-210$ days), and for the 13-month data collection, 395.60 ( $\underline{\mathrm{SD}}=6.14$, range 384-422 days).

Procedure at 3-months of age

Mothers were telephoned the day before a scheduled visit to remind them of the appointment and to briefly describe what would be happening. Each home visit consisted of three or four planned episodes interspersed with periods when the mother carried out usual caretaking routines. The visits often included feedings and diaper changes and lasted approximately two hours.

First visit. The planned episodes included:

(1) About 15 minutes. The first few minutes of the visit were spent answering questions and casually talking to the mother to put her at ease. After 
Table 3.1

Demographic variables

Percentage in each category at the beginning of the study

$$
[\mathrm{N}=68]
$$

Mother's age at baby's birth $17.85(\mathrm{SD}=1.94)$

Maternal education

(Gr. 13) $\quad 3 \%$

(Gr. 12) 32\%

(Gr. 11) $57 \%$

(Gr. 10) 7\%

Family Income

$\begin{array}{ll}<\$ 10,000 & 22 \% \\ <\$ 15,000 & \$ 3 \% \\ <\$ 20,000 & 16 \% \\ <\$ 25,000 & 8 \%\end{array}$

Single*

Married*

$91 \%[91 \%]$

$9 \%[7 \%]$

Co-habiting*

Attending school*

Living at home*

Male children

$35 \%[29 \%]$

$55 \%[38 \%]$

$38 \%[19 \%]$

Female children

$51 \%$

First-born

$49 \%$

$85 \%$

*number in parentheses indicates percentage at end of study 
the mother signed the informed consent, she was asked to do whatever she pleased "while the observers got the equipment ready for videotaping."

(2) About 10 minutes. The mother was instructed to plav ' 'th her baby for 5 minutes, as she would normally do if we were not present. At the end of the 5 minutes, she was to play a "statue" game for 2 minutes and remain completely still and unresponsive to her baby, after which she was free to interact with the baby in any way that felt comfortable to her. Mothers were prompted when to change from play to still-face and from still-face to play, but no further instructions were given. If the baby became too upset during the still-face procedure, the time was shortened. Mothers were told that we were interested in how different mothers play with their babies and how babies react when their mothers stop playing unexpectedly. The entire play episode was videotaped for later coding by naive observers.

(3) About 45 minutes. The High Scope Knowledge Scale and Infant Temperament Questionnaire Revised were explained to the mother and she was asked to complete them with the baby present in the room. She was told that we were interested in how the baby behaves when she is busy doing something. After 20 minutes, mothers were told that any uncompleted questionnaires would be left in the home, and that we were interested in knowing more about her baby and her experiences as a parent. The interview was conducted in a friendly, casual, conversation-like manner. The baby's presence during this time was not a requirement and mothers could put the baby down for a nap if they so wished. One questionnaire was usually unfinished and needed to be left for the mother to complete before the next visit.

Second Visit. This visit took place approximately one week after the first visit and usually lasted about two hours. The planned episodes included:

(1) About 15 minutes. The first few minutes of the visit were spent asking about the baby's week, answering questions that might have arisen since the last visit, and in general, making the mother feel at ease. The mother was then asked 
to do whatever she pleased "while the observers got the equipment ready for videotaping."

(2) About 40 minutes. The Bayley Scales of Infant Development was administered to the baby by a trained observer. A set of standardized manipulable objects, as well as objects for visual and auditory prese..tation were presented to the baby lying on a blanket spread out on the floor. The mother held the baby for those tasks that required the baby in a sitting position. The Infant Behaviour Record was completed following test administration. Administration of the BSID was videotaped for use as a reliability check.

(3) About 10 minutes. The semi-structured play episode described in Visit 1 was repeated. As in Visit 1, the entire play episode was videotaped for later coding by naive observers.

(4) About 45 minutes. The Parenting Stress Index and Parental Perception of Infant Vocalizations were explained to the mother and she was asked to complete the questionnaires with the baby present in the room. When the mother completed both questionnaires, she was told that we were interested in knowing a little more about her baby and her experiences as a parent. The interview was again conducted in a friendly, casual, conversation-like manner. The baby was usually present but was not required to be.

\section{Procedure at 6-Months of Age}

The procedure for the two home visits at 6-months was essentially the same as that at 3-months with the following changes:

(1) Two age-appropriate toys (a soft, cloth dog-rattle and a furry, white teddy-bear puppet) were provided for the play episode in the first home visit. The mother was told that she could use them or not, as she pleased. (No toys were provided for the play episode in the second home visit.)

(2) A 4th episode (about 25 minutes) was added in the first home visit. The Mastery Motivation task, described previously, was administered to the baby seated on his/her mother's kap. Six different toys were presented to the baby for three minutes each, according to the standard procedure outlined by Vietze and 
his colleagues (1981). [See Appendix B.] Five of the toys were purchased (Fisher Price chime ball, Fisher Price activity centre, Fisher Price turtle pull-toy, Playskool plastic eggs in a carton, and a plastic bucket with small plastic animals and figures that could be taken out and put back in), and one was made in the Psychology department workshop (a free-standing clear plastic barrier behind which a squeaky plastic animal could be placed). An effect-production task was presented first (chime ball), followed by a problem-solving task (toy behind clear plastic barrier), and a sensori. otor-skills task (objects in a tub). The same order of tasks was then repeated using the other three toys (activity centre, turtle pull-toy, eggs in carton). Each toy was demonstrated by the experimenter before being put down on the table before the baby. If the baby showed no interest in the toy it was demonstrated again at 30 seconds and at 90 seconds. The mother was asked to just observe her baby as we were interested in seeing what the baby did on his/her own. She was told to respond naturally if her baby initiated any social interaction and to comfort the baby if $s /$ he got upset.

\section{Procedure at 13-Months of Age.}

The procedure for the two home visits at 13 months was essentially the same as at 3 and 6 months with the following changes:

(1) A series of separations and reunions patterned after the Strange Situation procedure (Bohlin et al., 1989) were carried ou: at the beginning of the first visit. One observer came into the room to set up the semi-structured play situation before the second observer entered the room. A standard set of ageappropriate toys [Two telephones, a plastic car with figures, a train engine, a ball, a plastic toaster with pop-up toast, a cradle with a small doll, a soft plush animal, and two books] were placed on the floor and the mother was asked to introduce her baby to the toys. When the baby was engaged with the toys, the second observer entered the room, talked briefly with the mother and got down to play with the baby. The mother was instructed to leave the room and to stay outside until the observer signalled by knocking after approximately 3 minutes. The mother called the child's name and paused at the door before coming back into 
the room. The mother was told that she could return before the knock if she wished to. During the first separation, the infant's immediate search behaviour was noted and the observer stopped interacting and moved away from the child shortly before the mother re-entered. During reunion, mothers were told to do whatever felt comfortable for approximately 3 minutes, or longer if the baby was distressed. The mother was instructed to leave again and to return after 3 minutes, but this time, the observer did not interact with the baby. Instructions for the reunion episode were as before with mothers free to return sooner if the baby became very distressed.

(2) A standard set of age-appropriate toys was provided for use in the play episodes which the mother could or could not use, as she pleased. In the first home visit the toys included a tea set, stacking cups, a car with 2 Fisher-Price play people, a book, and a ball; in the second home visit the toys included a Playskool shape sorter, Fisher Price stacking rings, and a Fisher Price water puzzle.

(j) The Mastery Motivation task was administered to the baby a sscribed at 6-months. At this age, the baby was seated in a highchair and the toys presented were appropriate for 13-month-olds. Four toys were purchased [Fisher Price surprise box, Fisher Price barn, Fisher Price house, Fisher Price shape sorter], and two were made in the psychology department workshop [a wooden boat with 3 pegs and a detour box with a plexiglass sliding door].

(4) The Intentional Communications task was administered during the second home visit. This procedure involved the experimenter presenting a series of eight standard situations designed to entice child-initiated communicative acts and responding naturally to the child's acts. The child was seated in a highchair with the mother observing nearby. The stimulus items presented included: 1) a wind-up bird, 2) a balloon, 3) bubbles, 4) peek-a-boo, 5) blocks in a box, 6) Cheerios in a closed container, 7) five small toys in a bag, and 8) a book. The entire episode was videotaped for later coding by naive observers. In addition to the two home visits, 13-month-old infants and their mothers were picked up and brought to the Social Sciences Centre at the University of Western 
Ontario, within one month ( $+/-2$ weeks) after the second home visit, for the laboratory Strange Situation procedure, described in the Measures section.

Results

Prior to analysis, maternal and child variables were examined separately at each age level through SPSSPC programs for accuracy of data entry, missing values, and fit between their distributions and the assumptions of multivariate analysis. Since all variables were essentially normal in distribution no transformations were necessary. The results of the first study are presented in five sections. Analyses pertaining to the validation of the MBQS are reported in Section 1. Analyses pertaining to the first hypothesis (associations between maternal sensitivity and the infant's mastery of stage-salient tasks at 3 developmental levels) are presented in Section 2. Analyses pertaining to the second set of hypotheses (associations between Strange Situation classification and behaviour ass ssed in the home) are presented in Section 3. Analyses pertaining to the third set of hypotheses (maternal sensitivity and temperament at 6 months as predictors of attachment security at 13 months) are presented in Section 4 . A narrative description of maternal perceptions at the three ages is presented in Section 5. No statistical analyses were carried out on the data presented in this final section; the aim of this section is to generate ideas and hypotheses. Because the research design has both a cross-sectional and a longitudinal component, the number of subjects vary, depending on the analyses in question. Relatively small sample sizes and wide variability are often problematic for finding statistically significant results, and therefore, marginally significant results at $\mathbf{p}<.10$ are also presented as possible hypotheses for further study.

\section{Section 1: The Maternal Behaviour Q-Sort (MBOS)}

Further validation of the MBOS. The validity of this relatively new measure of sensitivity was assessed by Pearson product-moment correlational analyses. Intercorrelations between MBQS scores and other measures of maternal interactive behaviour at three age levels are summarized in Tables 3.2 to 3.4 . At 
Table 3.2

Correlations among measures of maternal behaviour:

Dyads with 3-month-old infants $(\mathbf{N}=22)$

\begin{tabular}{|c|c|c|c|c|}
\hline & MBQS & $\begin{array}{c}\text { AGRS } \\
(1-5)\end{array}$ & $\begin{array}{c}\text { HOME } \\
(1-7)\end{array}$ & $\begin{array}{l}\text { CARE } \\
(1-3)\end{array}$ \\
\hline MBQS 1. & 1.00 & $\begin{array}{l}.93^{2} \\
.74^{2} \\
.81^{*} \\
.73^{2} \\
.91^{2}\end{array}$ & $\begin{array}{l}.58^{b} \\
.55^{b} \\
.37^{d} \\
.13 \\
.18 \\
.63^{b} \\
.21\end{array}$ & $\begin{array}{c}.22 \\
-.44^{c} \\
.12\end{array}$ \\
\hline AGRS 1. & & $\begin{array}{c}1.00 \\
.87^{2} \\
.90^{2} \\
.74^{2} \\
.95^{2}\end{array}$ & $\begin{array}{l}.57^{b} \\
.5 \\
.18 \\
.18 \\
.17 \\
.64^{b} \\
.28\end{array}$ & $\begin{array}{l}.28 \\
-.39 \\
-.00\end{array}$ \\
\hline HOME 1. & & & $\begin{array}{c}1.00 \\
.83^{\mathrm{a}} \\
.20 \\
.52^{\mathrm{c}} \\
.68^{\mathrm{a}} \\
.86^{\mathrm{a}} \\
.51^{\mathrm{c}}\end{array}$ & $\begin{array}{r}.00 \\
-.20 \\
.17\end{array}$ \\
\hline CARE 1. & & & & $\begin{array}{l}1.00 \\
-.62^{b} \\
-.70^{a}\end{array}$ \\
\hline
\end{tabular}

${ }^{\prime}=\mathrm{p}<.001 \quad \mathrm{~b}=\mathrm{p}<.01 \quad \mathrm{c}=\mathrm{p}<.05 \quad \mathrm{~d}=\mathrm{p}<.1$

MBQS (Maternal Behaviour Q-Sort)

AGRS (Ainsworth Rating Scales) 1 = total;

2 = acceptance; 3 = accessibility; 4 = cooperation; 5 = sensitivity.

HOME (Home Observation for the Measurement of the Environment)

1 = total; 2 = emotional \& verbal responsivity; 3 = avoidance of restriction \& punishment; $4=$ organization of environment; 5 = provision of appropriate play materials;

$6=$ involvement with child; $7=$ variety in daily stimulation.

CARE (Child-Adult Relationship Experimental Index): 1 = overall pattern of responsiveness;

2 = intrusive; 3 = unr.sponsive. 
Table 3.3

Correlations amone measures of maternal behaviour:

Dyads with 6-month-old infants $\mathrm{N}=54$ )

\begin{tabular}{|c|c|c|c|c|c|}
\hline & MBQS & $\begin{array}{c}\text { AGRS } \\
(1-5)\end{array}$ & $\begin{array}{c}\text { HOME } \\
(1-7)\end{array}$ & $\begin{array}{l}\text { EAS } \\
(1-5)\end{array}$ & $\begin{array}{l}\text { CARE } \\
(1-3)\end{array}$ \\
\hline MBQS 1 & 1.00 & $\begin{array}{l}.89^{\circ} \\
.72^{\mathrm{a}} \\
.87^{\circ} \\
.79^{\mathrm{a}} \\
.87^{\mathrm{a}}\end{array}$ & $\begin{array}{l}.67^{\mathrm{a}} \\
.55^{\mathrm{a}} \\
.44^{\mathrm{a}} \\
.06 \\
.16 \\
.62^{\mathrm{a}} \\
.42^{\mathrm{b}}\end{array}$ & $\begin{array}{l}.40^{b} \\
.22 \\
.45^{\circ} \\
.31^{c} \\
-.27^{c}\end{array}$ & $\begin{array}{c}.60^{a} \\
-.42^{b} \\
-.39^{b}\end{array}$ \\
\hline AGRS 1. & & $\begin{array}{c}1.00 \\
.89^{\mathrm{a}} \\
.89^{\mathrm{a}} \\
.88^{\mathrm{a}} \\
.97^{\mathrm{a}}\end{array}$ & $\begin{array}{l}.73^{\mathrm{a}} \\
.57^{\mathrm{a}} \\
.57^{\mathrm{a}} \\
.15 \\
.24^{\mathrm{d}} \\
.58^{\mathrm{a}} \\
.42^{\mathrm{a}}\end{array}$ & $\begin{array}{l}.30^{\mathfrak{r}} \\
.24^{d} \\
.37^{\mathfrak{b}} \\
.24^{d} \\
-.22\end{array}$ & $\begin{array}{c}.51^{\mathrm{a}} \\
-.42^{\mathrm{b}} \\
-.28^{\mathrm{c}}\end{array}$ \\
\hline HOME 1. & & & $\begin{array}{c}1.00 \\
.78^{\mathrm{a}} \\
.46^{\mathrm{a}} \\
.31^{\mathrm{r}} \\
.55^{\mathrm{a}} \\
.78^{\mathrm{a}} \\
.59^{\mathrm{a}}\end{array}$ & $\begin{array}{l}.29^{\circ} \\
.42^{b} \\
.30^{\mathrm{c}} \\
.30^{\mathrm{c}} \\
-.23^{\mathrm{d}}\end{array}$ & $\begin{array}{r}.51^{a} \\
-.28^{c} \\
-.41^{b}\end{array}$ \\
\hline EAS 1. & & & & $\begin{array}{c}1.00 \\
.58^{\mathrm{a}} \\
.48^{\mathrm{a}} \\
.50^{\mathrm{a}} \\
-.40^{\mathrm{b}}\end{array}$ & $\begin{array}{l}.25^{d} \\
-.04 \\
-.28^{c}\end{array}$ \\
\hline CARE 1. & & & & & $\begin{array}{l}1.00 \\
-.63^{a} \\
-.70^{2}\end{array}$ \\
\hline
\end{tabular}

$\mathrm{a}=\mathrm{p}<.001 \quad \mathrm{~b}=\mathrm{p}<.01 \quad \mathrm{c}=\mathrm{p}<.05 \quad \mathrm{~d}=\mathrm{p}<.1$

EAS -Emotional Availability Scale

1. Attentiveness

2. Quality of touching

3. Quality of talking

4. Positive affect

5. Negative affect 
Table 3.4

Correlations among measures of maternal behaviour:

Dyads with 13-month-old infants ( $N=39)$

\begin{tabular}{|c|c|c|c|c|c|}
\hline & MBQS & $\begin{array}{c}\text { AGRS } \\
(1-5)\end{array}$ & $\begin{array}{c}\text { HOME } \\
(1-7)\end{array}$ & $\begin{array}{c}\text { EAS } \\
(1-5)\end{array}$ & $\begin{array}{l}\text { CARE } \\
(1-3)\end{array}$ \\
\hline MBQS 1 & 1.00 & $\begin{array}{l}.89^{2} \\
.86^{a} \\
.83^{2} \\
.67^{2} \\
.82^{2}\end{array}$ & $\begin{array}{l}.67^{\star} \\
.38^{c} \\
.54^{\star} \\
.06 \\
.11 \\
.63^{\circ} \\
.24\end{array}$ & $\begin{array}{c}.48^{b} \\
-.06 \\
.36^{c} \\
.36^{c} \\
-.36^{c}\end{array}$ & $\begin{array}{r}.37^{c} \\
-.38^{c} \\
-.03\end{array}$ \\
\hline AGRS 1 & & $\begin{array}{c}1.00 \\
.92^{a} \\
.90^{\circ} \\
.82^{a} \\
.92^{a}\end{array}$ & $\begin{array}{l}.68^{a} \\
.40^{b} \\
.48^{b} \\
.07 \\
.17 \\
.61^{a} \\
.16\end{array}$ & $\begin{array}{c}.46^{b} \\
-.16 \\
.40^{b} \\
.31^{d} \\
-.31^{d}\end{array}$ & $\begin{array}{c}.40^{\mathrm{c}} \\
-.44^{\mathrm{b}} \\
.01\end{array}$ \\
\hline HOME 1. & & & $\begin{array}{c}1.00 \\
.54^{\mathrm{a}} \\
.55^{\mathrm{a}} \\
.47^{\mathrm{b}} \\
.42^{\mathrm{b}} \\
.75^{\mathrm{a}} \\
.36^{\mathrm{c}}\end{array}$ & $\begin{array}{l}.41^{b} \\
-.11 \\
.45^{b} \\
.18 \\
-.18\end{array}$ & $\begin{array}{c}.31^{\mathrm{d}} \\
-.13 \\
-.24\end{array}$ \\
\hline EAS 1. & & & & $\begin{array}{c}1.00 \\
.42^{\mathrm{b}} \\
.47^{\mathrm{b}} \\
.27^{\mathrm{d}} \\
-.27^{\mathrm{d}}\end{array}$ & $\begin{array}{l}.39^{c} \\
-.18 \\
-.27^{d}\end{array}$ \\
\hline CARE 1 & & & & & $\begin{array}{l}1.00 \\
-.63^{\mathrm{a}} \\
-.70^{\mathrm{a}}\end{array}$ \\
\hline
\end{tabular}

${ }^{\prime}=\mathrm{p}<.001 \quad \mathrm{~b}=\mathrm{p}<.01 \quad \mathrm{c}=\mathrm{p}<.05 \quad \mathrm{~d}=\mathrm{p}<.1$

See Tables 3.2 and 3.3 for list of acronyms 
each age, MBQS scores were highly correlated with scores on a second measure of maternal sensitivity used extensively in research, the Ainsworth Global Rating Scales (AGRS). Significant correlations were found with each of the four subscales of the AGRS (acceptance, accessibility, cooperation, and sensitivity) as well as with the total score. MBQS scores were also significantly correlated, but to a lesser extent, with the other measures of maternal interactive behaviour used in the study. As indicated in the tables, mothers with higher sensitivity scores(MBQS) at 6 and 13 months provided more optimal emotional and social stimulation in the home (HOME), and during play, they were less intrusive (CARE) and more emotionally available (EAS-attentiveness) in their interactions, they showed more positive and less negative affect and communicated with their infants in a qualitatively higher manner (EAS). Mothers with higher sensitivity scores at 3 months, provided more optimal emotional and social stimulation in the home and they were less intrusive during play with their babies. The quality of the mother's communications and affect were not available at 3 months since the Emotional Availability Scale was not developed for use at this age.

As further validation of the MBQS, some of the analyses were performed using both MBQS and AGRS scores. Exploratory t-tests were performed on the 90 items in the Q-sort to see if domain-specific behaviours could be identified, that would reliably distinguish between insecure-avoidant and insecure-ambivalent attachment relationships. Contrary to expectations, such domains were not identified in the present sample but results suggested that mothers of babies judged to be securely attached engaged in interactions that were characterized by responsiveness to their baby's signals compared to mothers of babies judged to be insecurely attached. A list of the 90 items in the MBOS appears in Appendix B, those that differed significantly between the two groups of mothers are indicated. For example, mothers of securely attached babies slowed their pace and waited for their babies to respond and they interpreted their babies' cues accurately, whereas, mothers of insecurely attached babies were more intrusive during interactions and often missed their babies' cues or misinterpreted them. 
Section 2: Cross-sectional Data - Relation of maternal sensitivity to mastery of developmental tasks

Hypothesis 1: Pearson product-moment correlational analyses, standard multiple regressions, and MANOVA were used to assess the associations between maternal sensitivity and the infant's regulation of physiological and affective arousal (homeostasis) at 3 months; the infant's exploratory behaviour at 6 months; and secure infant-mother attachment relationships at 13 months. The results are presented for each age group separately.

For purposes of describing the quality of mother-infant interactions, means and standard deviations are shown for all variables but only a limited number of analyses were performed at each age in order to keep a reasonable subject-tovariable ratio. Correlations between maternal interactive behaviour and maternal age and perceptions were examined first, since such associations may need to be considered when testing the hypotheses. Associations between maternal sensitivity and a selected number of maternal interactive behaviours and the stage-salient developmental tasks were then assessed. The selection varied with the age of the child and was made on theoretical grounds or on the basis of previous findings reported in the literature.

\section{Dyads with 3-month-old infants $(\mathbf{N}=22)$.}

Maternal interactive behaviours. Table 3.5 presents the means and standard deviations of maternal interactive behaviours at 3 months. Although mean global sensitivity scores of these young mothers (MBQS mean $=.29, \underline{\mathrm{SD}}=$ .38 and $A G R S$ mean $=5.56, \underline{S D}=.95$ ) were lower than those reported in the literature for older, middle-class mothers (e.g. Pederson, Moran, et al. 1990, MBQS mean $=.73, \underline{\mathrm{SD}}=.18$ and $\mathrm{AGRS}$ mean $=7.11, \underline{\mathrm{SD}}=.93$ ), many mothers were responding to their infants' needs in reasonably sensitive ways. Approximately half of the mothers received MBQS scores greater than .30, and $68 \%$ had AGRS scores higher than 5, indicating maternal behaviour that is inconsistent but more sensitive than insensitive. However, nearly one-third of the mothers received negative pattern of responsiveness scores, indicating they were 
Table 3.5

Means and standard deviations for maternal behaviours:

Dyads with 3-month-old infants $(\mathrm{N}=22)$

\begin{tabular}{|c|c|c|c|c|}
\hline Maternal Variables & Mean & SD & Min. & Max. \\
\hline \multicolumn{4}{|l|}{ Global Sensitivity } & .84 \\
\hline AGRS & 5.56 & .95 & 3.75 & 7.13 \\
\hline \multicolumn{5}{|c|}{ Interaction Pattern in play (CARE) } \\
\hline Unresponsive & .15 & .17 & .00 & .64 \\
\hline Pattern of responsiveness & .44 & .64 & -.79 & 1.76 \\
\hline \multicolumn{5}{|l|}{ Quality of environment (HOME) } \\
\hline \multicolumn{5}{|c|}{ Knowledge of development (HSKS) } \\
\hline \multicolumn{5}{|l|}{ Maternal Perceptions } \\
\hline \multicolumn{4}{|l|}{ Infant vocalizations (PPIV) } & 26.00 \\
\hline \multicolumn{5}{|l|}{ Stress (PSI) } \\
\hline Parent Domain & 134.32 & 24.27 & 92.00 & 180.00 \\
\hline Social Support & 3.21 & 1.23 & 1.00 & 5.00 \\
\hline $\begin{array}{l}\text { MBQS = Maternal Behaviour } \\
\text { AGRS = Ainsworth Global R } \\
\text { CARE = Child-Adult Relation } \\
\text { HOME = Home Observation } \\
\text { HSKS = High Scope Knowled } \\
\text { PPIV = Parental Perception o } \\
\text { PSI = Parenting Stress Index }\end{array}$ & $\begin{array}{l}\text { al Index } \\
\text { t of the } \mathrm{E} \\
\text { tions }\end{array}$ & ronmer & & \\
\hline
\end{tabular}


more intrusive and unresponsive, than sensitively responsive, when playing with their babies. During a 3-minute play interaction, using Crittenden's coding scheme for dyadic relationships (CARE), 38\% of the mother's interactions with her baby were rated as intrusive, $14 \%$ as unresponsive, and $48 \%$ as responsive, resulting in a mean pattern of sensitive responsiveness score of $.44, \underline{\mathrm{SD}}=.64$. The social and emotional stimulation provided by these young mothers was within the normal range. HOME scores fell at the 5th stanine, on average, with approximately $23 \%$ of the sample in the 4th stanine or below.

Infant characteristics. A summary of the means and standard deviations for infant characteristics at 3 months are presented in Table 3.6. The mean mental development score fell within the normal range corroborating the mothers' reports that their babies were developing normally. The percentage of babies in the sample that were rated as temperamentally "difficult" by their mothers on the ITQR appeared to be slightly higher than in normative samples (Thomas \& Chess, 1984 ) but the mean score, $15.44, \underline{S D}=1.59$, was not significantly different from that reported by Medoff-Cooper, Carey, \& McDevitt (1993) for their standardization sarnple of 3-month-olds, mean $=14.88, \underline{S D}=1.72,(\underline{t}(75)=1.31$, $\mathrm{p}>.05)$. Approximately $18 \%$ of the infants in the current sample were reported to be arrythmic, withdrawing, slow to adapt, fussy, and intense in their responses compared to the $10 \%$ to $15 \%$ reported in other studies (Fulllard, McDevitt, $\&$ Carey, 1984). Modal scores on the behaviour dimensions comprising the IBR affect/emotionality dimension were similar to those reported for the normative sample in the manual accompanying the Bayley Scales of Infant Development. When rated by the experimenter during Bayley testing, scores were generally in the midrange indicating moderately sociable, happy, and cooperative babies.

Mastery of developmental tasks. Homeostasis, the developmental task to be mastered at 3 months, was operationally defined by the first factors (unrotated) obtained through factor analyses of the Infant Behaviour Record (IBR) and the Infant Temperament Questionnaire Revised (ITOR). This measure has not been used previously but was selected on the basis of factor analyses reported in the 
Table 3.6

Means and standard deviations for chiid characteristics:

Dyads with 3-month-old infants $(N=22)$

Child Variables

Cognitive tievelopment (BSID) (MDI)
Mean

110.27
SD

16.05

75.00

139.00

Temperament Ratings

Mother - ITQR "difficult"

15.44

1.59

12.21

18.60

Experimenter - IBR Emotionality/affect

4.11

.73

2.33

5.67

Vocalizations per minute

4.58

2.75

0.00

11.67

Developmental tasks

Homeostasis [factor scores]

[composite scores]

.00

8.32

1.47

.81

$-2.85$

3.18

8.32

6.76

10.01

BSID = Bayley Scales of Infant Development

MDI - Mental development index

IBR - Infant behaviour record

Homeostasis: factor scores = IBR +ITQR first factor (unrotated) scores composite scores $=$ IBR + ITQR composite scores

ITQR = Infant Tempesu.. ent Scale Revised 
literature for both the IBR and the ITQR and from personal judgments about which types of behaviours reflect homeostasis. The behavioural dimensions loading highly on both unrotated first factors describe babies who are good humoured, adaptäble, rhythmic, social, reactive, and attentive/persistent; in other words, babies who are physiologically and affectively ready to explore their world and thus meet the challenges of the next developmental tasks to be mastered. Following the lead of Matheny and his colleagues, composite scores were computed to estimate the IBR and ITQR first factors, as outlined in the measures section and in Appendix D. These were summed for use as the homeostasis measure in r.il subsequent analyses. This composite measure of homeostasis was significantly correlated with the homeostasis measure derived from the sum of the first factors of the IBR and ITQR $(\underline{r}=.86, \underline{p}<.001)$.

Test of Hypothesis 1 at 3 months: Relation of maternal sensitivity to homeostasis. The first hypothesis was supported at 3 months. HOME scores, in addition to aggregated maternal sensitivity scores, were used in the analyses at this age. As indicated in Table 3.7, maternal sensitivity scores were correlated with both measures of homeostasis, $\underline{\mathrm{r}}=.42, \mathrm{~g}<.05$, for first factor scores, and $\underline{\mathrm{I}}=$ $.36, \mathrm{p}<.10$, for ITQR + IBR composite scores. The overall quality of the home environment (HOME scores) was also correlated with both measures of homeostasis $\underline{r}=.44$ for composite scores and $\underline{r}=.49$ for first factor scores, $\underline{p}<$ .05). Maternal age, knowledge of infant development, and perceptions of stress and support did not appear to be related to the quality of maternal interactive behaviour at 3 montts. No direction of causality is inferred in these observations. Correlational analyses only reveal associations; apparently strong relationships between variables could stem from the influence of other, currently unmeasured variables.

Dyads with 6-month-old infants ( $N=54)$

Maternal interactive behaviours. Table 3.8 summarizes the means and standard deviations for maternal behaviour at 6 months. Approximately half of the mothers received MBQS scores greater than .30, and $63 \%$ of the mothers had 
Table 3.7

Correlations among maternal variables and infant homeostasis:

Dyads with 3-month-old infants $(\mathbf{N}=22)$

Maternal Variables

MatSen

HOME

Maternal Variables

.06

.16

Maternal Age

.24

.21

Maternal perceptions

Infant vocalizations (PPIV)

$.36^{d}$

meaningfulness

Stress (PSI) Total

Infant

Homeostasis - ITQR + IBR first factor scores

$=p<.001 ; \quad{ }^{b}=p<.01 ; \quad{ }^{c}=p<.05 ; \quad d=p<.10$

MatSen: MBQS + AGKS (Maternal Behaviour Q-sort + Ainsworth Rating Scales)

HOME: Home Observation for Measurement of the Environment

HSKS: High Scope Knowledge Scale

PPIV: Parental Perceptions of Infant Vocalizations

PSI: Parenting Stress Index

Homeostasis: - ITQR + IBR first factor scores

- ITQR + IBR composite scores

ITQR: Infant Temperament Questionnairc Revised

IBR: Infant Behaviour Record 
Table 3.8

Means and standard deviations for maternal behaviours:

Dyads with o month-old infants $(N=54)$

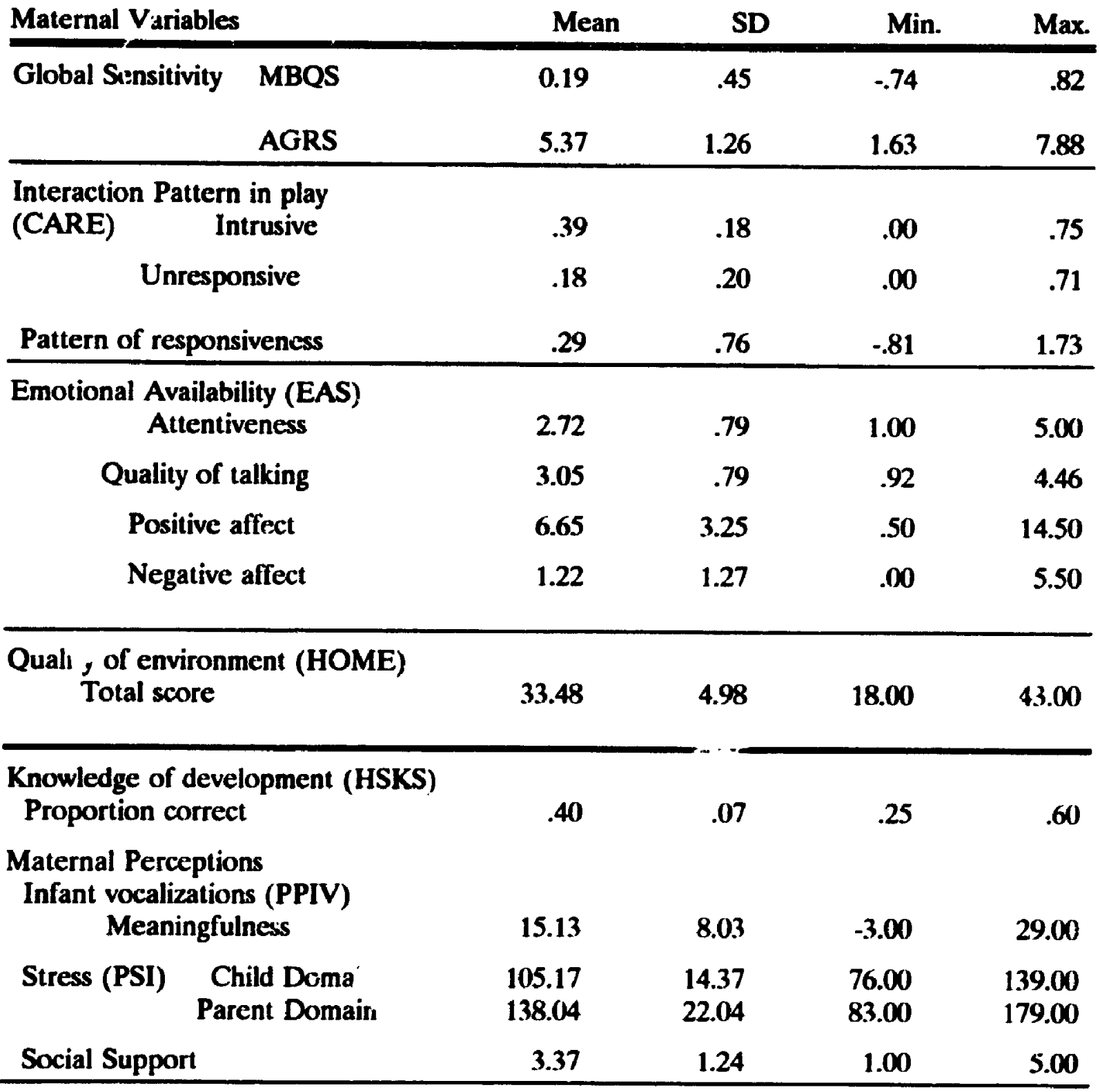

MBQS: Maternal Behaviour Q-sort AGRS: Air worth Rating Scales EAS: Emotional Availability Scale CARE: Child-Adult Relationship Experimental Index HOME: Home Observation for Measurement of the Environment HSKS: High Scope Knowledge Scale PPIV: Parental Perception of Infant Vocalizations PSI: Parenting Stress Index 
AGRS scores higher than 5 indicating maternal behaviour that was inconsistent but still more sensitive than insensitive. As at 3 months, mean global sensitivity scores were lower than those reported in the literature for older, middle-class mothers. Total HOME scores, as well as subscale scores, were again within normal ranges, falling into the middle half of the percentile range, with approximately $20 \%$ of the sample in the 4 th stanine or below.

However, half of the mothers had negative pattern of responsiveness scores on the CARE, indicating that they were more intrusive and unresponsive, than sensitively responsive, when playing with their babies. On average, $39 \%$ of the mother's interactions with her baby were rated as intrusive, $18 \%$ as unresponsive, and $43 \%$ as sensitively responsive, resulting in a mean overall pattern of responsiveness score of $.29, \underline{S D}=.76$. As :vell, mothers responded to only $35 \%$ of their babies' vocalizations during two coded three-minute play episodes [EAS]. Approximately one-third of the mothers responded to less than $20 \%$ of the infant's vocalizations and $11 \%$ responded to none of the vocalizations.

Correlations among maternal perceptions and maternal interactive behaviour. Table 3.9 presents the $\mathrm{c}$ rrelations between maternal interactive behaviours and maternal age and percestions. When babies were 6-months-ofage, levels of stress and matirnal age were associated with maternal intera tive behaviours. As overall levels of stress increased, maternal sensitivity decreased ( $\underline{r}$ $=-.36, \underline{\mathrm{p}}<.01)$ and they displayed mor: negaive affect during play $(\underline{\mathrm{r}}=.28, \underline{\mathrm{p}}<$ .05) $\therefore \mathrm{d}$ thcir overall pattern of interaction became less responsive $(\underline{r}=-.27, \underline{p}<$ $.05)$; they became more intrusive in their social interactions during play $(\underline{r}=.30, \mathfrak{p}$ $<.05)$ and tended to provide less optimal social and emotional stimulation in the home $(\underline{r}=-.25, \underline{p}<.10)$.

The quality of the language environment provided by the mother appeared to be associated with her age and her beliefs concerning the meaningfulness of her baby's vocalizations. Mothers who found their infants' vocalizations more meaningful provided more optimal social and emotional timulation in the h.sme $(\underline{r}=.35, \underline{p}<.01)$ and they tended to communicate with their babies in more 
Table 3.9

Correlations among maternal age, perceptions, and interactional behaviour: Dyads with 6-inonth-old infants $(N=54)$

\begin{tabular}{|c|c|c|c|c|c|}
\hline \multirow[b]{2}{*}{ Maternal Variables } & \multirow[b]{2}{*}{ Age } & \multicolumn{4}{|c|}{ Maternal Age and Perceptions } \\
\hline & & PPIV & $\begin{array}{l}\text { PSI } \\
{[\mathbf{T}]}\end{array}$ & HSKS & Sup. \\
\hline $\begin{array}{l}\text { Global sensitivity } \\
\qquad \text { MBQS + AGRS }\end{array}$ & .16 & -.03 & $-.36^{\mathrm{b}}$ & .10 & .03 \\
\hline $\begin{array}{c}\text { Interaction Pattern (CARE) } \\
\text { Intrusive }\end{array}$ & .16 & -.03 & $.30^{\circ}$ & .01 & .19 \\
\hline Unresponsive & -.18 & $-.24^{d}$ & .07 & -.18 & -.06 \\
\hline Pattern of responsiveness & .02 & .21 & $-.27^{c}$ & .14 & -.09 \\
\hline $\begin{array}{c}\text { Emotional Availability (EAS } \\
\text { Attentiveness }\end{array}$ & $.31^{\mathrm{c}}$ & -.04 & -.11 & -.07 & .03 \\
\hline Quality of Talk & $.38^{\mathrm{b}}$ & $.24^{d}$ & .10 & .11 & .13 \\
\hline Positive affect & .16 & .05 & .10 & -.01 & -.05 \\
\hline Negative affect & -.04 & -.17 & $.28^{c}$ & -.11 & .19 \\
\hline $\begin{array}{c}\text { Quality of environment (HC } \\
\text { Totai score }\end{array}$ & .13 & $.35^{b}$ & $-.25^{\mathrm{d}}$ & $.36^{\mathrm{b}}$ & -.01 \\
\hline
\end{tabular}

MBQS: Maternal Behaviour Q-sozt AGRS: Ainsworth Rating Scales

CA KE: Child-Adult Relationship Experimental Index

EAS: Emotional Availability Scale

HOME: Home Observation for Measurement of the Environment HSKS: High Scope Knowledge Scale

PPIV: Parental Perception of Infa , Vocalizations [meaningful] PSI[T: Parenting Stress Index [child domain + parent domain]

Sup. Perception of support 
optimal ways during social interactions $(\underline{r}=.24, \underline{p}<.10)$. These findings are consistent with those reported by Miller (1988). Relatively older mothers were more emotionally available (EAS:attentiveness) during play $(\underline{r}=.31, \underline{p}<.05)$, and the quality of their communications to their children increased ( $\mathrm{I}=.38, \underline{\mathrm{g}}<.01)$.

Infant characteristics. A summary of the means and standard deviations for infant characteristics at 6 months is presented in Table 3.10. As indicated by the mean MDI score on the Bayley, babies in this sample were developing normally. The percentage of babies that were rated as temperamentally "difficult" by their mothers on the ITQR appeared to be substantially higher than that reported in the literature (e.g. Fullard, McDevitt, \& Carey, 1984; Thomas \& Chess, 1984). Thirty-eight percent of the babies were reported to be arrythmic, withdrawing, slow to adapt, fussy, and intense in their responses, compared to $10 \%$ to $15 \%$ in other samples. The mean score $(14.33, \underline{S D}=2.20)$ was also significantly higher than that reported by Carey \& McDevitt (1978) for their standardization sample of 203 infants $(12.88, \underline{\mathrm{SD}}=1.72), \underline{\mathrm{t}}(255)=4.49, \mathrm{p}<.001$. The experimenter's ratings on the behavioural dimensions of the IBR reflecting affect/emotionality were in the mid-range, on average, indicating infants who were moderately happy, social, and cooperative during testing. Modal scores were similar to those reported in the BSID manual for the normative sample. Such discrepancies between mother and experimenter ratings of temperament suggest that the young mothers in this study may have been experiencing difficulty in reading their babies' emotions, or alternately, they were interpreting the babies' behaviour in negative ways. High numbers of elevated scores on the demanding and distractibility subscales of the PSI lend support to this interpretation as does the low congruence between the mothers' and the experimenters' rating of infant temperament at 6 months. (See Appendix D for comparisons bitween maternal and experinnenter ratings of infant temperament.)

Mastery of developmental tasks. The infant's exploratory behaviour during the Mastery Motivation tasks was used as an index of the infant's mastery of the developmental issues at 6 months of ayc. Although this measure has not been 
Table 3.10

Means and standard deviations for child characteristics:

Dyads with 6-month-old infants ( $N=54)$

Child Variable

Mean

SD

Min.

Max.

Cognitive development (BSID) (MDI)

113.57

14.44

$80.00 \quad 150.00$

Temperament Ratings

Mother - ITQR:difficult

14.33

2.20

9.94

18.00

Experimenter - IBR:Emotionality/affect

4.90

.84

2.67

7.00

Vocalizations per minute

4.36

3.08

.00

13.00

Developmental Tasks

Homeostasis

9.56

1.02

7.21

12.31

Exploratory Behaviour

.28

.06

.13

BSID = Bayley Scales of Infant Development

MDI - Mental Development index

IBR - Infant Behaviour Record

ITQR - Infant Temperament Questionnaire Revised

Homeostasis $=$ ITQR +IBR composite scores

Exploratory behaviour $=$ exploratory score in Mastery Motivation Task 
used for this purpose in previous studies, the infant's intrinsically motivated exploration of novel objects was chosen, on conceptual grounds, as a good reflection of how well the baby is managing cognitively produced arousal. To test the first hypothesis at 6 m.unihs, associations between maternal inte. active behaviours and the infant's exploratory behaviour were investigated through Pearson product-moment correlational analyses and standard multiple regressions. Because mothers reported large numbers of temperamentally "difficult" babies, associations between maternal sensitivity and the earlier developmental task (homeostasis) were also investigated. As well, associations between maternal age, mental development, and perceived stress and both developmental tasks were assessed since these three variables were significantly correlated with maternal interactive behaviours and may thus be indirectly associated with the infant's mastery of development tasks.

Test of Hypothesis 1 at 6 months: Relation of maternal sensitivity to exploratory behaviour. The first hypothesis was marginally supported at 6 months. As indicated in Table 3.11, maternal sensitivity [aggregated MBQS+AGRS scores] was marginally correlated with exploratory behaviour as measured in the Mastery Motivation task $(\underline{r}=.26, \underline{p}<.10)$ and with homeostasis as measured by aggregated ITQR and IBR composite scores, $\mathrm{I}=.44, \mathrm{p}<.001$ ). That is, more sensitive mothers had infants who were more likely to have mastered the developmental task for the 0 . to 3-month period and infants who were mastering the developmental tasks for the 4- to 6-month period. Also as indicated, exploratory behaviour was significantly correlated with maternal age $(\underline{r}=.29, \underline{p}<$ $.05)$ and with other aspects of maternal interactive behaviour: the quality of the social and emotional stimulation provided in the home [HOME] $(\underline{r}=.32, \mathfrak{p}<$ .05 ), and the quality of maternal communications during play [EAS, talking domain] $(\mathrm{r}=.32, \mathrm{p}<.05)$; and marginally correlated with maternal emotional availability [EAS, attentiveness] during play $(\underline{r}=.26, \underline{p}<.10)$. Homeostasis at 6 months was also associated with other measures of maternal interactive behaviour. As indicated, homeostasis scores were positively correlated with more optimal 
Table 3.11

Correlations among maternal variables and infant variables:

Dyads with 6-month-old infants $(\mathrm{N}=54)$

Infant Variables

Maternal Variables

MDI Vocs ITQR IBR Hom. Exp.

Global sensitivity MBQS+AGRS

BSID /min. "diff" A/E

Interaction Pattern (CARE)

Intrusive

$\begin{array}{llllll}-.32^{\mathrm{c}} & .18 & .09 & -.14 & -.23^{\mathrm{r}} & .06\end{array}$

Unresponsive

$.02-19$

.07

$\begin{array}{lll}-.23^{\mathrm{d}} & -.14 & -.15\end{array}$

Pattern of responsiveness

.2

21

.02

$-.12$

$.28^{\mathrm{c}}$

$.26^{\mathrm{d}}$

.07

Emotional Availability (EAS)

Attentiveness

$\begin{array}{llllll}.36^{\mathrm{c}} & .02 & -.19 & .14 & .17 & .26^{\mathrm{d}}\end{array}$

Quality of Talk

.03

.09

.06

$\begin{array}{lll}.13 & .00 & .32^{\mathrm{c}}\end{array}$

Positive affect

$-.01$

.15

.19

$.08 \quad-.13$

.04

Negative affect

$-.18$

.01

.10

$-.32^{\mathrm{c}} \quad-.29^{\mathrm{c}}$

.00

Quality of environment (HOME)

Total score

$.23^{\circ}$

$-.20$

.15

$.30^{\mathrm{c}} \quad .32^{\mathrm{c}}$

Maternal age

$\begin{array}{ll}-.02 & .29^{\mathrm{c}}\end{array}$

Mä:ernal perceptions of Stress (PSI)

$-.46^{\mathrm{a}} \quad-.26^{\mathrm{d}}$

${ }^{\mathrm{a}}=\mathrm{p}<.001 ; \quad \mathrm{b}=\mathrm{p}<.01 ; \quad{ }^{\mathrm{c}}=\mathrm{p}<.05 ; \quad \mathrm{d}^{\mathrm{d}}=\mathrm{p}<.10$

MBQS: Maternal Behaviour Q-sort

AGRS: Ainsworth Rating Scales

CARE: Child-Adult Relationship Experimental Index

EAS: Emotional Availability Scale

HOME: Home Observation for Measurement of the Environment

PSI: Parenting Stress Index - child domain + parent domain

BSID: Bayley Scales of Infant Development: MDI:Mental Development Index

IBR A/E: Infant behaviour record - Affect/emotionality composite score

ITQR: Infant Temperament Questionnaire Revised "difficult"

Hom.: Homeostasis - ITQR + IBR composite scores

Exp.: Exploratory behaviour score in the Mastery Motivation Task 
stimulation in the home $(r=.30, \underline{p}<.05)$ and with the overall pattern of responsiveness during play $(\underline{\mathrm{r}}=.26, \mathrm{p}<.10)$. Homeostasis was negatively correlated with levels of stress $(\underline{r}=-.46, \underline{p}<.001)$ and with intrusiveness during play $(\underline{I}=-.23, \mathfrak{p}<.10)$. Although homeostasis was not significantly related to the measure of exploration used as the index for the developmental task to be mastered at 6-months, it was significantly related to task persistence, the next higher level in the hierarchy of exploratory behaviours measured in the Mastery Motivation Task $(\underline{\mathrm{I}}=.33, \mathrm{p}<.05)$.

Standard multiple regressions. In order to assess the unique contributions of different aspects of maternal interactive behaviour to the prediction of mastery of both developmental tasks, two standard multiple regressions were performed using SPSSPC. In standard multiple regression all predictors enter into the regression equation simultaneously; each one is assessed as if it had entered the regression after all the other predictors had entered. Each predictor is evaluated in terms of what it adds to prediction of the criterion that is different from the predictability afforded by all the other predictors (Tabachnick \& Fidell, 1989, p. 143). Squared semi-partial correlations express the unique contribution of the predictor to the total variance of the criterion. It should be noted that regression analyses reveal relationships among variables but do not imply that the relationships are causal; an apparently strong relationship could ste m from other unmeasured variables. Both first-order correlations and the unique contribution of predictor variables need to be considered in interpreting results.

In the first regression, the infant's exploratory behaviour in the Mastery Motivation task was entered as the criterion with aggregated maternal sensitivity scores, maternal emotional availability (attentiveness) during play, HOME scores, level of stress in the child domain, maternal age, and infant mental development as predictors. Complete data were available for 51 of the dyads; the PSI was not completed by one mother and the mastery mocivation task was not available for two infants due to camera difficulties. Table 3.12 displays the correlations hetween the variables, beta coefficients, the semipartial correlations $\left(\underline{\mathbf{s}}{ }^{2}\right)$, and $\underline{\mathbf{R}}$ 
Table 3.12

Standard multiple regression of maternal behaviours, stress, and infant mental development on 6-month exploratory behaviour scores $(\mathrm{N}=51)$

\begin{tabular}{|c|c|c|c|c|c|c|c|c|c|}
\hline Variables & DV & 1. & 2. & 3. & 4. & 5. & 6. & Beta & $\underline{\mathbf{s r}}^{2}$ \\
\hline 1. MatSen & .27 & & & & & & & & \\
\hline 2. HOME & .39 & .73 & & & . & & & .43 & .08 \\
\hline 3. EAS & .26 & .36 & .30 & & & & & & \\
\hline 4. PSI & .26 & -.37 & -.24 & -.03 & & & & -.25 & 15 \\
\hline 5. MDI & .07 & .17 & .19 & .36 & $\mathbf{0}$ & & & & \\
\hline 6. Mom's age & .26 & .18 & .18 & .32 & -.02 & -.03 & & & \\
\hline Mean & .28 & .06 & 33.43 & 2.74 & 105.26 & 114.16 & 17.98 & & \\
\hline \multirow[t]{3}{*}{ Std. Dev. } & .06 & 1.97 & 5.00 & .82 & 14.62 & 14.61 & 2.02 & & \\
\hline & & & & & & & $\mathbf{R}^{2}$ & $=.28$ & \\
\hline & & & & & & & $l=$ & $.53^{*}$ & \\
\hline
\end{tabular}

$* p<.05$

For $\mathrm{N}=51$, all correlation coefficients $>.23$ are at $\mathrm{p}<.10$

- Exploratory behaviour score in Mastery Motivation Task

$\underline{s \mathbf{s}^{2}}=$ unique contribution

HOME: Home Observation and Measurement of the Environment MatSen: Maternal Behaviour Q-sort + Ainsworth Global Rating Scale EAS: Emotional Availability Scale - contingent reciprocal behaviour PSI: Parenting Stress Index - child domain MDI: Mental Development Index - Bayley Scales of Infant Development 
and $\underline{R}^{2}$. $\underline{R}$ for regression was significantly different from zero $(\underline{R}=.53, \underline{F}(6,44)$ $=2.92, \mathrm{p}<.05$ ). The quality of the social and emotional stimulation in the home was a significant predictor of the infant's exploratory behaviour $\left(\underline{\mathbf{s}^{2}}=.08, \mathfrak{p}<\right.$ .05 ), and stress in the child domain was a marginally significant predictor $\left(\underline{s}^{2}=\right.$ $.05, \mathrm{p}<.10$ ). Altogether, $28 \%$ of the variability in exploration scores was predicted by knowing the scores on these six variables.

The homeostasis measure was entered as the criterion in a second standard multiple regression together with the six predictor variables. Table 3.13 displays the correlations between the variables, beta coefficients, the semipartial correlations ( $\left.\underline{\mathbf{s}}^{2}\right)$, and $\underline{\mathbf{R}}$ and $\underline{\mathbf{R}}^{2}$. The infant's mental development, perceived stress in the child domain, and maternal sensitivity were significant predictors of homeostasis scores $\left(\underline{\mathrm{r}^{2}}=.16, .08\right.$, and .06 , respectively, $\left.\underline{\mathrm{p}}<.05\right)$. Altogether. $46 \%$ of the variability in homeostasis scores was predicted knowing the scores on these six variables $(\underline{\mathrm{R}}=.68, \underline{\mathrm{F}}(6,46)=6.57, \underline{\mathrm{p}}<.001)$.

Taking into account both first-order correlations and the unique contributions of maternal interactive behaviours to homeostasis and to exploratory behaviour, the results suggest that mothers who were higher in sensitivity and provided more optimally stimulating home environments were more likely to have children who mastered both the 3-month and 6-month developmental tasks.

Dyads with 13-month-old infants,$N=39$

Maternal interactive behaviours. Table 3.14 presents the means and standard deviations for maternal behaviour at 13 months. The interactive behaviours of young mothers with 13-month-old toddlers appeared to be less than optimal in several ways. Fifty-nine percent of the mothers received MBQS scores less than .10 and $56 \%$ of the mothers had AGRS scores below 5. Mcan global sensitivity score; were only $.023(\underline{\mathrm{SD}}=.43)$ and $4.90(\underline{\mathrm{SD}}=1.23)$, respectively, indicating young mothers who were insensitive to their toddlers' signals and needs, on average. These means appear to be considerably lower than the means at 6 and 3 months but differences could not be tested statistically because the three samples are not :ompletely independent. A visual presentation of the decline in 
Table 3.13

Standard multiple rearession of maternal behaviours, stress, and infant mental development on 6-month homeostasis scores $(\mathrm{N}=53)$

\begin{tabular}{|c|c|c|c|c|c|c|c|c|c|}
\hline Variables & DV & 1. & 2. & $\therefore$ & 4. & 5. & 6. & Beta & $\underline{\mathbf{s} \mathbf{r}^{2}}$ \\
\hline 1. MatSen & .44 & & & & & & & .38 & .06 \\
\hline 2. HOME & .27 & .73 & & & & & & & \\
\hline 3. EAS & .13 & .36 & .30 & & & & & & \\
\hline 4. PSI & -.46 & -.37 & -.24 & -.03 & & & &.- .31 & .08 \\
\hline 5. $\mathrm{MDI}$ & .47 & .19 & .19 & .36 & -.10 & & & .44 & .16 \\
\hline 6. Mom's age & -.02 & .16 & .18 & .32 & -.02 & -.03 & & & \\
\hline Mean & 9.87 & .06 & 33.43 & 2.74 & 105.26 & 114.16 & 17.98 & & \\
\hline \multirow[t]{3}{*}{ Std. Dev. } & 1.13 & 1.97 & 5.00 & .82 & 14.62 & 14.61 & 2.02 & & \\
\hline & & & & & & & $\mathbf{R}^{2}$ & $=.46$ & \\
\hline & & & & & & & $\mathbf{R}=$ & $.68^{*}$ & \\
\hline
\end{tabular}

$* \mathrm{p}<.05$

For $\mathrm{N}=53$, correlation coefficients $>.23$ are at $\underline{p}<.10$

- = Homeostasis score - ITQR + IBR first factor (unrotated) scores

$\underline{\mathbf{r}^{2}}=$ unique contribution

HOME: Home Observation and Measurement of the Environment

MatSen: Maternal Behaviour Q-soit + Ainsworth Global Rating Scale

CARE: Child-Adult Relationship Experimental Index (pattern of responsiveness)

PSI: Parenting Stress Index - child domain + parent domain

MDI: Mental Develcpment Index - Bayley Scales oi Infant Development 
Table 3.14

Means and standard deviations for maternal behaviours:

Dyads with 13-month-old infants $(N=39)$

Maternal Variables

Mean SD Min. Max.

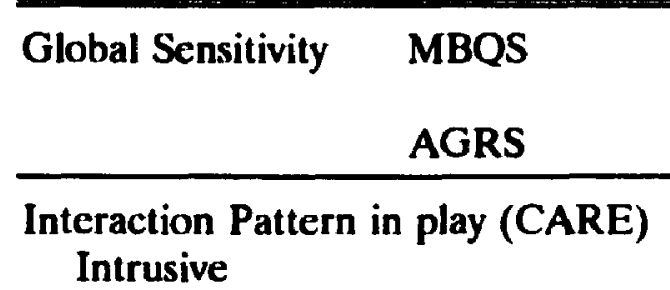

Unresponsive

Pattern of responsiveness

Emotional Availability (EAS)

Attentiveness

3.03

.31

0.02

.43

$-.65$

.79

Quality of talking

2.96

.68

1.23

2.75

7.75

Positivi: affect

3.96

.65

.24

.00

.73

27

.20

.00

.82

Negative affect

1.63

2.70

$.76 \quad-1.00$

1.70

.25

200

5.00

1.58

11.50

Quality of environment (HOME)

Total score
$\begin{aligned} & \text { Knowledge of development (HSKS) } \\ & \text { Proportion correct }\end{aligned}$

34.54

1.82

.00

8.50

.00

8.50

$5.13 \quad 23.00 \quad 43.00$

.39

$.13-.26$

.54
Maternal Perceptions
Infant vocalizations (PPIV)
Meaningfulness
Stress (PSI) Child Domain
Parent Domain

$\begin{array}{rrrr}19.53 & 6.59 & -3.00 & 30.00 \\ 104.30 & 14.77 & 80.00 & 136.00 \\ 131.51 & 21.16 & 83.00 & 181.00\end{array}$

3.10

1.24

5.00

MBQS = Maternal Behaviour Q-sort

AGRS = Ainsworth Rating Scales

EAS = Emotional Availability Scale

CARE $=$ Child and Adult Experimental Index

HOME = Home Observation for Measurement of the Environment

HSKS = High Scope Knowledge Scale

PPIV = Parental Perception of Infant Vocalizations

PSI = Parenting Stress Index 
maternal sensitivity across the 3 ages is shown in Figure 3.1.

Forty-six percent of the mothers had negative overall pattern of interaction scores on the CARE, indicating that they were more intrusive and unresponsive, than sensitively responsive, when playing with their babies during a 3-minute semistructured play interaction. Using Crittenden's coding scheme, $31 \%$ of the mother's interactions with her toddler were rated as intrusive, $28 \%$ as unresponsive, and $41 \%$ as responsive, resulting in a mean overall pattern of responsiveness score of $.25, \underline{S D}=.76$.

In contrast to the poorer quality of maternal interactional behaviour at 13 months, the overall social and emotional environment available to the toddlers in the home was within the normal range, with mean total HOME scores in the middle half of the percentile range at the 6th stanine. Mean subscale scores were also in the 5th or 6th stanine, with the exception of subscale 2, which measures acceptance of the child's behaviour, which was in the 3rd stanine.

Correlations between maternal interactive behaviour and maternal age and perceptions. Associations between maternal interactive behaviour at 13 months and maternal age and maternal perceptions are presented in Table 3.15. Maternal age was significantly correlated with the mother's pattern of responsiveness [CARE- $R$ ] during play $(\underline{r}=.33, \underline{p}<.05)$ and marginally correlated with HOME scores $(\underline{r}=.29, \mathrm{p}<.10)$. The mother's perception of stiess was marginally correlated with her pattern of responsiveness during play $(\underline{r}=.31, \mathfrak{p}<$ $.10)$ and her knowledge of infant development was marginally correlated with her sensitivity $(\mathrm{I}=.27, \mathrm{p}<.10)$.

Mothers of 13-month-olds responded to less than half (42\%) of their toddlers' vocalizations during two 3-minute play interactions, and both verbal and nonverbal interactions often lacked the 'conversation-like' quality that help children develop language skills. The mean score on the quality of communication subscale of the EAS (3.05 $(\underline{S D}=.79)$ indicated that motheis usually made descriptive comments or gave commands, rimer than engaging in verbal turntaking, when speaking to their toddlers. Mothers who endorsed "motherese" used 


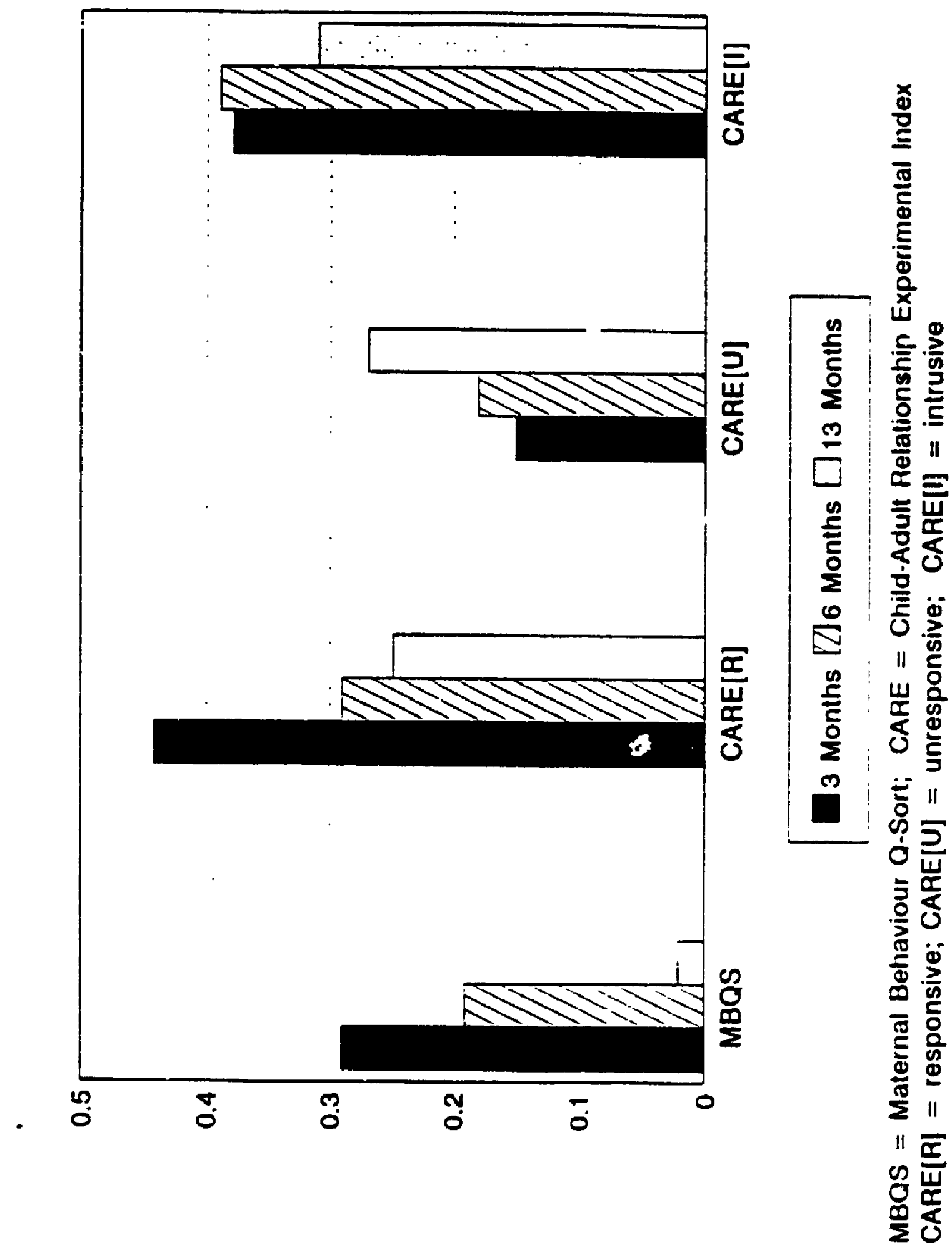

Figure 3.1. Global maternal sensitivity (MBQS) and maternal interactive behaviour during play (CARE) at infant ages 3, 6, and 13 months. 
Table 3.15

Correlations among maternal age, perceptions, and interactive behaviour: Dyads with 13-month-old infants $(N=39)$

Maternal Variables

Maternal Age and Perceptions

Age PPIV PSI HSKS Sup.

[T]

Global sensitivity
MBQS+AGRS
Interaction Pattern (CARE)
Intrusive
Unresponsive
Pattern of responsiveness

$\begin{array}{lllll}.25 & -.06 & -.03 & .27^{\mathrm{d}} & .09\end{array}$

Emotional Availability (EAS)

Attentiveness

Quality of talk

Positive affect

Negative affect

$\begin{array}{ccccc}.08 & .26 & -.14 & .02 & .01 \\ . .50^{\circ} & -.36^{\mathrm{c}} & -.22 & .02 & .22 \\ .33^{\mathrm{c}} & .04 & .32^{\mathrm{d}} & .04 & -.20\end{array}$

Quality of environment (HOME) Total scure

$\begin{array}{rrrrr}.17 & .10 & -.01 & -.01 & -.03 \\ .23 & .34^{\mathrm{c}} & .27^{\mathrm{d}} & .14 & -.16 \\ -.11 & .06 & .15 & .03 & .12 \\ -.07 & .14 & -.06 & .10 & -.02\end{array}$

${ }^{\mathrm{a}}=\mathrm{p}<.001 ; \quad{ }^{\mathrm{b}}=\mathrm{p}<.01 ; \quad{ }^{\mathrm{c}}=\mathrm{p}<.05 ;{ }^{\mathrm{d}}=\mathrm{p}<.10$

MBQS: Maternal Behaviour Q-so:t

AGRS: Ainsworth Rating Scales

CARE: Child-Adult Relationship Experimental Index

EAS: Emotional Availability Scale

HOME: Home Obseivation for Measurement of the Environment

HSKS: High Scope Kuowizdge Scale

PPIV: Parental Perceptivin of Infan: Vocalizations [alteration]

PSI[T]: Parenting Stress Irdex [child domain + parent demain]

Sup: Perception of support 
qualitatively higher modes of communication $(\underline{r}=.34, \underline{p}<.05)$. In lwa 1 , mothers who used qualitatively higher modes of communication had children who were communicatively more competent $(\underline{r}=.35, \underline{p}<.05)$.

Infant characteristics. Table 3.16 presents the means and standard deviations for infant characteristics at 13 months. As indicated by the mean MDI score on the Bayley, the mental development of the tuddlers was in the normal range. Only $8 \%$ of the toddlers were rated by their mothers as temperamentally "difficult" on the ITOR. Although this percentage appears slightly lower than the $10 \%$ reported in the normative sample of Thomas \& Chess (1984), the mean "difficulty" score $(15.95, \underline{\mathrm{SD}}=1.82)$ was not significantly different from that (15.87, $\underline{\mathrm{SD}}=2.06)$ in the Fullard, McDevitt, \& Carey (1984) standardization s9.nple of 167 toddlers $[\underline{t}(226)=.27, \underline{p}>.05]$.

The experimenter's ratings on the behavioural dimensions of the IBR were again in the mid-ra:ige, on average - a mean composite scc re reflecting affect/emotionality was $4.91, \underline{\mathrm{SD}}=1.27$ - indicating infants who were moderately happy, social, and cooperative. Although the majority of modal scores in the present sample were similar to those reported in the BSID manual for the normative sample, there were some differences. Modal scores were lower on 5 of the 16 behavioural dimensions and higher in one. Only $15 \%$ of 12 -month-olds in the normative sample had similar scores in ge neral sociability, $14 \%$ in cooperativeness, $27 \%$ in endurance to complete the test, and only one-quarter of the 12-month-olds in the rormative sample were as highly active or as low in fear during testing. Thus, toddlers in the current study appear to have been morc active, less sociable, less coonerative, less fearful, and less likely to hold up throughout the testing than children in the normative sample.

Mastery of developmental tasks. Attachment to the primary caretaker, the developmental task to be mastered at 13-months-of-age, was measured in two ways. First, a continuous measure of security was obtained from infant behaviours observed in the home, using Waters and Deane's Q-soit (AQS). Second, attach 'ent was measured qualitatively using Ainsworth's strange situation 


$$
2
$$


Table 3.16

Means and standard deviations for child characteristics:

Dyads with 13-month-old infants $(\mathrm{N}=39)$

Child Variables

Cognitive development (BSID) (MDI)

Temperament Ratings

Mother - ITQR: difficult

Experimenter - IBR: affect/emotionality
Mean

110.08

15.96

4.91
SD

Min.

Max.

$12.52 \quad 72.00$

136.00

Communicative acts per minute

110

1.32

5.29

Developmental Tasks

Homeostasis

Exploration

9.22

.31

1.20

6.61

.21

11.57

Attachment sccurity

Q-sort (AQS)

Strange situation (proportion secure)

BSID = Bayley Scales of Infant Development

MDI - Mental development index

IBR - Infant behaviour record

ITQR = Infant Temperament Questionnaire Revised

AQS = Attachment Q-sort

Homeostasis $=$ ITQR + IBR composite scores

Exploration $=$ Task persistence score from Mastery Motivation Task 
procedure. Correlational analyses and standard multiple regressions were used to assess associations between maternal interactive behaviours and AQS scores. A MANOVA and follow-up univariate analyses were performed to assess differences in maternal interactive behaviour in dyads judged to be securely or insecurely attached on the basis of the infant's behaviour in the strange situation. Post-hoc analyses were conducted using the Least Significant Differences (LSD) test of means.

Test of Hypothesis 1 at 13 months: Relation of maternal sensitivity to security of attachment [AQS scores]. Results of the correlational analyses conducted on 13-month assessment data supported the first hypothesis. Table 3.17 presents a summary of the correlations between attachment security scores (AQS) and various aspects of maternal interactive behaviour. As indicated, attachment security scores (AQS) were significantly correlated with maternal sensitivity ( $\underline{\mathrm{r}}=.59, \mathrm{p}<.001$ for aggregated MBQS and AGRS sc'sres), with maternal intrusiveness during play ( $\underline{r}=-.43, \underline{\mathrm{p}}<.01$ for CARE-I scores), and with maternal emotional availability during play $(\underline{r}=.40, \underline{p}<.01$ for EAS attentiveness scores). Correlations between AQS scores and the infants' scores on the two earlier developmental tasks were also computed. Also as indicated, AQS scores were significantly correlated with homeostasis $(\underline{r}=.47, \underline{p}<.01)$ but not with the infants' exploratory scores.

Standard multiple regression analyses. The unique contribution of maternal sensitivity to prediction of attachment security was assessed through standard multiple regression. Complete data sets were available for 37 dyads one mother did not complete the temperament questionnaire and the Mastery Motivation task was not available for one dyad due to camera difficulties. Attachment security scores (AQS) were entered as the criterion with maternal sensitivity [aggregated MBQS and AGRS scores], exploration [task persistence scores in the Mastery Motivation task], and homeostasis [ITQR + IBR composite scores] as predictors. Table 3.18 displays the correlations between the variables, beta coefficients, the semipartial correlations $\left(\underline{\mathbf{s}^{2}}\right)$, and $\underline{\mathbf{R}}$ and $\underline{\mathbf{R}}^{2}$. Maternal 
Table 3.17

Correlations between attachment security scores and maternal interactive behaviour and infant homeostasis and exploration: Dyads with 13-month-old infants $(\mathrm{N}=39)$

Attachment Security

Maternal Variables

AQS

Global sensitivity

MBQS+AGRS

Interaction Pattern (CARE)

Intrusive

Unresponsive

Pattern of responsiveness

Emotional Availability(EAS)

Attentiveness

Quality of talk

Positive affect

Negative affect

Quality of environment (HOME)

Total score

Infant Homeostasis

${ }^{d}=p<.001 ; \quad{ }^{b}=p<.01 ; \quad c=p<.05 ; \quad d=p<.10$

MBQS = Maternal Behaviour Q-sort

AGRS = Ainsworth Rating Scales

CARE = Child and Adult Experimental Index

EAS = Emotional Availability Scale

HOME = Home Observation for Measurement of the Environment

AQS = Attachment q-sort

Homcostasis $=$ ITQR + IBR composite scores

Exploration $=$ Task persistence scores from Mastery Motivation task 
Table 3.18

Standard multiple repression of maternal sensitivity, homeostasis, and task persistence on 13-month attachment security scores $(\mathrm{N}=37)$.

\begin{tabular}{|c|c|c|c|c|c|c|}
\hline Variables & DV* & 1. & 2. & 3. & Beta & $\mathbf{s r}^{2}$ \\
\hline 1. MatSen & .58 & & & & .48 & .19 \\
\hline 2. Homeostasis & .50 & .36 & & & .35 & .10 \\
\hline 3. Exploration & .11 & .21 & .28 & & -.09 & \\
\hline Mean & .17 & .01 & 9.18 & .31 & & \\
\hline \multirow[t]{3}{*}{ Std. Dev. } & .21 & 1.99 & 1.08 & .05 & & \\
\hline & & & & & $\mathbf{R}^{2}=$ & \\
\hline & & & & & $\mathbf{R}=$ & $67^{*}$ \\
\hline
\end{tabular}

$* \mathrm{p}<.001$

For $\mathrm{N}=37$, correlation coefficients equal to or greater than .28 are significant at $\mathrm{p}<.10$

- AQS = Attachment Q-Sort - security of attachment

MatSen: Maternal Behaviour Q-sort + Ainsworth Global Rating Scaie

Homeostasis $=$ ITQR + IBR composite scores

Exploration $=$ Task persistence score in Mastery Motivation Task 
sensitivity contributed significantly to prediction of attachment security scores ( $\underline{\mathbf{s}}^{2}$ $=.19, \mathrm{p}<.01)$, as did homeostasis scores $\left(\underline{\mathrm{r}^{2}}=.10, \mathrm{p}<.05\right)$. In combination, the three variables predicted another .14 in shared variability. Altogether, nearly $45 \%$ of the variance in AQS scores was predicted by these variables, $\underline{\mathrm{R}}=.67, \underline{\mathrm{F}}(3,33)$ $=8.80, \mathrm{p}<.001$.

\section{A second test of Hypothesis 1 at 13 months: Differences in maternal} sensitivity in dyads classified as securely or insecurely attached. Since security of attachment was measured in two ways, a second test of the association between maternal sensitivity and the infant's mastery of the developmental task at 13 months was conducted, using MANOVA. Complete data was available for 37 dyads - one mother declined to come to the University for the Strange Situation procedure, and as noted above, one mother did not complete the temperament questionnaire. The majority of children were judged to be insecurely attached on the basis of their behaviour in the strange situation: $39 \%$ were placed in the $\mathrm{A}$ (insecure-avoidant) category and $24 \%$ were placed in the $\mathrm{C}$ (insecure-ambivalent) category. Only $37 \%$ of the children were placed in the B (secure) category.

Results of the MANOVA (using Pillais' criterion) and follow-up univariate analyses on the data, provided marginal support for the first hypothesis at 13 months. Tables 3.19 and 3.20 present the means, standard deviations, and significant differences in maternal and child behaviours in dyads who were in secure and insecure attachment relationships. To test the hypothesis, maternal sensitivity [aggregated MBQS and AGRS scores], maternal intrusiveness [CARE scores], and maternal emotional availability [EAS attentiveness scores], together with infant homeostasis [ITQR +IBR composite scores] and infant exploration [task persistence scores in the Mastery Motivation task] were entered as dependent measures in a MANOVA with attachment security/insecurity (Strange Situation classification - B vs $A+C$ ) as the independent measure. There was a significant main effect for attachment security/insecurity $[\underline{E}(5,31)=3.43, \underline{p}<.05]$. Follow-up univariate tests revealed that differences in maternal sensitivity were only marginally significant $[\underline{F}(1,35)=3.61, \mathfrak{p}<.10]$, whereas differences were 
Table 3.19

Maternal variables by gr.uup (secure vs. insecure attachment)

Means, standard deviations, and significance values at 13 months $(N=38)$

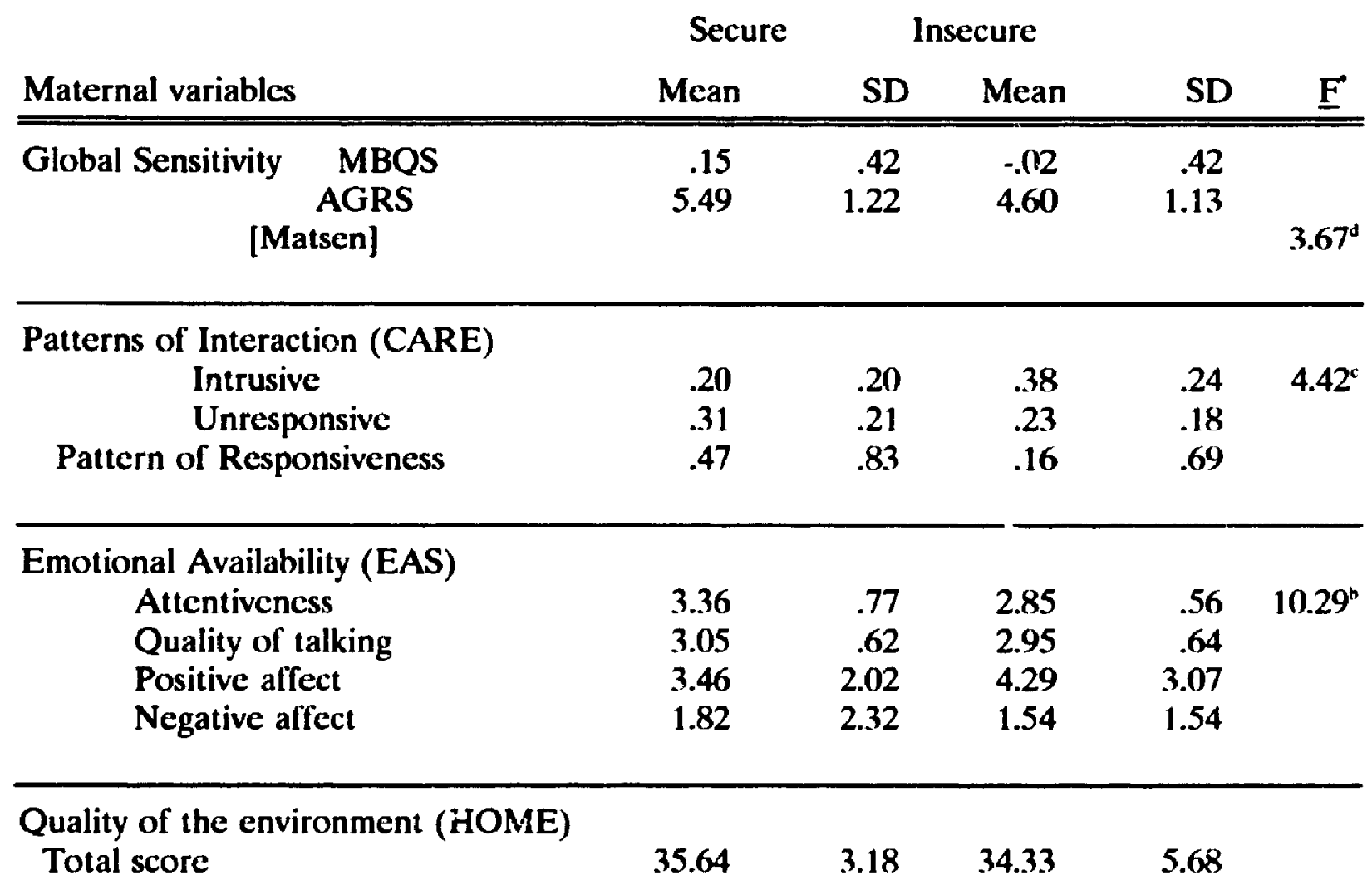

\footnotetext{
${ }^{\mathrm{a}} \mathrm{g}<.001{ }^{\mathrm{b}} \mathrm{p}<.01 \quad{ }^{\mathrm{c}} \mathrm{k}<.05 \quad{ }^{\mathrm{d}} \mathrm{p}<.10$

$\underline{F}(5,31)=3.43, \mathrm{p}<.05$

Matsen = MBQS + AGRS [Maternal Behaviour Q-sort + Ainsworth Global Rating Scales] CARE $=$ Child-Adult Relationship Experimental Index

EAS = Emotional Availability Scale HOME = Home Observation for Measurement of the Environment
} 
Table 3.20

Child variables by group (secure vs. insecure attachment)

Means, standard deviations, and significance values at 13 months $(N=38)$

Secure

Insecure

Child variables

Mean

SD

Mean

SD

$\underline{F}$

Cognitive development (MDI)

112.86

11.29

108.75

13.35

Infant temperament

Maternal rating - ITQR

Experimenter rating - IBR

15.66

5.33

1.94

16.13

1.83

Experimenter rating - IBR

Communicative acts per minute

\subsection{3}

1.14

3.14

1.11

Development tasks

Homeostasis

Exploration

9.68

.32

1.16

.05

8.85

.30

1.05

.05

$8.16^{b}$

Attachment (AQS)

SS (proportion)

.14

.12

.23

$\underline{\mathrm{F}}(5.31)=3.43, \mathrm{p}<.05$

BSID = Bayley Scales of Infant Devejopment

MDI - Mental Development Index

IB.:- - Infant Behaviour Record -Affect/emotionality composite

ITQR = Infant Temperament Questionnaire Revised - "difficult"

Homeostasis = ITQR + IBR compositc scores

Exploration = Task persistence score in Mastery Motivation task

AQS = Attachment Q-Sort

SS = Strange Situation 
significant for maternal intrusiveness $[\underline{F}(1,35)=5.14, \underline{p}<.05]$ and for emotional availability $[\underline{F}(1,35)=10.44, \underline{p}<.01]$. The univariate test for homeostasis was also significant $[\underline{F}(1,35)=8.16, \underline{p}<.01]$ but that for task persistence was not significant.

Post hoc tests (LSD) revealed that mothers in secure attachment relationships were more emotionally available during play than mothers in either insecure-avoidant $[\mathrm{t}(35)=2.30, \mathfrak{p}<.05]$ or insecure-ambivalent relationships $[\underline{t}(35)=2.12, \mathrm{p}<.05]$. Mothers in insecure-avoidant attachment relationships tended to be more intrusive during play than mothers in secure attachment relationships $[\mathrm{t}(35)=2.06, \mathrm{p}<.05]$. Infants in secure attachment relationships had significantly higher homeostasis scores than infants in insecure-avoidant or insecure-ambivalent relationships.

\section{Section 3: Associations between Strange Situation Classification} and Benaviour Assessed in the Home - All dyads with 13-month-olds ( $N=61$ )

Hypotheses 2a to 2c: The second set of hypotheses pertained to associations between attachment and several aspects of maternal interactive behaviour (sensitivity intrusiveness, emotional availability) and infant characteristics (temperament), which have been linked to the quality of the attachment relationship (See pages 41-42 for exact wording of the hypotheses). Since there were relatively few securely attached children in the 13-month crosssectional sample, analyses to test these hypotheses were performed on data from all dyads with 13-month-olds, including those who received a brief intervention aimed at enhancing maternal sensitivity. The increased sample size and the more nearly equal distribution of secure and insecure children in the combined sample allowed for more powerful analyses in assessing the relationships between maternal interactive behaviour and optimal child development at 13 months, including a secure attachment relationship.

Two MANOVA were performed to test the hypotheses. For the first MANOVA, complete daia were available on 57 dyads - one mother declined to 
come to the University for the Strange Situation procedure and three mothers did not complete the temperament questionnaire. Complete data were available on 60 dyads for the second MANOVA. Of the 60 dyads who had received attachment classifications, $48 \%(\mathrm{~N}=29)$ had been classified as securely attached, $37 \%(\mathrm{~N}=22)$ as insecure-avoidant, and $15 \%(\mathrm{~N}=9)$ as insecure-ambivalent.

Tests of Hypu,ieses 2a and 2b: Associations between attachment security, maternal interactive behaviour, and infant temperament. Results of the first MANOVA (using Pillais' criterion) and follow-up univariate analyses provided support for both hypotheses. Table 3.21 presents the means, standard deviations, and significant differences in maternal behaviours and in infant temperament in dyads who were in secure and insecure attachment relationships. Maternal sensitivity [aggregated MBQS and AGRS scores], intrusiveness [CARE scores], and maternal emotional availability [EAS attentive scores], together with attachment security scores [AQS scores] and infant temperament ratings [ITQR "difficult" scores for mothers and IBR affect/emotionality scores for experimenters] were entered as dependent measures in the MANOVA with attachment security/insecurity as the independent measure. There was a significant main effect for attachment security/insecurity $[\underline{E}(6,50)=4.62, \mathfrak{p}<.001]$. Follow-up univariate tests revealed significant differences for maternal sensitivity $[\underline{F}(1,55)=$ $11.31, \mathrm{D}<.001]$. maternal intrusiveness $[\mathrm{F}(1,55)=8.75, \mathrm{p}<.01]$, for emotional availability $[\mathrm{F}(1,55)=15.70, \mathrm{D}<.001]$, and for attachment security (AQS) scores $[\underline{F}(1,55)=5.84, \mathrm{p}<.05]$. In each case, the more favourable means were found in securely attached dyads. The results for temperament were equivocal. The univariate test for temperament, as measured by maternal report, was not significant whereas that for affect/emotionality during testing, as rated by the examiner, was marginally significant $(\mathrm{F}(1.55)=3.66, \mathfrak{p}<.10)$. Securely attached toddlers tended to be rated as more positive in affect/emotionality during testing than insecurely attached toddlers.

Post hoc tests (LSD) revealed that mothers in insecure-avoidant attachment

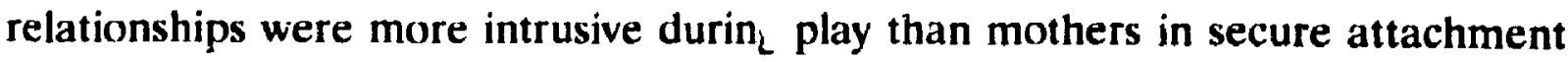


Table 3.21

Means and standard deviations by group (secure vs. insecure attachment) maternal beh. viours at infant-age 13 months $(N=60)$

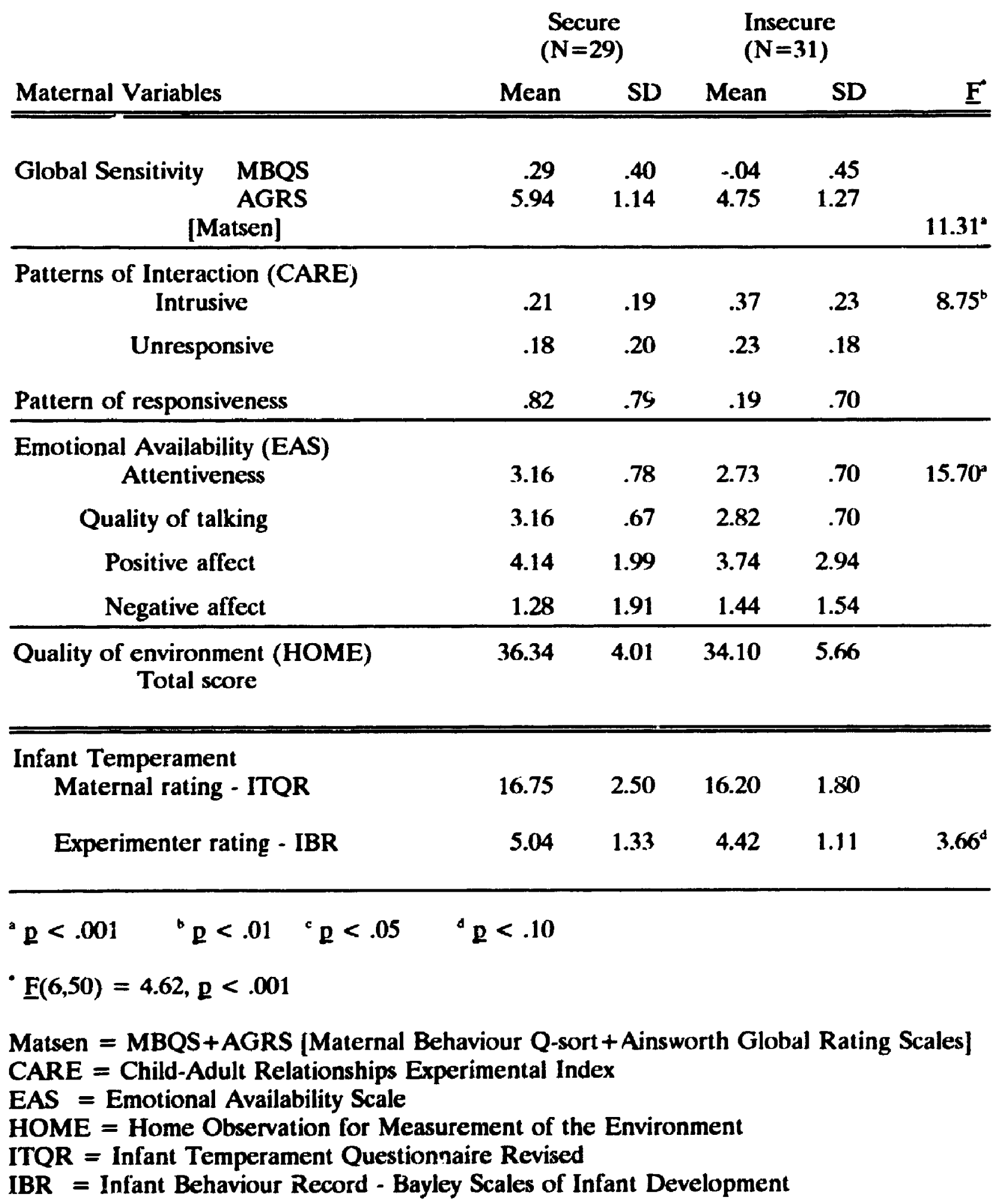


relationships $[\mathrm{t}(55)=2.83, \mathrm{p}<.05]$. Post hoc tests for affect/emotionality were not significant but this may have been due to the relatively small number of insecure-ambivalent toddlers compared to the numbers of secure and insecureavoidant toddlers in this sample. Therefore, a one-way ANOVA (temperament by attachment classification - A vs B vs C) was performe $t$ on the affect/emotionality scores of the 37 babies in the 13-inonth cross-sectional sample described in the previous section, where the rumbers of insecure-ambivalent and secure children were closer in size. The result was marginally significant $[F(2,35)=2.75, \underline{p}<$ .10]. Post hoc tests (LSD) revealed that children in insecure-ambivalent relationships tended to be fussier, less sociable, and less cooperative than children in secure attachment relationships $[\mathrm{t}(35)=2.78, \mathrm{p}<.0 .5]$.

Tests of Hypothesis 2c: the relation of attachment classifications (SS) to attachment security scores (AQS) and to domain specific attachment behaviours exhibited in the home. Composite scores reflecting secure base behaviour, compliance, affect sharing, physical contact, and fussiness were computed for each child from relevant scores on the AQS (Pederson \& Moran, 1994). Mean scores for the first three composites were entered as dependent measures in a second MANOVA with attachment security/insecurity as the independent measure. A priori contrasts for the last two composites were assessed by T-tests. Table 3.22 presents the means, standard deviations, and significant Cifferences in attachment security scores and in each of the domain-specific attachment behaviours for toddlers in secure and insecure attachment relationships. As indicated, five of the six predictions in Hypothesis $2 \mathrm{c}$ were supported. There was a significant main effect for attachment security/insecurity $[\mathrm{F}(3,56)=3.53$, $\mathrm{p}<.05]$. Follow-up univariate analyses revealed significant effects for secure base behaviour $(\underline{F}(1,58)$ $=7.86, \mathrm{p}<.01)$ and for affect sharing $(\mathrm{F}(1,58)=4.97, \mathrm{p}<.05)$; the univariate test for compliance was not significant. In each case, effects were in a positive direction, with secure chiidren having the higher means. Results of the T-tests revealed that fussy/difficult scores for toddlers in insecure-ambivalent relationships were significantly higher than for toddlers in secure or insecure-avoidant 
Table 3.22

Means and standard deviations by group (secure vs. insecure attachment) for attachment security (AOS) scores and domain specific attachment hehaviours at 13 months $(N=60)$

\begin{tabular}{lrrrrr} 
& \multicolumn{2}{c}{$\begin{array}{c}\text { Secure } \\
(\mathrm{N}=29)\end{array}$} & \multicolumn{2}{c}{$\begin{array}{c}\text { Insecure } \\
(\mathrm{N}=31)\end{array}$} \\
Child Variables & Mean & SD & Mean & SD & $\underline{\mathbf{F}}$ \\
\hline Attachment security [AQS] & .27 & .17 & .14 & .23 & $5.84^{\mathrm{c}}$ \\
Secure base & 6.22 & .49 & 5.70 & .89 & $7.86^{\mathrm{b}}$ \\
Affect sharing & 4.00 & 1.28 & 3.37 & .85 & $4.97^{\mathrm{c}}$ \\
Compliance & 6.30 & 1.01 & 5.78 & 1.52 & \\
Physical contact & 5.92 & 1.98 & 4.10 & 2.10 & 3.44 \\
Fussiness & 4.37 & 1.02 & 4.52 & .97 & $2.23^{\mathrm{c}}$ \\
\hline
\end{tabular}

${ }^{\mathrm{a}} \mathrm{p}<.001{ }^{\mathrm{B}} \mathrm{p}<.01{ }^{\mathrm{c}} \mathrm{p}<.05$

${ }^{\circ} E(3,56)=3.53 . \mathrm{p}<.05$

I values shown for Physical contact $[A$ us $B+C$ ] and for Fussiness $[C$ vs $B+A]$

AQS = Attachment Q-Sort 
relationships $(\underline{t}(58)=2.23, \underline{p}<.05)$. Toddlers in insecure-avididant relationships enjoyed physical contact less than infants in secure or insecuie-ambivalent relationships $(\mathrm{t}(58)=3.44, \mathrm{p}<.001)$.

Correlates of 13-month security of attachment (AQS) scores and maternal interactive behaviours. The following analyses provide further support for the associations between maternal interactive behaviour and attachment security. Table 3.23 presents the correlations between attachment security (AQS) and maternal age, and maternal interactive behaviours and infant temperament. In general, AQS scores increased as maternal interactive behaviours became more sensitive. As indicated, security of attachment scores were positively correlated with scores on both global measures of maternal sensitivity $(\underline{r}=.64, \underline{p}<.001$ for MBQS and $\underline{\mathrm{r}}=.63, \underline{\mathrm{p}}<.001$ for AGRS), with the provision of a stimulating social and emotional home environment $(\underline{r}=.48, \underline{p}<.001)$, with maternal responsiveness during play ( $\underline{\underline{ }}=.43, \mathrm{p}<.001$ ), and with maternal emotional availability during play $(\underline{r}=.33, \underline{p}<.05)$ and negatively correlated with maternal intrusiveness during play $(\underline{r}=-.44, \underline{\mathrm{g}}<.001)$. Security of attachment scores were also positively correlated with infant temperament rated during the Bayley testing situation ( $r=.46, \mathrm{p}<.001$, for affect/emotionality) but not as rated by the mothers. Maternal age was not significantly correlated with the two global measures of maternal sensitivity nor with infant attachment security.

Differential effects of maternal interactional hehaviours. In addition to forming insecure attachment relationships, children of adolescent mothers have also been shown to be at risk for cognitive and language delays. Although ro predictions were made regarding the latter two areas of infant development, based on principles implicit in developmental psychopathology, mure sensitive maternal behaviours would also be expected to be associated with enhanced cognitive and language development, in addition to enhanced social-emotional development at 13 months.

To determine if maternal sensitivity or other aspects of the mother's interactive behaviour explain unique amounts of variance in these three domains 
Table 3.23

Correlations between attachment security and maternal aze, and maternal interactive behaviours and infant temperament: Dyads with 13-month-old infants $(N=61)$

Variables

AQS AGE

MOM

Global sensitıvity

MBQS

$.64^{\mathrm{a}}$

.21

AGRS

Interaction Pattern (CARE)

Intrusive

Unresponsive

Pattern of responsiveness

$-.44^{\mathrm{a}} \quad-.04$

$-.09 \quad-.38^{\mathrm{b}}$

$.43^{\mathrm{a}} \quad .30^{\mathrm{c}}$

Emotional Availability(EAS)

Attentiveness

$.33^{b} \quad .20$

Quality of talk

.15

$.25^{\circ}$

Positive affect

$.08 \quad-.08$

Negative affect

Quality of environment (HOME)

Total score

Infant temperament

Mother's rating (ITUR)

Experimenter's rating (IBR)

$a=p<.001, \quad b=p<.01, \quad c=p<.05, \quad d=p<.10$

MBQS = Maternal Behaviour Q-sort

AGRS = Ainsworth Global Rating Scales

CARE = Child-Adult Relationship Experimental Index

EAS = Emotional Availability Scale

HOME = Home Observation for Measurement of the Environment

AQS = Attachment Q-Sort

ITQR = Infant Temperament Questionnaire Revised

IBR = Infant Behaviour Record (Bayley Scales of Infant Development) 
of the child's development, standard multiple regressions were perforined with maternal interactive behaviours as predictors and infant security of attachment, infant mental development, and infant communicative ability as the criteria. Four maternal interactive behaviours were chosen on conceptual grounds and on the basis of previous results published in the literature. Each maternal behaviour was obtained by a different measure; two measures were completed on the basis of observations in the home (MBQS and HOME) and two were completed through coding of semi-structured play interactions (CARE and EAS).

In the first multiple regression, AQS scores were entered as the criterion, with maternal sensitivity [aggregated MBQS + AGRS scores], quality of the home environment [total HOME scores], maternal pattern of responsiveness during olay [CARE scores], and quality of the mother's communications to her child [EAs, talking domain scores] as predictors. Table 3.24 displays the correlations between the variables, beta coefficients, the semipartial correlations $\left(\underline{\mathbf{s}^{2}}\right)$, and $\underline{\mathbf{R}}$ and $\underline{\mathbf{R}}^{2}$. Maternal sensitivity contributed significantly to prediction of attachment security scores $\left(\underline{s} \underline{r}^{2}=.14, \underline{D}<.001\right)$. Altogether, more than $43 \%$ of the variance in AQS scores was predicted by the four maternal variables $(\underline{R}=.66, \underline{F}(4,56)=10.64, \underline{p}$ $<.001)$. The sum of unique variances associated with each predictor explained approximately $15 \%$ of the variance in the criterion. This is substantially less than the total explained variance indicating that the predictor variables also have some predictive potency when considered in combination.

In the second multiple regression with infant mental development [MDI] as the criterion, more than $18 \%$ of the variance in Bayley mental development scores was predicted by the maternal variables $(\underline{R}=.43, \underline{F}(4.56)=3.08, \underline{p}<.03)$. Table 3.25 displays the correlations between the variables, beta coefficients, the semipartial correlations $\left(\underline{s^{2}}\right)$, and $\underline{R}$ and $\underline{R}^{2}$. Only HOME scores made a significant unique contribution to prediction of the child's mental development ( $\underline{\mathbf{s}} \mathbf{r}^{2}$ $=.06, \mathrm{D}<.05)$. The sum of unique variances associated with each predictor explained approximately $7 \%$ of the variance in the criterion. As in the first multiple regression, this is substantially less than the total explained variance 
Table 3.24

Standard multiple regression of maternal interactive behaviours on

13-month attachment security scores $(N=61)$

\begin{tabular}{|c|c|c|c|c|c|c|c|}
\hline Variables & $D^{1}$ & 1. & 2. & 3. & 4. & Beta & $\underline{\mathbf{s r}}^{2}$ \\
\hline 1. MatSen & .65 & & & & & .65 & .14 \\
\hline 2. HOME & .48 & .76 & & & & & \\
\hline $\begin{array}{l}\text { 3. Communication } \\
\text { (EAS) }\end{array}$ & .15 & .34 & .36 & & & & \\
\hline $\begin{array}{l}\text { 4. Responsiveness } \\
\text { (CARE) }\end{array}$ & .43 & .59 & .43 & .32 & & & \\
\hline Mean & .20 & .00 & 35.00 & 2.97 & .47 & & \\
\hline \multirow[t]{3}{*}{ Std. Dev. } & .21 & 1.95 & 5.18 & .71 & .81 & & \\
\hline & & & & & & $\mathbf{R}^{2}=$ & .43 \\
\hline & & & & & & $\mathbf{R}=$ & $.66^{*}$ \\
\hline
\end{tabular}

$* \mathrm{p}<.001$

For $\mathrm{N}=61$, correlacions $>.25$ are significant at $\mathrm{p}<.05$

${ }^{1}=$ Attachment Q-sort (AQS)

MatSen: Maternal Behaviour Q-sort + Ainsworth Global Rating Scale HOME: Home Observation and Measurement of the Environment EAS: Emotional Availability Scale - quality of maternal communication CARE: Child-Adult Relationship Experimental Index - Pattern of responsiveness 
Table 3.25

Standard multiple regression of maternal interactive behaviours on 13-month mental development scores $(N=61)$

\begin{tabular}{|c|c|c|c|c|c|c|c|}
\hline Variables & $\mathrm{DV}^{1}$ & 1. & 2. & 3. & 4. & Beta & $\underset{\text { unique }}{\underline{\mathbf{s r}}^{2}}$ \\
\hline 1. MatSen & .32 & & & & & & \\
\hline 2. HOME & .42 & .76 & & & & .39 & .06 \\
\hline $\begin{array}{l}\text { 3. Communication } \\
\text { (EAS) }\end{array}$ & .20 & .34 & .36 & & & & \\
\hline $\begin{array}{l}\text { 4. Responsiveness } \\
\text { (CARE) }\end{array}$ & .14 & .59 & .43 & .32 & & & \\
\hline Mean & 111.33 & .00 & 35.00 & 2.97 & .47 & & \\
\hline \multirow[t]{3}{*}{ Std. Dev. } & 11.47 & 1.95 & 5.18 & .71 & .81 & & \\
\hline & & & & & & $\mathbf{R}^{2}=$ & .18 \\
\hline & & & & & & $\mathrm{R}=$ & $.42^{*}$ \\
\hline
\end{tabular}

$* p<.05$

For $\mathrm{N}=61$, correlations $>.25$ are significant at $\mathrm{p}<.05$

${ }^{\prime}=$ Mental development index (MDI) -Bayley Scales of Infant Development

MatSen: Matcrnal Behaviour Q-sort + Ainsworth Global Rating Scale HOME: Home Observation and Measurement of the Environment EAS: Emotional Availability Scale - quality of maternal comsnunication CARE: Child-Adult Relationship Experimental Index - Pattern of responsiveness 
indicating that the predictor variables also have some predictive potency when considered in combination.

In the third multiple regression with infant communicative ability as the criterion, more than $21 \%$ of the variance in the number of communicative acts per minute during the Communicative Temptations task was predicted by the maternal variables $(\underline{R}=.46, \underline{F}(4,52)=3.46, \underline{p}<.05)$. Table 3.26 displays the correlations between the variables, beta coefficients, the semipartial correlations $\left(\underline{\mathbf{s}}^{2}\right)$, and $\underline{\mathrm{R}}$ and $\underline{\mathrm{R}}^{2}$. The quality of the mother's communications to her child during play made a significant unique contribution to the prediction of the child's communicative ability $\left(\underline{s}^{2}=.12, \underline{p}<.01\right)$. The sum of the unique variances associated with each predictor explained approximately $19 \%$ of the variance in the criterion. Unlike the pattern observed in the first two multiple regressions, the four variables in combination added little to the prediction.

\section{Section 4: Longitudinal Data - Associations between maternal and infant} behaviours across two ages

Although important associations between maternal sensitivity and the mastery of developmental tasks were found in the cross-sectional samples, longitudinal data is needed in order to better understand the developmental processes leading to insecure attachment relationships. The results presented here are from the 22 dyads assessed at both 3 months and 6 months, and the 25 dyads assessed at both 6 montr- ${ }^{-}$and 13 months. Although it would have been preferable to follow the same sample throughout the year, that was not possible in the present study. However, 12 of the 22 dyads in the first sample were part of the second sample, which may result in a clearer picture of the process of attachment over the first year than would otherwise have been possible if the samples had been completely independent.

Hierarchical multiple regressions, correlational analyses, and multivariate analyses were used to test Hypotheses 3a to $3 \mathrm{c}$ (See page 42 for exact wording of the hypotheses.) Because of the small sample sizes, only a limited number of the 
Table 3.26

Standard multiple regression of maternal interactive behaviours on

13 -month communicative ability scores $(N=61)$

\begin{tabular}{|c|c|c|c|c|c|c|c|}
\hline Variables & DV $^{\prime}$ & 1. & 2. & 3. & 4. & Beta & $\underset{\text { unique }}{\text { sr }^{2}}$ \\
\hline 1. MatSen & .14 & & & & & & \\
\hline 2. HOME & .25 & .76 & & & & & \\
\hline $\begin{array}{l}\text { 3. Communication } \\
\text { (EAS) }\end{array}$ & .37 & .34 & .33 & & & .37 & .12 \\
\hline $\begin{array}{l}\text { 4. Responsiveness } \\
\text { (CARE) }\end{array}$ & -.05 & .58 & .42 & .31 & & & \\
\hline Mean & 3.11 & .00 & 35.00 & 2.97 & .47 & & \\
\hline \multirow[t]{3}{*}{ Std. Dev. } & 1.22 & 1.95 & 5.18 & .71 & .81 & & \\
\hline & & & & & & $\mathbf{R}^{2}=$ & .21 \\
\hline & & & & & & $\mathbf{R}=$ & $.46^{*}$ \\
\hline
\end{tabular}

${ }^{*} \mathrm{p}<.05$

For $\mathrm{N}=61$, correlations $>.25$ are significant at $\mathrm{p}<.05$

${ }^{1}=$ Number of communicative acts/minute $\cdot$ Communication \& Symbolic Behaviour Scales

MatSen: Maternal Behaviour Q-sort + Ainsworth Global Rating Scale HOME: Home Observation and Measurement of the Environment EAS: Emotional Avallability Scale - quality of maternal communication CARE: Child-Adult Relationship Experimental Index - Pattern of responsiveness 
variables were used in the analyses. However, the analyses that follow are best regarded as exploratory, as the subject-to-variable ratio was still less than optimal (Marascuilo \& Levin, 1983).

3-months to 6-months-of-age ( $N=22)$

Stability of maternal sensitivity across two developmental periods.

Continuity in maternal interactive behaviours from 3 to 6 months was assessed by correlating the various scores at the two ages. Means, standard deviations, and stability coefficients are presented in Table 3.27. Significant correlations between 3 month and 6 month scores were found for global maternal sensitivity whether measured by MBQS or AGRS scores $[\underline{\mathrm{r}}=.44, \mathrm{p}<.05$ and $\underline{\mathrm{I}}=.59, \underline{\mathrm{p}}<.01$, respectively], for provision of a stimulating social and emotional home environment ( $\underline{\underline{a}}=.68, \underline{\mathrm{p}}<.001)$, and for unresponsiveness during play $(\underline{\mathrm{r}}=.41, \mathrm{p}$ $<.10$ ), indicating that mothers with higher scores when their babies were 3months-of-age continued to have higher scores when their babies were 6-monthsof-age. Stability coefficients for maternal perceptions of stress were: $\underline{r}=.52, \underline{p}<$ .05 , for the child domain and $\underline{\mathrm{r}}=.70, \mathrm{p}<.001$, for the parenting domain. Although visual inspection of the means suggested that maternal sensitivity decreased as the babies got older, the mean differences were not significant indicating some consistency in maternal sensitivity from 3 to 6 months.

Compared to maternal behaviours, infant characteristics showed less stability over the 3-month period. Visual inspection of Table 3.28, which shows means, standard deviations, and stability coefficients, reveals that only two of the five correlations were significant. Infants with higher scores in homeostasis at 3 months continued to have higher scores at 6 months $(\underline{r}=.68, \underline{p}<.001)$, and infants who were perceived as temperamentally "difficult" by their mothers at 3 months tended to be perceived as difficult at 5 months $(\underline{r}=.38, \mathfrak{p}<.10)$.

Correlations between maternal behaviour at 3 months and the infant's mastery of developmental tasks at 6 months. The correlations between 5 maternal variables at 3 months: maternal sensitivity (MBQS scores), maternal intrusiveness (CARE), quality of the social and emotional environment (HOME scores), 
Table 3.27

Means, standard deviations, and stability cuefficients for maternal behaviours: Longitudinal data from 3 months to 6 months $(N=22)$

\begin{tabular}{|c|c|c|c|c|c|c|}
\hline \multirow[b]{2}{*}{ Maternal Variables } & \multicolumn{2}{|c|}{ 3-,nonths } & \multicolumn{2}{|c|}{ 6-months } & \multirow[b]{2}{*}{$\underline{\mathbf{I}}$} & \multirow[b]{2}{*}{1} \\
\hline & Mean & SD & Mean & SD & & \\
\hline $\begin{array}{l}\text { Global Sensitivity } \\
\text { MBQS }\end{array}$ & .29 & .38 & .16 &. .36 & .44 & .05 \\
\hline AGRS & 5.56 & .95 & 5.22 & .94 & .59 & .01 \\
\hline $\begin{array}{l}\text { Patterns of Interaction } \\
\text { (CARE) Intrusive }\end{array}$ & .38 & .15 & .44 & .16 & .35 & \\
\hline Unresponsive & .15 & .17 & .15 & .17 & .41 & .10 \\
\hline Pattern of responsiveness & .44 & .64 & .25 & .71 & .61 & .01 \\
\hline $\begin{array}{l}\text { Quality of environment } \\
\text { (HOME) Total score }\end{array}$ & 31.82 & 4.67 & 33.27 & 4.15 & .68 & .01 \\
\hline Stress (PSI) & & & 10243 & 1193 & & us \\
\hline Parent Domain & 134.32 & 24.27 & 134.29 & 20.33 & $\begin{array}{l}.52 \\
.70\end{array}$ & .01 \\
\hline
\end{tabular}

MBQS = Maternal Beheviour Q-sort

AGRS = Ainsworth Rating Scales

CARE = Child-Adult Relationship Experimental Index

HOME = Home Observation for Measurement of the Environment

PSI = Parenting Stress Index 
Table 3.28

Means, standard deviations, and stability coefficients for child characteristics:

Longitudinal data from 3 months io 6 months $(N=22)$

$$
\text { 3-months 6-months }
$$

Child Variables

Cognitive development (BSID)

(MDI)

Mean SD Mean SD

$\begin{array}{llll}110.27 & 16.05 & 113.64 & 12.63\end{array}$

$.09 \mathrm{~ns}$

Infant temperament

$\begin{array}{lrrrrrr}\text { Maternal ratings - ITQR "difficult" } & 15.44 & 1.59 & 13.85 & 2.20 & .38 & .10 \\ \text { Experimenter ratings - IBR [A/E] } & 4.11 & .73 & 4.85 & .86 & -.03 & \text { ns }\end{array}$

Vocalizations per minute

4.58

2.75

4.24

3.08

$.30 \mathrm{~ns}$

Developmental Task:

Homeostasis

8.23

.81

9.54

1.06

.59

.01

BSID = Bayley Scales of Infant Development

MDI - Mental development index

IBR [A/E] - Infant behaviour record - affect/emotionality score

Homeostasis $=$ ITQR + IBR composite scores

ITQR = Infant Temperament Questionnaire Revised 
maternal perceptions of stress (PSI, child domain + parent domain), maternal perceptions of infant temperament (ITQR "difficult" scores) and 2 developmental tasks at 6 months: homeostasis (ITQR + IBR composite scores) and exploratory behaviour (Mastery Motivation task) were assessed. Three of the 10 correlations were significant: mothers who reported higher levels of stress at 3 months had babies with lower scores on the homeostasis measure at 6 months $(r=-.45, p$ $<.05)$. Mothers who perceived their babies as more temperamentally difficult at 3-months-of-age had babies with lower homeostasis scores at 6 months $(\underline{r}=-.45, \underline{p}$ $<.05$ ), and lower scores in exploratory behaviour during the mastery motivation task at 6 -months-of-age $(r=-.41, \mathrm{p}<.10)$. The correlations between the three measures of maternal interactive behaviour and the two developmental tasks were not significant.

\section{Correlations between infant characteristics at 3 months and maternal} behaviours at 6 months. Mastery of the developmental task at 3 months appeared to be associated with more positive maternal behaviour at 6 months. Higher homeostasis scores at 3 months were associated with higher HOME scores at 6 months $(\underline{\underline{ }}=.46, \underline{\mathrm{p}}<.05)$, lower scores on maternal perceptions of difficult temperament $(\underline{r}=-.55, \underline{p}<.01)$, and lower levels of stress $(\underline{r}=-.41, \underline{p}<.10)$.

Test of Hypothesis 3a: Continuity in adaptation at 3 and 6 months was marginally supported. The correlation between homeostasis scores at 3 months and exploratory scores at 6 months was not significant $(\underline{r}=.17)$. However, when the sample was divided into two groups of high and low scoring infants on the basis of median splits in homeostasis scores at 3 months, the mean exploratory score in the high scoring group was $.30, \underline{\mathrm{SD}}=.07$, in the low scoring group, the mean was $.25, \underline{\mathrm{SD}}=.05$. T-test analyses revealed that this difference was marginally significant $(\underline{t}(18)=1.75, \underline{\mathrm{p}}<.10$. A visual inspection of the scores in the two groups showed that 9 of the 11 children with homeostasis scores greater than the mean at 3 months also had scores in exploratory behaviour greater than the mean at 6 months, only 5 of the 10 children with lower scores in homeostasis at 3 months had higher scores in exploratory behaviour at 6 months. Such 
findings suggest that infants who had mastered the developmental task at 3 months were the same infants who were mastering the developmental task at 6 months.

6-months to 13-months-of-age ( $N=25)$

Stability of maternal interactional behaviours, maternal perceptions, and infant characteristics. Means, standard deviations, and stability coefficients for maternal variables are presented in Table 3.29. In general, both maternal interactive behaviours and maternal perceptions showed relative stability over the 7 month period, in that mothers with higher scores when their babies were 6months-of-age continued to have higher scores when their babies were 13-monthsof-age. Significant correlations between 6 month and 13 month scores were found for global maternal sensitivity whether measured by MBQS or by AGRS ( $\mathrm{r}=.55$, $\underline{p}<.01$ and $\underline{r}=.50, \underline{p}<.01$, respectively). for provision of a stimulating social and emotional home environment $(\underline{r}=.53, \underline{p}<.01)$, and for intrusiveness during play $(\underline{r}=.36, \underline{p}<.10)$. Stability coefficients for maternal perceptions of stress were $\underline{r}=.72, \underline{p}<.001$ for the child domain and $\underline{I}=.60, \mathfrak{p}<.01$ for the parenting domain. However, as in the cross-sectional sample, maternal sensitivity decreased as the babies got older: MBQS scores at 13 months were significantly lower than MBQS scores at 6 morths $(\underline{t}(24)=-2.62, \underline{\mathrm{g}}<.05)$.

Infant characteristics showed less stability over the 7 months than maternal behaviours. Means, standard deviations, and stability coefficients are presented in Table 3.30. Infants who were more vocal at 6 months continued to be more vocal during play at 13 months $(\underline{r}=.43, \underline{p}<.05)$ and infants with higher scores in mental development at 6 months continued to have higher scores at 13 months ( $\underline{\mathbf{r}}$ $=.50, \mathrm{p}=.01)$.

Correlations between maternal behaviours and perceptions at 6 months and infant characteristics at 13 months. Correlations between 5 maternal interactive behaviours at 6 months: maternal sensitivity (MBQS scores), maternal intrusiveness during play (CARE-I), inaternal unresponsiveness during play (CARE-U), maternal emotional availabiiity [EAS, attentiveness score], and the 
Table 3.29

Means, standard deviations, and stability coefficients for maternal behaviours:

Longitudinal data from 6 months to 13 months $(N=25)$

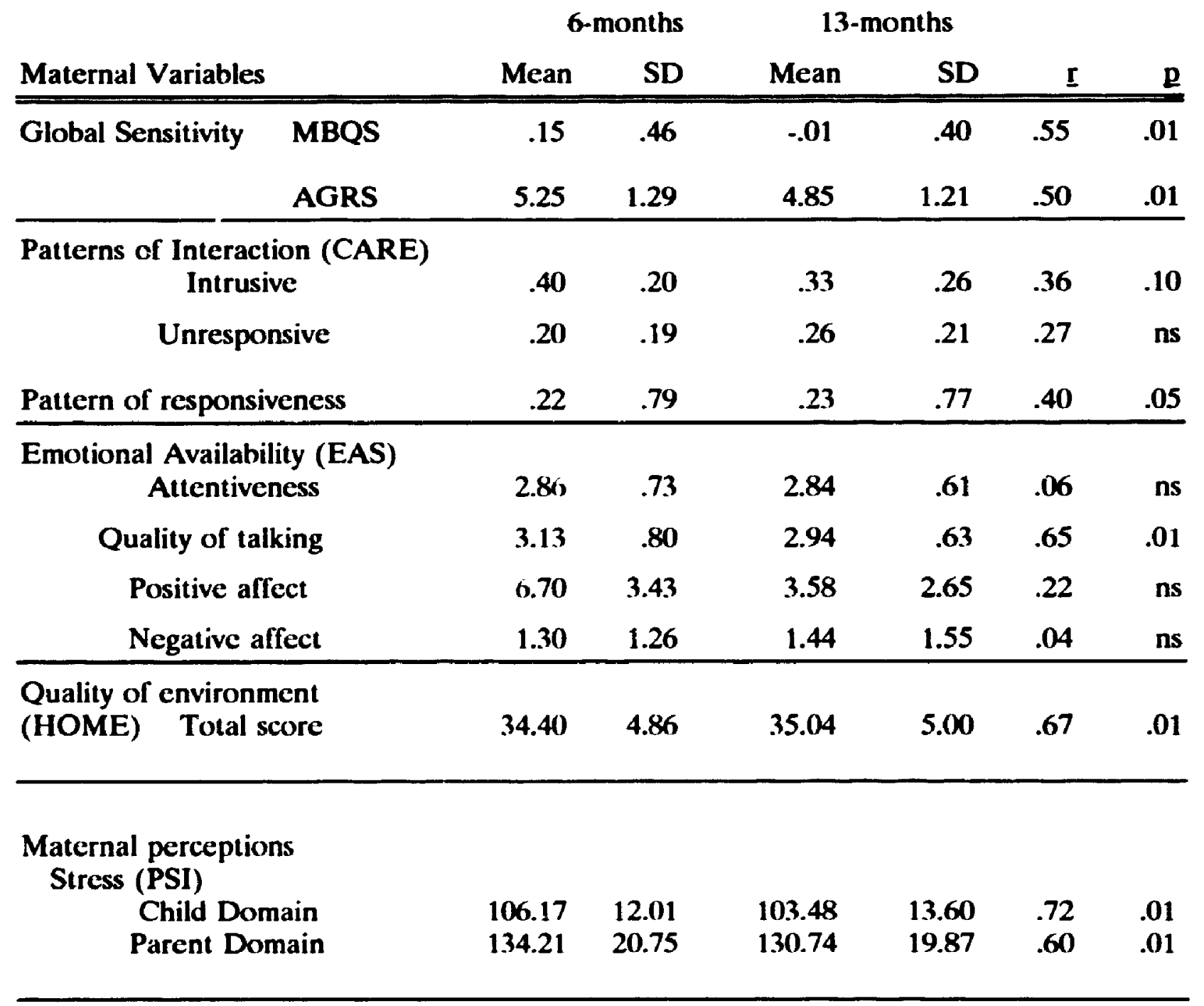

MBQS: Maternal Behaviour Q-sort

AGRS: Ainsworth Rating Scales

CARE: Child-Adult Relationship Experimental Index

EAS = Emotional Availability Scale

HOME = Home Observation for Measurement of the Environment

PSI = Parenting Stress Index 
Table $\mathbf{3 . 3 0}$

Means, standard deviations, and stability coefficients for child characteristics: Longitudinal data from 6 months to 13 months $(N=25)$

6-months 13-months

Child Variables

Mean

SD

Mean

SD

$\mathbf{2} \quad \mathbf{2}$

Cognitive development (BSID)

115.40

16.36

114.76

9.90

.50

.01

(MDI)

Infant temperament

Maternal ratings - ITQR "difficult"

13.95

2.15

15.95

1.80

.41

.10

Experimenter ratings - IBR [A/E]

4.79

.96

4.65

1.14

.21

ns

Vocalizations per minute

$4.16 \quad 2.85$

2.27

1.55

.43

.03

Developmental Tasks:

Homeostasis

9.74

1.14

$8.94 \quad 1.05$

.18

ns

Exploration

.28

.07

.31

.05

.35

ns

BSID = Bayley Scales of Infant Development

MDI - Mentà develspment index

IBR - Infant behaviour record

Homeostasis = ITQR +IBR composite scores

Exploration = Exploratory score in Mastery Motivation Task @ 6 mo.

= Task persistence score in Mastery Motivation Task@13 mo.

ITOR = Infant Temperament Questionnaire Revised 
quality of the environment (HOME scores) and 5 child variables at 13 months: infant vocalizations, infant temperament (ITQR "difficult" scores and IBR affect/emotionality scores), homeostasis (ITQR + IBR composite scores), and attachment security scores were assessed. The results are presented in Table 3.31. As indicated, higher scores in maternal unresponsiveness during play at 6 months were associa.ed with lower scores in affect/emotionality during testing $(\underline{r}=-.43, \underline{p}$ $<.05)$, as well as lower scores in homeostasis $(\underline{r}=-.38, \underline{\mathrm{p}}<.05)$, and lower attachment security scores at 13 months $(\underline{\underline{x}}=-.50, \underline{\mathrm{p}}<.05)$. Higher HCidE scores at 6 months were associated with more vocalizations during play at 13 months $(\underline{r}=.40, \underline{p}<.05)$. That is, unresponsive maternal behaviours at 6 mcinths appeared to be associated with less adaptive infant characteristics at 13 months.

Correlations between infant characteristics at 6 months and maternal behaviours at 13 months. Correlations between 5 child variables at 6 months: infant vocalizations, infant temperament (ITQR "difficult" scores and IBR affect/emotionality scores), homeostasis (ITQR + IBR composite scores), and exploratory behaviour, and the 5 maternal interactive behaviours at 13 months listed above, were assessed. Table 3.32 summarizes the results of the correlational analysis. As indicated, infants with higher scores in homeostasis at 6 months had mothers with higher sensitivity scones $(\underline{r}=.47, \underline{p}<.05$,), higher HOME scores $(\underline{r}$ $=.59, \mathrm{p}<.01)$, and higher emotional availability scores $(\mathrm{r}=.50, \mathrm{p}<.01)$ at 13 months. Infants who were more vocal during play at 6 months had mothers with higher sensitivity scores $(\underline{r}=.51, \underline{2}<.01)$ and higher HOME scores at 13 months $(\underline{r}=.53, \underline{p}<.01)$. That is, more adaptive child behaviours at 6 months appeared to be associated with more sensitive maternal behaviours at 13 months.

Test of Hypothesis 3a: Continuity in adaptation at 6 months and at 13 months was not supported. The correlation between exploratory behaviour scores at 6 months and attachment security scores at 13 months was not significant $(\mathrm{r}=$ $.03, \mathrm{p}>.10$ ). On visual inspection of the scores, no differences could be discerned in the numbers of secure or insecure infants at 13 months (SS classifications) who had higher or lower exploratory scores at 6 months - 50\% 
Table 3.31

Correlations between maternal behaviours at 6 months and infant characteristics at 13 months. $(N=25)$

Infant Characteristics at $\mathbf{1 3}$ months

Maternal Variables@6months Vocs ITQR IBR Homeo.

AQS diff $\quad A / E$

Global Sensitivity MBQS

.14

$-.30$

$-.13$

.08

.22

Patterns of Interaction (CARE)

Intrusive

.07

.22

.06

$-.29$

.08

Unresponsive

Emotional Availability (EAS)

Attentiveness

.03

$-.10$

$-.20$

$-.26$

.12

Quality of environment (HOME)

Total score

$\mathrm{a}=\mathrm{p}<.001, \mathrm{~b}=\mathrm{p}<.01, \mathrm{c}=\mathrm{p}<.05, \mathrm{~d}=\mathrm{p}<.001$

MBQS = Maternal Behaviour Q-sort

AGRS = Ainsworth Rating Scales

CARE $=$ Child-Adult Relationship Experimental Index

EAS = Emotional Availability Scale

HOME $=$ Home Observation for Measurement of the Environment

Vocs $=$ Number of vocalizations during play

ITQR = Infant Temperament Scale Revised -"difficult" score

IBR = Infant Behaviour Record

$\mathrm{A} / \mathrm{E}=\mathrm{IBR}$ affect/emotionality

Homeo $=$ Homeostasis (ITQR +IBR composite scores)

AQS = Attachment Behaviour Q-Sort 
Table 3.32

Correlations between infant characteristics at 6 months and maternal behaviours at 13 months $(\mathrm{N}=25)$

Infant Characteristics at 6 months

Maternal Variables@13 months 1 Vocs ITQR IBR Homeo. Explor. diff $\quad$ A/E

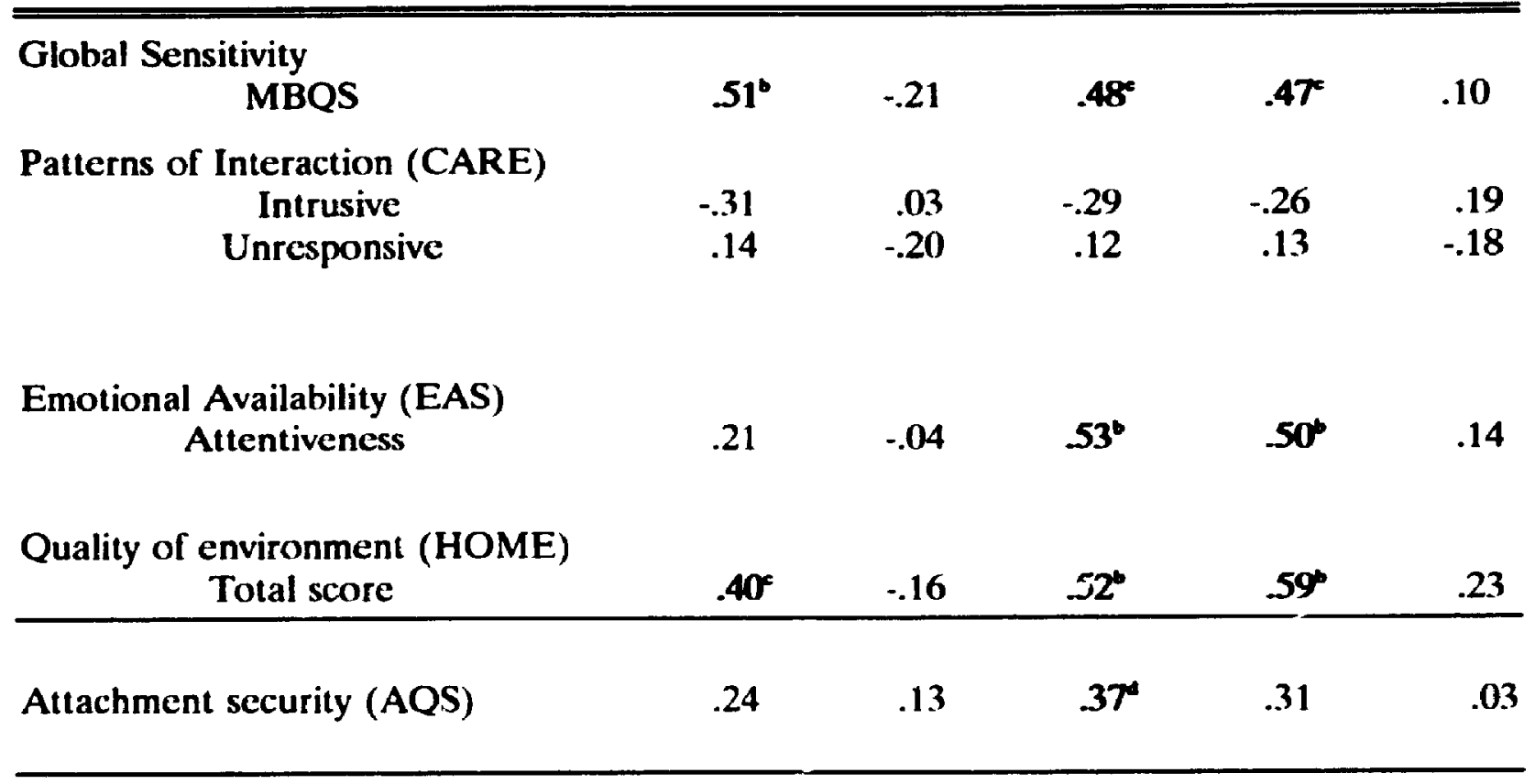

$\mathrm{a}=\mathrm{p}<.001, \mathrm{~b}=\mathrm{p}<.01, \mathrm{c}=\mathrm{p}<.05, \mathrm{~d}=\mathrm{p}<.001$

MBQS = Matcrnal Behaviour Q-sort

AGRS = Ainsworth Rating Scales

CARE = Child-Adult Relationship Experimental Index

EAS = Emotional Availability Scale

HOME = Home Observation for Measurement of the Environment

ITQR = Infant Temperament Scale Revised "difficult"

Vocs $=$ Number of vocalizations

IBR = Infant Behaviour Record

$\mathrm{A} / \mathrm{E}=\mathrm{IBR}$ affect/emotionality

Homeo $=$ Homeostasis - ITQR + IBR composite scores

AQS = Attachment Behaviour Q-Sort 
$(\mathrm{N}=4)$ of the infants in secure attachment relationships had explsratory scores above the mean at $6 \mathrm{mor}^{\circ} \mathrm{hs}, 50 \%$ had scores below the mean. The correlation between homeostasis scores at 6 months and AQS scores at 13 months was also not significant $(\underline{r}=.31, \underline{p}>.10)$. Visual inspection of the scores also showed that $50 \%$ of the babies in secure attachment relationships had home stasis scores above the mean at 6 months and 50\% had scores below the mean at 6 months.

Tests of Hypotheses $3 \mathrm{~b}$ and $3 \mathrm{c}$ : Sensitivity and temperament at 6 months as predictors of attachment security at 13 months. Hypothesis $3 \mathrm{~b}$ - that maternal sensitivity at 6 months would be predictive of attachment security at 13 months was not supported by the results of analyses using either measure of attachment security. Hypothesis $3 \mathrm{c}$ - that infant temperament at 6 months would not be predictive of attachment security at 13 months was supported by the iesults of these analyses.

On the basis of their behaviour in the strange situation, the majority of toddlers in the longitudinal sample had been classified as insecurely attached. Ten (40\%) dyads were classified as insecure-avoidant, $7(28 \%)$ as insecure-ambivalent, and $8(32 \%)$ as secure. To test the hypotheses, 6 -month scores in maternal sensitivity, maternal intrusiveness, emotional availability, and infant temperament (IBR affect-emotionality) were entered as dependent measures in a MANOVA with 13 month attachment (secure vs insecure) as the independent measure. There was a significant main effect for attachment security/insecurity $[\underline{E}(4,20)=$ $2.83, \mathrm{p}<.05$. The univariate test for maternal intrusiveness was significant $[\mathrm{F}(1,23)=4.74, \mathfrak{p}<.05]$, but that for maternal sensitivity and for infant temperament were not $[\underline{F}(1,23)=.69, p>.10$ and $E(1,23)=2.39, p>.10$, respectively]. Post hoc analyses (LSD) revealed that mothers of children in insecure-avoidant relationships at 13 months were marginally more intrusive during play with their children at 6 months, than mothers of children in $\therefore$ cure attachment relationships $($ mean $=.48, \underline{\mathrm{SD}}=.15$ vs mean $=.27, \underline{\mathrm{SD}}=.17, \underline{\mathrm{F}}(2,22)$ $=2.50, \mathrm{p}<.10)$. 
The results of correlational analyses also did not support Hypothesis $3 \mathrm{~b}$. See Tables 3.31 ard 3.32 for pertinent correlation coefficients. Correlations between maternal sensitivity scores at 6 months and attachment security (AQS scores) at 13 months were not significant $(\underline{r}=.22, \underline{p}>.05)$. The results for infant temperament were equivocal. AQS scores were not significantly correlated with maternal ratings of infant temperament at 6 months $(\underline{r}=.13, \underline{p}>.05)$, but were marginally correlated with the experimenter's rating of infant temperament during testing at 6 months (IBR affect/emotionality scores) $(\underline{r}=.37, \underline{p}<.10)$.

The effect of contemporaneous vs prior maternal interactive behaviour on attachment security. Maternal sensitivity scores at 13 months were significantly correlated with AOS scores at 13 months $(\underline{r}=.52, \underline{p}<.91)$ as were infant temperament scores, as rated by experimenters $(\underline{r}=.40, \underline{p}<.05)$ but not by mothers $(\underline{r}=.10, \mathfrak{p}>.10)$. Results of a hierarchical multiple regression revealed that maternal sensitivity accounted for $27 \%$ of the variance in AQS scores at 13 months $(\underline{R}=.52, \underline{F}(1,23)=8.41, \underline{p}<.01)$, infant affect/emotionali $\cdot$ tid not add significantly to the variance explained but an interaction between $s$,itivity and temperament accounted for an additional $10 \%$ which was marginally significant ( $\mathrm{F}$ change $=3.91 . \mathrm{p}<.10$ ). Altogether $45 \%$ of the variance in $\mathrm{AQ}=$ scores was accounted for by the three 13 -month variables $(\underline{R}=.67, \underline{F}(3,21)=5.78, \underline{p}<.01)$

However, interpretation of these results must be made with caution since 13-month maternal sensitivity scores did not distinguish between children who were classified as secure or insecure on the basis of their behaviour in the strange situation $($ mean $=.10, \underline{\mathrm{SD}}=.41$ vs mean $=. .11, \underline{\mathrm{SD}}=.41, \underline{\mathrm{t}}(23)=1.19, \mathrm{p}>$ .10). Significant differences may not have been found because there were so few securely attached children in this sample but the significant correlations may also be partly due to the fact that MBQS and AQS scores are based on the same observations in the home.

In summary, results of the longitudinal analyses supported the findings in the cross-sectional samples. The decline in maternal sensitivity seen in the two older age-levels was also seen in the two longitudinal samples, as were the links 
betwien maternal interactive behaviour and infant-mother attachment relationships. The results support a transactional model of mother-child interactional behaviours and suggest that contemporaneous maternal sensitivity is a better predictor of attachment security in this high risk sample, than earlier maternal sensitivity. Neither prior nor contemporaneous measures of infant temperament appeared to directly predici attachment security as measured by the Strange Situation procedure.

\section{Section 5: A Description of Maternal Perceptions}

Maternal knowledge of infant development and perception of infant vocalizations. A summary of maternal perceptions at the three age levels is presented in Table 3.33. In accord with findings in previous studies (Epstein, 1980; Field, et al., 1980; DeLissovoy, 1973), young mothers in the present study showed a poor knowledge of child development. Regardless of the age of their own baby, mothers overestimated the age at which most babies begin to exhibit certain behaviours in about $35 \%$ of their responses to questions on the High Scope Knowledge Scale, and underestimated the age in about $21 \%$ of their responses. In general, mothers tended to have too early expectations of a baby's behaviour in such areas as sleeping through the night, walking, and toilet training. More than half $(55 \%)$ of the mothers of 13 -month-olds overestimated the age at which they expected their own babies to begin using real words according to their responses on the Parental Perceptions of Infant Vocalizations questionnaire.

Since approximately $25 \%$ of mothers of 3-month-olds and 6-month-olds expected their babies to be using real words at or before 9 months of age, the late expectations of mothers of 13-month old babies may be an indication that many babies in this sample had not yet begun to use words and were thus beginning to fall behind in their language development. Such an interpretation would be consistent with the delays in language development reported in previous studies (e.g. Levine, et al., 1985; Osofsky, Osofsky, Kendall, \& Rajar, 1973). Although a 
Table 3.33

Maternal knowledge of infant development and maternal perceptions:

At infant-ages 3 months, 6 months, and 13 months

\begin{tabular}{|c|c|c|c|c|}
\hline & & $\begin{array}{l}3 \text { mo. } \\
N=22\end{array}$ & $\begin{array}{l}6 \text { mo. } \\
N=54\end{array}$ & $\begin{array}{l}13 \text { mo. } \\
N=39\end{array}$ \\
\hline \multicolumn{5}{|c|}{ Knowledge of development (HSKS) } \\
\hline Mean & Proportion correct & .46 & .40 & .39 \\
\hline SD & & .07 & .07 & .13 \\
\hline \multicolumn{5}{|c|}{ Maternal Perceptions } \\
\hline \multicolumn{5}{|c|}{ Infant temperament (ITQR) } \\
\hline Mean & "difficult" & 15.44 & 14.33 & 15.96 \\
\hline SD & & 1.59 & 2.20 & 1.81 \\
\hline Mean & "first factor" & 4.35 & 4.31 & 3.72 \\
\hline SD & (composite) & .42 & .50 & .33 \\
\hline \multicolumn{5}{|c|}{ Infant vocalizations (PPIV) } \\
\hline Mean & "Meaningfulness" & 10.18 & 15.13 & 19.53 \\
\hline SD & & 8.39 & 8.03 & 6.59 \\
\hline Mean & "Motherese" & 4.09 & 2.48 & .66 \\
\hline SD & & 4.50 & 4.50 & 5.27 \\
\hline \multicolumn{5}{|l|}{ Stress (PSI) } \\
\hline Mean & Total & 236.00 & 243.21 & 235.81 \\
\hline SD & & 31.25 & 31.68 & 32.05 \\
\hline Mean & Child Domain & 101.68 & 105.17 & 104.30 \\
\hline SD & & 10.39 & 14.37 & 14.77 \\
\hline Mean & Parent Doinain & 134.32 & 138.04 & 131.51 \\
\hline SD & & 24.27 & 22.04 & 21.16 \\
\hline
\end{tabular}

Social Support

Mean

HSKS = High Scope Knowledge Scale

ITQR = Infant Temperament Scale Revised

PPIV = Parental Perception of Infant Vocalizations

PSI = Parenting Stress Index 
majority of mothers believed their infants' vocalizations to be meaningful and/or related to meaningful language, most did not use "motherese" nor did they endorse the need for altering the quality of linguistic input to babies, suggesting a lack of awareness of the importance of the baby's language-learning environment to his or her developing language.

Maternal perceptions of stress and social support. The levels of perceived stress reported by these young mothers were high at all iniant-ages, a finding consistent with other reports of relatively high levels of stress in young, economically-disadvantaged families (e.g. Loyd \& Abidin, 1985). The number of mothers with clinically elevated scores varied with the age of the baby, as did the source of the stress. However, the highest level of stress at all three infant-age levels was reported for the subscale that focuses on the lack of emotional and active support from the baby's father in caring for the child. The percentage of mothers with clinically elevated scores on this scale ranged from $36 \%$ at infant-age 3 months to $48 \%$ at 13 months.

Total scores on the Parenting Stress Index (PSI) were above the clinical cutoff (mean $>260$ ) for $18 \%$ of the mothers of 3 -month-old babies and stress appeared to be related to the parent domain rather than to the child domain. Only one mother had clinically elevated scores in the child domain (mean $>122$ ) whereas $18 \%$ had clinically elevated scores in the parent domain (mean >153). Within the child domain, approximately $20 \%$ of the mothers had elevated scores in the areas of child adaptability and child reinforces parent. Within the parent domain, more than $20 \%$ of the mothers reported difficulties in parental attachment, sense of isolation, and personal health.

Thirty-two percent of the mothers of 6-month-olds had total PSI scores above the clinical cutoff. As at 3 months, stress related to the parenting domain was greater than stress related to the child domain. However, the percentage of mothers reporting excessively stressful characteristics of the child tripled while the percentage of mothers reporting clinically elevated scores in the parenting system doubled. Compared to 3-month-olds, 6-month-old babies were seen as more 
demanding, fussy, and overactive. Their mothers were more depressed and experienced more social isolation and a deterioration in health.

Nineteen percent of the mothers of 13-month-olds had total PSI scores above the clinical cutoff. This decrease was due to the lower numbers of mothers reporting stress associated with the parenting domain. Only $11 \%$ of the mothers reported clinically elevated levels of stress in the parenting domain compared to $32 \%$ of mothers with 6-month-olds and $18 \%$ of mothers with 3-month-olds. Mothers of toddlers reported fewer problems with feelings of competence, isolation, and personal health compared to mothers of 6-month-olds. Although, the percentage of mothers (16\%) reporting excessively stressful characteristics of the cliild was similar to that reported at 6 months, stress related to the child domain was now greater than stress related to the parenting domain. Figure 3.2 presents a visual summary of the percentages of mothers reporting clinically elevated levels of stress at the three age-levels, temperamentally "difficult" children, and the different sources of support.

At the two younger ages, parenting stress did not appear to be related to levels of support reported by mothers verbally. Mothers reported receiving moderate amounts of help in looking after their babies every day and in having time to themselves. The mean level of support, as assessed by two 5-point Likert scales ranging from 'no help' to 'lots of help,' was above 3.0 at all three infant-age levels. The source of support changed with the age of the baby, with fathers less involved at the two older age-levels. Sixty-two percent of the mothers of 3-montholds reported receiving daily help from the baby's father, $19 \%$ received help from their own parents, and $19 \%$ received help from close friends. Forty-eight percent of the mothers of 6-month-olds received help from their baby's father, $6 \%$ received help from a current partner, 36\% received help from their own parents, and $10 \%$ received help from close friends. Forty seven percent of mothers of 13 month-olds received help from their baby's father, $17 \%$ from a current partner, $31 \%$ from their own parents, and 5\% from close friends.

Although mothers reported receiving moderate amounts of support, many 


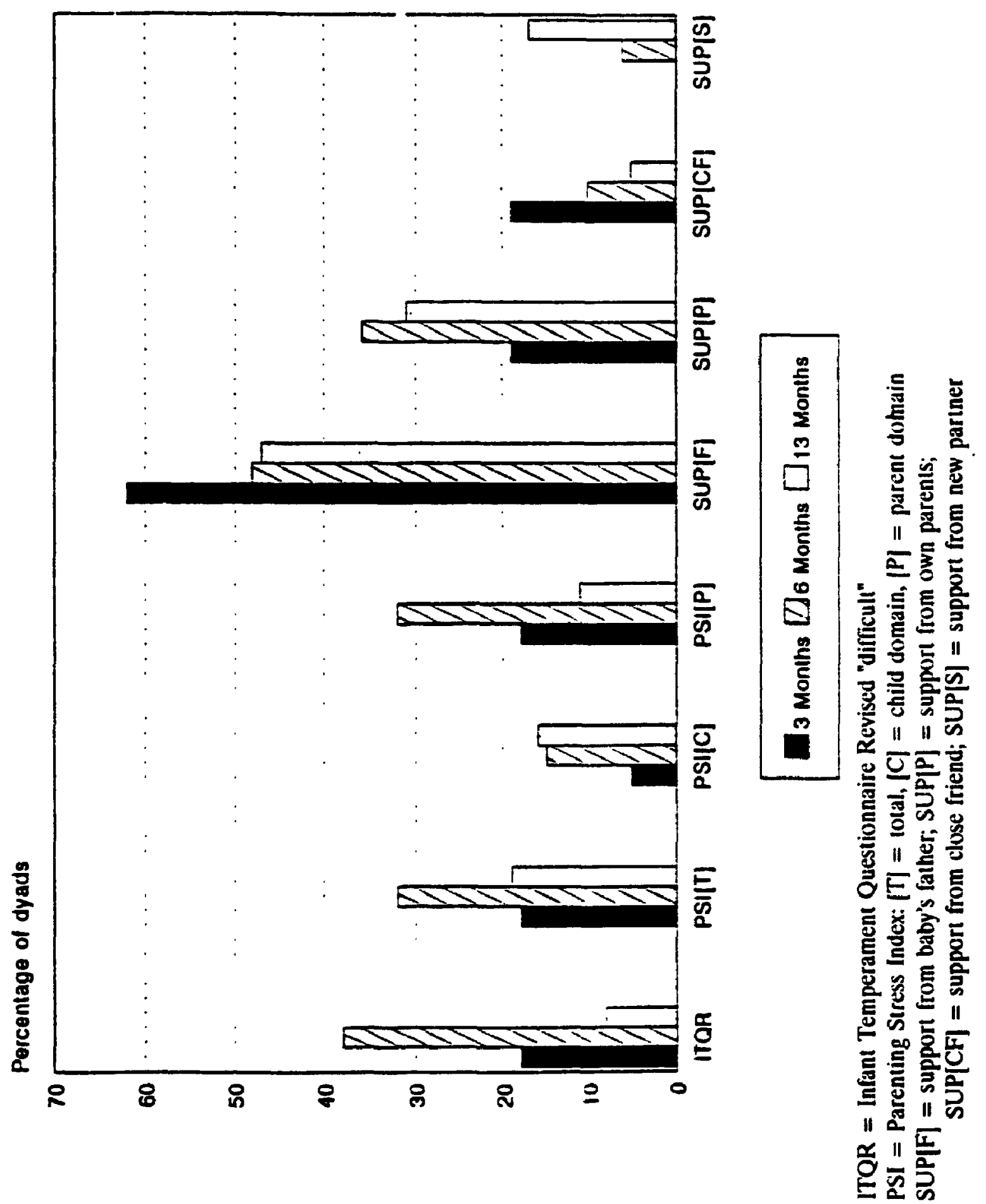

Figure 3.2 Percentages of mothers reporting "difficult" temperament, clinically elevated levels of stress, and sources of support. 
were experiencing high levels of stress ascribed to a lack of spousal support, as is evident from the PSI responses. The stress may indicate that relationships between mothers and the fathers of their babies were not positive in general. The reported decline in paternal involvement and the increase in new partners fit in with this observation.

\section{Discussion}

Findings of the present study are consistent with a growing body of literature on adolescent parenting demonstrating that too-early parenthood is associated with less than optimal mother-child interactions (e.g. Garcia Coll, et al., 1986, 1987; Culp, et al., 1991; Osofsky, 1990) and with the development of insecure attachment relationships (e.g. Frodi, Grolnick, Bridges, \& Berko, 1990; Lamb, Hopps, \& Elster, 19\&7; Levine, Tuber, Slade, \& Ward, 1991). This study extends the research to interactions with infants at three developmental stages in the first year of life and demonstrates that an infant's mastery of age- and stageappropriate tasks: the ability to achieve homeostasis at $\mathbf{3}$ months, to manage cognitively produced arousal at 6 months, and to form a secure attachment relationship at 13 months, is associated with the quality of mother-infant social interactions. The results indicate that dysfunctional patterns of interaction that culminate in insecure attachment relationships may occur increasingly more often after the first three months of age. The findings give support for a transactional model of the etiology of impaired mother-infant interactions and suggest that some critical balance of maternal, infant, and environmental characteristics determines parenting interactions.

The Maternal Behaviour Q-Sort (MBQS) appeared to capture meaningful variation in maternal sensitivity across the three times of measurement. Scores on the MBOS were consistently and highly correlated with scores on the Ainsworth Global Rating Scales and with infant attachment security scores derived from the Attachment Behaviour Q-Sort. They were also moderately correlated with several other measures of maternal interactive 
behaviour. The substantial relation between maternal sensitivity and attachment security reported in earlier studies using this technique (Moran, Pederson, et al. 1992; Pederson, Moran et al., 1990) was replicated in the current study and provides further validation of the MBOS as a reliable and useful measure of maternal sensitivity. However, contrary to expectations, domain-specific maternal behaviours that reliably distinguish between insecure-avoidant and insecureambivalent behaviours could not be identified. Failure to do so may have been due to the small number of insecure-ambivalent babies in the sample and/or to possible ambiguity in some of the items in the Q-sort. The MBQS has been refined recently and potentially ambiguous items have been rewritten. In addition, the range of items has been increased to include more items specifically cesigned to capture the interactive behaviour of mothers in ambivalent and avoidant relationships.

In the present study, individual dyads maintained their relative ranking in global ratings of maternal sensitivity from 3 to 13 months, a finding consistent with the low but significant continuity in global observations of maternal sensitivity from infancy to preschool reported in earlier studies (e.g. Pianta, Sroufe, \& Egeland, 1989; Belsky, Rovine, \& Taylor, 1984; Pettit \& Bates, 1984). Our results, however, suggest that adolescent mothers become less sensitive to their babies' cues over the first year of life. Subjective impressions that mothers and older babies appeared to have more difficulty achieving mutually rewarding social exchanges than mothers and younger babies were corroborated by the decline seen in the sensitivity ratings of mothers in the cross-sectional and longitudinal samples, as babies got older, and by the large number of insecure infant-mother attachment relationships. The finding of a significant decrease in maternal sensitivity over time is inconsiste - with that of Belsky et al. (1984) who reported no significant differences in nıan levels of reciprocal interaction across three times of measurement $(1,3$, and 9 months) in a sample of mothers who were predominantly middle-class and older. This discrepancy may be due to differences in the nature of the samples and/or the measures used, and illustrates some of the 
difficulies that arise when trying to compare the results of studies examining the nature, development, and impact of mother-infant interactions. Not only were their demographic differences in the two studies but the measures also might not be directly comparable. According to Belsky and his colleagues, their measure of reciprocal interaction captured the "nature and extent of contingent, stimulating, and synchronous social exchange" (p. 710) whereas, in the current study, a more global but behaviourally-precise measure of maternal sensitivity was used. In a study where the measures but not the sample were directly comparable (Pederson \& Moran, 1994), assessments of maternal sensitivity were reasonably stable between 8 -month and 12-month visits, and mean sensitivity ratings of the mothers in insecurely attached dyads but not in securely attached dyads, declined significantly over the $\mathbf{4}$ month period. Our findings are consistent with these results since a majority of dyads in the current study were insecurely attached.

Mothers in the study appeared to have inaccurate ideas about the rate of child development, a finding consistent with that reported in other studies (Epstein, 1980; DeLissovoy, 1973), but unlike the earlier studies, maternal knowledge appeared to have little or no effect on maternal behaviour. In general, mothers underestimated the rate of cognitive development and overestimated the rate of physical development. Similar findings by Epstein led him to conclude that young mothers may assume that infants have only physical needs and limited mental capacities. The fact that many mothers in the current study expressed great surprise at the cognitive competence of their babies during the Mastery Motivation and Bayley tasks suggests that this conclusion may be an accurate reflection of the attitudes of this sample as well.

Our results support other findings that show that too-early parenthood poses a serious challenge to parental responsiveness, and suggests that inadequate parenting skills and environmental changes occurring over the first year may be factors in the decline in maternal sensitivity. It may be that while marginally adequate mothers have the ability to cope with the needs of a 3-month-old child, they lack the knowledge and/or resources to cope with the needs of a more 
cognitively sophisticated child. As babies got older, the mother's age and her perceptions of stress began to influence her interactive behaviour negatively. Further, the following observations suggest that the interest and support generated by the appearance of a new baby may dissipate after the first few months: fewer fathers were involved on an everyday basis at 6 months and 13 months than at 3 months; also, fewer close friends were at hand, and moreover, mothers were entering into new relationships. Such changes, no doubt, made it more difficult for mothers to meet both their own developmentally appropriate needs and their babies' needs.

The results showed that mothers who received higher ratings in maternal sensitivity also exhibited more optimal behaviours in many aspects of their interactions with their babies. They provided more socially and emotionally stimulating environments for their babies and their interactions during play were less intrusive, they were more emotionally available and the quality of their communications to their babies was higher, and they displayed less negative affect, and more positive affect, than less sensitive mothers. Their babies were also more likely to have mastered the stage-appropriate developmental tasks for the first year of life, thus laying the foundation for subsequent competence/adaptation. No causal direction is implied, and indeed, results from the longitudinal sample suggest that relationships between maternal and infant behaviours are transactional. Although maternal behaviour may play a greater role in directing the course of mother-infant interactions when infants are very young, the links between maternal sensitivity, environmental factors, and infant characteristics become clearer as infants get older.

When babies were 3 months old, many young mothers seemed to view child rearing rather simplistically. They provided adequate physical care and enjoyed showing off their well-dressed and well-groomed babies to the home observers. They were enthusiastic about being mothers and were openly affectionate with their babies. More than $60 \%$ of the mothers were receiving daily help with their babies from the father, and nearly $20 \%$ were receiving daily help from close 
friends. However, subtle warnings of future problems were evident even at this early stage: mothers appeared to treat their babies like dolls that fulfilled some inner need rather than as separate little beings with their own needs. Maternal behaviours that play a major role in the formation of healthy, responsive relationships between mothers and infants, such as long periods of close physical contact (Anisfeld, Casper, Nozyee, Cunningham, 1990) and contingent responses to baby's cues (Ainsworth, et al., 1978) were rather sparse. The mother's attention to her baby during social interactions was often according to her own schedule rather than in response to her baby's signals. Mothers often responded quickly to signals of distress but missed many opportunities for social interaction with their babies. Many mothers diapered their babies in silence, and many did not hold their babies during feeding, preferring instead to place them in infant seats with propped bottles.

When babies were 6-months-old, indications that mothers and infants were experiencing greater difficulty in achieving a harmonious relationship were becoming more apparent. Mothers seemed less at ease with their mothering role than mothers of younger babies and stress was negatively related to both sensitivity and to task resolution. Nearly one-third of the mothers reported clinically elevated levels of stress and nearly $40 \%$ saw their children as temperamentally difficult suggesting that mothers of 6-month-old babies more so than mothers of 3-month-old babies had difficulty reading their babies' signals accurately. Alternately, mothers may have been interpreting their babies' behaviour in negative ways since researchers rated the babies as moderately happy, sociable, and task oriented during testing. Impaired mother-infant interactions that lead to insecure-avoidant re, tionships may have their beginnings in these maternal perceptions, as higher levels of stress were associated wit?, higher levels of maternal intrusive behaviour during play at 6 months. Since maternal intrusiveness at 6 months was marginally predictive of anxious-avoidant relationships at 13 months, the high percentage of mothers, whose interactions during play with their babies, were more intrusive and unresponsive, than 
sensitively responsive, may explain in part, the preponderance of insecure-avoidant attachment relationships in this sample.

The negative effects of high levels of stress appeared to be compounded in these dyads. Higher levels of stress were associated with lower levels of maternal sensitivity and both were associated with lower homeostasis scores and lower scores in exploratory behaviour. Thus, high levels of stress may have led to a scenario where sensitivity, homeostasis, and exploration were low, and much of the dyad's time was still devoted to resolving homeostatic difficulties, leaving little time for the infant to engage in exploration and mutually enjoyable interactions. In.ervening at this point would appear to be necessary from a developmental psychopathology perspective since great sensitivity is needed on the mother's part if disengagement is to be prevented.

The need to intervene at this point can also be seen in the growing lack in parenting skills as babies became more cognitively sophisticated. Although maternal age was not related to the mother's sensitivity, younger mothers appeared less able to effectively parent babies whose developmental tasks were the management of cognitively produced arousal and the differentiation of affect. Based on the results of previous studies (e.g. Dunham, et al. 1989), experience with contingencies can be expected to facilitate the baby's successful mastery of these stage-appropriate issues but younger mothers were less attentive to their infant's touching or vocalization cues during play, than older mothers. In turn, their babies received lower scores in exploratory behaviour than babies of older mothers. Behavioural interventions that help these mothers to perceive their babies' cues accurately and to respond contingently and appropriately to their babies' changing needs would enhance maternal sensitivity and facilitate the formation of a secure attachment relationship.

Mothers and their 13-month-old babies appeared to be having less fun than mothers and younger babies. Age did not appear to be related to global measur. ; of sensitivity nor to task resolution, but younger mothers were less responsive during play and they provided less stimulating home environments. In general, 
mothers of toddlers displayed less positive affect during play than mothers of 6month-old babies. Many had difficulty accepting their toddler's behaviour, and their own behaviour could best be described as disengaged or uninvolved. Environmental changes in the lives of these young mothers could also have contributed to less harmonious relationships between mother and child. Many mothers were involved in new relationships and $15 \%$ were pregnant again. Paradoxically, mothers who reported lower levels of stress in the parenting domain were less responsive during play with their toddlers and their mode of communication was qualitatively lower than mothers reporting higher levels of stress. Although this finding seems surprising, it may be a consequence of the new relationships in the lives of many of the young mothers. These mothers may perceive their new partners as supportive and thus report less parenting stress but because of their immaturity, mothers may be unable to meet both their own needs and those of their toddlers. Although fewer mothers reported clinically elevated levels of stress, mothers of toddlers were significantly less sensitive than mothers of 6-month-olds.

As predicted, many of the children were judged to be insecurely attached on the basis of their behaviour in the Strange Situation. Only 37\% of the children were classified as securely attached -- a marked contrast to the percentage of children born to older, middle class mothers who receive this classification. Although reports vary from study to study, percentages in the mid to high sixties are common in the latter (e.g. 66\% reported by Bates, et al., 1985). Consistent with findings reported in the literature, most were classified as insecure-avoidant (e.g. Frodi, Grolnick, Bridges, \& Berko, 1990; Levine, et al., 1991). Also consistent with findings was the association between maternal intrusivenss and insecure-avoidant attachment. For example, Isabella, \& Belsky (1991) reported that the 3- and 9- month intera:tions of avoidant dyads in their study were characterized by maternal intrusiveness and overstimulation.

As with older, middle-class mothers, young mothers of securely attached children were more sensitive than young mothers of insecurely attached children, 
and the children had higher security of attachment scores. Findings with respect to temperament were equivocal. Consistent with other reported findings (Bates, et al., 1985; Belsky et al., 1984; Egeland \& Farber, 1984, Sroufe \& Egeland, 1981), securely and insecurely attached children did not differ on maternal ratings of difficult temperament but insecure children were objectively rated as marginally less good humoured, cooperative, and social toward the examiner during testing, than securely attached children. However, uur findings that toddlers in insecureambivalent relationships were fussier/more difficult than toddlers in secure or anxious-avoidant relationships, when interacting with their mothers in the home, suggest that these temperament-like characteristics may play a role in how a child behaves in the Strange Situation but not in the nature of the attachment relationship, offering tentative support for other recent findings of a complex, interactive link between temperament and attachment (Belsky \& Isabella, 1988; Crockenberg, 1981). However, more studies are needed, using other objective measures of infant temperament before any firm conclusions can be drawn.

Although results from the cross-sectional data indicated that mothers who were more sensitively responsive to their infants' needs and signals had babies who were more likely to have mastered the first three stage-appropriate developmental tasks, two interpretations are clearly possible: (1) sensitive mothers facilitate mastery of the developmental tasks; (2) babies who more easily master developmental tasks engender more sensitive mothering. For example, it is possible that very young infants who have little difficulty achieving homeostatic regulation may be easier to read and to respond to appropriately, than babies who have great difficulty achieving homeostasis. It is equally possible that mothers who provide a predictable and optimally stimulating environment in which the infant can balance inner state and external stimuli facilitate the development of homeostasis, or they may hinder it by providing a chaotic, unpredictable environment which is too high or too low in stimulation. The latter may also exacerbate biologically-based homeostatic difficulties such as excessive irritability, passivity, or an inability to be easily calmed (Cicchetti et al., 1989). 
Notwithstanding the direction of influence, the coordination of the mother's inter entions with the infant's physiological processes may have a potential impact upon attachment development since mother-infant interaction serves as the context from which attachment evolves (Ainsworth, 1982; Isabella, 1995).

Results from the longitudinal data helped to clarify the links between mother-infant interaction and the patterns of attachment, but interpretations must be made cautiously since the longitudinal sample was small. Consistent with findings reported in earlier studies (e.g. Cohn \& Tronick, 1988; Lester, Hoffman, \& Brazelton, 1985; Martin, 1981; Sameroff \& Chandler, 1975; Lewis \& Rosenblum, 1974), results in this study suggest that the behaviour of mothers and their infants is mutually influential. Just as more sensitive maternal behaviours at earlier stages of the child's development were associated with more adaptive infant behaviours at later stages, more adaptive infant behaviours at earlier stages were associated with more sensitive maternal behaviour at later stages in the infant's development. However, it behooves us to remember that mothers shoulder the burden of responsibility in very early interactions and may thus indirectly affect the course of their children's development. From birth to three months, mutually satisfying relationships appeared to develop more easily when the infant was capable of clearly signalling his state needs and of responding to his mother's interventions and when the mother had the ability to perceive her infant's signals and to respond contingently, consistently, and appropriately, and when she provided an optimally stimulating home environm Consistent with the infant's increased social competence in the next developmental level, other aspects of the mother's interactive behaviour were also related to the infant's successful mastery of age-appropriate developmental issues and to attachment development. For example, maternal emotional availability (attentiveness) during play was related to the infant's exploratory behaviour at 6 months, and maternal intrusiveness during play at 6 months was related to insecure-avoidant attachment relationships at 13 months. Also consistent with the infant's increased capacity for more complex and organized behaviour in the next developmental period, mutual 
influences of mother and child behaviour became increasingly more apparent. Different aspects of the mother's interactional behaviour in combination appeared to contribute to the attachment relationship, although maternal sensitivity, as operationalized in behaviourally precise terms, accounted for a significant unique proportion of the variance in attachment security. As well, 13-month-old children exhibited increased goal-directed behaviour toward their mothers: children in secure attachment relationships exhibited more secure base behaviour and affect sharing, children in insecure-avoidant relationships showed less contact-seeking behaviour, and children in insecure-ambivalent relationships wo fussier and more difficult in their interactions with their mothers.

In a recent talk, Isabella (1995) argued for the need to examine the origins of attachment from an organizational perspective and suggested that patterns of change across the infant's developmental levels be measured and analyzed. The current research has attempted to do that. Results indicate that children of ad.slescent mothers may be susceptible to the formation of insecure attachment relationships and other developmental problems, because of their exposure to less than optimal care-giving environments during the first year. Although the quality of the social and emotional stimulation in the home appeared to be adequate at the three age-levels sampled, the language-learning environment appeared to be impoverished and the mother's sensitive responsiveness to her child declined over the year. Results showed that different aspects of the mother's interactive behaviour made important contributions to different domains of development: the mother's sensitivity and appropriate responses to her child's cues made a significant contribution to the child's formation of a secure attachment relationship, the quality of the social and emotional stimulation in the home made a significant contribution to the child's mental development, and the quality of her communications during play made a significant contribution to the child's communicative competence. These findings are consistent with other findings reported in the literature (Pederson, Moran, et al., 1990; Ramey, et al., 1984; Pawlby \& Hall, 1980). However, it is noteworthy that the different aspects of 
maternal interactive behaviours in combination also made important contributions to the cognitive and social-emotional domains of development but not to the language domain. For the child's language development, the quality of the mother's communications to her child appeared to be the most important aspect of maternal interactional behaviour. Maternal sensitivity, the quality of the home environment, and the pattern of maternal responsiveness during play appeared to be less important in the development of communicative competence. This result supports Bruner's (1977) contention that the infant's exposure to maternal contingent vocal responsiveness may serve as the foundation for later communicative competence. These findings offer possible explanations of the mechanisms underlying the insecure attachment relationships and the deficits in the language development of young children of adolescent mothers, often reported in the literature (e.g. Culp, et al., 1991; Levine et al., 1991; Frodi, et al., 1990).

Replication studies which include a comparison group of economically disadvantaged older mothers are needed in order to assess the actual risk for suboptimal development in children of ad-'escent parents. Some adolescent mothers were meeting their children's changing needs with great sensitivity and responsivity and their children were mastering their developmental tasks easily and appropriately, suggesting that low maternal age may not be the most important factor in maladaptive parenting. Further studies that examine relations between the quality of maternal interactive behaviour and the infant's mastery of developmental tasks will further our understanding of the patterns of maternal behaviour that are associated with the infant's successful adaptation at each developmental level and across the first year. Programs can then be planned that would benefit mothers, teenage or otherwise, who are in need of additional support in develoring the kinds of parent-infant interaction that risult in optimal infant development. 


\section{CHAPTER IV}

\section{Study 2: The benefits of early intervention}

The increasing number of adolescent pregnancies is a concern for the community at large in Canada and the United States (Osofsky, Culp, \& Ware, 1988) since both adolescent mothers and their infants have been shown to be "atrisk" for psychosocial problems (cf. Gotlib \& Avison, 1993, for reviews). Too-early parenthood not only compromises the educational and economic future of the teen parent (Furstenberg, Brooks-Gunn, \& Chase-Lansdale, 1989; Lamb, 1988), it also increases the probability of developmental difficulties (Brooks-Gunn \& Furstenberg, 1986; Crockenberg, 1985) and behaviour problems for the developing child (Furstenberg, et al., 1989; Garcia Coll, Vohr, Hoffman, \& Oh, 1986). Since primary prevention efforts aimed at preventing teen pregnancy (e.g. London Teen Pregnancy Panel Project) have had only limited success (Wolfe, 1987), the need for an alternative approach to counterbalance the risks of adolescent parenting has become urgent. The approach proposed and evaluated in the current study involves bolstering both the mother's and child's resilience to the myriad effects of disadvantage by facilitating secure infant-mother attachment relationships through fostering mutually enjoyable social interactions. The need to implement intervention strategies in early infancy if future maladaptation is to be prevented, is stressed.

Intervention programs for high risk infant-mother dyads. A survey of the intervention literature shows that training parents to be more sensitive and responsive to their infant's signals and needs is a relatively recent endeavour. The 
quality of parent-infant interactions has been of diagnostic value in infant psychiatry for more than a decade (Wesner, Dowling, \& Johnson, 1982), and innovative techniques have been developed to teach mothers how to interact with their infants in a positive and mutually enjoyable manner. Mahrer, Levinson, and Fine (1976) describe a technique they call "Watch, Wait, and Wonder" for promoting infant-centred activities with mothers. The baby is placed on the floor of the therapy room containing toys and allowed to explore. Mothers are instructed to get down on the floor with the baby and watch what he or she does. Mothers are asked not to initiate activity or interfere with the baby's exploration, and are instructed only to "watch, wait, and wonder." Persistent initiation by the mother or a lapse into a traditional caretaking mode ends the session. Interactions are videotaped and mothers are asked to critically evaluate what has taken place. A major benefit of the program, as seen by staff members, is that the mother's relationship with her baby becomes a happier one, and she becomes more aware of her own style and significance to the infant (Wesner, Dowling, \& Johnson, 1982).

On the basis of their clinical work with developmentally-delayed infants, Clark \& Seifer (1983), argue that sensitivity may be the single most important parental characteristic for mutually-beneficial interactions, and indeed, this notion forms the core of most early infant stimulation programs. For example, a program developed for high-risk and developmentally delayed infants at the Institute for the Study of Developmental Disabilities (Clark \& Seifer, 1983) is based on a hierarchy of parent interactional behaviours ranging from least to most sensitive behaviour. Nine levels are defined (uninvolved, forcing, overriding, involved, acknowledging, imitating, expanding, elaborating, extended engaging), and mothers who are interacting with their infants in less than optimal ways are given individual treatment sessions. During these sessions the mother is helped to increase her level of sensitivity to her infant during social interactions. Videotape feedback of 1-minute play interactions and direct coaching from the sidelines are used to produce the changes desired. The program was found to be clinically 
effective in improving patterns of interaction in this target population with concomitant improvement in the child's development.

In recent years, a small number of intervention programs have attempted to optimize the quality of mother-infant interactions in socially-disadvantaged families at high-risk for dysfunctional parenting. These programs have reported varying degrees of success. In general, programs that helped young parents experience positive interactions with their babies promoted feelings of self-worth and effectiveness, which in turn, enhanced parental sensitivity and made parents more receptive to basic child-rearing information (e.g. Olds \& Henderson, 1989; Crittenden \& Snell, 1983).

Some programs were intensive and long-term, others were behaviour focused and short-term, but they had two features in common. First, maternal behaviour was the initial focus for evaluation and intervention. Second, by changing the mother's behaviour, the child's behaviour changed, which in turn produced further changes in the mother's subsequent behaviour. As well, videotape technology often played an important role in treatment. In some studies, immediate feedback was available to the mother regarding her own behaviour and its effect on her infant's behaviour, and with repeated viewing of the videotape, the mother became better able to focus on subtle interactive behaviours.

In one well-designed study, a comprehensive home-based intervention program was implemented in a sample of high-risk families (Olds and Henderson, 1989). First-time parents who were teenaged, single, or poor were randomly assigned to one of four treatment conditions which varied in intensity and duration. In the most comprehensive treatment condition, trained nurses visited mothers approximately once every two weeks during the last trimester of pregnancy, and then on a varied schedule until the infant was two years of age. They prepared mothers for labour, delivery, and early care of the newborn, and they taught parents the importance of a healthy pregnancy and responsive caregiving for optimal physical, cognitive, and socio-emotional development in 
children. Rather than focusing specifically on maternal sensitivity and the attachment relationship, nurses tried to improve the mother's understanding of her baby's need for responsive caretaking. As well, they sought to enhance the mother's informal support by encouraging husbands, boyfriends, and other family members to participate in the home visits and by assisting parents who wanted to go back to school, find work, use effective birth control, or find appropriate community services. This integrative approach was successful in improving many aspects of maternal, child, and family functioning, although it did not prevent maltreatment completely.

The Menninger Infant Project (Osofsky, Culp, \& Ware, 1988) was a longitudinal preventive intervention program designed to decrease the incidence of problems in teen-age mothers and their infants. One-hundred and thirty pregnant young women, mean age 16 years, were randomly assigned to one of two intervention groups. All young mothers participated in a health department program, consisting of prenatal care, social service, and nutritional guidance for the first 18 months of the infant's life. In addition, one of the two groups of young mothers received home visits from trained nonprofessionals once a week during the first month and monthly visits thereafter until infants were 30 months of age. During these visits mothers were shown some activities that would be stimulating for the babies and fun for both mother and baby. Crisis intervention, 24-hour emergency help, and a weekly drop-in centre were also available to mothers and babies in this group. Analyses of data collected in a laboratory setting at 6, 13, and 20 months showed few significant differences in maternal and infant outcome measures between the two groups. Closer examination of the home visitor reports revealed that less than half of the mothers were actually participating fully in the home visitation intervention. Some significant differences in infant developmental outcome (e.g. mental development) and maternal behaviours (e.g. maternal play) were found at 13 months between those mothers who were participating fully and those who were not. No differences were found in attachment security. 
Short-term. goal-specific intervention programs have also reported positive changes in maternal interactional style with concomitant increases in infant development and/or infant-mother attachment. Crittenden \& Snell (1983), in sixteen weekly group sessions, taught severely disadva itaged mothers to use the "facing position" when socially interacting with their infants. Mothers were instructed to take their infants to a small blanket spread on the floor and to play with them. Toys and an infant seat were available nearby, but no further instructions were given about how the dyads were to behave. Intervention consisted of replaying one-minute videotapes of the mother playing with her baby for the entire group to observe and discuss. Emphasis was focused on the mother's position relative to her baby and its effect on her own and her baby's behaviour. Modelling, role playing, and discussions of the videotaped interactions were used to help mothers learn to change their position when playing with their babies. Improvement in the mother's position relative to $r_{i}$ baby was related to increases in both maternal interactional behaviour and infant develc ment.

In another study, Anisfeld, Nozyce, and Cunningham (1990) manipulated the amount of physical contact experienced by newborns in two groups of low SES mother-infant dyads by giving mothers in the experimental group soft baby carriers and mothers in the control group plastic infant seats. Mothers in the experimental group carried their infants significantly more in the first 8 months of life resulting in more physical contact for infants in that group. Mothers in the experimental group received higher ratings in maternal sensitivity when infants were 3 months old but mean differences were not significant. At 13 months, significantly more infants in the experimental group were securely attached when assessed in the Strange Situation procedure.

A highly effective and short-term intervention program was reported by Van den Boom (1994). One-hundred low-income Dutch mothers and their highly irritable babies were randomly assigned to intervention and control groups when infants were 6 months old. Intervention was directed at promoting secure attachment by improving the mother's sensitivity to her baby's cues and signals. 
The intervention was implemented in the home during naturally occurring motherchild interactions and 3 intervention sessions were scheduled while infants were be ween 6 and 9 months of age. The author was the sole intervenor and visits lasted about 2 hours. When infants were 9 months of age, intervention group mothers were found to be significantly more sensitively responsive than control group mothers. At 12 months of age, significantly more intervention group dyads were securely attached than control group dyads.

In a recent review of the effects of attachment-based interventions, Van Ijzendoorn, Juffer, \& Duyvesteyn (in press), compared the results of 12 studies (almost 900 mother-infant dyads) in which the focus of the intervention was either preventive or therapeutic. In the former, intervention efforts were usually directed at enhancing parental sensitivity (i.e. a behavioural approach). In the latter, interventions focused on parents remembering and re-experiencing their childhood anxieties in order to be sensitive to their infants' attachment signals (i.e. a representational approach). The authors reported a combined effect size for sensitivity of $\underline{d}=.58$ and for attachment security of $\underline{d}=.17$. Both intervention effects were statistically significant at the $\mathrm{p}<.05$ level. Short-term behavioural interventions were found to be more effective $(\underline{\mathrm{d}}=.48)$ than long-term, more intensive therapeutic interventions $(\underline{\mathrm{d}}=.00)$. However, the authors caution that long-term follow-up studies are needed to see if the effects of behavioural interventions generalize to mother-child interactions at later developmental stages.

Intervention in the current study. Inte: vention in the current study was theory-based with roots firmly planted in attachment theory and developmental psychopathology. According to proponents of developmental psychopathology, the nature and etiology of the maladaptation must be understood in order to plan effective intervention strategies that are appropriately timed, since similar difficulties with task resolution may be present in children with various problems (Cicchetti et al., 1989). For example, both the children of adolescent mothers and of depressed mothers may experience difficulties forming secure attachment 
relationships but the pathways whereby these difficulties develop may differ and thus different intervention strategies and/or timing may be needed.

Adolescent mothers are generally less responsive to their infants than older mothers and more intrusive when they do respond. They provide less verbal stimulation (Garcia Coll, et al., 1986, 1987; Culp, et al., 1991), attempt to promote independence prematurely (Osofsky, 1990), and use more physical interventions. Their own stage of development (e.g. poorly defined personal identities; selfcentredness; the inability to anticipate the needs of others) may also increase the risk of maltreating their children. In turn, their children exhibit an increased frequency of insecure-avoidant attachment relationships (Frodi, Grolnick, Bridges, \& Berko, 1990; Levine, et al., 1991). Adolescent mothers are more likely to have experienced maladaptive parenting during their own childhoods, including sexual and physical abuse, (Osofsky, et al., 1988) and may therefore lack appropriate parenting role-models. There is also an increased probability that they themselves experienced insecure attachment relationships.

Thus, adolescent mothers may require help in learning to enjoy their infants and to experience positive interactions. Based on our knowledge of infantmother attachment and considering the age-related needs of both members of the dyad, mother-infant play interactions were judged to be the appropriate vehicle for implementing intervention strategies aimed at enhancing maternal sensitivity. Several subgoals were identified: (1) to reinforce the strengths already present in the mother's behaviour; (2) to increase the mother's awareness of how her behaviour influences her baby's behaviour; (3) to increase the mother's awareness of her baby's cues; (4) to establish positive experiences for both the mother and the baby. The ultimate goal was to increase the mother's sensitivity to her baby so that she read his/her cues accurately and responded in a contingent and appropriate manner, thus facilitating the establishment of a secure infant-mother attachment relationship.

Intervention in the current study was based on the premise that improving early mother-infant interactions through enhancing the mother's sensitivity to the 
signals and needs of her child would produce positive contingency experiences for both the mother and the infant. These, in turn, would produce feelings of efficacy in both interactants and lead to a mutually satisfying relationship. Mothers would enjoy their infants and thus engage in more numerous and effective social interactions; infants would form secure infant-mother attachment relationships. Such an intervention might decrease the likelihond of child abuse and neglect even where parents with a history of insecure attachment were more vulnerable to environmental and child-induced stresses.

Although the area of infant-mother attachment was chosen for initial intervention, the timing (at 6 months) was selected to correspond to a point of reorganization in the developmental process when the infant would be especially amenable to change. In keeping with the transactional model implicit in developmental psychopathology, the importance of transactions among all areas of development was stressed and the planned intervention (enhancing maternal sensitivity through social play) contained components that tapped each developmental domain, another important aspect in effective intervention strategies (Cicchetti, et al., 1989).

Based on our understanding of the infant-mother attachment relationship, it was predicted that mothers in the intervertion group would be more sensitively responsive to their infants' cues at the end of the intervention period than mothers in the comparison group and that more infants in the intervention group would be in secure attachment relationships than in the comparison group.

\section{Method}

\section{Subjects}

Forty-five mother-infant dyads participated in Study 2. Twenty-two dyads were in the intervention group and twenty-three dyads were in the matched comparison group. One dyad assigned to the intervention group moved before the first intervention visit could be made. Repeated attempts to locate the mother were unsuccessful. She eventually contacted us shortly before her baby's first 
birthday. She had left town for personal reasons but consented to complete the two 13-month assessment visits and the laboratory Strange Situation. Data from this dyad were included in Study 1 only.

Group placement was random with the exception of mothers who were friends or in the same class at school. When this occurred the two (or more) mothers were placed in the same group in order to avoid potential horizontal diffusion of the treatment. In the intervention group, the mean age of mothers when their baby was born was 17.77 years, $\underline{S D}=1.88$; in the comparison group, the mean age was 18.39 years, $\underline{\mathrm{SD}}=\mathbf{2 . 2 1}$. Mean age of the babies at entry into the study was 187.57 days, $\underline{\mathrm{SD}}=6.8$ in the comparison group and 188.00 days, $\underline{\mathrm{SD}}$ $=8.6$ days in the intervention group. The two groups did not differ on the following demographic variables: marital status, years of education, income, history of abuse, sex of infant, and number of first born infants. Table 4.1 displays relevant demographic information - the numbers in parentheses indicate the changes that occurred over the 7-month period.

\section{Procedure}

The procedure for the two assessment visits carried out in the home at 6 months of age, for both the intervention and comparison groups was identical to that for the 6-month visits described in Study 1. Following the second visit, biweekly intervention sessions were instituted for dyads in the intervention group. Comparison group dyads received one visit from the author when babies were 9months old so that mothers would have a video-record of their babies at that age. As well, Christmas cards were sent to all mothers and birthday cards to all babies.

Following the second assessment visit, bi-weekly visits were made by the author to all dyads in the intervention group. The word "intervention" was not used in any description of these visits. Mothers were told, that in this part of the study, we were interested in not only seeing how mothers and babies played together but also in trying new ways of playing that would be fun for both mothers and babies. Mothers were told that we were hoping to eventually plan programs 
Table 4.1

Demographic Variables: Intervention vs. comparison groups

\begin{tabular}{|c|c|c|}
\hline & $\begin{array}{l}\text { Intervention } \\
\text { Group } \\
\mathrm{N}=\mathbf{2 2}\end{array}$ & $\begin{array}{l}\text { Comparison } \\
\text { Group } \\
N=23\end{array}$ \\
\hline Mean maternal age (years) & $\begin{array}{r}17.77 \\
\underline{\mathrm{SD}}=1.88\end{array}$ & $\begin{array}{r}18.39 \\
S \mathrm{SD}=2.21\end{array}$ \\
\hline Mean maternal education (years) & $\begin{array}{r}11.36 \\
\underline{\mathrm{SD}}=.73\end{array}$ & $\begin{array}{r}11.35 \\
\mathrm{SD}=.84\end{array}$ \\
\hline Mean annual income (dollars) & $<\$ 15,000$ & $<\$ 16,000$ \\
\hline Abused in childhood & 9 & 8 \\
\hline Single* & $11[13]$ & $13[14]$ \\
\hline Co-habiting* & $11[9]$ & $10[9]$ \\
\hline Attending school* & $11[12]$ & $12[10]$ \\
\hline Living at home* & $7[2]$ & $7 \quad[3]$ \\
\hline Male children & 12 & 14 \\
\hline Female children & 10 & 9 \\
\hline First-born & 15 & 17 \\
\hline
\end{tabular}

Except as indicated, the numbers represent number of subjects

* number in parentheses indicates number at end of study 
for young mothers which would help them to play with their babies in ways that would be enjoyable for both, and which at the same time would foster the baby's development. Mothers were left with the impression that their input would contribute in an important way to our understanding of how to help other young mothers and infants play together.

The C'ark and Seifer (1983) program described earlier was instrumental in shaping many of the ideas that were used in developing specific strategies to enhance the sensitivity of the young mothers in the current study. Descriptions of the 9 levels of the hierarchy described in their study and a manual containing sensitivity-enhancing strategies based on their program appear in Appendix E.

Since previous studies have shown that the therapist-mother relationship may play an important role in whether mothers accept and participate fully in home-based interventions (Osofsky, et al., 1988; Beckwith, 1988), part of each visit was spent conversing with the mother and trying to develop a supportive, trusting relationship. When the time seemed appropriate, the mother was asked to play with her bary on the floor. A standard set of age-appropriate toys was provided for the mother's use but no further instructions were given about how the mother and baby were to play. A one-minute videotape was made of the play interaction and played back to the mother to observe and discuss. Emphasis in the discussion was placed on the baby's enjoyment of the interaction and on the mother being the "expert" in interpreting her own baby's responses. The mother was liberally praised for appropriate behaviours, e.g. eye contact, smiles, verbalizations, following the baby's lead, and so on. Mothers were encouraged to express their ideas and opinions, and teaching was indirect and often subtle. When needed, modelling and role playing were used to help mothers learn new ways of interacting with their babies. For example, some mothers were encouraged to imitate their baby's behaviour, to respond to both positive and negative signals, to play infant games, to maintain silence when their baby averted gaze, and so on. To accomplish the four identified goals, maternal strengths were always 
emphasized rather than maternal inadequacies and each "intervention" session was specifically tailored for the particular dyad.

For both groups, when the babies reached 13 months of age, two observers, naive to the experimental condition of the dyads, made 2 home visits to collect data. The dyads were also brought to the University Laboratory for the Strange Situation. The procedures followed were identical to that described in Study 1. Statistical Analyses

The effectiveness of the intervention was tested in two ways. First, MANOVA was used to assess differences between the two groups in security of attachment scores [AQS] and in maternal sensitivity scores [MBQS and AGRS] at the completion of the study. Second, a repeated measures MANOVA was used to test differences in maternal sensitivity scores across time in both groups. Chisquare analyses were used to test differences in the numbers of children being classified as secure or insecure on the basis of their behaviour in the Strange Situation.

\section{Results}

In order to ensure that scores derived from home observations at 6 and 13 months were from independent sources, analyses were conducted with maternal sensitivity scores of Observer A at 6 months and those of Observer B at 13 months, together with attachment security scores of Observer $\mathrm{C}$ at 13 months. Demographic analyses of intervention and comparison groups

The two groups were well matched on important demographic variables at the beginning of the study and multivariate analysis indicated that the two groups were still matched on these variables at the end of the study. (See Table 4.1). However, as in the larger cross-sectional sample, change appeared to be characteristic of the lives of these young mothers. Three mothers in each group dropped out of school, and three mothers in the intervention group and one mother in the comparison group returned to school. Five mothers in the intervention group and four in the comparison group moved out of the parental home to live on their own or with a new partner. Relationships with the fathers 
of their babies or other male partners appeared particularly unstable. Five mothers in the intervention group and three mothers in the comparison group separated from their partners at some time during the seven months of participation. One mother in each group, who had previously lived at home, began to cohabit with a partner. Approximately $35 \%$ of the mothers in both groups reported being abused and/or negle: ted as young children.

Descriptive analyses of maternal behaviours at infant-age 6 months. The two groups did not differ significantly from each other on either maternal or child variables when tested in a multivariate analysis. Means and standard deviations of mother and infant variables for the comparison and intervention groups are presented in Tables 4.2 and 4.3. Preliminary analyses carried out on the combined data were compared with the 6-month cross-sectional sample in Study 1. Results were essentially the same, so only a brief synopsis of findings relevant to the hypotheses being tested are given here. The reader is referred to Study 1 (Pages 61-72) for a detailed account of different analyses carried out at 6 months and the results.

Maternal behaviours. At 6 months, the mothers' mean global sensitivity scores indicated inconsistent behaviour that was more sensitive than insensitive, on average. However, when playing with their babies, approximately $50 \%$ of the mothers were more intrusive and unresponsive in their interactions with the baby than sensitively responsive, as indicated by a negative overall responsiveness score. The overall social and emotional stimulation in the home, as measured by HOME scores, was within normal ranges, falling into the middle half of the percentile range.

Maternal perceptions of stress. Mothers reported high levels of stress. Nearly one-third had total PSI scores above the clinical cutoff, with stress related to the parenting domain greater than stress related to the chi!d domain. High levels of stress were significantly associated with many aspects of maternal behaviour. As stress increased, maternal sensitivity decreased, mothers displayed 
Table 4.2

Means and standard deviations by group (intervention vs. comparison):

Maternal Behaviours at Infant-Age 6 months

\begin{tabular}{|c|c|c|c|c|}
\hline Maternal Variables & \multicolumn{2}{|c|}{$\begin{array}{c}\text { Intervention } \\
\text { Group }\end{array}$} & \multicolumn{2}{|c|}{$\begin{array}{l}\text { Comparison } \\
\text { Group }\end{array}$} \\
\hline $\begin{array}{l}\text { Global Sensitivity } \\
\text { MBQS }\end{array}$ & 0.18 & .42 & .18 & .46 \\
\hline AGRS & 5.45 & 1.18 & 5.32 & 1.29 \\
\hline $\begin{array}{l}\text { Interaction Pattern in play (CA } \\
\text { Intrusive }\end{array}$ & .42 & .17 & .38 & .20 \\
\hline Unresponsive & .12 & .15 & .16 & .21 \\
\hline Pattern of responsiveness & .40 & .75 & .34 & .81 \\
\hline $\begin{array}{l}\text { Emotional Availability (EAS) } \\
\text { Attentiveness }\end{array}$ & 2.68 & .92 & 2.76 & .60 \\
\hline Quality of talking & 3.11 & .75 & 3.09 & .79 \\
\hline Positive affect & 7.10 & 3.37 & 6.74 & 3.56 \\
\hline Negative affect & 1.07 & 1.16 & 1.09 & .93 \\
\hline $\begin{array}{l}\text { Quality of environment (HOM } \\
\text { Total score }\end{array}$ & 32.55 & 5.02 & 34.61 & 4.93 \\
\hline $\begin{array}{l}\text { Knowledge of development (H) } \\
\text { Proportion correct }\end{array}$ & .38 & .07 & .42 & .08 \\
\hline Maternal Perceptions & & & & \\
\hline $\begin{array}{c}\text { Infant vocalizations (PPIV) } \\
\text { Meaningfulness }\end{array}$ & 15.68 & 7.42 & 16.39 & 8.21 \\
\hline $\begin{array}{l}\text { Stress (PSI) } \\
\text { Child Domain } \\
\text { Parent Domain }\end{array}$ & $\begin{array}{l}104.82 \\
140.23\end{array}$ & $\begin{array}{l}15.09 \\
21.07\end{array}$ & $\begin{array}{l}106.95 \\
133.82\end{array}$ & $\begin{array}{l}12.03 \\
21.67\end{array}$ \\
\hline Social Support & 3.48 & 1.28 & 3.31 & 1.27 \\
\hline
\end{tabular}

See Table 2.3 for list of acronyms 
Table 4.3

Means and standard deviations by group (intervention vs. comparison):

Child characteristics at Infant-Age 6 months

\begin{tabular}{|c|c|c|c|c|}
\hline \multirow[b]{2}{*}{ Child Variables } & \multicolumn{2}{|c|}{$\begin{array}{l}\text { Intervention } \\
\text { Group }\end{array}$} & \multicolumn{2}{|c|}{$\begin{array}{l}\text { Comparison } \\
\text { Group }\end{array}$} \\
\hline & Mean & SD & Mean & SD \\
\hline Cognitive development (BSID) (MDI) & 112.45 & 13.51 & 114.43 & 16.71 \\
\hline \multicolumn{5}{|l|}{ Temperament (BSID) } \\
\hline Maternal ratings - ITQR "difficult" & 14.90 & 2.10 & 14.10 & 2.15 \\
\hline Experimenter ratings - IBR $[\mathrm{A} / \mathrm{E}]$ & 4.94 & .74 & 4.81 & .99 \\
\hline Vocalizations per minute & 4.80 & 3.59 & 4.33 & 2.91 \\
\hline Homeostasis & 9.28 & .78 & 9.75 & 1.18 \\
\hline Exploratory Behaviour & .20 & .04 & .22 & .06 \\
\hline
\end{tabular}

List of Acronyms - Tables 4.2 and 4.3

MBQS = Maternal Behaviour Q-sort

AGRS = Ainsworth Rating icales

CARE $=$ Child-Adult Relationship Experimental Index

EAS = Emotional Availability Scale

HOME = Home Observation for Measurement of the Environment

HSKS = High Scope Knowledge Scale

ITQR = Infant Temperament Scale Revised

PPIV = Parental Perception of Infant Vocalizations

PSI = Parenting Stress Index

BSID = Bayley Scales of Infant Development

MDI - Mental development index

IBR - Infant behaviour record

Homeostasis = ITQR + IBR composite scores

Exploratory behaviour $=$ Martery Motivation task 
more negative affect when socially interacting with their babies, and they provided less than optimal social and emotional stimulation in the home. Higher levels of stress were also associated with higher levels of maternal intrusiveness. In Study 1, maternal intrusiveness at 6 months was marginally associated with insecureavoidant relationships at 13 months.

Maternal perceptions of infant temperament. The high number of babies rated by their mothers as temperamentally "difficult" and the low congruence between the mothers' and the experimenters' ratings of infant temperament suggest that these young mothers were experiencing some difficulty in reading their babies' emotions, or alternately, they were interpreting the babies' behaviour in negative ways.

\section{Descrip:ive analyses of the intervention sessions}

Mothers in the intervention group received an average of 11.32 intervention visits over a 7 -month period ( $\underline{\mathrm{SD}}=1.32$, range 9 to 14 visits). The majority of visits lasted approximately one hour and were carried out by the author. Only one mother who had consented to be in the intervention group dropped out, and that occurred before the first intervention session could be arranged. This low attrition rate was probably due to the small number of subjects in the group, to the strong inducement of a video record of the baby and mother at the end of the study, and to the persistence and flexibility of the therapist in setting up visits. However, missed appointments were a constant aggravation for both the therapist conducting the intervention sessions and for the two observers conducting the assessment visits, and are probably a reflection of the immaturity of the subjects. Often no explanation was given for not being at home at the appointed time. When an explanation was volunteered, it was usually that a friend had come by unexpectedly and they had gone out together.

Great care was taken to make the bi-weekly intervention sessions informal and non-threatening so that a trusting relationship could be developed with the mother. The candour of these young mothers was striking. They seemed at ease before the camera and appeared to interact with their babies in their usual, 
everyday way. The mothers enjoyed watching their babies at play on the television screen, and reviewing the videotape at each session proved an effective means of helping the young mothers become better observers of their babies. Commenting on what seemed to please the baby, asking the mother to comment on her baby's feelings, and praising the mother for appropriate interactions seemed to be more effective in bringing about desired changes in maternal behaviour than direct teaching strategies. For example, commenting on the baby's obvious enjoyment at being imitated, or the baby's increased vocalizations in response to his/her mother's verbalizations, often increased the mother's imitation or verbalizations during subsequent play. More than one mother expressed pleasure in knowing that she was doing something that her baby was enjoying and doing it well.

Techniques for getting mothers to become better observers of their babies were often idiosyncratic: for example if a mother did not respond to her baby's vocalizations but did not seem to notice this in reviewing the videotapes, she might be asked in a casual way, what she thought would happen if she or the therapist made a funny sound every time her baby vocalized. What did she think the baby would do? Both therapist and mother would then take turns playing with the baby in this way, and a second one-minute videotape would be made of mother and baby playing together in this manner. It too was viewed and discussed. As mothers became better observers of their babies' cues, they became more adept at responding appropriately and following their baby's lead. Indirect teaching often took the form of the therapist playing with the baby in a contingent, reciprocal manner during spontaneous interactions. Mothers became better observers of their babies quite quickly and often expressed surprise at how much their babies were able to do. They enjoyed responding to questions about their babies, and during these "spontaneous" conversations, the importance of having fun with their babies, of playing and talking in a contingent and reciprocal manner, and of following their babies' lead was emphasized in many subtle ways. Although each session was individually tailored to the needs of the particular dyad, the focus was always on enhancing the mother's sensitive responsiveness to her baby's cues. 
Statistical analyses at 13 months

Effect of interventic 1 on maternal sensitivity and infant security of attachment. MANOVAs were used to assess the effectiveness of the intervention. The means, standard deviations, and significant $\underline{F}$ values for maternal interactive behaviours and child characteristics at 13 months are summarized in Tables 4.4 and 4.5. First, maternal sensitivity (MBQS \& AGRS scores) and attachment security (AQS scores), together with HOME scores and scores in maternal responsiveness (CARE-R) and emotional availability (EAS attentiveness scores) during play were entered as dependent measures with group (intervention/comparison) as the independent measure. As predicted, there was a significant main effect for group $[\underline{F}(6,38)=2.83$, $\mathfrak{p}<.05]$. Follow-up univariate tests indicated that intervention mothers were significantly more sensitive to their baby's needs and cues, $\mathrm{F}(1,43)=4.43, \mathrm{p}<.05$ for MBQS scores and $\mathrm{F}(1,43)=$ $5.28, \underline{p}<.05$ for AGRS scores, and more sensitively tesponsive during play, $\mathrm{F}$ $(1,43)=6.19, \mathrm{p}<.05)$ than comparison mothers. The univariate tests for HOME scores and for emotional availability during play were not significant. Toddlers in the intervention group had significantly higher attachment security scores, $\mathrm{F}(1,43)=8.82, \mathrm{p}<.01$, than toddlers in the comparison group.

Second, a repeated measures MANOVA was performed with maternal sensitivity scores (MBOS and AGRS) at 6 and 13 months as the dependent variables and group membership (intervention or comparison group) as the groups factor. A marginally significant Time by Groups interaction was revealed $[F(1,2)$ $=2.50, \mathrm{p}<.10]$. The univariate tests showed that the interaction effects were significant for MBOS scores $[F(1,43)=5.01, \mathrm{p}<.05]$ and marginally significant for AGRS scores $[F(1,43)=3.90, p<.10]$. In the intervention group, MBQS and AGRS scores increased by an average of $.08, \underline{\mathrm{SD}}=.44$ and $1.64, \underline{\mathrm{SD}}=6.04$, respectively, over the 7 -month period. In the comparison group, these scores

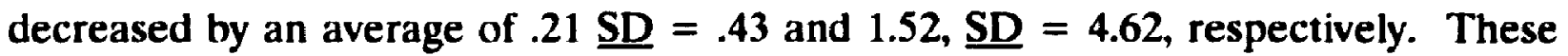
results are illustrated in Figure 4.1. [The same results were obtained when difference scores were compared using oneway ANOVA. Difference scores in the 
Table 4.4

Means and standard deviations by group (intervention vs. comparison):

Maternal behaviours at infant-age 13 months

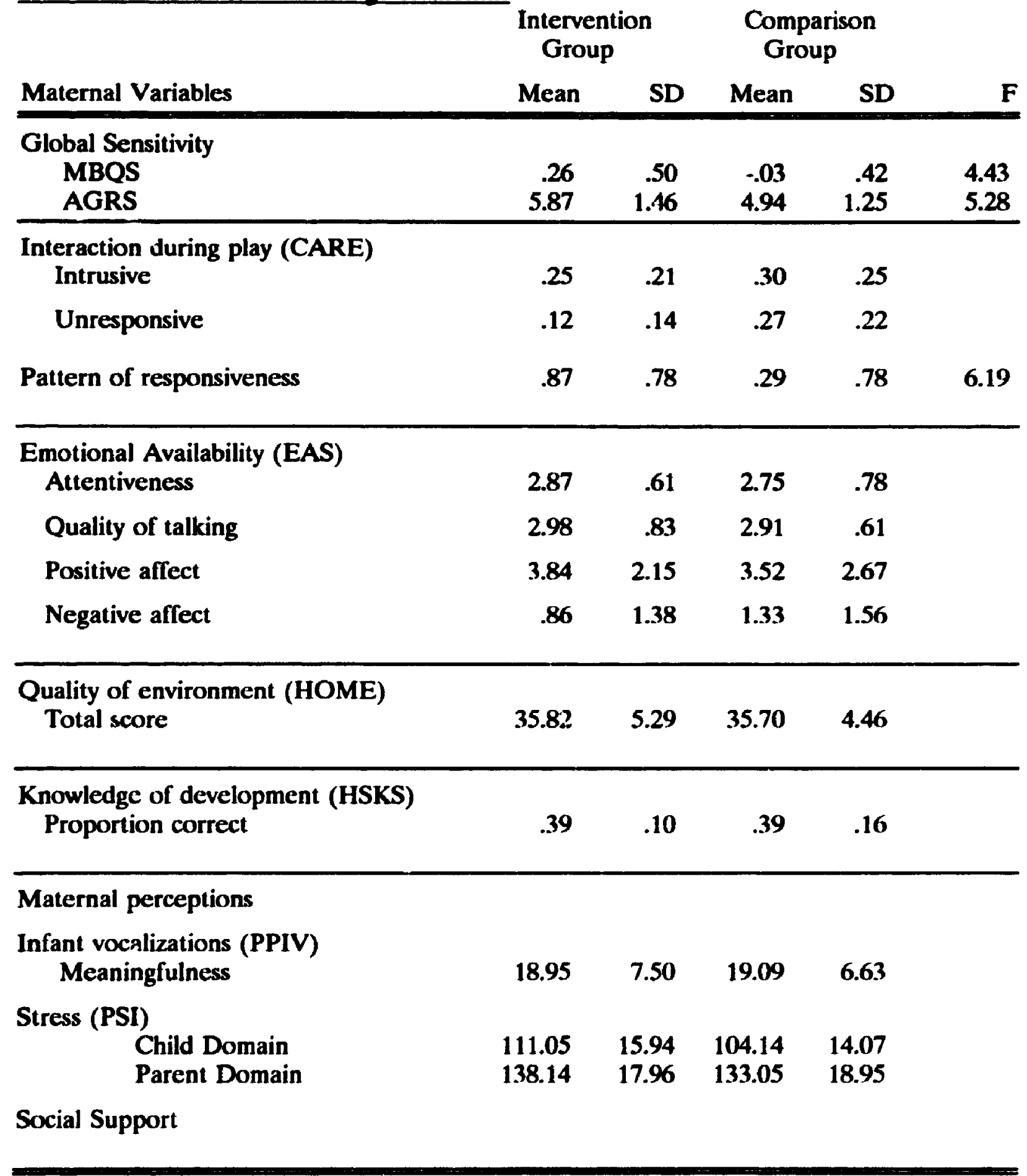

See Table 2.5 for list of acronyms 
Table 4.5

Means and standard deviations by group (intervention vs. comparison): Child characteristics at infant-age 13 months

Intervention Comparison

Group Group

Child Variables

Mean

SD

Mean

SD

$\underline{F}$

Cognitive development (BSID) (MDI)

113.55

$9.17 \quad 115.09$

10.26

Temperament

Maternal ratings - ITQR "difficult"

17.04

2.09

15.78

1.80

7.14

Experimenter ratings - IBR $[\mathrm{A} / \mathrm{E}]$

4.93

$1.34 \quad 5.41$

1.03

3.88

Communicative Acts per minute

$3.11 \quad 1.46 \quad 3.41$

1.17

\footnotetext{
Attachment Security

Attachment security Q-sort

.29

Strange Situation (proportion secure)

.68

$\mathrm{p}<.05$ for $\underline{\mathrm{F}}$ values $\quad{ }^{*} \mathrm{p}=.025$ for chi-square value

List of Acronyms - Tables 2.4 and 2.5

MBOS = Maternal Behaviour Q-sort

AGRS = Answorth Rating Scales

CARE = Child-Adult Relationship Experimental Index

EAS = Emotional Availability Scale

HOME = Home Observation for Measurement of the Environment

HSKS = High Scope Knowledge Scale

ITQR = Infant Temperament Scale Revised

PPIV = Parental Perception of Infant Vocalizations

PSI = Parenting Stress Index

BSID = Bayley Scales of Infant Deyelopment

MDI - Mental development index

IBR - Infant behaviour record
}

.20

.11

.21

8.82

.35

$5.01^{*}$ 


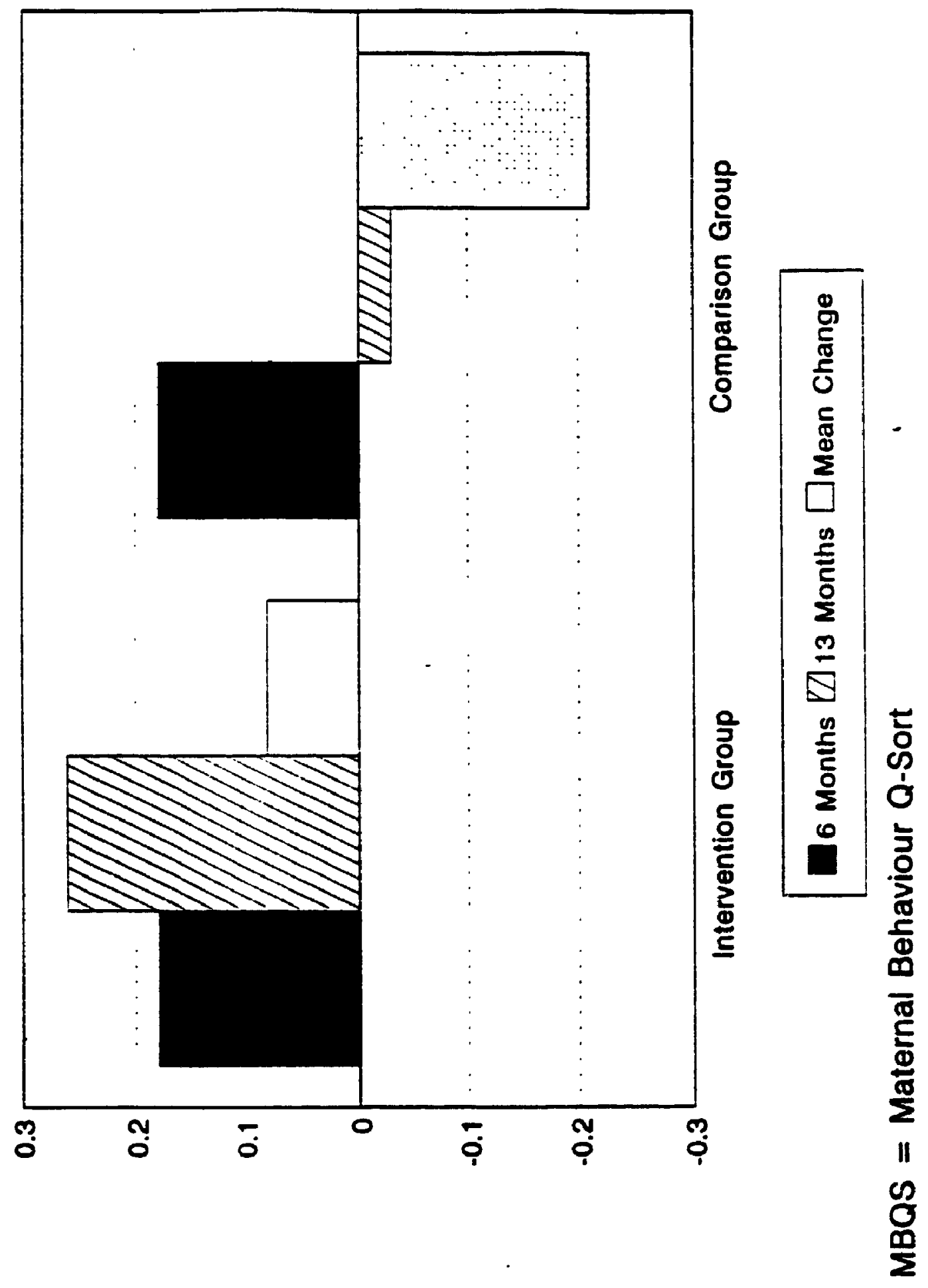

Figure 4.1 Change in maternal sensitivity (MBQS scores) from 6 to 13 months in the Intervention and Comparison groups. 
pattern of responsiveness during play and in HOME scores were also marginally higher for mothers in the intervention group, $\underline{F}(1,43)=3.44, \underline{p}<.10$ and $\underline{F}(1,43)$ $=3.32, \mathrm{p}<.10$, respectively.]

The effectiveness of the intervention in facilitating secure attachment relationships was also assessed by chi-square analysis of the strange situation results. As predicted, significantly more children in the intervention group were judged to be in secure attachment relationships, $\underline{X}^{2}=5.01, \underline{p}<.05$. In the intervention group, fifteen (68\%) children were placed in the B category (secure), 6 in the A ca.egory (insecure-avoidant), and 1 in the C category (insecureambivalent). In the comparison grcup, 8 (35\%) children were placed in the B category, 9 in the A category, and 6 in the $C$ category. A comparison of the differences in attachment security in the intervention and comparison groups, measured by two different methods, is illustrated in Figure 4.2.

Finally, Cohen's d was used to determine the degree of effectiveness of the intervention. Effect sizes were computed for maternal sensitivity (MBQS scores) and security of attachment (AQS scores) using the standardized difference between the means of the intervention and comparison groups (Cohen, 1988). The effect size for sensitivity was $\underline{d}=.63$ and for attachment security, $\underline{d}=.82$, both statistically significant. Based on Cohen's criteria for weak $(\underline{d}=.20)$, medium ( $\underline{\mathrm{d}}=.50)$, and strong ( $\underline{\mathrm{d}}=.80$ ) effect sizes, the intervention was very successful in enhancing both the mother's sensitivity to her baby's cues and the infant's security of attachment.

Infant characteristics. Scores on measures of infant mental development, corrmunicative ability, "difficult" temperament, and affect/emotionality were entered as dependent measures in a MANOVA with group membership (comparison/intervention) as the independent measure. There was a marginally significant main effect for group $[\mathrm{E}(1,5)=2.12, \mathrm{p}<.10]$. Follow-up univariate tests indicated that intervention toddiers were rated as significantly more temperamentally "difficult" by their mothers than comparison group toddlers, $\mathbf{F}$ $(1,39)=7.14, p<.05$ and marginally less sociable, cooperative, and happy by the 
Attachment Security at 13 Months Intervention and Comparison Groups

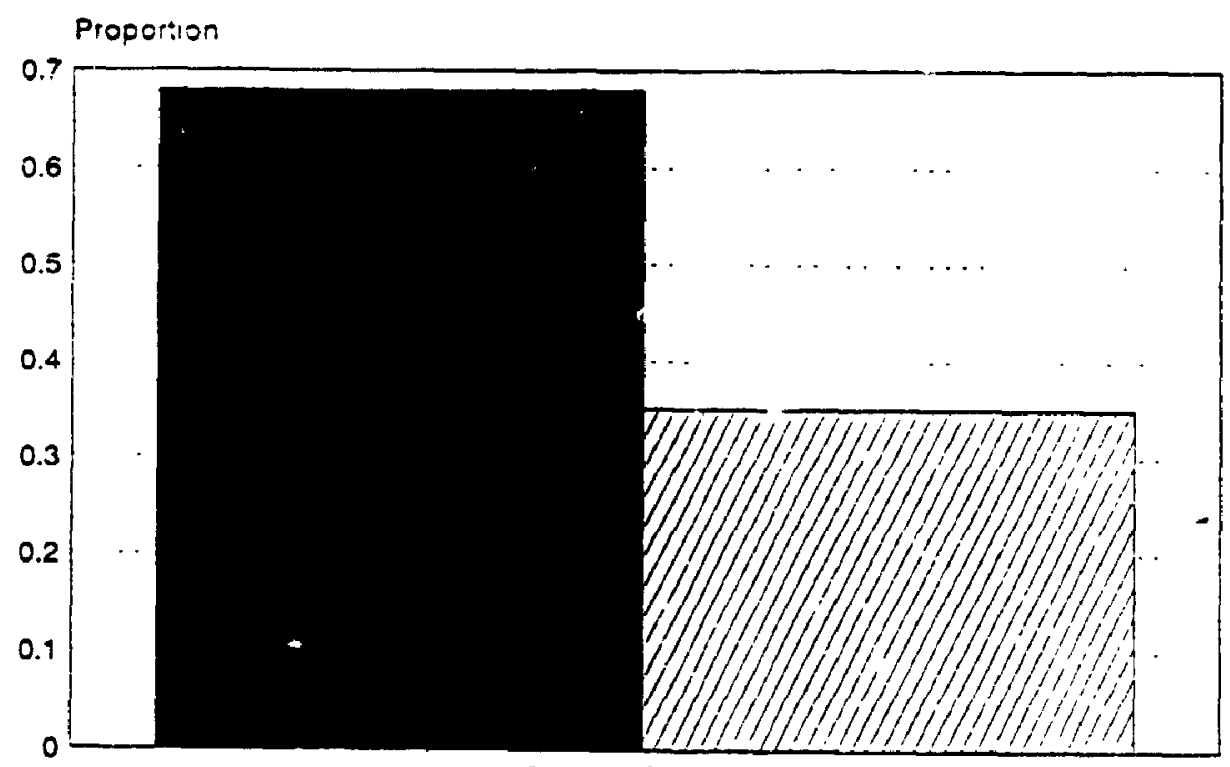

Strange Situation

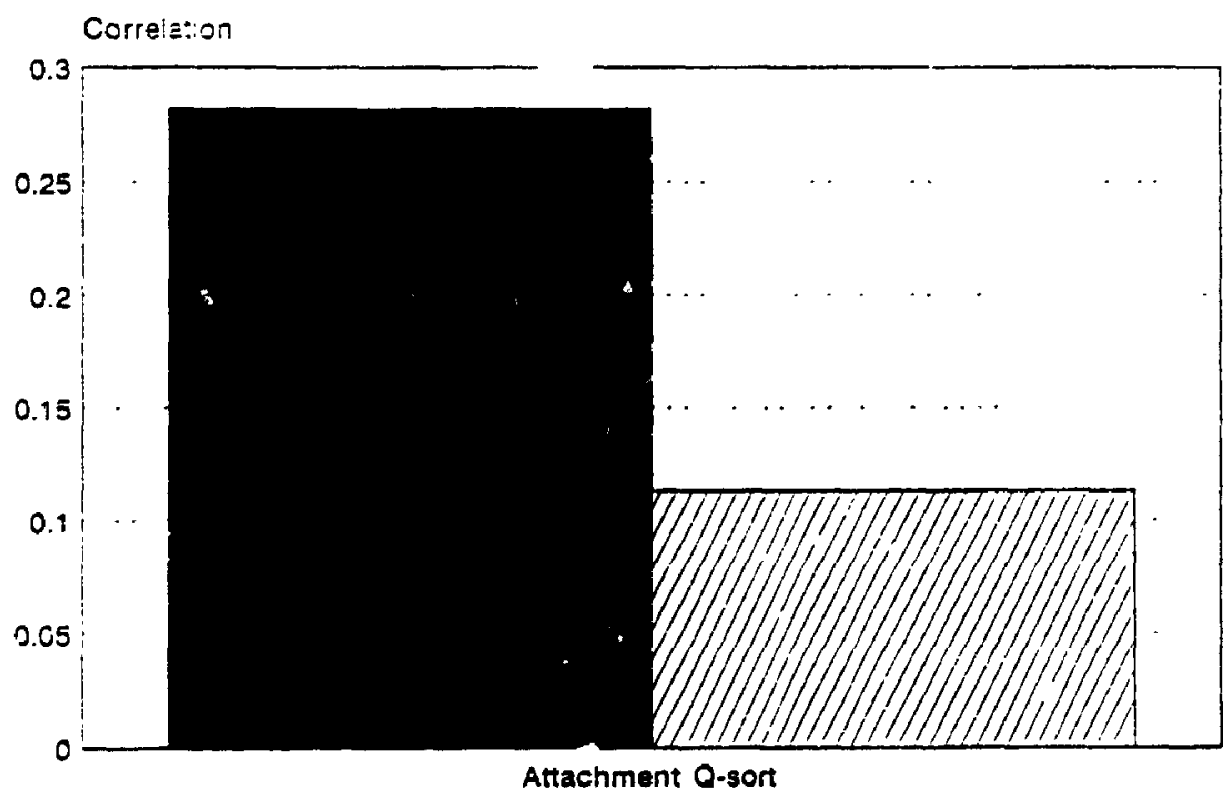

Intervention Group $\Pi$ comparison Group

Figure 4.2 Differences in attachment security in the Intervention and Comparison groups. measured by two different methods. 
examiner during Bayley testing, $\underline{F}(1,39)=3.88, \underline{p}<.10)$. Although these findings appear surprising at first glance, they may be a reflection of some recent changes in the home environments of five of the children in the intervention group.

Mothers of three children left their partners and mothers of two children moved out of the family home within 6-weeks of the 13-month assessment visits. Children could react negatively to such changes in their lives which could be expressed in increased fussiness. Nevertheless, three of the five toddlers were judged to be securely attached on the basis of their behaviour in the Strange Situation procedure.

Support for this interpretation of the paradoxical finding comes from the congruence in temperainent ratings between mothers in the intervention group and the experimenters who tested the children. Maternal ratings of infants as happy, easily adapting to neiv situations, willing to approach new stimuli, persistent, and predictable in the home were marginally correlated with experimenter's ratings of these infants as sociable, cooperative, and happy during the testing situation ( $\underline{r}=.44, \underline{p}<.10$ ). As well, in the intervention group, higher levels of stress in the child domain were marginally associated with children being rated as less cooperative, social, and happy during the testing situation $(\underline{r}=-.37, \mathfrak{p}$ $<.10)$ but not with maternal ratings $c$ infant "difficult" temperament. In the comparison group, higher levels of stress in the child domain were marginally correlated with children being perceived as "difficult" by the mothers, $\underline{\mathrm{r}}=.42, \mathfrak{p}<$ .10 , and with children being rated as happy, sociable, and cooperative by the experimenter, $\underline{\mathrm{r}}=.37, \mathrm{p}<.10$. As well, stress in the parenting domain was significantly correlated with higher "difficult" scores in the comparison group ( $\underline{r}=$ $.48, \mathrm{p}<.05)$ but not in the intervention group despite the higher mean "difficult" score in the latter group. Taken together, these findings suggest that intervention mothers may have been coping inore successfully with their difficult toddlers.

Discussion

In the present study, maternal sensitivity was experimentally manipulated in dyads considered to be at risk for developing insecure attachment relationships. 
Results indicate that the intervention was effective in enhancing maternal sensitivity with concomitant increases in the number of securely attached children. Similar findings are usually regarded as supporting a causal relationship between sensitivity and attachment (cf. Vanljzendorn et al., in press, for a review; van den Boom, 1994; Lieberman, Weston, \& Pawl, 1991; Lyons-Ruth, Zoll, Connell, and Odom, 1987), but within the transactional framework adopted in the present study, maternal sensitivity is not seen as being causally related to secure attachment but rather, as a probe into the process of attachment formation.

Many factors may have contributed to the intervention's success. The intervention was based on attachment theory and research, and the model chosen emphasized strengths in both mother and haby, rather than focusing on maternal inadequacies. Great care was taken not to disempowe- the young mothers. In this regard, guided viewing of the videotapes proved to be a useful tool in getting mothers to identify and build on their own and their babies' strengths and positive qualities. Intervention efforts were also targeted at a period of reorganization in the infant's development when opportunities for change are high. The adolescent mother, too, may be in a period of reorganization, as she tries to resolve issues of identity (Erickson, 1968) and may thus be more amenable to change, as well.

Although enhancing maternal sensitivity through play appears deceptively simple, play contains components that tap each developmental domain and improvements in the quality of early social interactions can lead to a selfperpetuating system of adaptive behaviour in both mother and child. Early mother-infant social interaction is essential to the development of the interactive communication process (Kaye, 1982). As mothers become more sensitive to their infants' cues and respond appropriately and contingently, their infanis become more skilled in communication and social interaction. In turn, increases in the infant's skills make the mother more confident in her ability to engage her infant in interaction. The mother feels more competent and experiences greater selfesteem which makes her an even more effective parent; in turn the child's optimal 
development is facilitated. Interactions become more and more mutually satisfying to the benefit of both parent and child.

In the present study, encouraging signs of positive change were seen in more frequent, spontaneous, and mutually enjoyable interactions between mother and baby as the intervention visits progressed. As well, mothers became more assertive in expressing their feelings, and demonstrated a better understanding of their baby's behaviour when viewing the videotape. Mothers were also better able to cope with their toddler's difticult behaviour during stressful periods of change in family circumstances. Other signs of progress were unique to each mother's situation and may indicate that the intervention had a positive effect o: the mother's self-esteem: for example, one young mother enrolled at a Community College and another young mother ended an emotionally-abusive relationship.

Although the intervention was successful at the behavioural level, the process of intervention and its effective ingredient remain somewhat ambiguous since intervention strategies were individualized for each parent and changes in the mother's mental representations of attachment were not measured. Strategies at each visit had the specific goal of enhancing the mother's sensitive responsiveness to her baby's cues and signals but the therapist-parent relationship may also have played an important role in the effectiveness of the intervention (Lieberman, 1991; Beckwith, 1988; Osofsky, et al., 1988). The development of a healthy, supportive relationship may have shown the mother that such relationships are possible and thus allowed an opportunity for change. According to Lieberman (1991), such "corrective attachment experiences" challenge a maladaptive working model and may allow a mother to see herself as someone who deserves support and attention, and by extension, see her child as deserving the same. Unresolved attachment issues may be particularly salient during the early stages of motherhood, and a trusting relationship at this time may allow the mother to rework existing negative representational models into more integrated models of attachment (Main \& Goldwyn, 1984). 
The mothers' behaviour was consistent with this hypothesis. At first, mothers seemed somewhat guarded in the bi-weekly visits and many left the television set on for the entire visit. As mothers came to feel that their behaviour was not being judged and that their opinions were valued, they turned off the television and focused on their babies during the visits. In general, it took only a few visits to establish an emotionally supportive relationship with the mother and in a few cases it took several months. With two mothers, the relationship remained somewhat tenuous to the end and in both dyads, the babies were judged to be insecurely attached.

As in other studies (Beckwith, 1988; Osofsky, et al., 1988), multiproblem mothers were found to be unable to focus on their infant's needs until they themselves received nurturing. Many mothers never really felt cared for, and the demands of caring for a new baby appeared to trigger their own feelings of sadness, loss, and anger. Mothers often wanted to talk about their troubled childhoods or current boyfriend problems. At times, visits lasted 2 hours or more when mothers were trying to deal with pressing and often developmentally related adolescent issues. Nurturance was given in other ways as well: a ride to an important appointment, small gifts for the baby at Christmas and on his/her birthday, a special occasion card for the mother, a small treat for afternoon tea, and so on. Videotapes of the baby proved to be a powerful incentive for participation in the study but unconditional acceptance of the mother, sensitivity, commitment, and flexibility on the therapist's part were also needed to keep the young mothers actively involved in the intervention program. The therapist always showed up for an appointment and no mother was dropped from the program because of missed appointments.

Results of the present study clearly support the effectiveness of behavioural interventions in improving mother-infant interactions and thus facilitating healthy infant-mother attachment relationships. However, concern has been expressed (Van ljzendoorn, in press) that interventions which provide no specific training for the next phase in infant development may be counterproductive if maternal 
representations of attachment are also not changed, in that children's expectations of sensitive interactions may not be fulfilled at a later stage. This concern is valid and highlights the need for interventions that are based on principles implicit in developmental psychopathology, namely that intervention strategies reflect developmental changes and vary in accordance with the infant's developmental level (Cicchetti, et al., 1989). Cicchetti and others suggest that "booster" sessions may also be necessary during developmental transition periods to facilitate positive outcomes in those infants with a history of vulnerability for maladaptation.

Replication studies are needed to see how easily the intervention strategies used in the current study might be taught to others, since one therapist made all the intervention visits. As well, nonspecific placebo effects need to be examined in future studies, by employing at least one other comparison group which receives an alternate intervention. The possibility that the intervention group showed improvement in their behaviour simply because they received more attention than the comparison group cannot be ruled out in the present study. Follow-up studies are also needed to determine the long-term effects of behavioural interventions. Although Lieberman (1991) refers to the positive effect of the "corrective attachment experience" on maladaptive internal working models and SternBruschweiler and Stern (1990) argue that:

"...effective therapeutic interventions always involve both a change in the overt interactive behaviours and a change in the mother's representation of her infant and herself in the mothering role, no matter whether it was directed exclusively at the mother's representations or at the overt interactive behaviours of mother and infant" (p.143),

studies are clearly needed to determine if changes at the behavioural level are accompanied by changes at the representational level.

In the present study, home visitation was chosen over more cost-effective, centre-based intervention sessions in order to acquire as complete a picture as possible of factors in the home and family that may facilitate or interfere with the establishment of mutually satisfying parent-child relationships. Such information is 
important not only from a clinical viewpoint but also from a theoretical perspective. Empirical evidence for a reliably predictable relationship between sensitivity and attachment would lead to a better understanding of this important process in child development as well as to more effective programs for preventing maladaptive behaviour in at-risk dyads. It was felt that young mothers would feel more comfortable in their own homes and interact with their babies in typical ways. They would also be less likely to drop out of the study since easy transportation is usually not readily available for economically disadvantaged dyads and considerable effort is required for young mothers to get to a Centre with babies in tow. In addition, home visitation may provide a means of reaching out to parents who are at greatest risk for dysfunctional caregiving since they often lack self-confidence and trust in formal service providers, and thus are less likely to attend group meetings (Olds \& Henderson, 1989).

The need to implement prevention/intervention programs in the first year of the child's life appears to be essential. Many adolescents with young infants are not yet experiencing the serious child behaviour management problems which often bring them to the attention of child protection agencies when their children are older. Parent-child interactions are still relatively benign although subtle indications of future problems may be present. If adolescent parents can be reached at this early stage, the chances of influencing patterns of parenting and promoting healthier parent-infant relationships are improved, and the likelihood of future maladaptation in both child and parent is diminished.

Ideally, all adolescent parents should be included in school-based programs. Programs that make it possible for a young mother to continue her education, to be reintegrated into her peer group, and to become an effective parent not only have the greatest potential for long-term gains in preventing child maltreatment, they may, in the long run, prove to be the most cost-effective. Focusing preventive services on all parents who are at more general risk for dysfunctional parenting by virtue of their life circumstances, rather than on parents suspected of being at risk for maltreatment per se has many advantages. Programs can be 
presented in a more positive, constructive light, thus ensuring continued cooperation from parents, and labelling and inappropriate interventions by government agencies may be avoided (Olds \& Henderson, 1989).

The City of London has taken a progressive approach to providing preventive services for young, economically disadvantaged parents with very young children. Community drop-in centres offering support and educational programs to parents of young children from birth to age 5 have been set up in several areas of the city where large numbers of young families live in high density, low-cost housing. A model program that is the result of a collaborative effort between the Board of Education and Merrymount Children's Centre, should go a long way in reducing the vocational disadvantage many adolescent parents face when they get older. Daycare is provided for infants under two years of age on the premises of two high schools, while their mothers attend regular classes. Mothers receive individual supportive counselling through the school guidance department. They also are encouraged to take relevant courses in Family Studies and to attend weekly group meetings at the Daycare Centre where topics include problem solving, budgeting, child development, and career planning in addition to parenting skills.

An intervention component similar to the one used in the current study but centre-based could be incorporated into any of the existing community programs. Intervention procedures aimed at enhancing early interaction skills through social play can be a non-threatening and enjoyable way to increase parental sensitivity and nurturing behaviour which are so necessary for healthy parent-child relationships and optimal child development. There is no denying that a variety of parent variables influence both the long- and short-term effectiveness of any parent training program (Wolfe, Edwards, Manion, \& Koverola, 1988; Griest \& Forehand, 1982), bur the presence of mutually satisfying interactions and a secure attachment relationship in the first two years of life may enhance both the parent's and child's resiliency to the myriad effects of disadvantage. 


\section{CHAPTER V}

\section{Conclusions}

The current research addressed issues of both clinical and conceptual significance and has theoretical value as well as pactical applications. The results extend our knowledge of important developmental processes in a population at risk for maladaptive parenting. The developmental psychopathology approach was successful in delineating a possible pathway to insecure attachment relationships and provided a rationale for implementing prevention/intervention programs during the child's first year of life. Continuity in infant adaptation was found from 3 months to 6 months of age but not from 6 to 13 months. The marked change in the quality of environmental support available to the infants in the last half of the first year, as measured by maternal interactive behaviour, may have led to fundamental changes in the infant's adaptation at 13 months. Studies investigating the progression through early developmental issues, by low-risk infants as well as other groups of high-risk infants, are needed to determine if discontinuity in adaptation between 6 and 13 months is a characteristic of high-risk samples, and if there is an accompanying decline in the quality of the mother's interactive behaviour. Previous research (e.g. Sroufe, 1983) has shown continuity in broadband measures of adaptation from toddlerhood (secure attachment) to preschool (peer relationships) but few studies have looked at adaptation across the first year. Such studies, based on an organizational perspective of development, will lead to a better understanding of the origins of attachment (Isabella, 1995). 
Results of the two studies suggest that infant behaviour in the strange situation is guided by the history of the infant's daily interactions with his/her mother in various contexts. When mother-infant interactions are mutually satisfying and pleasurable, a secure infant-mother attachment relationship may become more likely. The findings are consistent with those reported in the attachment literature that show security of attachment to be related to stability in maternal sensitivity (Pederson \& Moran, 1994) and to stability in positive emotionality during mother-infant interactions over the first year (Belsky, Fish, \& Isabella, 1991). The findings did not support a temperament-based interpretation. Maternal ratings of "difficult" temperament did not distinguish between secure and insecurely attached dyads. Indeed children in the Intervention group received higher ratings in difficult temperament from both mothers and experimenters than children in the Comparison group and yet the majority of Intervention children were securely attached. A marginally significant difference in the experimenter's rating of infant affect/emotionality during testing was found between children who were judged securely and insecurely attached in the cross-sectional sample. Other analyses revealed that children in insecure-ambivalent relationships were fussier than children in either secure or insecure-avoidant relationships. Had the subjects included a larger number of infants classified as insecure-ambivalent, it is possible that a significant correlation would have been found for that group.

The current studies add to the growing body of research on attachment processes in aiypical populations (Crittenden, 1988; Cummings \& Cicchetti, 1990; Greenberg \& Speltz, 1988; Radke-Yarrow, Cummings, Kuczynski, \& Chapman, 1985). The findings suggest that some adolescents adjust well to early parenthood and provide the nurturing behaviour necessary for optimal child development and others are able to do so with help. The results of both studies lend support to Cicchetti and Greenberg's stated belief that "research on attachment from a developmental psychopathology perspective, in concert with the implementation of prevention and intervention programs based on the principles of attachment theory, will usher in a new era in the field of attachment" (1991, p. 348). 


\section{APPENDIX A}

Information letter for Study 1

Demographic return sheet

Consent form for Study 1

Information letter for Study 2

Consent form for Study 2 
Letter in the information package given to potential subjects for Study 1.

\section{A STUDY OF INTERACTIONS BETWEEN MOTHERS AND THEIR BABIES}

\section{Dear Parent:}

We are conducting a study of mother-infant social interactions in order to gain a better understanding of the ways in which mothers and their babies develop a mutually rewarding and loving relationship. Your participation in this project will not only further our understanding of this ir.pportant process, it may ultimately aid in the development of programs that will help childten reach their developmental potential.

If your agree to participate, we will come to your home to observe you and your baby while you are engaged in a few planned activities. In each case we are tterested in seeing how your baby reacts to different situations. We will also play with your baby using a variety of different toys and administer a simple developmental test, again using toys. As well, we will ask you to complete brief questionnaires related to your baby's behaviour and to your views on parenting. You will be free to answer only those questions that you wish to answer.

We will come for two visits, one week apart, when your baby is 3 months old, when your baby is 6 months old, and when your baby is 13 months old. The planned activities will include: (1) Free play - in this activity we would like you to play with your baby in any way you want for approximately 10 minutes; (2) "Statue Game" - after the free play we would like you to remain still and not to play with the baby for 2 minutes; (3) Separation-reunion episode (at 13 months only) in this activity we would like you to leave the room for 3 minutes (we will remain with the baby to make sure that he/she will not get into any harm), return to the room fur 3 minutes, leave again for 3 minutes, and then return once more. You will be free to return earlier if the baby becomes too distressed by your absence.

Participation will take about two hours of your time on each of these visits and no harmful procedures are involved. Approximately 10 minutes of each activity will be videotaped, and if you wish, we will give you a copy of the videotape which may be shown to family and friends on a home VCR unit. As well, in appreciation for your participation, you will receive a token payment of ten dollars for each of ihe two home visits at 3 months, ten dollars for each of the two home visits 2. 6 months, and ten dollars for each of the two home visits at 1 nonths. You and your baby should find the experience enjoyable, and you will be free to with the study at any time.

If you would like to participate in this study, please sign the attached consent form and return it to us. We have provided a stamped, self-addressed envelope for your convenience. Our records will bc confidential and individual parents and infants will not be identified at any time. Parents will have the opportunity to receive information about the results of the study if they so desire. Please call us if you have any further questions.

Thank you for considering this request.

Greg Moran, Ph.D. C.Psych.

Associate Professor,

Dept. of Psychology
Arne Krupka, M.A.

Ph.D. Candidate

679-2111, Ext. 4702 
Form included in the information package.

A STUDY OF INTERACTIONS BETWEEN MOTHERS AND THEIR INFANTS

(A. Krupka, M.A. and G. Moran, Ph.D., C. Psych.)

Name

Address

Phone

Your date of birth

Your baby's name

Your baby's date of birth

For fי-ther information return this form to:

Anne Krupka, M.A. Department of Psychciogy, University of Western Ontario, London, .nt.

N6A 5C2 
Consent form signed by all mothers on the first assessment visit.

\section{A STUDY OF MOTHER-INFANT INTERACTIONS}

\section{Confirmation of Informed Consent}

I have read the accompanying description, and I give consent for myself and my child to be videotaped for the study of mother-infant interactions to be conducted by Anne Krupka, M.A. and Dr. Greg Moran.

I understand that the videotapes and any other records of my participation are strictly confidential, subject to provisions of the Child and Fausily Services Act, and will be looked at only by those directly involved with the study. After the data are analyzed, the tapes vill be destroyed unless further consent is obtained to use the tapes for teaching and educational purposes. The results of this study may be published but individual parents and children will not be identified. The expected completion date for the project is September, 1994 .

I understand that this study will not result in any direct benefit to me, but may help to further our knowledge of factors involved in child social development. I also understand that participation in thi .tudy is completely voluntary and that I may refuse to participate in the study or may wihdraw at any time for any reason.

\section{Signature}

Address

Postal Code

Date

Do you wish to receive a summary of the research results when it becotises available? _Yes _No. 
I etter sent to mothers who had been randomly assigned to the intervention group.

\section{A STUDY OF INTERACTIONS BETWEEN MOTHERS AND THEIR BABIES}

\section{Dear Parent:}

As you inow, we are conductin $\bar{i}_{-}$study of mother-infant social interactions in order to gain a better understanding of the ways in which mothers and their babies develop a mutually rewarding and loving relationship. Your participation in this project not only furthers our understanding of this important process, it may ultimately aid in the development of programs that will help children reach their developmental potential.

You are currently involved in the first part of the study, which wil! take about two hours of your time on each of the two home visits made when your baby is 6 months and 13 months old. In a second part of the study, we would like to come to your home for approximately $\mathbf{4 0}$ minutes every two weeks between the two sets of visits (approximately 12 to 14 times in total), to watch you and your baby play together and to talk about different way: that mothers play with their babies. We may ask you to play with your baby in new ways for a few minutes each day and we will be interested in hearing about the things you and your baby enjoyed doing the most together. Since you know your baby best, your opinions are very important to us. We will also be able to answer, in an informal way, any child-related concerns you may have. You and your baby should find the experience enjoyable, and you will be free to withdraw from the study at any time.

If you would like to participate in this part of the study also, please sign the attached consent form. As always, our records are confidential and individual ${ }_{i}$ arents and infants will not be identified at any time. You will have the opportunity to receive information about the results of th" study if you so desire. Please call us if you have any further questions.

Thank you for considering this request.

Anne Krupka, M.A. 679-21. . Ext. 4702

Greg Moran, Ph.D. C.Psych. Associat Professor, Dept. of Psychology 
Consent form accompanying the letter sent to mothers assigned to the intervention group.

\title{
A STUDY OF INTERACTIONS BETWEEN MOTHERS AND THEIR BABIES
}

\author{
(A. Krupka, M.A. and G. Moran, Ph.D., C.Psych.)
}

I have read the accompanying description, and I give consent for myself and my child to be videotaped for the second part of the mother-infant interaction study to be conducted by Anne Krupka, M.A. and Dr. Greg Moran.

I understand that the information gathered is for research purposes and will be treated as confidential. I further unjerstand that participation is completely voluntary and that I am free to withdraw at any time for any reason.

Signature

Date 


\section{APPENDIX B}

Maternal Behaviour Q-sort (Pederson \& Moran, 1989)

Domain-Specific Attachment Behaviours (Pederson \& Moran, 1994)

Child-Adult Experimental Index (Crittenden, 1981)

Mastery Motivation Tasks (Vietze et ai., 1983; 1981) 
Maternal Behaviour Q-Sort Items

October 12, 1989

Version 2.1

David R. Pederson \& Greg Moran

University of Western Ontario

(Numbers in the left margin are the criterion weights used to calculate maternal sensitivity scores. The criterion sorts were completed with mothers of 12 -month-old infants in mind.)

$8.00 * * 1$. Notices when her B smiles and vocalizes.

1.00 2. Unaware of or insensitive to B's signs of distress

$1.92 * * 3$. Often interprets B's signals according to cwn wishes and moods

$1.33 * * 4$. Response so delayed that B cannot connect M's response with the action that initiated it.

$7.92 * * 5$. Notices when B is distressed, cries, fusses, or whimpers

8.50 *6. Int:ractions appropriately vigorous and exciting as judged from B's responses

1.25 *7. Responds only to frequent, prolonged or intense signals

1.33 8. Responses to B's communications are inconsistent and unpredictable

8.92 9. Responds consistently to B's signals

Low: Responses are unpredictable or arbitrary

$7.25 * * 10$. Greets $B$ when re-entering room

2.25 11. Sometimes is aware of B's signals of distress, but ignores or does not responu immediately to these signals

$9.00 * * 12$. Interprets cues correctly as evidenced by B's response

2.75 13. Is irritated by demands of $B$ (note information from interview including comments on caregiving demands)

4.08*14. Scolds B

7.58 15. Aware of how her moods affect B

$2.00 * * 16$. Will often interfere with B's ongoing apprerriate behaviour Low: Stands back and lets B carry on with activity without interruption 
3.92 17. Worried about spoiling, has lots of "shoulds" about B's care

7.17 18. Structures environment considering B's and own needs (consider the balance in this item)

2.58 *19. Perceives B's negative behaviour as rejection of her, takes misbehaviour "personally"

2.50 20. Seems to resent B's signals of distress or bids for attention

5.75 21. Is delighted over $B$

6.83 ${ }^{*} 22$. Resolves negative feelings about $B$; that is has some negative feelings about $B$, but can set these aside in interacting with $B$

7.67 *23. Respects B as individual, i.e., able to accept B's behaviour even if it is not consistent with her ideal

7.17 24. Knows a lot about her B; good informant

4.25 25. Idealizes B -- does not acknowledge negative aspects

3.50 26. Critical in her descriptions of $B$

4.67 27. Seems "long suffering" in her attitude about her maternal duties

1.67 28. Teases B beyond point where B seems to enjoy it

8.83 *29. Slows pace down, waits for B's response in face-to-face interactions

5.67 *30. Plays games with B such as peek-a-boo, patty cake

5.58 31. Makes an effort to take B on "outings" such as shopping, visiting friends

5.83 32. Provides age appropriate toys

6.00 33. Creates interesting environment

7.00 **34. Seeks face-to-face interactions

6.17 35. Points to and identifies interesting things in B's environment

6.75 *36. Predominantly positive mood about B

6.25 37. Comments are generally positive when speaking about B 
6.50 **38. Displays affection by touching

6.00 39. When holding, cuddles $B$ as a typical mode of interaction; molds $B$ to seli

6.75 40. Praise directed toward B

3.67 41. Fiat affect when interacting with $B$

6.92 42. Is animated in social interactions with B

4.25 43. Kisses $B$ on head as major mode of expressing affection

7.42 44. Balances task and B's activities when changing diapers

7.58 45. Encourages B's initiatives in feeding

8.17 46. Cues B and waits for response in feeding

7.67 47. Balances lask and B's activities in feeding

$5.08 \quad 48$. Provides nutritional snacks

6.17 49. Environment is safe, "baby proofed"

3.75 50. Sometimes will interfere with appropriate activity if it is likely to get B messy or soiled

$3.58 * * 51$. Disturibed by B becoming messy during feeding, these concerns sometimes interfere with feeding

1.67 52. M fails to interrupt activity by her $B$ that is likely to be dangerous

8.58 *53. Well resolved interaction with B -- interaction ends when B is satisfied (also consider termination of ongoing interactions that $B$ is enjoying)

$9.00 * * 54$. Interactions revolve around B's tempo and current state

2.42 55. Repeated series of interventions in scarch for best method to satisfy B, often resorts to trial and crror

4.33 56. Very concerned that baby is well-dressed and attractive at all times.

1.25 57. Subjects B's to constant and unphased barrage of stimulation, B overwhelmed

8.08 58. Aware of B's moods and fluctuations in state

1.75**59. Rough or intrusive in interactions wi,, $B$ 
8.75 60. When $B$ is distressed, $M$ is able to quickly and accurately identify the source

$8.08 * 61$. Seems to be aware of B even when not in the same room

2.17 **62. Preoccupied with interview - seems to ignore B

8.83 *63. Monitors and responds to B even when engaged in some other activity such as cooking or having a conversation with visitor

8.17 64. Responds immediately to cries/whimpers

2.58 65. Not skilful in dividing her attention between $B$ and competing demands thus misses B's cues

8.25 66. Arranges her location so that she can perceive B's signals

7.67 **67. When in the same room as B, provides B with unrestricted access to her

$1.42 * 68$. Often appears to "Tune out" and not $\cdot$ tice distress or bids for attention

3.92 69. Seems overwhelmcd, depressed

3.33 70. Responds accurately and promptly to signals of distress, but often ignores (is unresponsive to) signals of positive affect

2.08 71. When $B$ is in a bad mood or cranky, $M$ often will place $B$ in another room so that she will not be disturbed

4.33 72. At first glance, home shows little evidence of presence of infant.

$1.50 * * 73$. Content and pace of interactions with the baby seem to be set by mother rather than according to baby's responses.

$1.58 * * 74$. Often misses "slow down" or "back off" signals from baby during face-to-face play.

3.83 75. Attempts to involve baby in games or activities that are obviously beyond the child's current capability.

3.50 76. Sometimes will break off from the ctild in mid-interaction to speak to visitor or attend to some other activity that suddenly comes to mind.

3.42 77. Often "parks" the baby in front of the television in an attempt to keep her entertained.

2.42 78. Naptimes are determined by mother's convenience rather than the immediate needs of the baby, (determined from interview). 
5.58 79. Frequently repeats words carefully and slowly to the baby as if teaching meaning or labelling an activity or object.

2.67 80. Seldom speaks to the baby directly.

4.25 81. Makes frequent use of playpen in order to permit carrying out normal household chores.

5.50 82. Feels at ease leaving the child with a babysitter in the evening.

3.50 83. Leaves the room without any sort of "signal" or "explanation" to the baby, e.g. "I'll be back in just a minute."

2.67 *84. Sometimes seems to treat baby as an inanimate object when moving her around or adjusting her posture.

5.08 85. Is very reluctant to leave the baby with anyone other than husband or close relative (determine from interview).

6.25 86. Encourages interaction of baby with visitor. e.g. Invites visitor to hold baby; ensures that baby is "introduced" to visitor, i.e. "Look who's here!"

3.08 *87. Seems awkward and ill at ease when interacting directly with the baby face-toface.

2.33 **88. Often seems to forget baby is present in the room during interaction with visitor.

5.75 89. Very alert to "dirly diaper"; seems to change diapers as soon as indication of need.

6.08 **90. Olten brings toy or other object within baby's reach and attempts to interest her in it.

Starred items distinguished between securely and insecurely attached dyads

$* \mathrm{p}<.10$

${ }^{* *} \mathrm{p}<.05$ 


\author{
Domain-Specific Attachment Behaviour \\ [From the Attachment Q-Sort - Waters (1986)] \\ D. Pederson \& G. Moran (1994)
}

Secure-Base [14 items]

3. When he is upset or injured, child will accept conforting from adults other than his mother.

15. Child is willing to talk to new people, show them toys, or show them what he can do, if mother asks him to.

21. Child keeps track of mother's location when he plays around the nouse. (e.g., Calls to her now and then. Notices her go from room to room. Notices if she changes activities.)

25. Child is easy for mother to lose track of when he is playing out of her sight.

33. Child sometimes signals mother (or gives the impression) that he wants to be put down, and then fusses or wants to be picked rigr: back up.

34. When child is upset about mother leaving him, he sits right where he is and cries. Doesn't go after mom.

36. Child clearly shows a pattern of using mother as a base from which to explore. (c.g., Moves out to play. Returns or plays near her. Moves out to play arain, etc.)

47. Child will accept and enjoy loud sounds or being bounced around in play, if mother smiles and shows that it is supposed to be fun.

60. If mother reassures him by saying "It's ok" or it won't hurt you", child will approach or play with things that initially made him cautious or afraid.

71. If held in mother's arms, child stops crying and quickly recovers aftcr being frightened or upset.

75. At home, child gets upset or cries when mother walks out of the room. :May or may not follow her)

80. Child uses mother's facial expressions as a good source of information when something looks risky or threatening.

88. When something upsets the child, he stays where he is and cries.

90. If mother moves very far, child follows along and continues his play in the area she has moved to. (Doesn't have to be called or carried along; doesn't stop play or get upset)

\title{
Affective Sharing [3 items]
}

14. When child finds something new to play with, he carries it to mother or shows it to her from across the room.

70. Child quickly greets mother with a big smile when he enters the room. (Shows her a toy, gestures, or says "Hi Mommy")

86. Child tries to get mother to iusitate him, or quickly notices and enjoys it when mom imitates him on her own. 
Compliance [6 items]

1. Child readily shares with mother or lets her hold things if she asks to.

18. Child follows mother's suggestions readily, even when they are clearly suggestions rather than orders.

19. When mother tells child to bring or give her something, he obeys. (Do not count refusals that are playful or part of a game unless they clearly become disobedient)

32. When mother says "no" or punishes him, child stops misbehaving (at least at that time). Doesn't have to be told twice.

41. When mother says to follow her, child does so.

(Do not count refusals or delays that are playful or part of a game unless they clearly become disobedient.)

65. Child is ea:ily upset when mother makes him change from one activity to another. (Even if the new activity is something child often enjoys)

\section{Enjoyment of Physical Contact [5 items]}

11. Child often hugs or cuddles against mother, without being asked or invited to do so.

28. Child enjoys relaxing in mother's lap.

44. Child asks for and enjoys having mother hold, hug, and cuddle him.

53. Child puts his arms around mother or puts a hand on mom's shoulder when she picks him up.

64. Child enjoys climbing all over mother when they play.

\section{Fussy-Difficult Domain [14 items]}

2. When child returns to mother after playing, child is sometimes fussy for no clear reason.

8. When child cries, he cries hard.

9. Child is lighthearted and playlul most of the time.

10. Child often cries or resists when mother tukes him to bed for naps or at night.

13. When the child is upset by mother's leaving, he continues to cry or even gets angry after mother is gone.

20 Child ignores most bumps, falis, or startles.

26. Child cries when mother leaves him at home with babysitter, father, or grandparert.

30. Child easily becomes angry with toys.

38. Child is demanding and impatient with mother. Fusses and persist. inless mom does what he wants right away.

61. Plays roughly with mother. Bumps, scratches, or hites during active play. (Does not necessarily mean to hurt mom)

62. When child is in a happy mood, he is likely to stay that way all day.

74. When mother doesn't do what child wants right away, child behaves as if mom were not going to do it at all. (Fusses, gets angry, walks off to other activities, etc.)

79. Child easily becomes angry at mother.

81. Child cries as a way of getting mother to do what he wants. 
DYAD:

PLAY EPISODE: VISIT ONE or VISIT TWO

AGE:

CODER/DATE:

\section{CRITTENDEN SCALE OF MOTHER-INFANT INTERACTION MATERNAL BEHAVIORS}

*Score on the basis of a single instance

Facial Expression

1. $\quad$ Mutual smiling.

2. Alert, or responsive, or attentive, or appropriate for the situation and the baby's response.

3. Inappropriately happy (happy when the baby is displeased, or when the baby can't see the mother's face, or too exaggerated for the situation, or unchanging in spite of situational change).

4. Blank, impassive, or expressionless.

5. Looks away from baby and toys (and not to camera); looks at nothing.

Vocal Expression

6. Slow, gentle, rhythmic tone - appropriate for the baby's age and state.

7. Flat voice tone or mother rarely speaks.

8. Pseudo-appropriate voice tone - uses infant-elicited intonation and rhythm but is exaggerated, or fast-paced, or artificial sounding - may be used to express rather sharp demands of the baby and does not usually match the baby's affect.

9. Commands are behaviorally inconsistent (e.g., sweet voice and insistent hands, sharp voice nuatched with a disarming smile, gentle insistence combined with brief indications of disgust when the baby does not comply).

10. Commands or requests, when given, are consistent with the rest of the mother's behaviour.

\section{Position and Body Control}

11. Sits so can't see baby's face most of the time.

12. Sits awkwardly or as though ready to leave; positions the baby awkwardly (baby is suspended from the shoulders, held on mother's lap but away from her body, or seated alone but unsteadily and unsupported).

13. Holds baby comfortably, or positions it comfortably on the floor, so that both toys and mother's face are visually available.

14. *Adjusts the baby's body for the baby's comfort or ease of toy play.

15. "Manipulates the baby's body, arms, or legs to accomplish something the mother wants. 
16. *Mother suddenly and unexpectedly moves toys or her face in close to the baby's face, producing a startle, wince, or withdrawal (unlike the "Boo!" in the common game "Ah, Boo!", this behaviour is not part of a rhythmic game format).

17. Mother spends most of the interaction with her face 2 feet or more from the baby's face or her body beyond arm's range from a seated child's.

\section{Expression of Affection}

18. Affectionate behaviour - gentle patting, stroking, or tickling, usually on the baby's body or outer parts of the face, producing pleasure in the baby.

19. *Pseudo-affectionate behaviour similar to the affectionate behaviour but is irritating to the baby and is more like jabbing, poking, or pinching (does not include nose cleaning), and produces a startle, wince, or withdrawal - may be done with an object.

20. *Repeats pseudo-affectionate behaviour.

21. Expresses no affection (or pseudo-affection) to the baby; affection is conspicuously absent.

22. *Mother pulls back from, cuts short, avoids, or appears uneasy with physical or visual closeness initiated by the baby.

Pacing

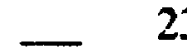

23. Contingent pacing - mother is sensitive to the baby's rhythms and signals; gives baby time to respond before stimulating him further; clear effort by mother to create turn-taking dialogue.

24. Non-contingent pacing - mother is involved and active but her pacing is not contingent on the baby's rhythms or cues; pacing is often, but not always, fast-paced or intense.

25. Long, empty pauses between instances of stimulation - maternal involvement in the infant's play is only sporadic and does not involve turn-taking.

\section{Control}

26. Initiate: almost no activities.

27. Leaves the baby doing nothing during much of the interaction.

28. Takes turns acting or vocalizing with the baby.

29. Baby controls the play without the involvement of the mother (mother is either totally uninvolved or functions only to keep the infant playing with the toy; she is not playing with the baby) or no play occurs.

30. Either the mother or the baby chooses the activity; however, they both are clearly enjoying it and taking turns playing together. 
31. Mother controls the choice and duration of the activity in spite of clear signals that the activity is not liked by the in.ant, has been continued too long, or is too difficult.

32. Responds positively to eye contact.

33. Modifies her behaviour when the baby expresses a preference or displeasure (the change must be an attempt to meet the baby's need, not just an attempt to stave off crying while still pursuing the mother's goals).

34. *Interferes with the baby's play to change or correct an activity or to limit the baby's range of activity.

35. *Does not respond to baby's initiation (offer, reach, eye contact, vocalization, point, etc.) in a way that furthers the interaction - either ignores it or passively accepts it without overt involvement (e.g., returns eye contact but doesıi $i t$ add smile or vocalization).

36. *Keeps an interesting toy just out or reach or takes away an object of baby's interest.

37. ${ }^{*}$ Makes baby wait and watch while mother performs an activity (this does not refer to a brief demonstration, but rather, instances in which the baby wants involvement but the mother ignores or prevents it).

38. Gives the baby an opportunity to explore the toy or room freely and yet still maintains interest and attention.

Choice of Activity

39. Chooses developmentally appropriate activities.

40. Makes demands beyond the baby's developmental level.

41. Offers stimulation far below the baby's developmental or interest level.

42. Appears unable to think of things to do with the baby (inappropriateness of choices is not an issue here).

\section{INFANT CODING DEVICE}

Involvement with Mother and Activity

43. Responds co-operatively to maternal requests (e.g., smile, brightens, vocalizes. activates toy or body, carries out request).

44. Repels mother or offered objects by wincing, arching back, pushing away with hands and feet, throwing out arms and legs, turning away. Usuasly does several of these at once.

4.. Refuses to let go of loys when mother reaches for them.

46. Initiates little or no contact with mother or toys.

47. Imitates mother or answers mother - infant's responses are clearly related to mother's behaviour (e.g., In:itates vocalization or hand moveinents, vocalizes in turn, plays give-and-take).

48. Responds to mother's plan for the interaction with frustration, opposition, or conflict. 
49. Gives delayed responses or very low-key responses to maternal initiatives; often does not acknowledge maternaı behaviour.

50. Seeks or maintains contact with the mother through any means (e.g., vocalization, eye contact, smiling, touching, give-and-take of toys).

51. Makes little or no protest when left with nothing to do.

52. Expresses anger either directly or through toy play (e.g., fisting hands, throwing toys, angry face, random hitting or banging of toys).

\section{Facial Expression}

53. Attends visually to toys and/or mother; infrequent gaze aversion.

54. Looks bored (i.e., vacant expression, eyes wide open but unseeing and unblinking or downcast and dull, glazed look, minimal change of expression).

- 55 . Alternates grimaces with pleasant or expressionless face (unlike the blank face described in the item above, in this case the eyes are alert but turned fully away from mother).

56. Avoidance of eye contact hy letting eyes drift just out of a direct gaze line; a subtle means of evasion $i_{1}$ which the infant appears available arid yet consistently eludes opportunities for contact.

57. Shows playfulness (e.g., coy, teasing looks, pleased with outcome of activities), or shows serious concentration on or attention to activity.

58. factively avoids eye contact; turns head av ay fully from mother. usually in response to disliked behaviour.

59. Displays brief expressions of resignation (i.e., shrug of shoulders, pursing of lips, dropping of eyes, etc.) in response io lack of activity rather than to disliked activity. Expressions are fleeting and generally not visible to or directed at mom.

60. Responds to eye contact with a sustained look, followed by brightening or smiling.

\section{Vocal Expression}

61. Vocalizes with pleasure (e.g., coos, gurgles, babbles, laughs, talks).

62. Cries or protests more than uses pleasure vocalizations.

63. Sighs, makes uninterpretable sounds, or is silent.

\section{Rhythmicity}

64. Changes hehaviour abruptly; does not make smooth transitions from one compied behaviour to the beginning of another; activities seem cut off.

65. Responds rapidly and negatively to mother's behaviour.

66. Moves lethargically and slowly; long gaps between activities or movements. 

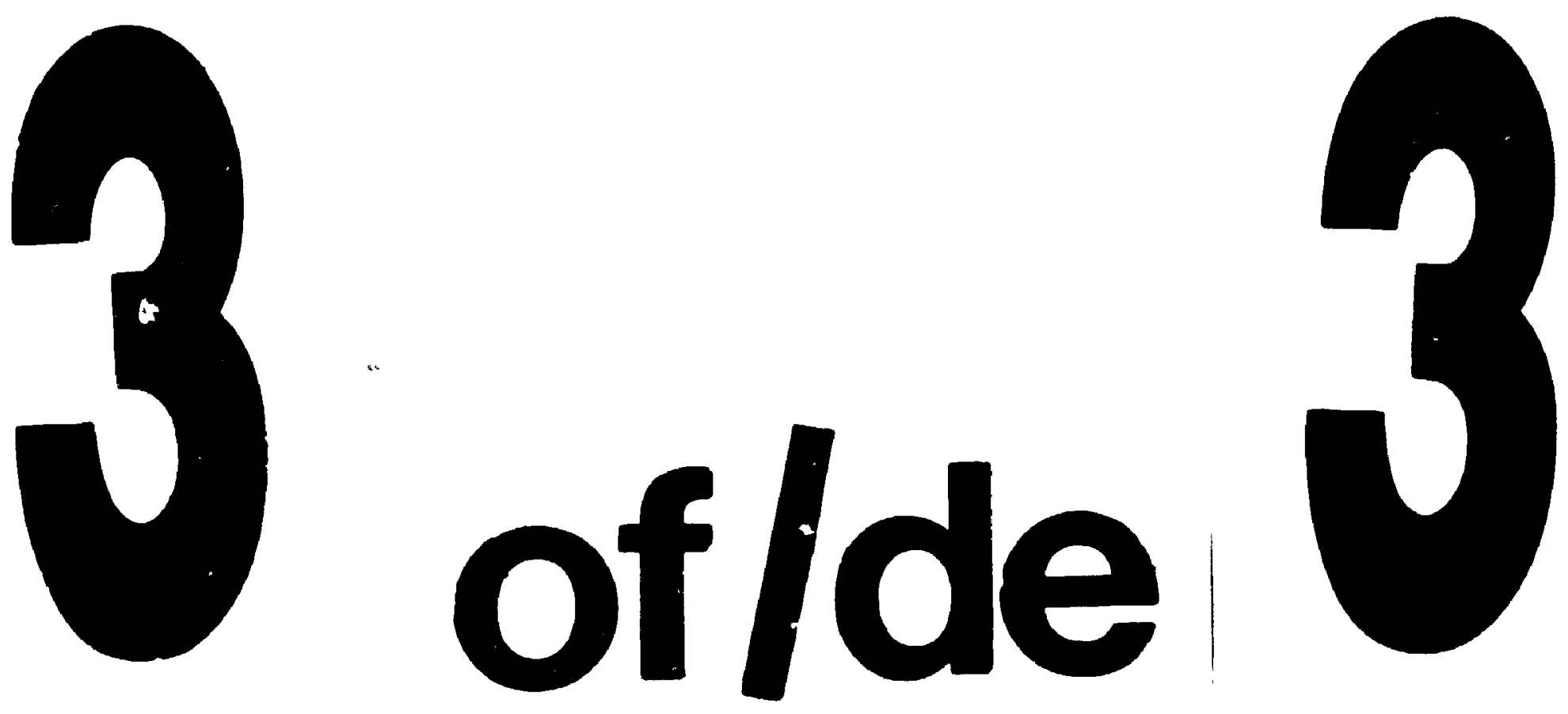

PM-1 31/2"X4" PHOTOGRAPHIC MICROCOPY TARGET NBS 1010a ANSI/ISO \#2 EQUIVALENT

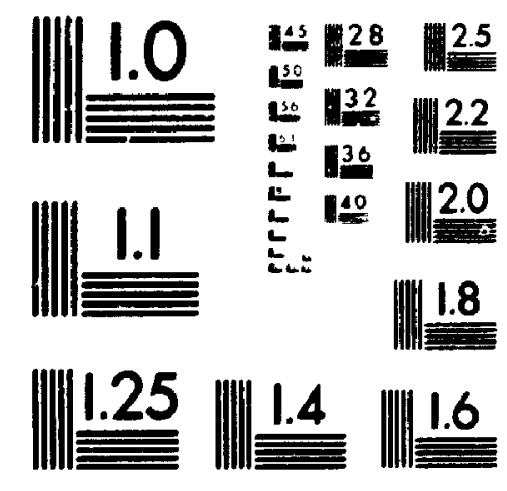


67. Shows smooth transitions between activities; each activity is completed and the infant's interest drops before the next activity is begun.

68. Changes facial expression in response to changes in interest in activity (usually bright-eyed or attentive with briefer expressions of surprise, pleasure, etc.).

69. Gives multiple, related positive cues (e.g., reach, eye contact, smile, vocalize).

70. Lises isolated cues which seem partial, tentative, or ambiguous (e.g., reaches for mother with hand but does not look at her, smile or vocalize); cues are only part of what would usually be a "package" of coordinated cues.

Body Tone and Co-ordination

71. Responds to stimulation with rigidity and resistance. Whole body is involved.

72. Moves smoothly involving necessary parts of body; neither rigid nor lethargic.

73. Minimal involvement of body parts in movement (e.g., fingers toy but does not use full hand or arm and shoulder).

74. Slumped body posture; rag-doll responses to being moved; flaccid muscle tone.

75. Coordinates activity toward a goal.

Reaction to Physical Contact

76. Struggles against awkward positioning.

- 77. Resists maternal manipulation or adjustment of infant's body with whole body (e.g., arches back, kicks feet, refuses to bend, stiffens).

78. Limply accepts maternal manipulation or adjustment of his body; limply leans against mother without either sinking in or pulling back.

79. Assists mother when she manipulates or adjusts the infant's body

80. Withdraws when body space is invaded (e.g., blink, throw head back, thrust arms and legs out, turn away, pull back).

81. Remains impassive to naternal attention or closeness or does nct have such contact. 


\title{
MASTERY MOTIVATION TASKS
}

\author{
6-Month Mastery Tasks
}

Task 1 - Effect Production (EP1)

Chime Ball: This Fisher Price spherical toy has a solid green lower half and a clear upper half. It makes noises when hit or rolled about, and has four small animals inside which move.

\section{Mastery Coding}

1 - look at apparatus

- [Note that this code has been changed from 0 to 1 for all tasks - 0 will not be used

- only touch apparatus

- only mouth apparatus

- only passively hold apparatus

2 - watching horses moving

- mouthing and looking

- throw toy

- push away or drop off table

- offer, give

3 - two hand grasp

- reach for the apparatus

4 - push, hit, bat, shake

5 - make bell ring or horses move

7 - end of task

8 - look at experimenter

- vocalize to experimenter

- look at mother

- vocalize to mother

- leans back

9 - engage in non-task object

- other 
6-Month Mastery Tasks

Task 2 - Problem Solving (PS1)

Squeeze toy behind barrier: A colourful green sq ueeze tny is placed behind a clear plastic rectangular barrier within reach of the child, toy can be obtained by reaching around the barrier.

\section{Mastery Coding}

1 - look at apparatus

- only touch apparatus

- only mouth apparatus

- only passively hold apparatus

2 - manipulate plastic toy

- examine toy or reach for toy when not behind barrier

- bang toy, or barrier when toy is not behind it

- shake toy

- hit toy

- drop toy

- throw toy, or barrier when toy is no longer behind it

- offer, give toy

3 - hit barrier, flip barrier but does not reach for toy

- hold edge of barrier, may mouth or try to put in mouth

- scratches barrier, reaches toward barrier when toy is behind

4 - reaches behind barrier

- replaces toy behind barrier

5 - gets toy

7 - end of task

8 - look at experimenter

- vocalize to experimenter

- look at mother

- vocalize to mother

- leans back

9 - engage in non-task object

- other 
6-Month Mastery Tasks

Task 3 - Practicing Emerging Skills (PES1)

Plastic objects in tub: A grey plastic bucket containing small plastic objects (monkey, play people, lion, block) is placed upright in front of baby. The child can obtain the objects by removing them, or by tipping the basket over.

\section{Mastery Coding}

1 - look at apparatus

- only touch apparatus

- only mouth apparatus

- only passively hold apparatus

2 - manipulates object or empty tub

- examines object or empty tub or reaches for object/tub

- bang object or empty tub

- shake object or empty tub

- hits object or empty tub

- drops object or empty tub

- rejects object or tub

- offer, give

3 - shake, push, pull, etc. tub with objects in

- hold tub with objects in

- reach for tub with objects

4 - tip tub, grasp or lift objects in tub

- return object to tub

5 - remove object from tub

7 - end of task

8 - look at experimenter

- vocalize to experimenter

- look at mother

- vocalize to mother

- leans back

9 - engage in non-task object

- other 
6-Month Mastery Tasks

Task 4 - Effect Production (EP2)

Activity Centre: This Fisher Price toy is a plastic rectangular board with a variety of moveable parts which produce noises and colours when manipulated correctly. The mirror on it is covered. It is presented upright to the infants, and one of the effects is demonstrated.

\section{Mastery Coding}

1 - look at apparatus

- only touch apparatus

- only mouth apparatus

- only passively hold apparatus

2 - examine, back or handle, watching manipulandum

- bang

spinning around

- shake

- hit board

- push away

3 - examine board or manipulandum

- hold board or manipulandum

- reach

4 - push, hit, slide, etc. appropriate manipulandum

5 - produce effect

7 - end of task

8 - look at experimenter

- vocalize to experimenter

- look at mother

- vocalize to mother

- leans back

9 - engage in non-task object

- other 
6-Montn Mastery Tasks

Task 5 - Problem Solving (PS2)

Animal on string: This is a brightly coloured turtle attached to a string. The free end of the string is placed in front of the child, the animal is placed out of reach. The infant can obtain the toy by pulling the string.

\section{Mastery Coding}

1 - look at apparatus

- only touch apparatus

- only mouth apparatus

- only passively hold apparatus

2 - manipulates string

- examines turtle, string

- bangs turtle

- shakes turtle, string

- hits turtle, string

- rejects turtle, string

- offer, give toy

3 - relates turtle and string

- holds turtle

- reaches for turtle at a distance, reaches for string

4 - pulls string but unaware that turtle comes closer

5 - pulls string and turtle approaches

7 - end of task

8 - look at experimenter

- vocalize to experimenter

- look at mother

- vocalize to mother

- leans back

9 - engage in non-task object

- other 


\section{6-Month Mastery Tasks}

\section{Task 6 - Practicing Emerging Skills (PES2)}

Eggs in carton: This Child Guidance toy consists of a yellow plastic egg carton and twelve plastic eggs. It is presented open, with six eggs in place, within reach of the child. The experimenter demonstrates that an egg can be obtained by grasping and removing it.

\section{Mastery Coding}

1 - look at apparatus

- only touch apparatus

- only mouth apparatus

- only passively hold apparatus

2 - roll egg, bang eggs together

- examine carton or eggs

- bang

- shake egg or empty carton

- hit, bat empty carton

- drop egg or empty carton

- push away, drop over side

- offer, give

3 - shake, push, pull, etc. carton with eggs inside

- hold or lift carton $:$ ith eggs inside

- reach for eggs or carton

4 - tip carton, grasp or pick eggs in carton, open carton

- replace eggs in carton

5 - get one or more eggs from carton

7 - end of task

8 - look at experimenter

- vocalize to experimenter

- look at mother

- vocalize to mother

- leans back

9 - engage in non-task object

- other 
13-Month Mastery Tasks

Task 1 - Effect Production (EP1)

Surprise Box: This is a rectangular box with five horizontal trap doors. Each door can be opened by operating one of five manipulanda: a pushbutton, sliding knob, switch, dial, or lever. Small plastic heads of animals pop up when the doors are opened.

1 - look at apparatus - Note that this code has been changed from 0 to 1 for all tasks - 0 will not be used

1 - only touch apparatus (any part)

- only mouth apparatus (any part)

- only passively hold apparatus

2 - manipulating animal inside, sliding box back and forth

- examine handle, bottom, back

- bang box

- shake box

- hit box or part of box

- drop box

- push away box

- offer, give box back

3 - wiggle door when opened or closed

- wiggle manipulandum with door open

- hold manipulandum, figure, door

- rear .1 for box, figure

4 - move manipulandum with door closed

- :lose door, try to close door

5 - make figure pop up by manipulating the manipulandum

6 - cannot code due to experimenter interference

or experimenter ;esetting the task

7 - end of task

8 - look at experimenter

- vocalize to experimenter

- look at mother

- vocalize to mother

- leans back

9 - engage in non-task object, cry, protest, stand up

- other - [baby is touching or manipulating the apparatus in some way but is looking elsewhere i.e. his mind is not on the task] 


\section{3-Month Mastery Tasks}

\section{Task 2 - Problem Solving (PS1)}

Farm Door: This small bright replica of a barn is produced by Fisher Price as part of its Play Family Farm. Double doors on the front open outward when a white plastic latch is unhooked, revealing the small plastic horse which has been hidden inside. A "mouing" noise is also produced.

1 - look at apparatus

1 - only touch apparatus

- only mouth apparatus

- cnly passively hold apparatus

2 - manipulates horse

- examines parts other than door or latch

- bangs, hits, or shakes barn, horse

- drops horse

- rejects barn or horse

- offer, give

3 - open upper door, play with latch or open door

- hold latch, door, upper door, horse

- reach for barn or into empty barn

- close door with horse outside of barn

4 - manipulate latch (opens/pulls but does not open door)

- baby's hand is inside the barn and so is the horse

- take horse out of barn

- replace horse in barn

- closes barn door with horse inside of barn, or tries to close

5 - open door, has to open latch and open door - can be either door as long as he opens the latch first

6 - cannot code due to experimenter interference or experimenter resetting the task

7 - end of task

8 - look at experimenter

- vocalize to experimenter

- look at mother

- vocalize to mother

- leans back

9 - engage in non-task object

- other [baby is touching the apparatus in some way but is looking elsewhere i.e. his mind is $I_{\text {s }} \mathrm{st}$ on the task] 


\section{3-Month Mastery Tasks}

Task 3 - Practicing Emerging Skillss (PES1)

Wooden Boat with pegs: This natural wood flatboat has three holes and a rectangular depression on it top surface. Fat wooden cylindrical pegs can be placed vertically in the holes, or laid horizontally in the depression.

1 - only look at apparatus

1 - only touch apparatus

- only mouth apparatus

- only passively hold apparatus

2 - roll, slide pegs, move boat, stack pegs out of boat

- finger hole, examine peg or boat

- bang peg on table

- shake peg or boat

- hit or bat peg or boat

- drop peg or boat on table

- push board or pegs away, drop over side

- offer, give

3 - place peg in centre,

- relate peg to boat (bang, push, etc.)

- stack pegs in boat

- hold peg over boat

- reach for peg or boat

4 - try to put peg in hole, touch peg to hole

- hold peg directly over hole

- remove peg from hole

5 - put peg in hole

6 - cannot code due to experimenter interference or experimenter resetting the task

7 - end of task

8 - look at experimenter

- vocalize to experimenter

- look at mother

- vocalize to mother

- leans back

- making a game out of throwing the pegs on the floor so that the experimenter has to pick them up

9 - engage in non-task object

- other [baby is touching the apparatus in some way but is looking elsewhere i.e. his mind is not on the task] 


\section{3-Month Mastery Tasks}

\section{Task 4 - Effect Production (EP2)}

Plastic Barn: This is a small, colourful barn which can be used to produce a variety of effects. A windvane rotates when hit and a duck quacks when squeezed, a cow, bird, dog, and horse emerge from behind doors when one of four manipulanda (lever, knob, switch, or dial) are operated. Some of the manipulanda also produce sounds (moo, quack, bark).

1 - look at apparatus

1 - only touch apparatus

- only mouth apparatus

- only passively hold apparatus

2 - manipulate, turn barn

- examine parts other than figures, door or manipulandum

- bang barn on table

- shake barn

- hit or bat barn

- drop

- push away

- offer, give

3 - move any figure or doors

- hold any manipulandum, figure or door

- reach for barn, figure

4 - move any of the manipulandum without producing effect

- close door

5 - produces any effect: make cow moo, figure move or disappear, duck quack, weather vane turn, etc.

6 - cannot code due to experimenter interference

or experimenter resetting the task

7 - end of task

8 - look at experimenter

- vocalize to experimenter

- look at mother

- vocalize to mother

- leans back

9 - engage in non-task object

- other [baby is touching the apparatus in some way but is looking elsewhere i.e. his mind is not on the task] 


\section{3-Month Mastery Tasks}

\section{Task 5 - Problem Solving (PS2)}

Detour Box: This large box was specially constructed for laboratory use, and contains a clear plexiglass panel which slides from side to side in its lower front wall. An attractive yellow plastic duck is flaced behind this barrier.

1 - look at apparatus

1 - only touch apparatus

- only mouth apparatus

- only passively hold apparatus

2 - manipulate, squeeze duck

- examine duck

- bang or shake duck

- hit duck, box

- drop duck on table

- throw duck away, push box away

- offer, give

3 - examine box, scratch, push on glass

- hold edge of glass

- reach for box

- reach hand into empty box

4 - slide glass barrier to make opening

- reach around barrier, try to get hand in to get duck

- replace duck

- close barrier

5 - reach around barrier and touch duck

- reach around barrier and grasp duck

- reach into box, remove duck

6 - cannot code due to experimenter interference or experimenter resetting the task

7 - end of task

8 - look at experimenter

- vocalize to experimenter

- look at mother

- vocalize to mother

- leans back

9 - engage in non-task object

- other [baby is touching the apparatus in some way but is looking elsewhere i.e. his mind is not on the task] 


\section{3-Month Mastery Tasks}

\section{Task 6 - Practicing Emerging Skillss (PES2)}

Shape Sorter: Made by Fisher Price, this white plastic box has four vertical doors on its front. Each door opens from a different side, and is painted with the shape and colour of the small block contained within (red circle, yellow rectangle, green triangle, blue square). On the top surface of the toy, abuve each door, is a hole cut in the shape of the block within.

1 - look at apparatus

1 - only touch apparatus

- only mouth apparatus

- only passively hold apparatus

2 - relate two blocks, slide box, biciks or push head

- examine blocks, figure head, box or finger hole

- bang, shake, hit box or blocks

- drop box or blocks

- reject box

- offer, give box back

3 - push door from hole, put blocks near holes,

- relate blocks to box

- hold block at door

- reach for the box, blocks

4 - move or wiggle door using the handle, put hand in chamber, try io put block in correct hole

- close door, replace block through door

5 - open door, remove block through door

- place block in correct hoie

6 - cannot code due to experimenter interference or experimenter resetting the task

7 - end of task

8 - look at experimenter

- vocalize to experimenter

- look at mother

- vocalize to mother

- leans back

9 - engage in non-task object

- other [baby is touching the apparatus in some way but is looking elsewhere i.e. his mind is not on the task] 
APPENDIX C

Schematic Diagram of Group Composition Interrater Reliabilities 
Schematic Diagram of 3 Cross-sectional Groups in Study 1 and 2 Longitudinal Groups in Study 2.

Study 1 - Relationships between babies and mothers during the first year.

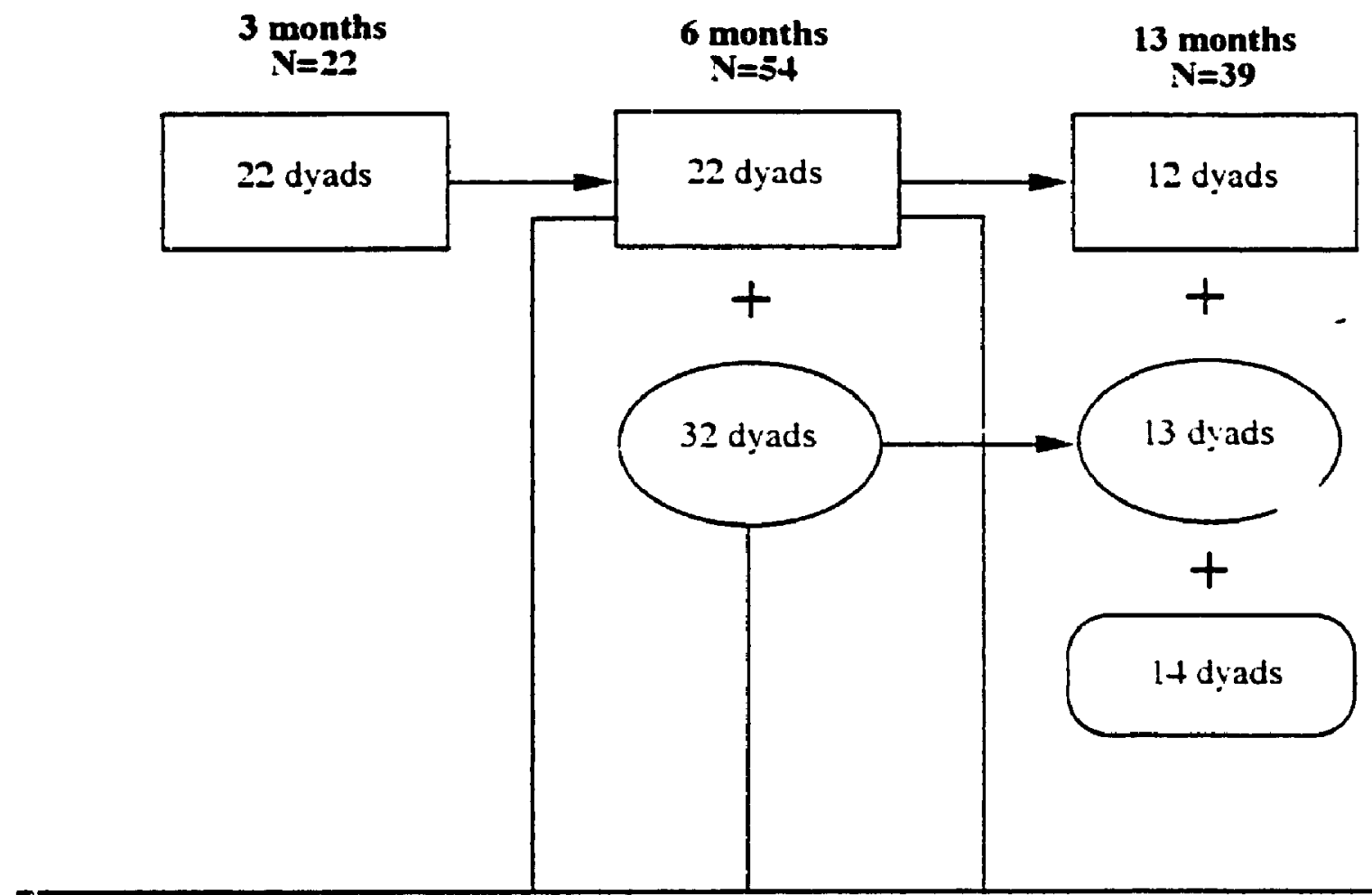

Study 2 - The benefits of early intervention.

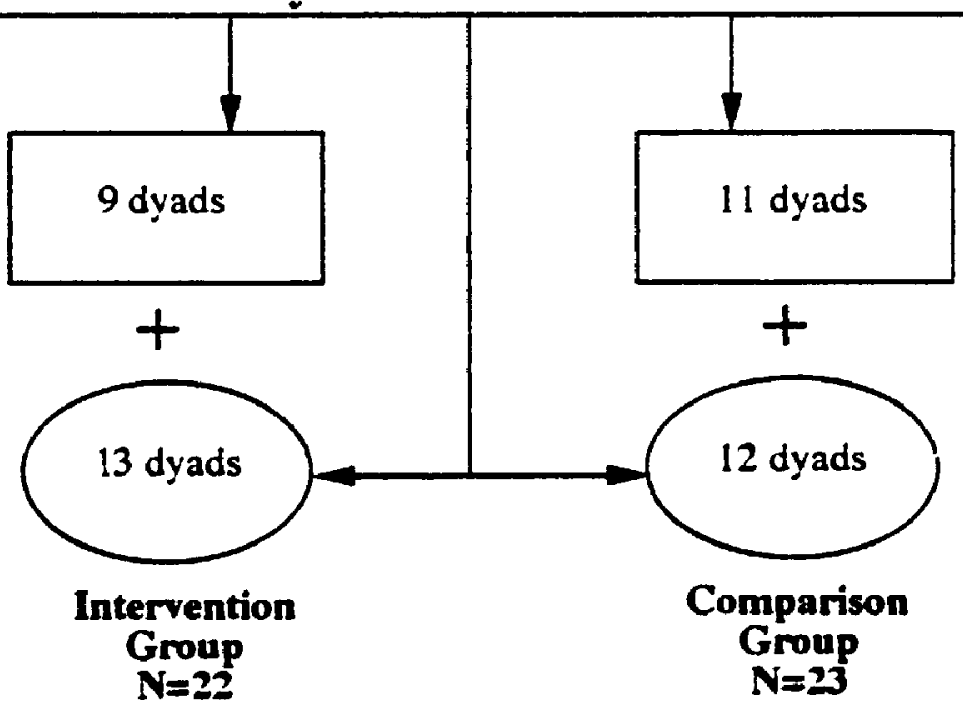


The diagram on the preceding page illustrates the makeup of 3 of the cross-sectional groups in Study 1 and the 2 longitudinal groups in Study 2. The shape of the box denotes the same dyads in each of the designated groups.

For example, in Study 2, 9 dyads [square box] in the Intervention group were randomly assigned from the 22 dyads [square box] in the cross-sectional sample at 6 months who had been seen originally at 3 months. Eleven dyads [square box] from this group of 22 were randomly assigned to the Comparison group. [Of the remaining 2 dyads from this group of 22, 1 dropped out of the study due to a marital dispute and 1 was not included in either group in Study 2 due to scheduling problems - data from the latter, was included only in the cross-sectional sample of 39 dyads.] Thirteen dyads (oval box) in the Intervention group were randomly assigned from the 32 dyads (oval box) seen originally at 6 months, 12 dyads (oval box) in the Comparison group were randomly assigned from these 32 dyads. [Of the remaining 7 dyads from this orignal group of 32,6 dropped out of the study for various reasons and 1 dyad had been assigned to the Intervention group but dropped out of sight before the first intervention visit could be set up. Contact was again made before the baby's first birthday and their data was included only in the cross-sectional sample of 39 dyads.]

The 23 dyads in the Comparison group were part of the cross-sectional sample of 39 dyads at 13 months along with the 2 dyads mentioned above plus 14 new dyads seen only at 13 months. None of these dyads had received intervention and therefore, the results of analyses performed on the 39 dyads at 13 months were considered to be equivalent to the analyses performed on the 54 dyads at 6 months and the 22 dyads at 3 months. Analyses were conducted only within each group as in typical cross-sectional samples. No statistical analyses were done across the groups since they were not completely independent groups. However, the results within each cross-sectional group generated hypotheses that could be tested in the smaller longitudinal samples and in future studies.

Longitudinal data was available from 2 different groupings of dyads who were also part of the 3 cross-sectional samples listed above. The first grouping is readily apparent in the diagram - the 22 dyads seen at both 3 months and 6 months. The second grouping of dyads seen at 6 months and 13 months is not as readily apparent in the diagram but consisted of the Comparison group dyads plus the 2 dyads seen at 6 and 13 months but not included in the Comparison group.

And finally, a set of analyses to test specific hypotheses were performed on a sample of all dyads assessed at 13 months - this grouping of 61 dyads included the 39 dyads from the cross-sectional sample plus the 22 dyads from the Intervention group. 
Interrater Reliabilities

Variables

Maternal variables

MBQS

AGRS

HOME

EAS (Attentive)

EAS (Talk)

EAS (Positive)

EAS (Negative)

CARE**
3 months

.93

.82

.93

.84

.83

.72

.73

.67

.96

.94
$\underline{I}^{*}$

6 months 13 months

97

.93

.95

.86

.82

.74

.71

$.75 \quad .76$

Child variables

AQS

Attachment classification*** IBR (affect/arousal) .87

IBR (task orientation)

MM (exploratory behaviour)

MM (task persistence)

Vocalizations

Communicative Acts

* Pearson correlation coefficient

* Kappa

*** Agreements

Agreements + Disagreements

MBQS = Maternal Behaviour Q-sort

AGRS = Ainsworth Global Rating Scales

HOME = Home Observation for Measurement of the Environment

EAS = Emotional Availability Scale

CARE = Child-Adult Relationship Experimental Index

AQS = Attachment Behaviour Q-sort

IBR = Infant Behaviour Record (Bayley Scales)

MM = Mastery Motivation Task 
APPENDIX D

Comparison of the two measures of infant temperament 


\section{Comparison of the Two Measures of Infant Temperament}

Since the relationship of infant temperament to maternal sensitivity and to infant attachment is of prime interest in several of the hypotheses being tested, the following analyses were used to examine the validity of the two measures of temperament for the population in the current study. Factor analyses using the principal-component method were carried out on boih measures. Since sample sizes were small, caution must be exercised in interpreting the results of the factor analyses, but nevertheless, results appear comparable to those reported in the literature (Matheny, 1980; Matheny \& Wilson, 1981; Kaplan, Jacobson, \& Jacobson, 1991).

The Infant Temperament Questionnaire Revised (ITQR). The mother's perception of her child's temperament at each age was assessed using the ITQ-R devised by Carey and his associates $(1984,1991)$. Nine scores were obtained for the following temperament dimensions (Thomas \& Chess, 198i): (1) Activity level - motor activity during daily routines; (2) Rhythmicity - regularity of sleeping, eating, elimination; (3) Approach/Withdrawal - initial positive or negative response to a new stimulus; (4) Adaptability - ease of adjusting to new situations; (5) Intensity of Reaction - degree of response; (6) Quality of Mood - amount of positive or negative affect; (7) Attention Span and Persistence - degree to which interest is maintained or activity is pursued; (8) Distractibility - how easily ongoing behaviour can be shifted; at 3 and 6 months, the extreme points on the scale are reversed, so that problem behaviours correspond to low scores on distractibility (i.e. an infant who is not easy to soothe); and (9) Threshold of Responsiveness - degree of sensitivity to sensory stimulation. Scores on the 9 dimensions were factor analyzed to determine if mothers reported a common core of temperament at each age. For the sake of clarity, the scoring was inverted on six scales at 13 months, as suggested by Matheny and his colleagues (1981), so that high scores would represent the maximum attribute in each category (i.e. high attentiveness, high soothability, high adaptability, etc.). Since distractibility had a different behavioural meaning at 3 and 6 months than at 13 months, scores in this category were also inverted at these two ages.

Factor analyses were performed with Varimax rotation. Three factors with eigenvalues greater than one were extracted at 6 and 13 months. The first factor at both ages was largely defined by the categories of mood, approach/withdrawal, adaptability, and rhythmicity. Soothability and persistence also defined this factor at 6 months but not at 13 months. Thus, high scoring 6-month olds were reported by their mothers as happy, predictable in their sleeping and eating habits, easily adapting to new situations, willing to approach new stimuli, persistent, and easily soothed. By contrast, low scoring toddlers were reported as irritable, slow to adapt, withdrawing from new people and situations, and arrythmic. The first factor accounted for $32 \%$ and $23 \%$ of the variance in temperament scores at 6 and 13 months respectively. It was highly correlated with Thomas and Chess' (1984) measure of "difficult" temperament (sum of rhythmicity, approach, adaptability, mood, and intensity), $\mathrm{I}=-.73, \mathrm{p}<.001$, at 6 months, and $\mathrm{I}=-.93, \mathrm{~g}<.001$, at 13 months.

Four factors with eigenvalues greater than one were extracted at 3 months of age. The first factor, which accounted for $29 \%$ of the variance in scores, was largely defined by the categories of mood, attention/persistence, and soothability. Approach/withdrawal and adaptability defined a second factor which accounted for $19 \%$ of the variance in temperament 
scores. The second factor was significantly related to the "difficult" measure, $\underline{\mathrm{r}}=-.85, \underline{\mathrm{p}}<$ .001 .

At each age, one factor was largely defined by the category of activity, and accounted for approximately $15 \%, 16 \%$, and $19 \%$ of the variance at 3,6 , and 13 months.

The loadings for the rotated factors are presented in Table D.1. Visual inspection suggests that loadings are reasonably comparable at the 3 ages, indicating that a common temperament core was reported by the young mothers. Pearson product-moment correlation coefficients, used to compare both the pattern and magnitude of loadings across the three ages, supported this conclusion. Significant correlations signify similarities in the core temperament clusters across the specified ages (Tabachnick \& Fidell, 1989).

Correlation coefficients for factor loadings on a core temperament cluster that roughly corresponds to the difficult/easy dimension of temperament were:

$\underline{r}=.68 \mathrm{p}<.05$, for $3-6$ months,

$\underline{\mathrm{r}}=.61 \mathrm{p}<.10$, for $6-13$ months,

$\underline{I}=.67 \mathrm{Q}<.05$, for 3.13 months

Correlation coefficients for factor loadings on the activity dimension were:

$\underline{I}=.87, \underline{\mathrm{p}}<.01$, for $3-6$ months,

$\underline{\underline{r}}=.95, \underline{\mathrm{g}}<.001$, for $6-13$ months,

$\underline{\underline{r}}=.80, \underline{\mathrm{g}}<.01$, for $3-13$ months.

The Infant Behaviour Record (IBR). Following the lead of other researchers (e.g. Matheny, 1980), an objective measure of infant temperament was obtained through factor analysis of scores from the Bayley Infant Behaviour Record (principal components method with subsequent varimax rotation). Since small sample sizes were problematic in factor analysing the 25 behavioural dimensions used by Matheny (1980), an alternative approach suggested by Kaplan, Jacobson, \& Jacobson (1991) using only 16 behavioural dimensions (Numbers 1-8, 11-15, and 25-27) was employed. Item numbers from the IBR and their loadings are presented in Table D.2 together with the item numbers from the Louisville and Detroit studies. Three factors extracted at 3 months and at 13 months were similar in structure to the three primary clusters (emotionality, activity, and attentiveness/persistence) reported by Matheny (1980) for his Louisville sample of $\mathbf{4 0 0}$ twins and by Kaplan and her associates for their Detroit sample of 182 black, low-income infants. However, the same factor structure was not obtained at 6 months. The first factor extracted appears to represent both task persistence/attentiveness and test affect/emotionality, and in this way is similar to findings reported for a group of Mexican-American infants at 12 months (McGowan, Johnson, \& Maxwell, 1981).

Despite a seeming difference in factor structure at 6 months, significant correlations suggest similarities in factor structure across the three ages.

Pearson correlation coefficients computed on the loadings for Attentiveness/Persistence were:

$\underline{I}=.51, \mathrm{p}<.05$, for $3-6$ months,

$\underline{I}=.76, \underline{\mathrm{p}}<.001$, for $6-13$ months,

$\mathrm{I}=.81, \mathrm{~g}<.001$, for $3-13$ months; 
Table D.1

First-Factor Loadings for Infant Temperament Scale - Revised (ITQR)

\begin{tabular}{lccc}
\hline & First & factor & loadings \\
\cline { 2 - 4 } ITQR dimensions & 3 months & 6 months & 13 months \\
\hline Activity & & & \\
\hline Rhythmicity & & .64 & .57 \\
\hline Approach/withdrawal & $*$ & .54 & .75 \\
\hline Adaptability & $*$ & .59 & .75 \\
\hline Intensity & .56 & & \\
\hline Mood & .67 & .76 & .78 \\
\hline Attention/persistence & .86 & .73 & \\
\hline Distractibility & .73 & .78 & $23 \%$ \\
\hline Threshold &. .75 & & \\
\hline$\%$ Total variance & $29 \%$ & $32 \%$ & \\
\hline \hline
\end{tabular}

Note: Factor loadings less than .30 omitted.

* Loadings on Factor 2 were .83 and .81 respectively

$N=22 @ 3$ months, $N=54 @ 6$ months, $N=61 @ 13$ months 
Table D.2

Comparison of IBR Items with Clusters from the Louisville and Detroit Studies - at approximately one-year-of-3ge

Affect/emotionality

Item Item

No. Loading

\begin{tabular}{ll}
\hline Louisville & \multicolumn{1}{c}{ 7. General emotional tone } \\
Sample & 2. Responsiveness to examiner \\
& 4. Cooperativeness \\
& 13. Endurance \\
& 5. Fearfulness \\
& 6. Tension \\
Detroit & 2. Responsiveness to examiner \\
Sample & 5. Fearfulness \\
& 1. Responsiveness to persons \\
& 7. General Emotional tone \\
& 3. Responsiveness to mother
\end{tabular}

Attentiveness/Persistence

\begin{tabular}{llrrr} 
Louisville & 8. Object orientation & London & 12. & .85 \\
Sample & 12. Attention span & Sample & 8. & .80 \\
& 11. Goal directedness & & 13. & .80 \\
& 15. Reactivity & & 11. & .76 \\
Detroit & 12. Attention span & 4. & .70 \\
Sample & 11. Goal directedness & & 15. & .58 \\
& 13. Endurance & & \\
& 8. Object orientation & & \\
& 4. Cooperativeness & & \\
\hline
\end{tabular}

Activity

\begin{tabular}{lccrc}
\hline Louisville & 14. Activity & London & 14. & .86 \\
Sample & (21. Body motion)* & Sample & 25. & .83 \\
& 25. Level of energy & & 15. & .54
\end{tabular}

Detroit 14. Activity

Sample 25. Level of energy

6. Tension

15. Reactivity

Items are listed in order of the magnitude of their item loadings.

* Body motion was not rated in the Detroit and London studies. 
For Affect/Emotionality, correlation coefficients were:

$$
\begin{aligned}
& \underline{\mathbf{r}}=.81, \mathrm{~g}<.001, \text { for } 3-6 \text { months, } \\
& \underline{\mathbf{r}}=.71, \mathrm{p}<.01, \text { for } 6-13 \text { months, } \\
& \underline{\mathbf{r}}=.81, \mathrm{p}<.001, \text { for } 3-13 \text { months; }
\end{aligned}
$$

For Activity, correlation coefficients were:

$$
\begin{aligned}
& \underline{\mathbf{r}}=.55, \mathrm{p}<.05, \text { for } 3-6 \text { months, } \\
& \underline{\mathbf{r}}=.71, \mathrm{~g}<.01, \text { for } 6-13 \text { months, } \\
& \underline{\mathbf{r}}=.87, \mathrm{p}<.001, \text { for } 3-13 \text { months. }
\end{aligned}
$$

\section{Correlations between ITOR and IBR factor scores}

The two measures of temperament were compared through Pearson productmoment correlational analyses of factor scores generated for each child on both measures. There were very few significant correlations between the factor scores, and these were mainly marginal, indicating low congruence between the two sources. In general, reports by mothers and experimenters of 3-month-old and 13-month-old infants appeared to be more congruent than those by experimenters and mothers of 6-month-old infants.

At 3 months:

Infants reported by their mothers to be highly active during daily routines were seen by experimenters as active and energetic in the test situation, $\mathrm{I}=.43, \mathrm{p}<.05$.

Infants reported by their mothers to be good-humoured and happy, adaptable, persistent, and easily soothed were seen by experimenters as sociable, reactive, attentive and persistent in the test situation, $\mathrm{r}=.38, \mathrm{Q}<.10$.

At 6 months:

Infants described by an experimenter as being energetic, goal-oriented, somewhat interested in objects, and having good motor skills were reported by their mothers as good-humoured, willing to approach new stimuli, highly adaptable to new situations, rhythmic, and persistent, $\underline{I}=.25, \mathrm{p}<.10$.

Both mothers and experimenters described the same 6-month-old babies as intense, reactive, and somewhat fearful of approaching new stimuli, $\underline{r}=.24, p<.10$.

At 13 months:

Babies reported by their mothers to be happy, rhythmic, willing to approach new stimuli, and quick to adapt to new situations were described by the experimenter as social, happy, low in fear, $\underline{r}=.32, \mathrm{~g}=.01$, and as attentive/persistent in the testing situation, $\mathrm{r}=.28, \mathrm{p}<.10$.

Babies reported to be very active and intense by their mothers were also seen as active babies who reacted quickly to the test materials, $\mathrm{I}=.27, \mathrm{p}<.05$.

The degree of similarity in the two sets of factor scores were also compared through canonical analysis, which searches for the linear combination of scores in each set that will 
yield the largest correlation between the two sets (Cohen \& Cohen, 1975). At 3 months and at 13 months, results revealed significant canonical correlations between the first canonical variates, indicating substantial linkage between the two sets of factor scores $(\underline{I}=.74, \underline{p}<.05$ and $\mathrm{I}=.57, \mathrm{p}<.05$, respectively). Canonical correlations at 6 months were not significant. Again, because of small sample sizes, these findings must be interpreted with caution.

Overall, the results suggest that the ITQR and IBR scores obtained for the economically-disadvantaged dyads in this study are valid indicators of infant temperament-like characteristics. Composite ITQR and IBR scores were computed for use in further analyses. A composite ITQR score reflecting the difficult/easy dimension was obtained by averaging the sum of the five temperament dimensions (rhythmicity, approach, adaptability, mood, and intensity). This measure has been used in previous studies and thus allows a direct comparison of results. Composite IBR scores reflecting attention/persistence and affect/emotionality clusters were obtained by averaging the sum of scores on four behavioural dimensions (goal directedness, object orientation, attention, and reactivity) for the first cluster, and three behavioural dimensions (sociability toward the examiner, emotional tone, and cooperativeness) for the second cluster. These rating scales were previously selected by Matheny $(1976,1983)$ to estimate factors extracted from the IBR.

In the current study, the composite score estimating the affect/emotionality cluster of the IBR was used as the experimenter's rating of infant temperament. This composite together with composite score estimating the attention/persistence cluster are seen as an estimate of the unrotated first factor extracted in the factor analyses of the IBR. The composite score estimating the difficult/easy dimension from the ITQR was used as the mother's rating of infant temperament. A second composite score was obtained from the ITQR by averaging the sum of six temperament dimensions (scores were inverted to reflect high rhythmicity, high adaptability, high approach, high soothability, high persistence, and positive mood). These rating scales were selected to estimate the unrotated first factor extracted in factor analyses of the ITQR. Although this measure has not been used previously, ITQR unrotated first factors scores have been used by Matheny in comparisons of laboratory and maternal measures of infant temperament. This measure is seen as being roughly equivalent to the first two clusters obtained from the IBR; it was combined with the average of the two IBR composites to form the measure of homeostasis used in the study. 
APPENDIX E

Intervention 


\section{PROGRAM OF PREVENTION}

\section{RATIONALE:}

If maladaptation at the early stages of development is to be prevented the role of the mother and her ability to alter dysfunctional patterns of interaction must be addressed since direct intervention with the infant is limited by developmental constraints.

-Individual differences in maternal sensitivity are used as the basis for a brief intervention to inprove dyadic interaction by changing the mother's behaviour.

-When maternal behaviours are changed, child behaviour changes, which in turn changes mother's subsequent behaviour.

\section{GOAL:}

To increase the mother's sensitivity to her baby so that she reads his/her cues accurately and responds in a contingent and appropriate manner, thus facilitating the establishment of a secure infant-mother attachment relationship.

Subgoal 1: to reinforce the strengths already present in the mother's behaviour.

Subgoal 2: to increase the mother's awareness of how her behaviour influences the baby's behaviour

Subgoal 3: to increase the mother's awareness of her baby's cues and needs.

Subgoal 4: to establish positive experiences for both the mother and the baby.

\section{PROCEDURES:}

A 9-level hierarchy of parental interactional behaviours ranging from least to most sensitive behaviour (Clark \& Seifer, 1983) provides both the framework for examining maternal behaviour and the guidance for helping mothers to interact with their babies in increasingly more adaptive and mutually satisfying ways.

-Programs are individually tailored to reflect strengths in the interactions of each mother-infant pair since the reasons vary for problems experienced by young, socially disadvantaged mothers in achieving an easy exchange with their babies.

-Identified strengths (i.e. behaviours that are conducive to good interaction) are reinforced through praise; if mothers identify weaknesses, these can be modified through discussions of the videotaped one minute play sessions, and by modelling, and role-playing when appropriate. Immediate feedback is available to the mother regarding her own behaviour and its effect on her infant's behaviour, and with repeated viewing of the videotape, the mother becomes better able to focus on subtle interactive behaviours.

-Bi-weekly intervention sessions continue until the mother routinely interacts with her baby at Level 9 in the hierarchy of sensitive behaviours. Follow-up contacts are 
continued for evaluative purposes until the baby is 13 months old. Infants' seeds change quickly in this early period of development and mothers may require periodic "refresher" sessions to remain at Level 9 in the hierarchy of interactional behaviours.

-Mothers are assessed in terms of their current interactional behaviours using the 9-level hierarchy.

THE HIERARCHY (Clark \& Seifer, 1983, p.74-75)

1. Uninvolved includes frequent occasions of caretaking that are mechani-i l, minimal eye contact, minima! smiling, and brief or no apparent moments of delight in vaby's behaviors.

2. Forcing occurs when the mother verbally or physically demands that her child perform a particular behaviour. These interactions are characterized by high mother coercion. This consists of turning the child's head to establish eye contact, restraining the child's movements, and/or manipulating the child's posture.

3. Overriding occurs when the mother spontaneously inte; rupts the flow of behaviour or intrudes on the child's activity. These interruptions are not coercive, but simply direct the child's behaviour to a new path. They are more than simple elaborations of the child's behaviour in that they demand implicitly that the child engage in a new behaviour. This may consist of providing alternate forms of a game, prompting vocalizations, requesting imitation, or continuing to imitate when the infant is disengaging.

4. Involved is usually manifested through consistent eye contact or attempts at eye contact, mutual smiling or attempts at mutual smiling, obvious enjoyment of being with baby, and pleasure in what baby is doing.

5. Acknowledging is a response from the mother that indicates that she has noticed the baby's behaviour. This consists of an animated facial expression, verbal comment. head nodding, watching with appropriate waiting, and/or responsive caretaking.

6. Imitating is any maternal mirroring of child behaviour such as vocalizations, motor responses, or facial expressions.

7. Expanding consists of imitating a behaviour and adding a variation, or possibly chaining several behaviors describing the activity, inferring affect, asking questions, or describing larger contexts for behaviour.

8. Elaborating consists of commenting on baby's activities, describing the activity, inferring affect, asking questions, or describing larger contexts for behaviour.

9. Extended Engaging occurs when the mother interacts with her baby and demonstrates knowledge of when her baby will be receptive to interaction, when to introduce variety in play, and the ability to engage her baby for extended periods. 


\section{MATERNAL BEHAVIOURS OF INTEREST}

Some Positive Behaviours to reinforce:

-allows baby self-soothing behaviour (sucking, mouthing)

-consistent eye contact or attempts at eye contact

-cuddles baby when holding

-describes baby's activity or infers affect

-describes larger contexts for baby's behaviour, labels objects and actions

-engages in face-to-face play

-follows the baby's lead (e.g. makes synchronous responses)

-imitates baby's vocalizations and gestures

-maintains moderate level of arousal

-mother is animated in social interactions with baby (e.g. wide-eyed expression, smiles, vocalizes)

-mother's smile or look of animation is appropriate (not in response to baby's distress, etc.)

-mother touches baby affectionately (pats, kisses)

-mutual smiling or attempts at mutual smiling

-obvious enjoyment of being with baby, obvious pleasure in what baby ir doing -pays close attention to baby's non-vocal behaviour (e.g. pauses when baby averts gaze)

-plays typical infant games (eg. Itsy Bitsy Spider, I'm Gonna Get You)

-reads subtle cues of interest and fatigue (e.g. yawning, fidgeting, fussing) and

responds appropriately

-responds immediately ( $<2 \mathrm{sec}$.) to signals of distress and to positive signals

(smile, vocs.)

-responds to overarousal (laughing, crying) with comfort noises, soothing behaviors, reducing stimulation

-responds to underarousal by varying activity, e.g. chaining a behaviour to the baby's behaviour

-waits for the baby's response, waits until baby finishes response

Some Negative Behaviours to watch for:

-a great deal of prodding, face thrusting, or prolonged mouth kissing

-blank, impassive, or expressionless face

-excessive touching, talking, and head movements

expresses no affection to baby, affection seems false or is conspicuously lacking

-flat voice or mother rarely speaks

-interactions are determined by the mother, i.e. mother doesn't wait for the baby's

responses

-mother rarely waits until the baby looks at her before beginning a new interaction

-mother rarely stops interacting when the baby looks away

-mother has difficulty monitoring baby's signals

-mother has difficulty in allowing any breaks in the interaction

-pseudo-appropriate voice tone, artificial sounding

-restraining the cilild's movements, manipulating the baby's posture

-sits so can't see baby's face most of the time 
-teases baby with bottle or toy, e.g. holds toy out to baby, moves it away as baby reaches for it

-turning the child's head to establish eye contact

-when baby begins to fuss and turn away, mother holds baby's face in midline and attempts a new interaction

\section{Intervention Strategies to Help Mothers Move up the Hierarchy}

Uninvolved: minimal eye contact and/or minimal smiling

-have the mother carry her baby and note signs of hunger, discomfort, or contentment. -encourage mothers to recognize differences in crying behaviour so that they might not misinterpret the babies' cries as either caregiving failure or as an indication that the babies are intentionally trying to annoy them.

-emphasize the mother's position relative tu her baby and its effect on her own and her baby's behaviour

-have mother face her baby during play interactions so that each has easy access to eye contact

-have mother make eye contact and smile when her baby looks at her

-have mother make eye contact and vocalize when her baby looks at her and vocalizes

-have mother notice when her baby averts his/her gaze and stop smiling or vocalizing.

Forcing: excessive touching, talking, head movements, etc.

-showing the videotape without the sound may be effective if the mother engages in a great deal of prodding or face thrusting -have the mother wait until her baby looks at her and then imitate the baby's behaviour. To help mothers relax, assure them that the slowed-down exaggerated quality is the important aspect of imitation. If they feel self-conscious imitating some behaviors (e.g. hands or fingers in mouth, arm flailing) do not require that mothers imitate them.

Overriding: spontaneous interruption of the baby's ongoing behaviour or directing the baby's attention to a new activity.

-have mothers play conventional infant games such as "Tell me a story" [Mother asks the child to "tell a story," and then uses any facial expression, gesture, body movement, or vocalization as a piece of information for the story. She responds with comments such as "oh really," "you don't say," "imagine that," and "what else do you have to say?" Any baby response is sufficient to keep the game going.]

-have mothers wait for the baby to look at them before beginning the game, pause when the baby looks away, and wait until the baby looks at them to continue the game.

-use the "Watch, Wait, and Wonder" technique. [The baby is placed on the floor with some toys. The mother is asked to get on the floor with her baby and watch what he or she does. She is asked to not initiate activity and not to interfere with the baby.] 
Involved: mutual eye contact and mutual smiling, pleasure in what the baby is doing -strategies depend ur $\mathrm{n}$ the deficits in the mother's repertoire of interaction behaviors: some mothers may need to learn the importance of maintaining eye contact, how to read subtle cues of waning attention and fatigue, how to use specific infant attention-getting behaviors, and how to chain behaviors to sustain interest.

-have mothers learn to appreciate their infant's use of eye contact in initiating interaction by asking them to respond only to eye contact and to ignore all other behaviors for a short period of time.

-have mothers identify their baby's subtle cues of interest and waning attention by reviewing the videotapes for anticipation, yawning, glassy eyes, fidgeting. or fussing. (Turning off the sound may help mothers attend more closely to their baby's non-vocal behaviour.)

-if mothers show little or no game playing, demonstrate by playing typical infant games with the babies (Itsy Bitsy Spider, I'm Gonna Get You, Pat-a-Cake, etc.). -stress taking time to enjoy the baby and the importance of mutual enjoyment in interactions.

-help mothers recall feelings of delight and playfulness.

Acknowledging: mother notices her baby's behaviour and responds contingently with an appropriate gesture or vocalization.

-review the videotapes to identify and praise specific behaviors that were acknowledged witn a look of animation, a smile, or a verbal response.

-discuss how the frequency of an infant's behaviour is affected by the contingency of parental bet.aiour.

-place speciai emphasis on the exchange of appropriate cmotions since emotional signalling between infant and caregiver forms the basis for communicating needs, intentions, and satisfactions.

Imisating: Imitation of the baby is a very effective means of increasing maternal sensitivity. Mothers reinforce their baby's behaviour in ways that promote reciprocal interaction and enhance the baby's sense of effectance.

-mothers can be asked to imitate the baby in many different ways: first only gestures, then vocalizations.

-when reviewing the videotapes, particular attention is paid to the baby's affect during the interaction.

-discussion about the importance of shared emotional experiences begun in the previous level is continued.

-discussion also focuses on the role vocal imitation (or any contingent verbal response) plays in turn taking and on the importance of turn taking to language development.

Elaborating and Expanding: Adolescent mothers usually look after their babies' physical needs but often do not talk to their babies.

-mothers are encouraged to use a variety of strategies to increase their verbal interactions: 
(1) to expand on the baby's behaviour by imitating that behaviour and then chaining other behaviour to sustain the baby's interest.

(2) to talk to the baby describing what s/he is doing or how s/he is feeling.

(3) to label the objects and actions in which she and her baby are jointly involved. During dressing, feeding, bathing, mothers can label body parts and items of clothing as well as the baby's movements.

-mothers are encouraged to speak in a slow, exaggerated manner. The content of the speech is not as important as the way in which it is delivered.

Extended Engaging: mothers are able to modify existing interaction patterns and engage in novel means of interaction with their babies. Mothers at this level are considered to demonstrate the most sensitive behaviour. 


\section{REFERENCES}

Aber, J.L. \& Cicchetti, D. (1984). The socio-emotional development of maltreated children: An empirical and theoretical analysis. In H. Fitzgerald. B. Lester, \& M. Yogman (Eds.) Theory and research in behavioral pediatrics (vol. 2, pp. 147-199). New York: Plenum.

Abidin, R. (1983). The Parenting Stress Index Charlottesville, Virginia: Pediatric Psychology Press.

Ainsworth, M.D.S. (1972). Attachment and dependency: A comparison. In J.L. Gewirtz (Ed.) Attachment and dependency (pp.97-137). Washington, D.C.: Winston.

Ainsworth, M.D.S. (1982). Attachment: Retrospect and prospect. n C.M. Parkes \& J. Stevenson-Hinde (Eds.), The place of attachment in human behaviour (pp. 49-67). New York:Basic.

Ainsworth, M. \& Bell, S.M. (1974). Mother-infant interaction and the development of competence. In K.J. Connolly \& J.S. Bruner (Eds.) The growth of competence. New York: Academic Press.

Ainsworth, M.D.S., Bell, S.M. \& Stayton (1974). Infant-mother attachment and social development: "Socialization" as a product of reciprocal responsiveness to signals. In M.P.M. Richards (Ed.). The integration of a child into a social world. Cambridge, MA: Cambridge University Press.

Ainsworth, M., Blehar, M., Waters, E., \& Wall, S. (1978). Patterns of attachment: A psychological study of the strange situation.Hillsdale, N.J.: Erlbaum.

Ainsworth, M. \& Wittig, B. (1969). Attachment and exploratory behaviour of one year olds in a strange situation. In B.M. Foss (Ed.), Determinants of infant behaviour (Vol. 4, pp. 113-136). N.Y: Wiley.

Allen, D., Affleck, G., McGrade, B. \& McQueeny, M. (1983). Characteristics of the Home Observation for Measurement of the Environment Inventory in a sample of high-risk-developmentally disabled infants. Infant Behaviour and Development, 6 , 53-60. 
Anisfeld, E., Casper, V., Nozyce, M., \& Cunningham, N. (1990). Does infant carrying promote attachment? An experimental study of the effect of increased physical contact on the development of attachment. Child Development, 61, 1617-1627.

Antonucci, T. \& Levitt, M.J. (1984). Early prediction of attachment security: A multivariate approach. Infant Behaviour and Development, I, 1-18.

Bates, J. \& Bayles, K. (1984). Objective and subjective components in mothers' perceptions of their children from 6 months to 3 years. Merrill-Palmer-Quarterly, 30, 111 130.

Bates, J. (1987). Temperament in infancy. In J.D. Osofsky (Ed.). Handbook of infant development (2nd ed.pp.1101-1144). New York: Wiley.

Bates, J. \& Bayles, K. (1988). Attachment and the development of behaviour problems. In J.Belsky \& J.Nezworski (Eds.), Clinical implications of attachment. Hillsdale, NJ: Lawrence Erlbaum Assoc. (pp.41-94).

Bates, J., Freelanc, C., \& Lounsbury, M. (1979). Measurement of infant difficultness. Child Development, 50, 794-802.

Bates, J., Maslin, C. \& Frankel, K. (1985). Attachment security, mother-child interaction, and temperament as predictors of behaviour problem ratings at age three years. In I.Bretherton \& E.Waters (Eds.), Growine points in attacnment theory and research. Monographs for the Society for Research in Child Development. 50 (Serial No. 209, pp. 167-193).

Bayley, N. (1969). Manual for the Bayley Scales of Infant Development. New York: Psychological Corp.

Beckwith, L. (1988). Intervention with disadvantaged parents of sick preterm infants. Psychiatry, 51, 242-247.

Beckwith, L. \& Cohen, S. (1984). Home environment and cognitive competence in preterm children during the first five years. In A.W. Gottfried (Ed.) Home environment and early cognitive development (pp. 235-271). Orlando: Academic Press Inc.

Belsky, J. \& Isabella, R. (1988). Maternal, infant, and social contextual determinants of attachment security. In J.Belsky \& J.Nezworski (Eds.), Clinical implications of attachment. Hillsdale, NJ: Lawrence Erlbaum Assoc. (pp.41-94).

Belsky, J. \& Most, R.K. (1981). From exploration to play: A cross-sectional study of infant free-play behaviour. Developmental Psychology, 17, 630-639.

Belsky, J., Fish, M., \& Isabella, R. (1991). Continuity and discontinuity in infant negative and positive emotionality: Family antecedents and attachment consequences. Developmental Psychology, 27, 421-431. 
Belsky, J., Rovine, M.. \& Taylor, D. (1984). The Pennsylvania Infant and Family Development Project II: Origins of individual differences in infant-mother attachment: Maternal and infant contributions. Child Development, 55, 706-717.

Blehar, M.C., Lieberman, A.F., \& Ainsworth, M.D.S. (1977). Early face-to-face interaction and its relation to later infant-mother attachment. Child Development, 48 , 182-194.

Bohlin,G., Hagekull,B., Germer,M., Andersson,K., \& Lindberg,L. (1989). Avoidant and resistant reunion behaviours as predicted by maternal interactive behaviour and infant temperament. Infant Behaviour and Development, 12, 105-117.

Bornstein, M. \& Tamis-LeMonda, C. (1989). Maternal responsiveness and cognitive development in children. In M.Bornstein (Ed.) Maternal responsiveness: Characteristics and consequences. New Directions for Child Development, No.43. San Francisco: Jossey-Bass.

Bowlby, J. (1969). Attachment and loss: Vol. 1. Attachment. New York: Basic Books.

Bowlby, J. (1973). Attachment and loss: Vol. 2. Separation. New York: Basic Books.

Bowlby, J. (1980). Attachment and loss: Vol. 3. Loss, sadness, and depression. New York: Basic Books.

Brazelton, T.B. (1979). Evidence of communication during neonatal behavioral assessment. In M. Bullowa (Ed.) Before speech. Cambridge: Cambridge University Press.

Brazelton, T.B., Koslowski, B., \& Main, M. (1974). The origins of reciprocity: Early mother-infant interaction. In M.Lewis \& L.Rosenblum (Eds.) The origins of behaviour. New York: Wiley.

Bretherton, I. (1985). Attachment theory: Retrospect and prospect. In I.Bretherton \& E.Waters (Eds.), Growing points of attachment theory and research. Monographs of the Society for Research in Child Development, 50, (Serial No. 209) pp. 3-35.

Brooks-Gunn, J. \& Furstenberg, F.F. (1986). The children of adolescent mothers: Physical, academic, and psychological outcomes. Developmental Review, 6, 224-251.

Brooks-Gunn, J. \& Lewis, M. (1984). Maternal responsivity in interactions with handicapped infants. Child Development, 55, 782-793.

Bruner, J. (1982). The organization of action and the nature of the adultinfant transaction. In E.Z. Tronick (Ed.) Social interchange in infancy: Affect, cognition, and communication. Baltimore: University Park Press. 
Bruner, J. (1977). Early social interaction and language acquisition. In H.R. Schaffer (Ed.) Studies in mother-infant interaction. London: Academic Press.

Caldwell, B. \& Bradley, R. (1984). Home observation for the measurement of the environment. Little Rock: University of Arkansas.

Campos, J.J., Barrett, K.C., Lamb, M.E., Goldsmith, H.H., \& Stenberg, C. (1983). Socioemotional development. In P.H. Mussen (Ed.) Handbook of child psycholow, Vol. II. Infancy and developmental psychobiology (ed. by M. Haith \& J. Campos). New York: Wiley.

Carey, W.B. \& McDevitt, S.C. (1977). Revision of the infant temperament questionnaire. Pediatrics, 61, 735-739.

Carlson, D., LaBarba, R., Sclafani, J. \& Bowers, C. (1986). Cognitive and motor development in infants of adolescent mothers: A longitudinal analysis. International Journal of Behavioral Development, 9, 1-13.

Cicihetti, D. (1989). How research on child maltreatment has informed the study of child development: perspectives from developmental psychopathology. In D.Cicchetti and V. Carlson (Eds.) Child maltreatment: Theory and research on the causes and consequences of abuse and neglect (pp. 377-431). New York: Cambridge University Press.

Cicchetti, D. (1990). An historical perspective on the discipline of developmental psychopathology. In J.Rolf, A.Masten, D.Cicchetti, K.Nuechterlein, \& S.Weintraub (Eds.) Risk and protective factors in the development of psychopathology (pp.2-28). New York: Cambridge University Press.

Cicchetti, D. \& Greenberg, M.T. (1991). The legacy of John Bowlby. Development and Psychopathology, 3, 347-350.

Cicchetti, D., Ganiban, J. \& Barnett, D. (1990). Contributions from the study of high risk populations to understanding the development of emotion regulation. In K.Dodge \& J.Garber (Eds.). The development of emotion requlation (pp. 1-59). New York: Cambridge University Press.

Cicchetti, D., Toth, S., \& Bush, M. (1989). Developmental psychopathology and incompetence in childhood: Suggestions for intervention. In B. Lahey \& A. Kazdin (Eds.) Advances in clinical child psychology. N.Y.:Plenum Press.

Clark, G.N. \& Seifer, R. (1983). Facilitating mother-infant communication: A treatment model for high-risk and developmentally-delayed infants. Infant Mental Health Journal, 4, 67-82.

Cohen, J. (1988). Statistical and power analysis for the behavioral sciences, second edition. Hillsdale, NJ: Erlbaum Associates. 
Cohn, J.F. \& Tronick, E.Z. (1988). Mother-infant interaction: Influence is bidirectional and unrelated to periodic cycles in either partner's behavior. Developmental Psychology, 24, 386-394.

Crnic, K., Greenberg, M., Ragozin, A, Robinson, N., \& Basham, R. (1983). Effects of stress and social support on mothers and premature and full-term infants. Child Development, 54, 209-217.

Crittenden, P.M. (1981). Abusing, neglecting, problematic, and adequate dyads: Differentiating by patterns of interaction. Merrill-Palmer Quarterly, 27, 201-218.

Crittenden, P.M. (1988). Relationships at risk. In J.Belsky \& T.Nezworski (Eds.), Clinical implications of attachment theory (pp 136-174). Hillsdale, NJ: Erlbaum.

Crittenden, P.M. \& Ainsworth, M. (1989). In D.Cicchetti \& V.Carlson (Eds.), Child Maltreatment: Theory and Research on the Causes and Consequences of Child Abuse and Neglect. NY: Cambridge University Press.

Crittenden, P.M. \& Snell, M. (1983). Intervention to improve mother-infant interaction and infant development. Infant Mental Health Journal, 4, 23-31.

Crockenberg, S. (1981). Infant irritability, mother responsiveness, and social support influences on the security of infant-mother attachment. Child Development, 1, 169-176.

Crockenberg, S. (1985). Infant irritability, mother responsiveness, and social support influence on the security of mother-infant attachment. Child Development, 52 , 857-865.

Crockenberg, S. (1986). Are temperamental differences in babies associated with predictable differences in caregiving? In J.V. Lerner \& R.M. Lerner (Eds.), New Directions for child development: Temperament and social interaction during infancy and childhood (pp.53-73). San Francisco: Jossey-Bass.

Culp, R.E., Culp, A.M., Osofsky, J.D., \& Osofsky, H.D. (1991). Adolescent and older mothers' interaction patterns with their six-month-old infants. Journal of Adolescence, 14, 195-200.

Cummings, E.M. \& Cicchetti, D. (1990). Attachment, depression, and the transmission of depression. In M.T. Greenberg, D.Cicchetti, \& E.M. Cummings (Eds.), Attachment during the preschool years: Theory, research and intervention (pp. 339-374). Chicago: University of Chicago Press.

Delissovoy, V. (1973). Child care by adolescent parents. Child Today, 2, 23-25.

Dollard, J. \& Miller, N. (1950). Personality and psychotherapy. New York: McGraw Hill. 
Donovan, W.L., Leavitt, L.A. \& Balling, J.D. (1978). Maternal physiological response to infant signals. Psychophysiology,15, 68-74.

Dunham, P., Dunham, F., Hurshman, A \& Alexander, T. (1989). Social contingency effects on subsequent perceptual-cognitive tasks in young infarts. Child Development, 60, 1486-1496.

Egeland, B. \& Farber, E. (1984). Infant-mother attachment: Factors related to its development and changes over time. Child Development, 55, 753-771.

Egeland,B. \& Sroufe, A. (1981). Attachment and early maltreatment. Child Development, 52, 44-52.

Emde, R. (1988). Development terminable and interminable. I. Innate and motivational factors from infancy. International Journal of Psychoanalysis, 68, 3-22.

Epstein, A.S. (1980). Assessing the child development information needed by adolescent parents with very young children. Ypsilanti, MI: High Scope Educational Research Foundation.

Estes, D., Lamb, M., Thompson, R., \& Dickstein, S. (1981). Maternal affective quality and security of attachment at 12 and 19 months. Paper presented to Society for Research in Child Development, Boston.

Fernald, A. (1984). The perceptual and affective salience of mothers' speech of infants. In L.Feaghans, C.Garvey, \& R.Golinkoff (Eds.), The origins and growth of communication. Norwood, New Jersey: Ablex.

Field, T.M. (1980). Interactions of preterm and term infants with their lower- and middle-class teenage and adult mothers. In T. Field, S. Goldberg, D. Stern, \& A. Sostek (Eds.) High risk infants and children: Adult and peer interactions. New York: Academic Press.

Field, T.M. (1982). Interaction coaching for high-risk infants and their parents. In H.A. Moss, R. Hess, \& C. Swift (Eds.), Early intervention programs for infants (pp. 5-24). New York: Haworth.

Field, T.M. (1985). Attachment as psychobiological attunement: Being on the same wavelength. In The psychobiology of attachment and separation (pp. 415-454). New York: Academic Press.

Field, T.M., Dempsey, J. \& Shuman, H.H. (1981). Developmental follow-up of pre- and post-term infants. In S.Friedman \& S. Sigman (Eds.) Preterm birth and psychological development (pp. 219-312). New York: Academic Press.

Field, T.M., Widmayer, S., Stringer, S., \& Ignatoff, E. (1980). Teenage, lower-class black mothers and their preterm infants: An intervention of developmental follow-up. Child Development, 51, 426-436. 
Fraiberg, S. (1974). Blind infants and their mothers: an examination of sign system. In M.Lewis \& L. Rosenblum (Eds.) The effect of the infant on its caregiver. New York: John Wiley \& Sons.

Freud, S. (1940). An outline of psychoanalysis. New York: Norton.

Frodi, A. (1983). Attachment behaviour and sociability with strangers in premature and full-term infants. Infant Mental Health Journal, 4, 13-22.

Frodi, A. \& Lamb, M. (1980). Child abusers' responses to infant smiles and cries. Child Development, 51, 238-241.

Frodi, A., Grolnick, W., Bridges, L, \& Berko, J. (1990). Infants of adolescent and adult mothers: Two indices of socioemotional development. Adolescence, 25, 364-374.

Fry, P.S. (1985). Relations between teenagers' age, knowledge, expectations, and maternal behaviour. British Journal of Developmental Psychology 3, 47-55.

Fullard, W., McDevitt, S.C., \& Carey, W.B. (1984). Assessing temperament in one- to three-year-old children. Journal of Pediatric Psychology, 9, 205-217.

Furstenberg, F.F., Brooks-Gunn, J., \& Chase-Lansdale, L. (1989). Teenaged pregnancy and childbearing. American Psychologist, 44, 313-320.

Galluzzo, D. (1989). Attachment and dependency: Their relation using two attachment methodologies. Poster presented at the Biennial Meeting of the Society for Research in Child Development, April, Kansas City.

Garcia Coll, C., Vohr, B.R., Hoffman, J., \& Oh, W. (1986). Maternal and environmental factors affecting developmental outcome of infants of adolescent mothers. Developmental and Behavioral Pediatrics, 1, 230-235.

Garcia Coll, C., Vohr, B.R., Van Houten, LJ., \& Oh, W. (1987). The social context of teenage childbearing: Effects on the infant's caregiving environment. Journal of Youth and Adolescence, 16, 345-360.

Garmezy, N., Masten, A. \& Tellegen, A. (1984). Child Development, 55, 97-111. George, C. \& Main, M. (1979). Social interactions of young abused children. Child Development, 50, 306-318.

Gekoski, M.J., Rover llier, C.K, \& Carulli-Rabinowitz, V. (1983). A longitudinal analysis of inhll... $\mathrm{n}$ of infant distress: The origins of social expectations? Infant Behavior and Development, 6, 339-351.

Goldberg, S., Brachfeld, S., \& Divitto, B. (1980). Feeding, fussing, and play: Parent-infant interaction in the first year as a function of prematurity and perinatal medical problems. In T. Field, S. Goldberg, D. Stern, \& A. Sostek (Eds.) High risk infants and children: Adult and peer interactions. New York: Academic Press. 
Goldsmith, H. \& Alansky, J. (1987). Maternal and infant temperamental predictors of attachment: A meta-analytic review. Journal of Consulting and Clinical Psycholory, 55, 805-816.

Goldsmith, H. \& Campos, J. (1982). Toward a theory of infant temperament. In R.Emde \& R. Harmon (Eds.), The development of attachment and affiliative systems (pp. 161-193). New York: Plenum.

Goldsmith, H. \& Gottesman, I. (1981). Origins of variation in behavioral style: A longitudinal study of temperament in young twins. Child Development, 52, 91 103.

Goldsmith, H., Bradshaw, D., \& Rieser-Danner, L. (1986). Temperament as a potential developmental influence on attachment. In J.Lerner \& R.Lerner (Eds.). "Temperament and social interaction in infancy and childhood". New directions for child development, No.31. San Francisco: Jossey Bass. (pp. 5-34)

Gotlib, I.H. \& Avison, W.R. (1993). Children at risk for psychopathology. In C.G. Costello (ed.), Basic Issues in Psychopatholowy. (pp. 271-319). New York: Guilford Press.

Greenberg, M. \& Speltz, M. (1988). Attachment and the ontogeny of conduct problems. In J. Belsky \& T. Nezworski (Eds.), Clinical implications of attachment (pp. 177-218). Hillsdale, NJ: Erlbaum.

Griest, D.L. \& Forehand, R. (1982). How can I get any parent training done with all these other problems going on?: The role of family variables in child behaviour therapy. Child and Family Behaviour Therapy, 4, 73-80.

Hann, D., Osofsky,J., Barnard,K., \& Leonard,G. (1990). Maternal emotional availability in two risk groups. Poster presented at the International Conference on Infant Studies, April 19-22, Montreal.

Hann, D., Oscfsky, J., \& Carter, S. (1990). A comparison of affects between infants of adolescent and older mothers. Paper presented at the International Conference on Infant Studies, April 19-22, Montreal.

Hazen, N.G. \& Durrett, M.E. (1982). Relationship of security of attachment to exploration and cognitive mapping abilities in 2-year-olds. Developmental Psychology, 18, 751-759.

Hunt. J. McV. (1979). Psychological development: Early experience. In M.Rosenzweig \& L.Porter (Eds.), Annual Review of Psychology, 30, 103-143.

Isabella, R. (1993). Origins of attachment: Maternal interactive behaviour across the first year. Child Development, 64, 605-621.

Isabella, R. (1995). Origins of attachment: Individual and dyadic organization. Paper presented at the Biennial Meeting of the Society for Research in Child Development. Indianapolis, Ind. Mar.31-Apr.2. 
Isabella, R. \& Belsky, J. (1991). Interactional synchrony and the origins of infantmother attachment: A replication study. Child Development, 62, 373-384.

Jones, F., Green, V., \& Krauss, D. (1980). Maternal responsiveness of primiparous mothers during the postpartum period: Age differences. Pediatrics, 65, 579 . 584.

Kagan, J. (1982). A reply to Thomas, Chess, and Korn. Merrill-Palmer-Quarterly, 28, 21-24.

Kagan, J. (1984). Continuity and change in the opening years of life. In R.N. Emde \& R.J. Harmon (Eds.) Continuities and discontinuities in development. New York: Plenum.

Kaplan, M.G., Jacobson, S.W., \& Jacobson, J.L. (1991). Alternative approaches to clustering and scoring the Bayley Infant Behaviour Record at 13 months. Poster presented at the Biennial meeting of the Society for Research in Child Development, Seattle, Washington.

Kaye, K. (1982). The mental and social life of babies. Chicago: University of Chicago Press.

Lamb, M. (1988). The ecology of adolescent pregnancy and parenthood. In A.R. Pence (Ed.) Ecological Research with Children and Families (pp. 99-121). New York: Teachers College Press.

Lamb, M. \& Easterbrooks, M.A. (1981). Individual differences in parental sensitivity: Origins, components, and consequencer. In M.E. Lamb \& K.R. Sherrod (Eds.), Infant social comition: Theoretical and empirical considerations. (pp. 127-154). Hillsdale, NJ: Erlbaum.

Lamb, M., Gaensbauer, T., Malkin. C., \& Shultz, L. (1985). The effects of child maltreatment on security of infant-adult attachment. Infant Behaviour and Development, 8, 35-45.

Lamb, M., Hopps, K, \& Eleter, A. (1987). Strange situation behaviour of infants with adolescent mothers. Infant Behaviour and Development, 10, 39-48.

Lamb, M., Hwang, C., Frodi, A., \& Frodi, M. (1982). Security of mother-andfather-infant attachment and its relation to sociability with strangers in traditional and non-traditional Swedish families. Infant Behaviour and Development, 5, 355-367.

Lamb, M., Thompson, R., Gardner, W., \& Charnov, E. (1985). Infant-mother attachment. The origins and developmental significance of individual differences in strange situation behaviour. Hillsdale, NJ: Lawrence Erlbaum Associates. 
Landy, S. (1981). An Investigation of Teenage Mothers. Their Infants, and the Resulting Mother-Infant Dyads, PhD dissertation. University of Regina, Regina, Saskatchewan.

Larrance, D. \& Twentyman, C. (1983). Maternal attributions and child abuse. Journal of Abnormal Psycholory, 92, 449-457.

Lawrence, R., McAnarney, E., Aten, M., et al. (1981). Aggressive behaviours in young mothers: Markers of future morbidity? Pediatric Research, 15, 443.

Leavitt, L.A \& Donovan, W.L. (1979). Perceived infant temperament, locus of control, and maternal physiological esponse to infant gaze. Journal of Research in Personality, 13, 267-278.

Levine, L.V., Garcia Coll, C., \& Oh, W. (1985). Determinants of mother-infant interaction in adolescent mothers.

Levine, L.V., Tuber, S.B., Slade, A. \& Ward, M.J. (1991). Mothers' mental representations and their relationship to mother-infant interaction. Bulletin of the Menninger Clinic, 55, 454-469.

Lewis, M., Feiring, C., McGuffog, C., \& Jaskir, J. (1984). Predicting psychopathology in six-year-olds from early social relat Jns. Child Development, 55, 123136.

Lewis, M. \& Goldberg, S. (1969). Perceptual cognitive development in infancy: A generalized expectancy model as a function of mother-infant interaction. Merrill-Palmer Quarterly, 15, 87-100.

Lewis, M. \& Rosenblum, L. (1974). (Eds.) The affect of the infant on its caregiver. New York: Wiley.

Lewis, M., Sullivan, M., \& Michalson, L. (1984). The cognitive-emotional fugue. In C.Izard, J.Kagan, \& R. Zajonc (Eds.) Emotions, Coenition and Behavior (pp.264-288). New York: Cambridge University Press.

Lieberman, A. (1991). Infant-parent psychotherapy with toddlers. Development and Psychopathology, 4, 559-574

Lieberman, A., Weston, D.R., \& Pawl, J.H. (1991). Preventive intervention and outcome with anxiously attached dyads. Child Development, 62, 199-209.

Lipsett, L. (1983). Stress in infancy: Toward understanding the origins of coping behaviour. In N.Garmezy \& M.Rutter (Eds.) Stress, coping, and development in children (pp. 161-190). New York: McGraw-Hill.

Loyd, B. \& Abidin, R. (1985). Revision of the parenting stress index. Journal of Pediatric Psychology, 10, 169-177. 
Lyons-Ruth, K, Zoll, D., Connell, D., \& Odom, (1987, April). Maternal depression as inediator of the effects of home-based intervention services. Paper presented at the biennial meeting of the Society for Research in Child Development, Baltimore.

MacLellan, B. \& Miller, C. (1984). Maternal speech to 6- to 9-month-old infants. Paper presented at the Fourth International Conference on Infant Studies, New York.

Mahrer, A., Levinson, J., \& Fine, S. (1976). "Infant psychotherapy: Theory, research, and practice." Psychotherapy: Theory, Research and Practice, 13, 131-140.

Main, M. \& Goldwyn, R. (1984). Predicting rejection of her infant from mother's representation of her own experience: Implications for the abused-abusing intergenerational cycle. Child Abuse and Neglect, 8, 203-217.

? 'ain. M., Kaplan, N., \& Cassidy, J. (1985). Security in infancy, childhood, and adulthood: A move to the level of representation. In I.Bretherton \& E.Waters (Eds.), Growing points of attachment theory and research. Monographs of the Society for Research in Child Development, 50, (Serial No. 209) pp. 41-65.

Marascuilo, L. \& Levin, J. (1983). Multivariate statistics in the social sciences. Monterey, Ca.: Brooks/Cole Publishing Company.

Matas, L., Arend, R.A., \& Sroufe, A. (1978). Continuity of adaptation in the second year: The relationship between quality of attachment and later competence. Child Development, 49, 547-556.

Matheny, A.R. (1980). Bayley's Infant Behaviour Record: Behdviour components and twin analyses. Child Development, 51, 1157-1167.

Matheny, A.R. (1983). A longitudinal twin study of stability of components from Bayley's Infant Behaviour Record. Child Development, 54, 356-360.

Matheny, A., Wilson, R., \& Thoben, A (1987). Home and mother: Relations with infant temperament. Developmental Psychology, 23, 323-331.

McAnarney, E., Lawrence, R., \& Aten, M. (1979). Premature parenthood: A preliminary report of adolescent mother-infant interaction. Pediatric Research, 13, 328. Miller, S.A. (1988). Parents' beliefs about children's cognitive development. Child Development. 59, 259-285.

Miller, S.A. (1988). Parents' beliefs about children's cognitive development. Child Development, 59, 259-285.

Miyake, ‥, Chen, S., \& Campos, J.J. (1985). Infaut temperament, mother's mode of interaction, and attachment in Japan: An interim report. In I.Bretherton \& E.Waters 
(Eds.), Growing points of attachment theory and research (pp. 276-297). Monographs of the Society for Research in Child Development, 50, (1-2, Serial No. 209).

Mogford, K. (1977). The play of handicapped children. In B. Tizard \& D.Harvey (Eds.) Biology of play. London: W.Heinemann Medical Books.

Moran, G. \& Pederson, D.R. (1993). Secure base behaviour, attachment security, and the attachment relationship: A conceptual analysis. Unpublished paper.

Moran, G., Pederson, D., Pettit, P., \& Krupka, A. (1992). Maternal sensitivity and infant attachment in a high-risk sample. Infant Behaviour and Development, 15, 427-442.

Newson, J. (1977). An intersubjective approach to the systematic description of mother-infant interaction. In H.R. Schaffer (Ed.) Studies in mother-infant interaction. (pp. 47-61). New York: Academic Press.

Newson, J. (1979). The growth of shared understandings between infant and caregiver. In M. Bullowa (Ed.) Before speech: The beginning of interpersonal communication, (pp. 207-222). Cambridge: Cambridge University Press.

Olds, D.L. \& Henderson, C.R. (1989). The prevention of maltreatment. In D.Cicchetti \& V.Carlson (Eds.), Child Maltreatment: Theory and Research on the Causes and Consequences of Child Abuse and Neqlect. NY: Cambridge University Press (pp.722763).

Osofsky, J.D. (1990). Risk and protective factor teenage mothers and their infants. Newsletter of the Society for Research in Child Development.

Osofsky, J. \& Eberhart-Wright, A. (1988). Affective exchanges between high risk mothers and infants. International Journal of Psycho-Analysis, 69, 221-231.

Osofsky, H.J. \& Osofsky, J.D. (1970). Adolescents as mothers: Results of a program for low-income pregnant teenagers with some emphasis on child development. American Journal of Orthopsychiatry, 40, 825-834.

Osofsky, J., Culp, A., Eberhart-Wright, A., \& Hann, D. (1988). Emotional Availability Scale. Unpublished manuscript.

Osofsky, J.D., Culp, A M., \& Ware, L.M. (1988). Intervention challenges with adolescent mothers and their infants. Psychiatry, 51, 236-241.

Pawlby, S. \& Hall, F. (1980). Early interactions and later language development of children whose mothers come from disrupted families of origin. In T.M. Field (Ed.), High risk infants and children: Adult and peer interaction (pp. 61-75). New York: Academic Press. document.

Pederson. D. \& Moran, G. (1989). The Maternal Behaviour Q-sort. unpublished 
Pederson, D. \& Moran, G. (1994). Expressions of attachment relationships outside of the strange situation. Submitted to Child Development.

Pederson, D. \& Moran, G. (in press). A categorical description of infant-mother relationships in the home and its relation to q-sort measures of infant-mother interaction. Chapter submitted to B. Vaughn and E. Waters (Eds.) Constructs, caregiving and cultures: New rowing point of attachment theory and research. Monographs of the Society for Research in Child Development.

Pederson, D., Bento, S., Evans, B., Chance, G. \& Fox, A. (1987). Maternal emotional responses to preterm birth. Journal of Orthopsychiatry, 57, 15-21.

Pederson, D., Moran, G. \& Bento, S. (1993). The development of mother-infant attachment relationships. Paper presented at the biennial meetings of the Society for Research in Child Development, New Orleans, LA.

Pederson, D. \& Moran, G., Sitko, C., Campbell, K, Ghesquire, K. \& Acton,H. (1990). Maternal sensitivity and the security of infant-mother attachment: A Q-sort study. Child Development, 61, 1974-1983.

Pettit, G. \& Bates, J. (1984). Continuity of individual differences in mother-infant relationship from 6 to 13 months. Child Development, 55, 729-739.

Pianta, R., Sroufe, A. \& Egeland, B. (1989). Continuity and discontinuity in maternal sensitivity at 6, 24, and 42 months in a high-risk sample. Child Development, 60, 481-487.

Prior, M., Kyrios, M. \& Oberklaid, F. (1987). Temperament in Australian, American, Chinese, and Greek infants. Journal of Cross-cultural Psychology, 17, 455-474.

Radke-Yarrow, M., Cummings, M., Kuczynski, L., \& Chapman, M. (1985). Patterns of attachment in two and three-year-olds in normal families and families with parental depression. Child Development, 56, 884-893.

Ramey, C., Yeates, K. \& Short, E. (1984). The plasticity of intellectual development: Insights from preventive intervention. Child Development, 55, 1913-1925.

Rothbart, M.K. (1981). Measurement of temperament in infancy. Child Development, 52, 569-578.

Sameroff, A \& Chandler, M. (1975). Reproductive risk and the continuum of caretaking casualty. In F. Horowitz (Ed.) Review of child development research IV. Chicago: University of Chicago Press.

Schaffer, H.R. (1984). The child's entry into a social world. London: Academic Press. 
Schieffelin, B.B. \& Eisenberg, A.R. (1984). Cultural variations in children's conversations. In R.L. Schiefelbusch \& J. Pickar (Eds.), The acquisition of communicative competence (pp. 377-422). Baltimore: University Park Press.

Schneider-Rosen, K. \& Cicchetti, D. (1984). The relationship between affect and cognition in maltreated infants: Quality of attachment and the development of visual selfrecognition. Child Development, 55, 648-658.

Siegel, L. (1982). Reproductive, perinatal, and environmental factors as predictors of the cognitive and language development of preterm and full-term infants. Child Development, 53, 963-973.

Skeels, H.M. (1966). Adult status of children with contrasting early life experiences. Monographs of the Society for Research in Child Development, 31, 1-65.

Smith, P. (1988). The relations of maternal sensitivity, social cognitions, and social support to quality of infant-mother attachment. Unpublished doctoral dissertation, Department of Psychology, UWO, London.

Smith, P. \& Pederson, D.(1988). Maternal sensitivity and patterns of infant-mother attachment. Child Development, $\underline{56}, 1-14$.

Snow, K. (1977). The development of conversation between mothers and babies. Journal of Child Language, 4, 1-22.

Sorce, J. \& Emde, R. (1981). Mother's presence is not enough: Effect of emotional availability on infant exploration. Developmental Psychology, 17, 737-745.

Sroufe, A. (1979). The coherence of individual development. American Psychologist, 34, 834-841.

Sroufe, A. (1983). Infant-caregiver attachment and adaptation in the preschool: The roots of competence and maladaptation. In M.Perlmutter (Ed.), Minnesota symposium in child development (Vol. 16, pp. 41-81). Hillsdale, NJ: Erlbaum.

Sroufe, A. (1985). Attachment classification from the , spective of infantcaregiver relationships and infant temperament. Child Development, 56, 1-14.

Sroufe, A. (1988). The role of infant-caregiver attachment in development. In J. Belsky \& T. Nezworski (Eds.) Clinical implications of attachment. (pp. 18-38). Hillsdale, NJ: Erlbaum.

Sroufe, A. \& Fleeson, J. (1987). Attuchment and the construction of relationships. In W.W. Hartup \& Z.Rubin (Eds.) Relationships and development. New York: Cambridge University Press.

Sroufe, A. \& Rutter, M. (1984). The domain of developmental psychopathology. Child Development, 55, 17-29. 
Sroufe, A., Egeland, B., \& Kreutzer, T. (1990). The fate of early experience following developmental change: Longitudinal approaches to individual adaptation in childhood. Child Development, 61, 1363-1373.

Stern, D.N. (1974). Mother and infant at play: The dyadic interaction involving facial, vocal, and gaze behaviours. In M.Lewis \& L.Rosenblum (Eds.) The effect of the infant on its careqiver. New York: Wiley.

Press.

Stern, D.N. (1977). The first relationship. Cambridge: Cambridge University

Stern, D.N. (1985). The interpersonal world of the infant. New York: Basic Books.

Stern, D.N., MacKain, K., \& Spieker, S. (1982). Intonai. ' rontours as signals in maternal speech to pre-linguistic infants. Developmental Psychology, $18,727-735$.

Stern-Bruschweiler, N. \& Stern, D. (1990). A model for conceptualizing the role of the other's representational world in various mother-infant therapies. Infant Mental Health Journal. 10, 142-156.

Stevens, J.H. (1989). Black grandmothers' and black adolescent mothers' knowledge about parenting. Developmental Psycholooy, 20, 1017-1025.

Stevenson-Hinde, J. \& Simpson, A (1985). Attachment and temperament. Paper presented at the Society for Research in Child Development. Toronto.

Stevenson, M.D., VerHoeve, J.N., Roach, M.A, \& Leavitt, L.A. (1986). The beginnings of conversation: Early patterns of mother-infant responsiveness. Infant Behaviour and Development, 9, 423-440.

Symons, D. (1989). Behavioural indices of emerging social competence of infants: A microanalysis of early mother-infant face-to-face interactions. PhD dissertation. University of Western Ontario, London, Ontario.

Tabachnik, B.G. \& Fidell, L.S. (1989). Using multivariate statistics. Second edition. New York: Harper \& Row, Publishers, Inc.

Thomas, A. \& Chess, S. (1977). Temperament and development. New York: Bruner/Mazel.

Thomas, A. \& Chess, S. (1984). Origins and evolution of behavior disorders: From infancy to adult life. New York: Brunner/Mazel.

Thomas, A, Chess, S., \& Korn, S.J. (1982). The reality of difficult temperament. Merrill Palmer Quarterly, 28, 1-20. 
Thompson, R.A \& Lamb, M.E. (1984). Assessing qualitative dimensions of emotional responsiveness in infants: Separation reactions in the Strange Situation. Infant Behaviour and Development, I, 423-445.

Trevarthen, C. (1980). The foundations of intersubjectivity: Interpersonal and cooperative understanding in infants. In D. Olson (Ed.) The social foundations of lanquage and thought (pp.316-342). New York: W.W. Norton \& Co.

Tronick, E.Z., Ricks, M., \& Cohn, J.F. (1982). Maternal and infant affective exchange: Patterns of adaptation. In T.Field \& A.Fogel (Eds.) Emotion and early interaction. Hillsdale, NJ: Lawrence Erlbaum Associates.

Van den Boom, D. (1994). The influence of temperament and mothering on attachment and exploration: An experimental manipulation of sensitive responsiveness among lower-class mothers with irritable babies. Child Development, 65, 1457-1477.

Van Ijzendoorn, M., Juffer, F., \& Duyvesteyn, M. (in press). Breaking the intergenerational cycle of insecure attachment: $A$ review of the effects of attachmentbased interventions on maternal sensitivity and infant security. Journal of Child Psychology and Psychiatry.

Vaughn, B., Taraldson, B., Crichton, L., \& Egeland, B. (1981). The assessment of infant temperament: A critique of the Carey Infant Temperament Questionnaire. Infant Behavior and Development, 4, 1-17.

Vaughn, B.E., Egeland, B., \& Sr .ie, L.A. \& Waters, E. (1979). Individual differences in infant-mother attachment at twelve and cighteen months: Stability and change in families under stress. Child Development, 50, 971-975.

Vietze, P., McCarthy, M., McQuiston,S., MacTurk, R. \& Yarrow,L. (1983). Attention and exploratory behaviour in infants with Down's syndrome. In $\mathrm{T}$. Field $\& A$. Sostek (Eds.) Infants born at risk: Physiological, perceptual, and cognitive processes. (pp. 251-270). New York: Grant \& Stratton.

Vietze, P., Pasnak, Tremblay, McCarthy, \& Klein, (1981). A manual for assessing mastery motivation in 6- and 12 -month-old infants. Unpublished manuscript.

Wachs, T.D. \& Gruen, G.F. (1982). Early experience and human development. New York: Plen:um Press.

Wallace, P. (1989). Convergence among measures of response to novelty and intellectual abilaties in six-month-old infants. Unpublished doctoral dissertation. Department of Psychology, Cornell University.

Waters, E. (1986). The Attachment Behaviour O-Set. State University of New York at Stony Brook. Unpublished. 
Waters, E. \& Deane, $K$ (1985). Defining and assessing individual differences in attachment relationships: Q-methodology and the organization of behaviour in infancy and early childhood. In I.Bretherton \& E.Waters (Eds.), Growing points of attachment theory and research. Monographs of the Society for Research in Child Development, 50, (Serial No. 209) pp. 41-65.

Waters, E. \& Sroufe, A. (1983). Competence as a developmental construct. Developmental Review, 3, 79-97.

Watson, J. (1979). Perception of contingency as a determinant of social responsiveness. In E.B. Thomas (Ed.), Origins of the infant's social responsiveness (pp. 33-64). Hillsdale, N.J.: Lawrence Erlbaum Assoc.

Watson, J. (1985). Contingency perception in early social development. In T. Field \& N.N. Fox (Eds.) Social perceptions in children (pp.157-176). New Jersey: Ablex.

Wedell-Monnig, J. \& Lumley, J.M. (1980). Child deafness and mother-child interaction. Child Development, 51, 766-774.

Wesner, D., Dowling, J., \& Johnson, F. (1982). What is maternal-infant intervention? The role of infant psychotherapy. Psychiatry, 45, 307-315.

Wetherby, A. \& Prizant, B.M. (1990). Communication and Symbolic Behaviour Scales Manual. San Antonio, Texas: Special Press.

Wetherby, A., Cain, D., Yonclas, D., \& Walker (1988). Analysis of intentional communication of normal children from the prelinguistic to the multiword stage. Journal of Speech and Hearing Research. 31, 240-252. 47.

Whatley, J.L. (1987). Bayley Scales of Infant Development. Test Critiques, 1, 38-

White, R.W. (1959). Motivation reconsidered: The concept of competence. Psycholorical Review, 66, 297-333.

Widmayer, G. \& Field, T.M. (1980). Effects of Brazelton demonstrations on early interaction of pre-term infants and their teenage mothers. Infant Behaviour and Development, 3, 79-89.

Wiesenfeld, A \& Malatesta, C.Z. (1983). Assessing caregiver sensitivity to infants. In L.Rosenblum \& H.Moltz (Eds.) Symbiosis in parent-offspring interaction (pp. 173-188). N.Y.:Plenum Press.

Wolfe, D. (1987). Child Abuse: Implications for child development and paychopatholory. Newbury Park: Sage Publications. 
224

Wolfe, D., Edwards, B., Marion, I., \& Koverola, C. (1938). Early intervention child abuse and neglect: $A$ preliminary investigation. Journal of Consulting and Clinical Psychology, 56, 40-47.

Wong, J. (1986). Maternal perceptions in relation to their speech to infants. Unpublished Masters thesis, University of Western Ontario.

Wurlbert, M., Inglis, S. \& Kriegsmann, E. (1975). Language delay and associated mother-child interactions. Developmental Psychology, 2, 61-70.

Yarrow, L.J. \& Maser, D.J. (1983). Motivation and cognition in infancy. In M.Lewis (Ed.), Origins of intelligence in infancy and early childhood Second edition (pp. 451-477). New York: Plenum Press. 